\title{
Application of Spatial Data Modeling Systems, Geographical Information Systems (GIS), and Transportation Routing Optimization Methods for Evaluating Integrated Deployment of Interim Spent Fuel Storage Installations and Advanced Nuclear Plants
}

June 2012

\author{
Prepared by \\ G. T. Mays (Project Manager) \\ R. J. Belles \\ S. M. Cetiner \\ R. L. Howard \\ C. Liu \\ D. E. Mueller \\ O. A. Omitaomu \\ S. K. Peterson \\ J. M. Scaglione
}

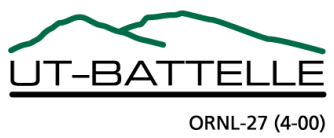




\section{DOCUMENT AVAILABILITY}

Reports produced after January 1, 1996, are generally available free via the U.S. Department of Energy (DOE) Information Bridge.

Web site http://www.osti.gov/bridge

Reports produced before January 1,1996, may be purchased by members of the public from the following source.

National Technical Information Service

5285 Port Royal Road

Springfield, VA 22161

Telephone 703-605-6000 (1-800-553-6847)

TDD 703-487-4639

Fax 703-605-6900

E-mail info@ntis.gov

Web site http://www.ntis.gov/support/ordernowabout.htm

Reports are available to DOE employees, DOE contractors, Energy Technology Data Exchange (ETDE) representatives, and International Nuclear Information System (INIS) representatives from the following source.

Office of Scientific and Technical Information

P.O. Box 62

Oak Ridge, TN 37831

Telephone 865-576-8401

Fax 865-576-5728

E-mail reports@osti.gov

Web site http://www.osti.gov/contact.html

This report was prepared as an account of work sponsored by an agency of the United States Government. Neither the United States Government nor any agency thereof, nor any of their employees, makes any warranty, express or implied, or assumes any legal liability or responsibility for the accuracy, completeness, or usefulness of any information, apparatus, product, or process disclosed, or represents that its use would not infringe privately owned rights. Reference herein to any specific commercial product, process, or service by trade name, trademark, manufacturer, or otherwise, does not necessarily constitute or imply its endorsement, recommendation, or favoring by the United States Government or any agency thereof. The views and opinions of authors expressed herein do not necessarily state or reflect those of the United States Government or any agency thereof. 
ORNL/TM-2012/237

Reactor and Nuclear Systems Division

Computational Sciences \& Engineering Division

\title{
APPLICATION OF SPATIAL DATA MODELING SYSTEMS, GEOGRAPHICAL INFORMATION SYSTEMS (GIS), AND TRANSPORTATION ROUTING OPTIMIZATION METHODS FOR EVALUATING INTEGRATED DEPLOYMENT OF INTERIM SPENT FUEL STORAGE INSTALLATIONS AND ADVANCED NUCLEAR PLANTS
}

\author{
G. T. Mays (Project Manager) \\ R. J. Belles \\ S. M. Cetiner \\ R. L. Howard \\ C. Liu \\ D. E. Mueller \\ O. A. Omitaomu \\ S. K. Peterson \\ J. M. Scaglione
}

Date Published: June 2012

Prepared for
Department of Energy Office of Nuclear Energy

Prepared by

OAK RIDGE NATIONAL LABORATORY

Oak Ridge, Tennessee 37831-6283

managed by

UT-BATTELLE, LLC

for the

U.S. DEPARTMENT OF ENERGY

under contract DE-AC05-00OR22725 



\section{CONTENTS}

LIST OF FIGURES

Page

LIST OF TABLES

EXECUTIVE SUMMARY

1. BACKGROUND, INTRODUCTION, AND METHODOLOGY …......................................... 1

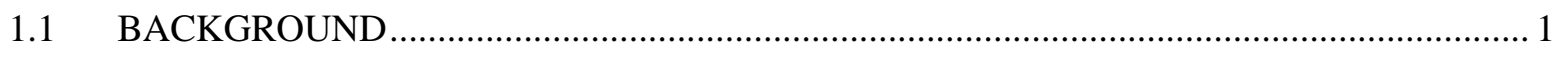

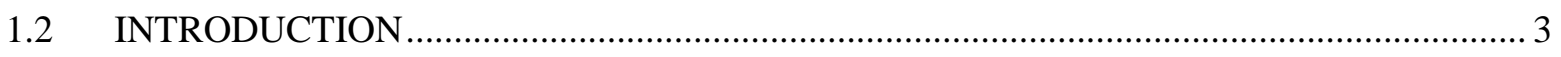

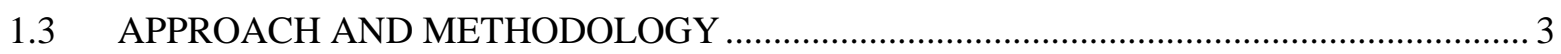

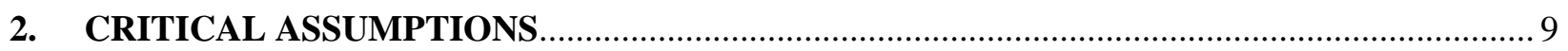

2.1 METHODOLOGY FOR AGGREGATING LAND FOR THE TYPICAL ISFSI SIZE ......... 9

2.1.1 Basic Approach to Collect GIS Cells ..................................................................... 9

2.1.2 Alternative Approach to Collect GIS Cells ............................................................ 11

2.2 METHODOLOGY TO ACCOUNT FOR OPERATING CYCLES AND THE ACCUMULATION OF SPENT NUCLEAR FUEL AT INDIVIDUAL REACTOR

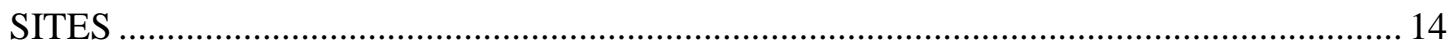

2.3 METHODOLOGY TO REPRESENT RAILROAD ACCESS FOR SHIPPING AND POPULATION ALONG THE ROUTE....................................................................... 14

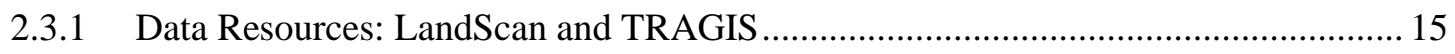

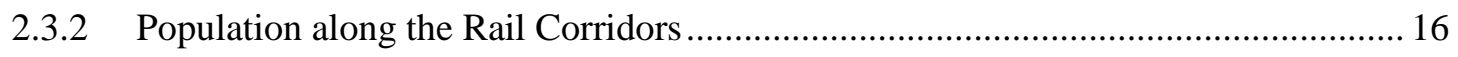

2.3.3 Mapping the Reactors and Potential Storage Sites to the Railway Network............. 19

3. INTERIM SPENT FUEL STORAGE INSTALLATION EVALUATION ............................... 23

3.1 NOMINAL INTERIM SPENT FUEL STORAGE INSTALLATION DESCRIPTION ........ 23

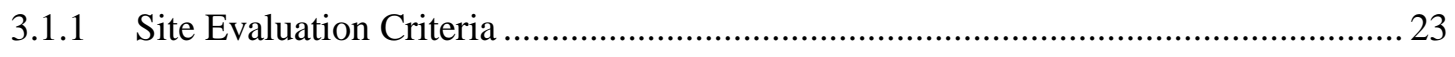

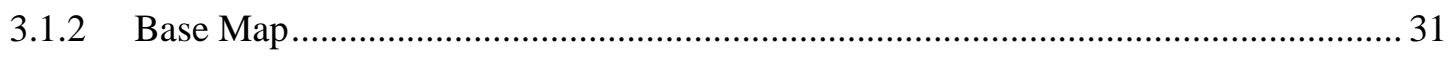

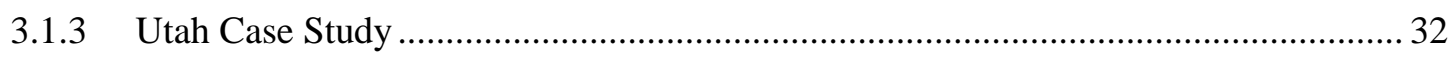

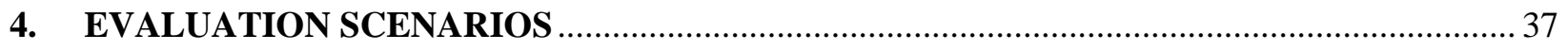

4.1 NO NUCLEAR GROWTH (STATUS QUO) SCENARIO................................................ 37

4.2 MODERATE NUCLEAR GROWTH SCENARIO ….................................................... 41

4.3 AGGRESSIVE NUCLEAR GROWTH WITH ADVANCED TECHNOLOGIES ................ 45

4.3.1 Small Modular Reactors (SMRs) ..................................................................... 45

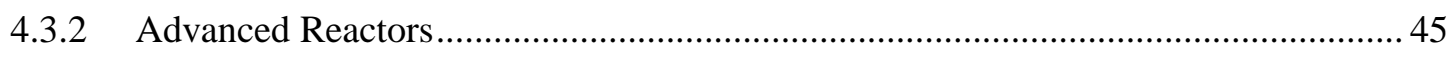

4.4 NUCLEAR GROWTH PREDICTION ….................................................................... 51

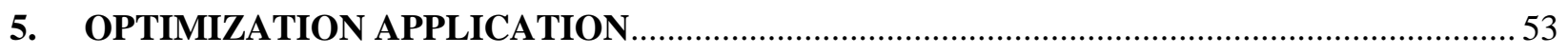

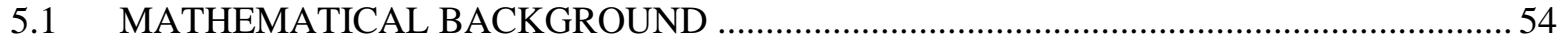

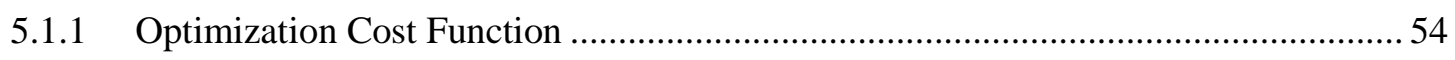

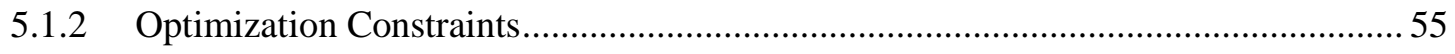

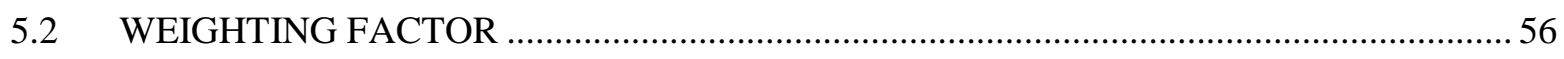

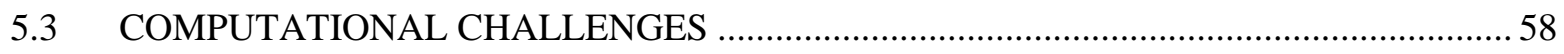




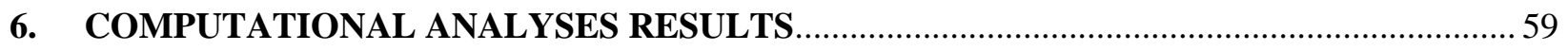

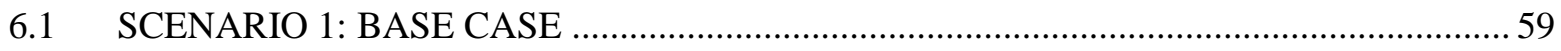

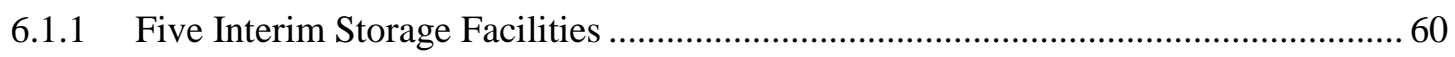

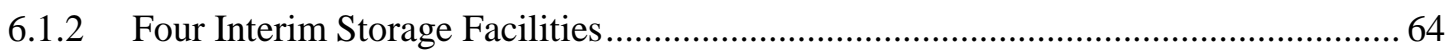

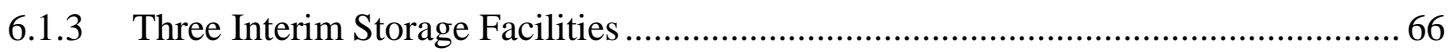

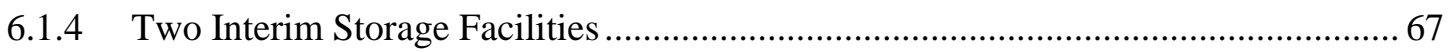

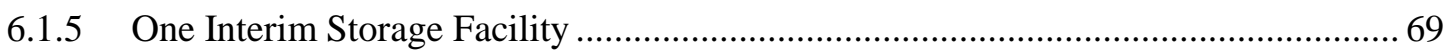

6.1.6 Sensitivity Study with a Forced ISFSI Siting at Skull Valley, Utah ..........................69

6.1.7 Sensitivity Study for Optimized ISFSI Location for Orphaned Nuclear Plants......... 71

6.2 SCENARIO 2: MODERATE NUCLEAR POWER GENERATION GROWTH

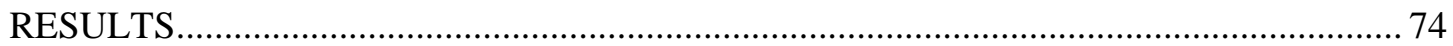

6.3 SCENARIO 3: AGGRESSIVE NUCLEAR POWER GENERATION

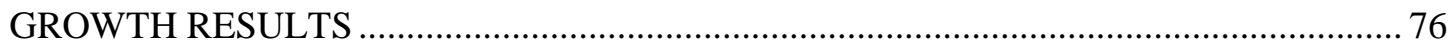

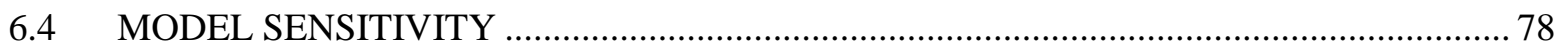

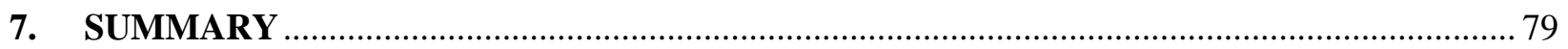

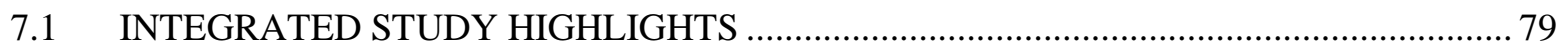

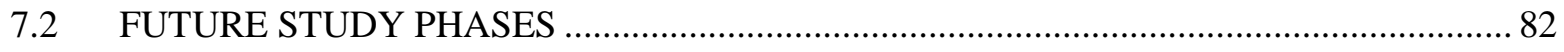

7.2.1 State, Tribal, or Local Government Transportation Limitations ................................. 82

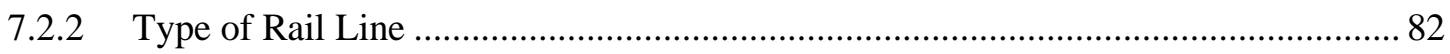

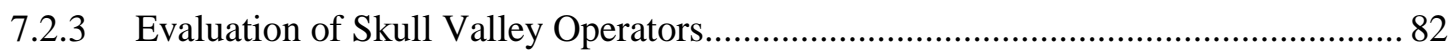

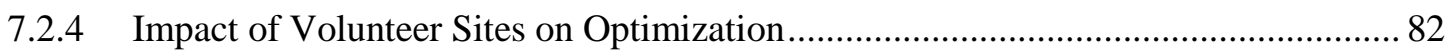

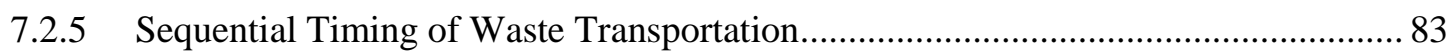

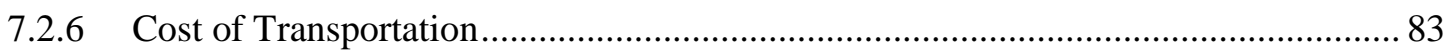

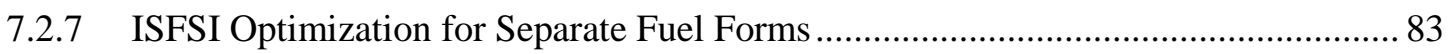

7.2.8 Development of a Graphical User Interface and Decision Support Application for Independent Spent Fuel Decision Making .......................................................... 83

7.2.9 Development of a Framework for Optimization Model in Case of ISFSI Facility

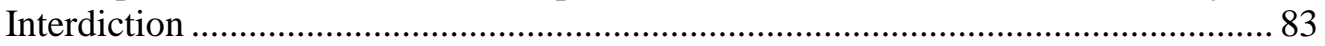

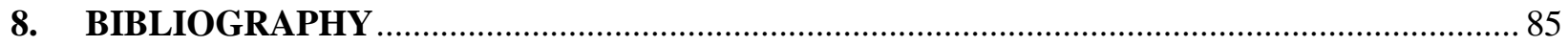

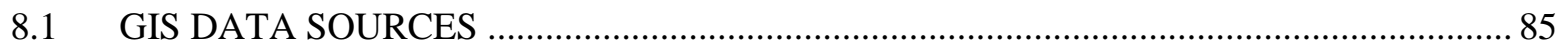

8.2 ENERGY SOURCE MATERIALS THAT PROVIDED INSIGHTS ON SELECTING ISFSI SSEC AND SUBSEQUENT OPTIMIZATION 86 


\section{LIST OF FIGURES}

Figure

ES-1

ES-2

ES-3

ES-4

ES-5

ES-6

ES-7

1

2

3

4

5

6

ISFSI available siting results aggregated for nominal 400-acre sites .....

Page

Base case two-site ISFSI solution based on limiting transportation distance.....

Base case three-site ISFSI solution based on limiting transportation distance .................... Xv

Base case five-site ISFSI solution based on limiting transportation distance ...................... xvi

Base case five-site ISFSI solution based on limiting population dose ............................... xvi

Advanced reactor locations generated for the aggressive growth scenario......................... xvii

Aggressive growth five-site ISFSI solution based on transportation distance ....................

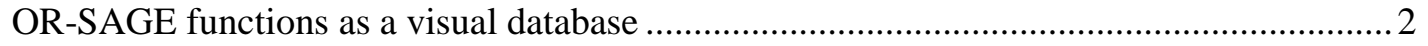

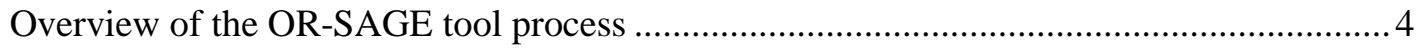

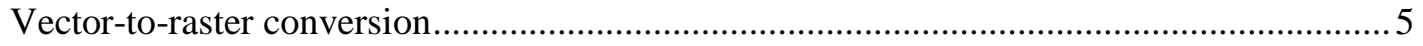

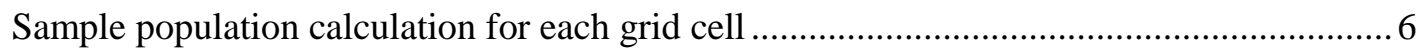

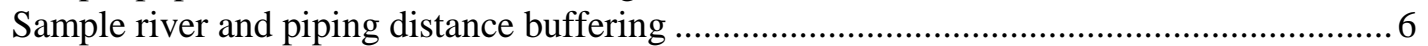

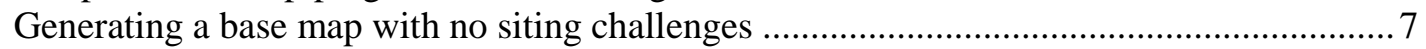

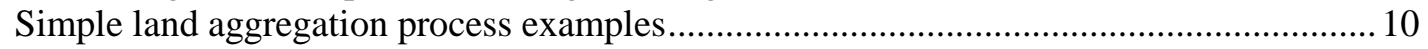

Sample land aggregation process results over a larger area ............................................ 11

Land aggregation example results with consideration for small flaws ............................... 12

Sample 500-acre power plant aggregation results with no cells with siting challenges ....... 13

Sample 500-acre power plant aggregation results with less than $10 \%$ cells with siting

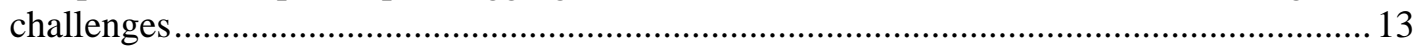

2010 LandScanUSA and National Railway Network around Knoxville, Tennessee ........... 16

Population buffering for a single rail link using TRAGIS and LandScan ........................... 17

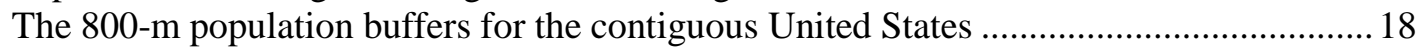

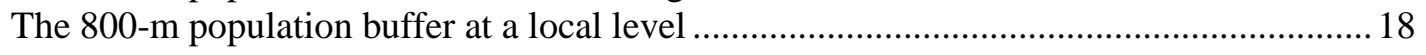

Representative calculation of transfer link between reactor sites and nearest

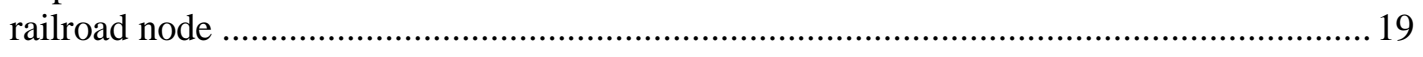

Vectors limited to 50 miles in length between potential ISFSI sites and nearest

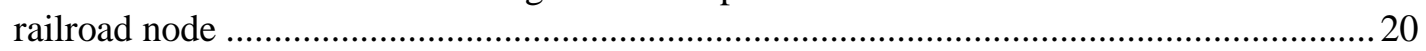

National niew of area available for ISFSI optimization using railroad network ..................21

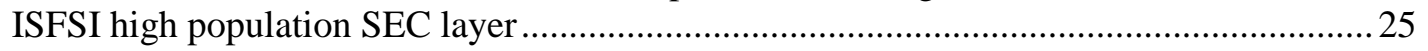

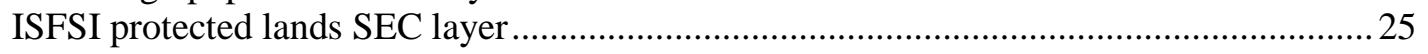

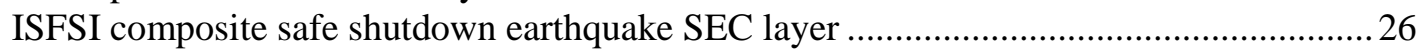

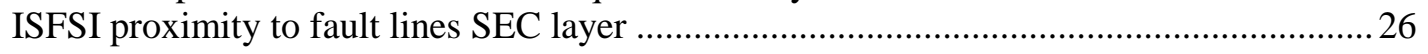

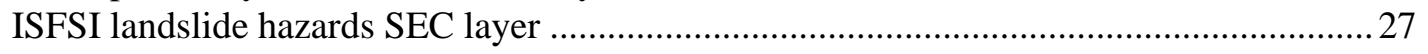

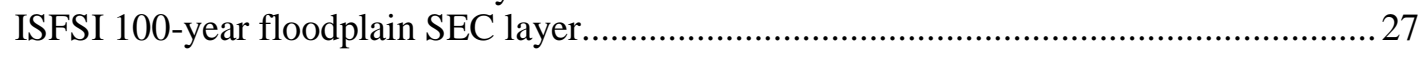

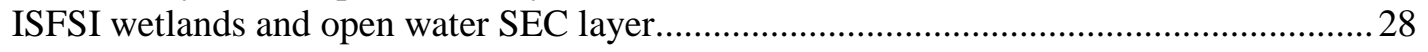

ISFSI coastal flooding, environmental corrosion, and security SEC layer .........................28

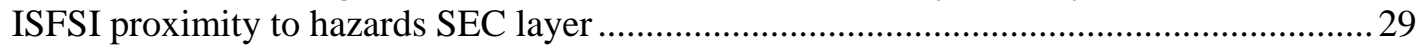

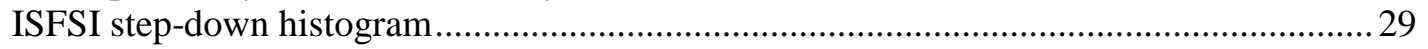

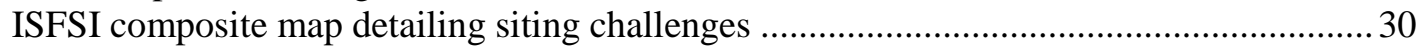

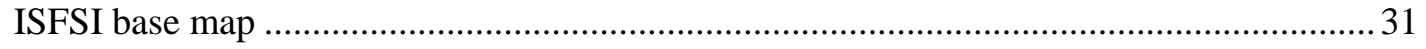

ISFSI base map aggregated for 400 -acre sites .............................................................. 32

ISFSI composite map with state of Utah outlined in blue ............................................... 33

ISFSI composite map showing Goshute Indian Reservation in red box

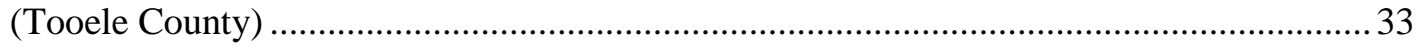

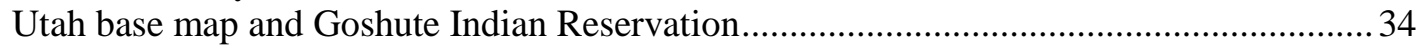

ISFSI base map highlighting fault line SEC with standoff distances in red .........................35

ISFSI base map highlighting protected land SEC in red.................................................. 35 
ISFSI base map highlighting proximity to hazards SEC with buffer in red.........................36

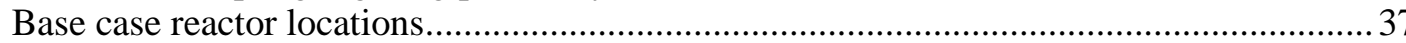

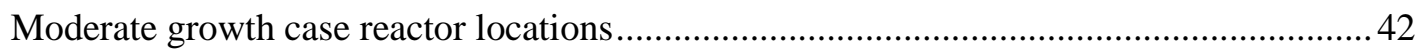

Current US demand for high-temperature process heat across various industries .............. 48

Selected sites for high-temperature reactors

Aggressive growth case reactor locations

Calculation of the population that live within $800 \mathrm{~m}$ on each side of the railroad

Base case five-site ISFSI solution based on transportation distance $(\alpha=1.0)$

Base case five-site ISFSI solution based on population along the transportation corridor $(\alpha=0.0)$.

Base case five-site ISFSI solution based on mixed factors with equal weights $(\alpha=0.5) \ldots .63$

Base case four-site ISFSI solution based on transportation distance $(\alpha=1.0)$

Base case three-site ISFSI solution based on transportation distance $(\alpha=1.0) \ldots \ldots \ldots \ldots \ldots \ldots . . . . .66$

Base case two-site ISFSI solution based on transportation distance $(\alpha=1.0) \ldots \ldots \ldots \ldots \ldots \ldots \ldots . . . . . . .68$

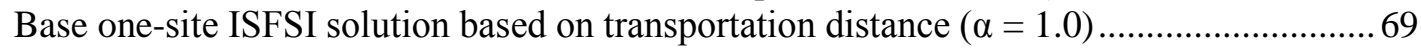

Base case storage sites with the Skull Valley facility and four additional facilities ............ 70

Base case storage sites with the Skull Valley facility and three additional facilities............71

Most favorable locations for two storage sites for shutdown plants ................................. 73

Most favorable location for a single storage site for shutdown plants ..............................74

Moderate growth five-site ISFSI solution based on transportation distance $(\alpha=1.0) \ldots \ldots \ldots .75$

Aggressive growth five-site ISFSI solution based on transportation distance $(\alpha=1.0) \ldots \ldots .77$

Artificial SNF loading in 2050 to demonstrate optimization model sensitivity................... 78

Summary of the most favorable ISFSI locations for the five-site ISFSI calculation based solely on transportation distance.

59 Summary of the most favorable ISFSI locations for the five-site ISFSI calculation based solely on population risk. 


\section{LIST OF TABLES}

Table

Page

1 Contiguous US land available for ISFSI siting.

Base case scenario nuclear power plants and SNF

Additional reactors and SNF for moderate growth scenario.

Base case plants with license extension for moderate growth scenario ................................4 44

Products, processes, and temperature ranges applicable to high-temperature reactors........ 47

Additional reactors and SNF for aggressive growth scenario ............................................51

Base case SNF inventory and capacity factors for each storage site with five ISFSIs

$(\alpha=1.0)$.

Base case SNF inventory and capacity factors for each storage site with five ISFSIs

$(\alpha=0.0)$.

Base case SNF inventory and capacity factors for each storage site with five ISFSIs $(\alpha=0.5)$.

Base case SNF inventory and capacity factors for each storage site with four ISFSIs ........65

Base case SNF inventory and capacity factors for each storage site with two ISFSIs ........68

SNF inventory and the capacity factors for each storage facility with five ISFSI sites ...... 70

SNF inventory and the capacity factors for each storage facility with four ISFSI sites .....71

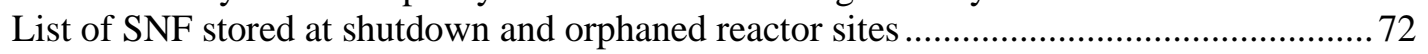

SNF inventory for Scenario 2 with capacity factors for each storage site with five ISFSIs $(\alpha=1.0)$...

17 SNF inventory for Scenario 3 with capacity factors for each storage site with five 



\section{ACRONYMS}

\begin{tabular}{|c|c|}
\hline AHTR & advanced high-temperature reactor \\
\hline BLM & Bureau of Land Management \\
\hline BRC & Blue Ribbon Commission \\
\hline $\mathrm{CCC}$ & closed cycle cooling \\
\hline COL & combined license \\
\hline DOE & US Department of Energy \\
\hline DOT & US Department of Transportation \\
\hline EIA & Energy Information Administration \\
\hline EPA & Environmental Protection Agency \\
\hline EPRI & Electric Power Research Institute \\
\hline ESP & early site permit \\
\hline GIS & geographic information systems \\
\hline HLW & high-level waste \\
\hline HTGR & high-temperature gas reactor \\
\hline iPWR & integral pressurized water reactor \\
\hline ISFSI & interim spent fuel storage installation \\
\hline LWR & light-water reactor \\
\hline MHTGR & modular high-temperature gas-cooled reactor \\
\hline MILP & mixed-integer linear programming \\
\hline MTHM & metric tons of heavy metal \\
\hline NCRP & National Council on Radiation Protection and Measurements \\
\hline NEMS & National Energy Modeling System \\
\hline NETL & National Energy Technology Laboratory \\
\hline NGNP & next generation nuclear plant \\
\hline NHDPlus & National Hydrography Database Plus \\
\hline NRC & Nuclear Regulatory Commission \\
\hline NREL & National Renewable Energy Laboratory \\
\hline ORNL & Oak Ridge National Laboratory \\
\hline OR-SAGE & Oak Ridge Siting Analysis for Power Generation Expansion \\
\hline SFR & sodium-cooled fast reactor \\
\hline SMR & small modular reactor \\
\hline SNF & spent nuclear fuel \\
\hline SEC & site evaluation criteria \\
\hline TVA & Tennessee Valley Authority \\
\hline USGS & US Geological Survey \\
\hline
\end{tabular}





\section{EXECUTIVE SUMMARY}

\section{Objective}

The objective of this siting study work is to support DOE in evaluating integrated advanced nuclear plant and ISFSI deployment options in the future. This study looks at several nuclear power plant growth scenarios that consider the locations of existing and planned commercial nuclear power plants integrated with the establishment of consolidated interim spent fuel storage installations (ISFSIs). This research project is aimed at providing methodologies, information, and insights that inform the process for determining and optimizing candidate areas for new advanced nuclear power generation plants and consolidated ISFSIs to meet projected US electric power demands for the future.

\section{GIS Methodology to Site Waste Facilities and Nuclear Power Plants}

The potential siting for aboveground, ${ }^{1}$ away-from-reactor, consolidated dry-storage ISFSIs is based on a process developed by Oak Ridge National Laboratory (ORNL) for electric power plant siting. The geographic information systems (GIS)-based ORNL tool used in the power plant siting evaluation process is known as OR-SAGE (Oak Ridge Siting Analysis for power Generation Expansion). The objective in developing OR-SAGE was to use industry-accepted approaches and/or develop appropriate criteria for screening sites and employ an array of GIS data sources at ORNL to identify candidate areas for a particular power generation technology application. The basic premise requires the development of exclusionary, avoidance, and suitability criteria for evaluating sites for a given siting application. For specific applications of the tool, it is necessary to develop site evaluation criteria (SEC) that encompass a number of key benchmarks that essentially form the site environmental characterization for that application. These SEC might include population density, seismic activity, proximity to water sources, proximity to hazardous facilities, avoidance of protected lands and floodplains, susceptibility to landslide hazards, and others.

The same principles that make the OR-SAGE tool useful in energy siting evaluations are equally applicable to other industrial concepts such as providing insight to siting consolidated storage facilities. A waste storage and disposal solution for spent nuclear fuel (SNF) is essential to the continued deployment of advanced reactors.

The OR-SAGE tool is essentially a dynamic visualization database. The SEC are the fields of the database, and the GIS data for a given variable represent the values against which searches are performed. The evaluation process divides the contiguous United States into $100 \mathrm{~m} \times 100 \mathrm{~m}$ (1-hectare) squares (cells), applying successive ISFSI-appropriate SEC to each cell. There are just under 700 million cells representing the contiguous United States. If a cell meets the requirements of each criterion, the cell is included as a candidate to be integrated in the possible siting of a consolidated ISFSI for a predefined nominal storage facility. Some SEC parameters preclude siting a facility because of an environmental, regulatory, or land-use constraint. Other SEC assist in identifying less favorable areas, such as proximity to hazardous operations. All of the selected SEC tend to recommend against sites. The focus of the ORNL SNF waste storage siting study is on demonstrating how candidate areas might be identified, stopping short of performing any detailed site evaluations or comparisons. This approach is designed to quickly identify favorable candidate areas. The results shown in this report represent a single static set of ISFSI siting results using a specific set of input parameters for a predefined nominal storage facility. The available areas for siting a nominal consolidated ISFSI based on the study parameters are shown by the green shading on the map in Fig. ES-1. A single set of individual results should not be construed as an ultimate SNF storage solution, since the United States waste storage policy is very complex. However, the strength of the OR-SAGE tool is that numerous alternative scenarios can be quickly generated to

\footnotetext{
${ }^{1}$ Geology was not factored into site evaluation criteria. Therefore, dry storage systems designed for an underground configuration such as the Holtec HI-STORM 100U may not be appropriate for all sites.
} 
provide additional insight into nuclear waste storage based on known GIS-based information. Additional selection criteria can be added easily and existing selection criteria can be quickly adjusted to evaluate many alternatives.

Critical assumptions supporting this work include a methodology to provide an adequate siting footprint for a typical storage facility; a methodology to account for power plant operating cycles and the accumulation of SNF at individual reactor sites; a methodology to represent railroad access for shipping; and a methodology to account for population along various rail routes. For report purposes, the target year to optimize the storage of accumulated SNF is 2050, though any point in time can be forecast using the process methodology. For simplicity, the ISFSI siting solutions assume that the necessary ISFSI facilities are all available in 2050 and have been designated to receive all of the accumulated SNF waste through 2050. No solution for eventual waste disposal is considered by this study. No time sequence for building multiple ISFSI facilities or the subsequent waste shipment campaigns are factored into the limited siting optimization results at this stage. As a result, neither stranded plant waste nor the amount of accumulated waste at an individual site is prioritized because time is not a factor at this stage of the study. The total nuclear utility industry SNF calculation drives the number of ISFSI sites using an integer optimization (i.e., 1.5 ISFSI sites is not an acceptable solution). To limit the overall data set size for the optimization routine, only acceptable ISFSI sites within 50 miles of existing rail lines are considered. This further reflects the difficulty in securing right-of-way for a necessary railroad spur.

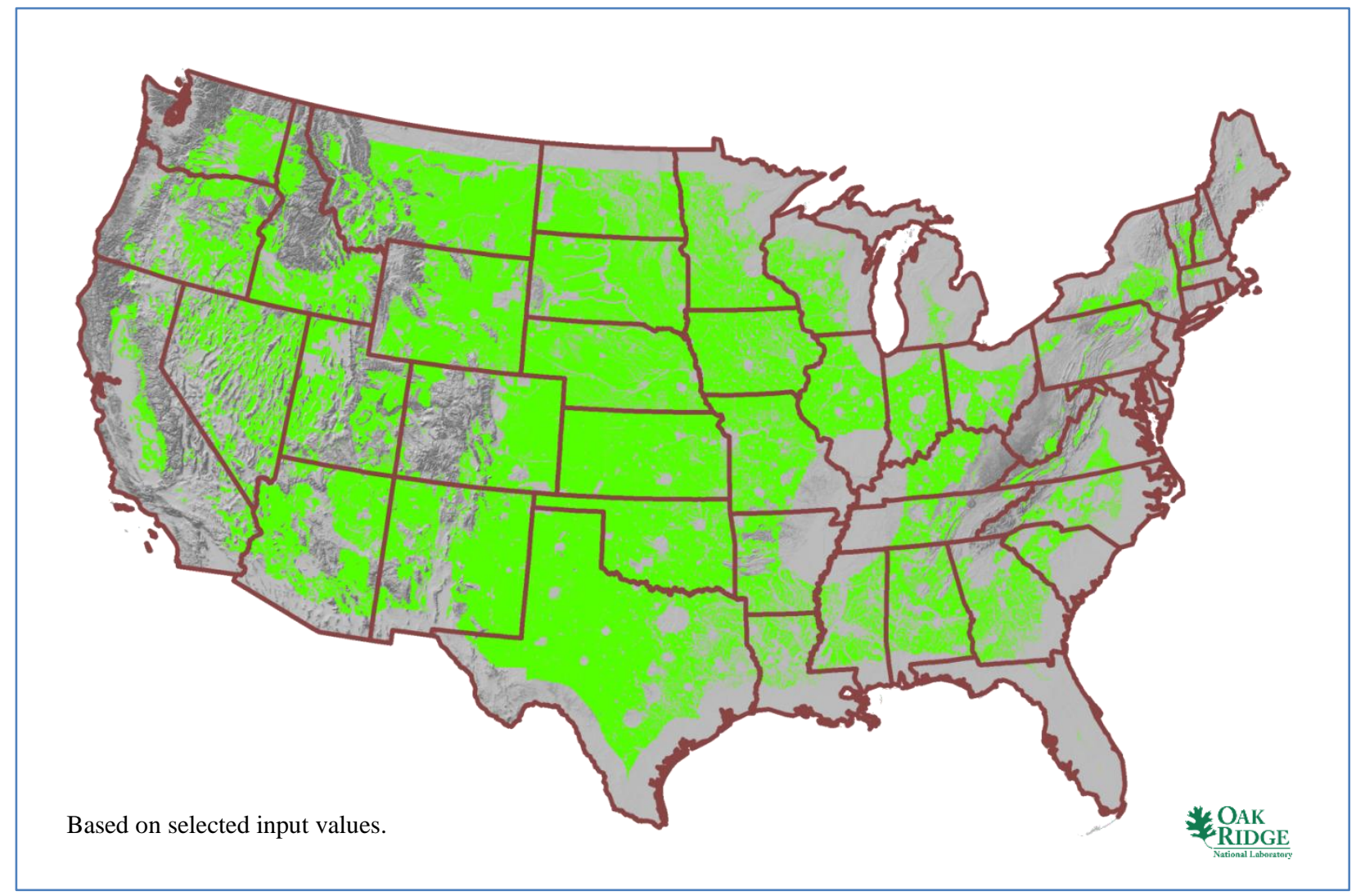

Fig. ES-1. ISFSI available siting results aggregated for nominal 400 -acre sites. 


\section{Definition of Reactor Power Growth Scenarios}

Based on land clustering techniques to aggregate the individual cells, over 1.7 million potential 400 acre sites were generated by the ISFSI siting process described in Section 2.1 this report based on the selected ISFSI SEC and values. A 400-acre ISFSI site can store 70,000 metric tons of heavy metal. Three possible scenarios for commercial nuclear power growth in the United States were evaluated relative to the most favorable or optimized ${ }^{2}$ location(s) for consolidated ISFSIs. The three commercial nuclear power scenarios are (1) a status quo scenario with no future commercial nuclear power growth, (2) a scenario with moderate commercial nuclear power growth: and (3) a scenario with aggressive commercial nuclear power growth that includes advanced reactor concepts. Two sensitivity studies based on the status quo scenario were also conducted; one assessing an ISFSI location at the Skull Valley, Utah, location, and the second focused on calculating the most favorable ISFSI location relative to the orphaned reactor sites only. Forcing an ISFSI site at the Skull Valley location in Utah as part of a larger optimized solution demonstrates possible methods for down selection alternatives for volunteer sites as recommended by the Blue Ribbon Commission (BRC) on waste storage. ${ }^{3}$ An additional sensitivity study based on an aggressive growth scenario was performed to demonstrate the optimization model sensitivity to changes in SNF quantities and location. Each scenario was analyzed by optimizing one to five consolidated ISFSI sites with weighting factors for shipping distance and rail corridor population risk.

\section{Consolidated ISFSI Siting for the Base Case}

For the status quo reactor (base case) growth scenario in 2050, at least two consolidated ISFSI locations would be required to store the accumulated 123,720 metric tons of heavy metal (MTHM) in SNF and stay within the nominal maximum storage capacity of 70,000 MTHM at a single ISFSI location ${ }^{4}$. A two-site storage solution for the base case would require $88 \%$ of the available capacity of the storage facilities in 2050 without consideration of further nuclear industry expansion. The optimized ${ }^{2}$ two-site ISFSI result for the status quo scenario based solely on limiting transportation distance is shown in Fig. ES-2. The amount of accumulated waste at a given reactor site is also a factor in the consolidated site location(s). The individual transportation routes from the reactors to each consolidated ISFSI site are shown as the colored spoke lines. Recognizing that SNF is stored at the end of each spoke and spur, this solution makes good sense visually. Both sites are within the specified capacity when the optimization is based only on minimizing transportation distance. When the weighting is shifted toward minimizing population dose, one facility begins to exceed capacity. Therefore, to minimize capacity and transportation distance, a three-site consolidated ISFSI solution may provide a better minimal storage solution based on the simplistic inputs used in this study.

\footnotetext{
${ }^{2}$ Two optimization factors, among multiple factors to consider, were used in the study; minimizing SNF quantity-transportation distance and minimizing population along the transportation route.

${ }^{3}$ Blue Ribbon Commission on America's Nuclear Future, Report to the Secretary of Energy, January 2012.

${ }^{4}$ Based on current requirements of 10 CFR 72 .
} 


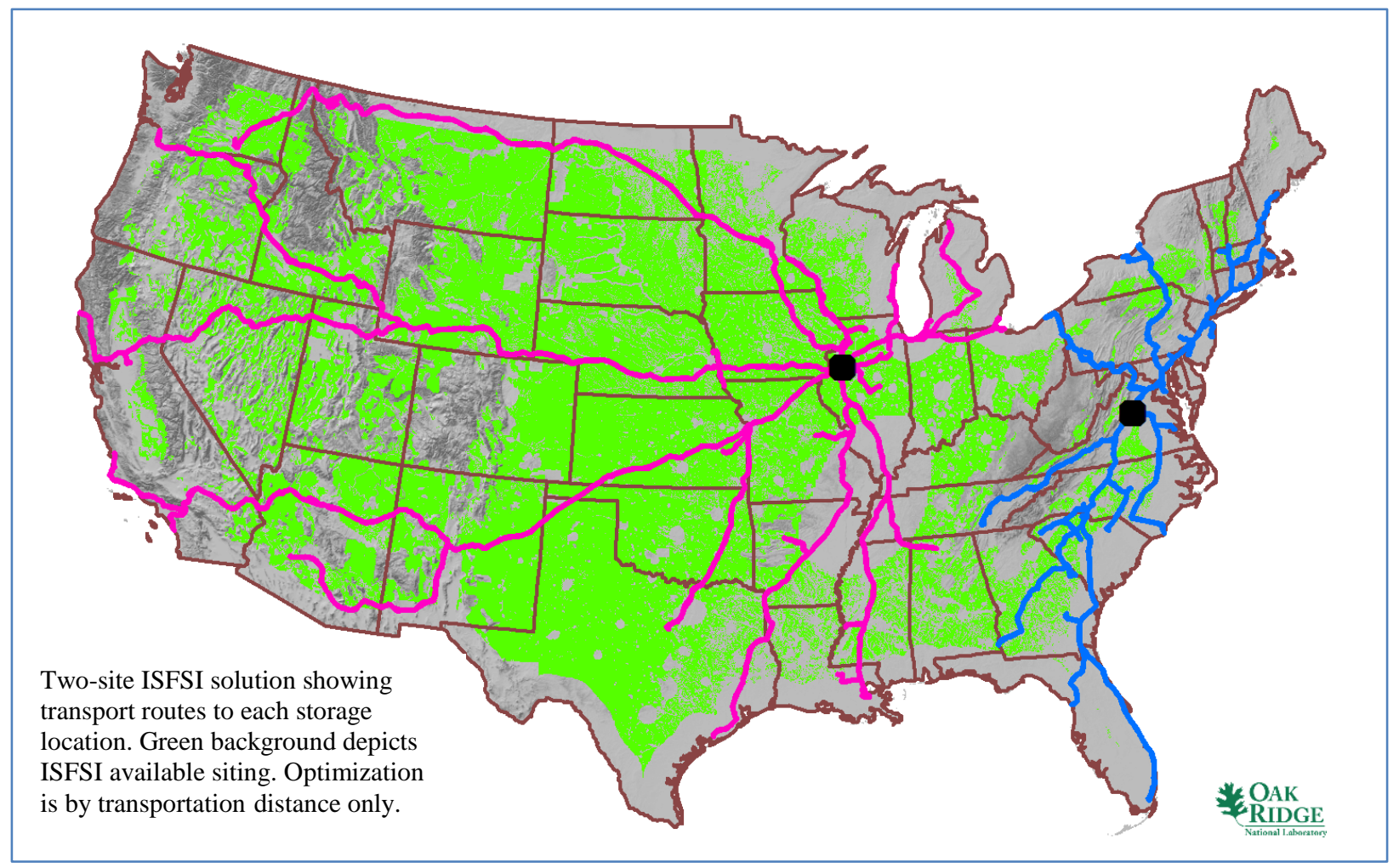

Fig. ES-2. Base case two-site ISFSI solution based on limiting transportation distance.

The optimized ${ }^{2}$ three-site ISFSI result for the base case scenario constructed solely by minimizing transportation distance is shown in Fig. ES-3. A three-site storage solution for the base case would require $59 \%$ of the available capacity of the storage facilities in 2050, leaving ample space to accommodate nuclear industry expansion. In this calculation, a western consolidated ISFSI location is established, reducing the burden on the central United States location. Again the results make visual sense.

Calculations were made for up to five consolidated ISFSI locations. For comparison to what might be considered the minimal solution in Figs. ES-2 and ES-3, a solution for the optimized ${ }^{2}$ five-site ISFSI result is shown in Fig. ES-4 based on minimizing transportation distance. Note that the western and the Great Lakes consolidated ISFSI locations are unchanged from the three-site ISFSI solution. A solution with five storage facilities forces the most diverse waste storage location solution for consideration.

Note that these results as presented from all the various siting analyses reflect a set of technical assumptions, parameters, and constraints. There was no attempt to incorporate or reflect political factors, although that is certainly within the capability of the OR-SAGE tool. 


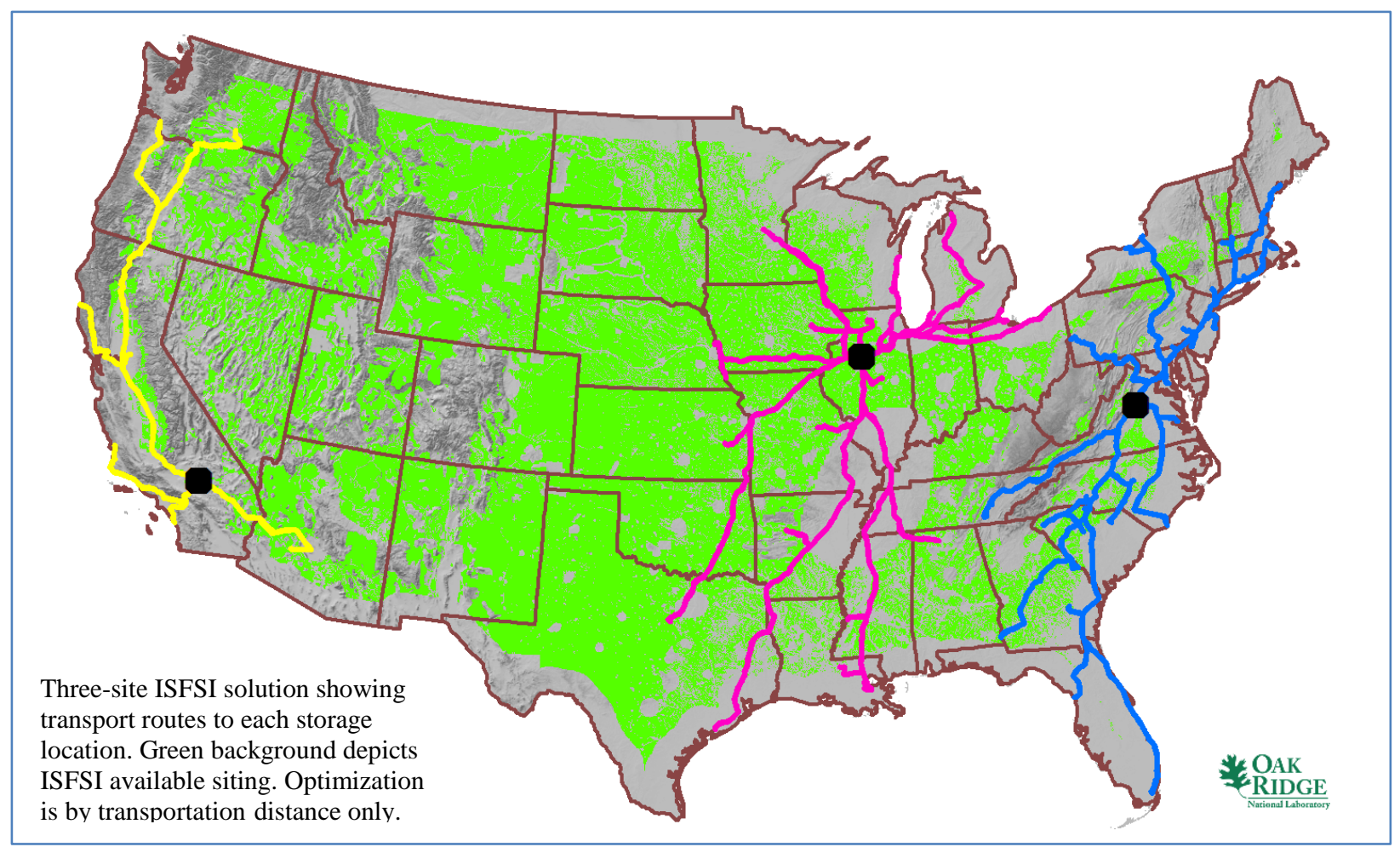

Fig. ES-3. Base case three-site ISFSI solution based on limiting transportation distance.

Calculations were also made based on minimizing population dose along the railroad routes. This was done by looking at the population in a one-mile corridor along rail lines. A five-site consolidated ISFSI solution based on minimizing population risk or dose is shown in Fig. ES-5. Slight shifts in the forecast consolidated ISFSI locations away from population centers can be observed. In addition, the alignment of reactors and consolidated ISFSI locations shift, as noted by the colored spoke lines. Calculations based on a combination of minimizing transportation distance and minimizing population risk were also performed and are discussed in Chapter 6. 


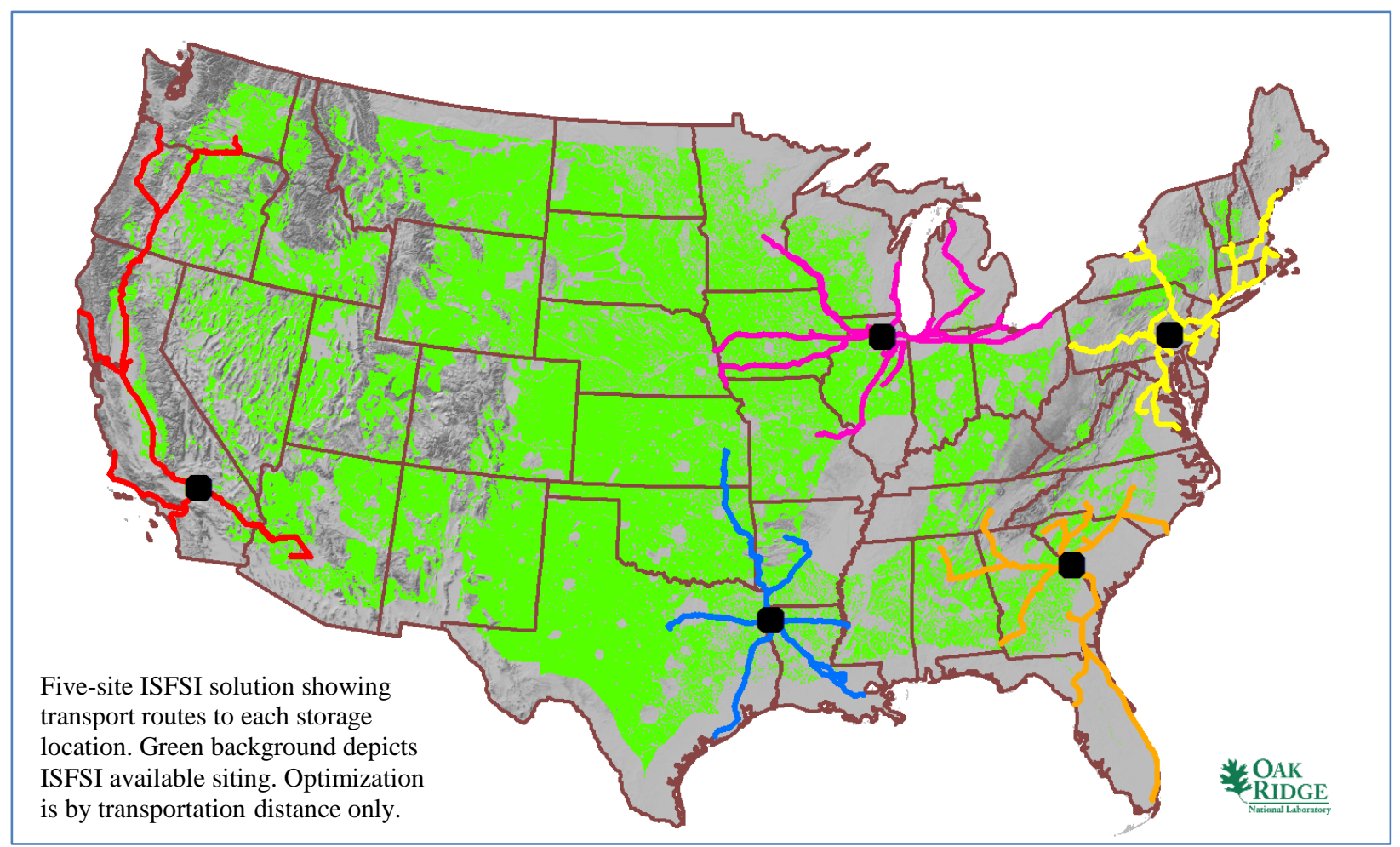

Fig. ES-4. Base case five-site ISFSI solution based on limiting transportation distance.

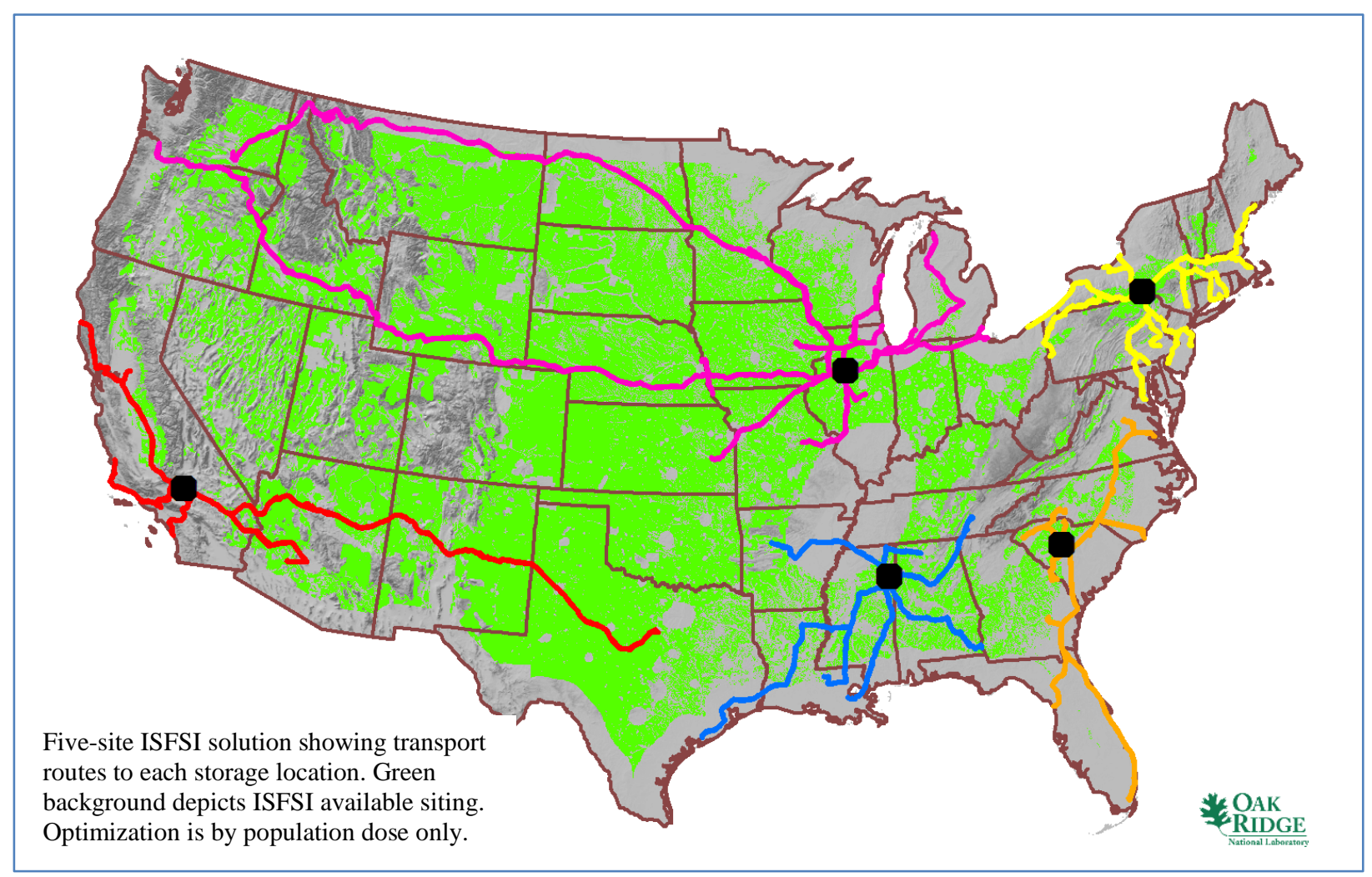

Fig. ES-5. Base case five-site ISFSI solution based on limiting population dose. 


\section{The Moderate and Aggressive Growth Scenarios-Including Advanced Reactors}

The status quo scenario demonstrates the near-term expectation for SNF accumulation. The moderate growth and aggressive growth scenarios offer alternate growth possibilities for the nuclear industry. Appropriate assumptions for both scenarios were made as described in Section 4 as to continued relicensing of existing commercial nuclear power plants, deployment time frames for additional advanced reactors, and identification of suitable locations for these plants. The advanced reactors deployed for the aggressive growth scenario are shown in Fig. ES-6. In the near-term, integral pressurized water reactors were proposed for retired or retiring coal plants with similar capacities operated by nuclear utilities largely in the southeast. Several military bases were also assumed to install a small advanced reactor. High temperature reactors were proposed in areas with significant chemical industry.

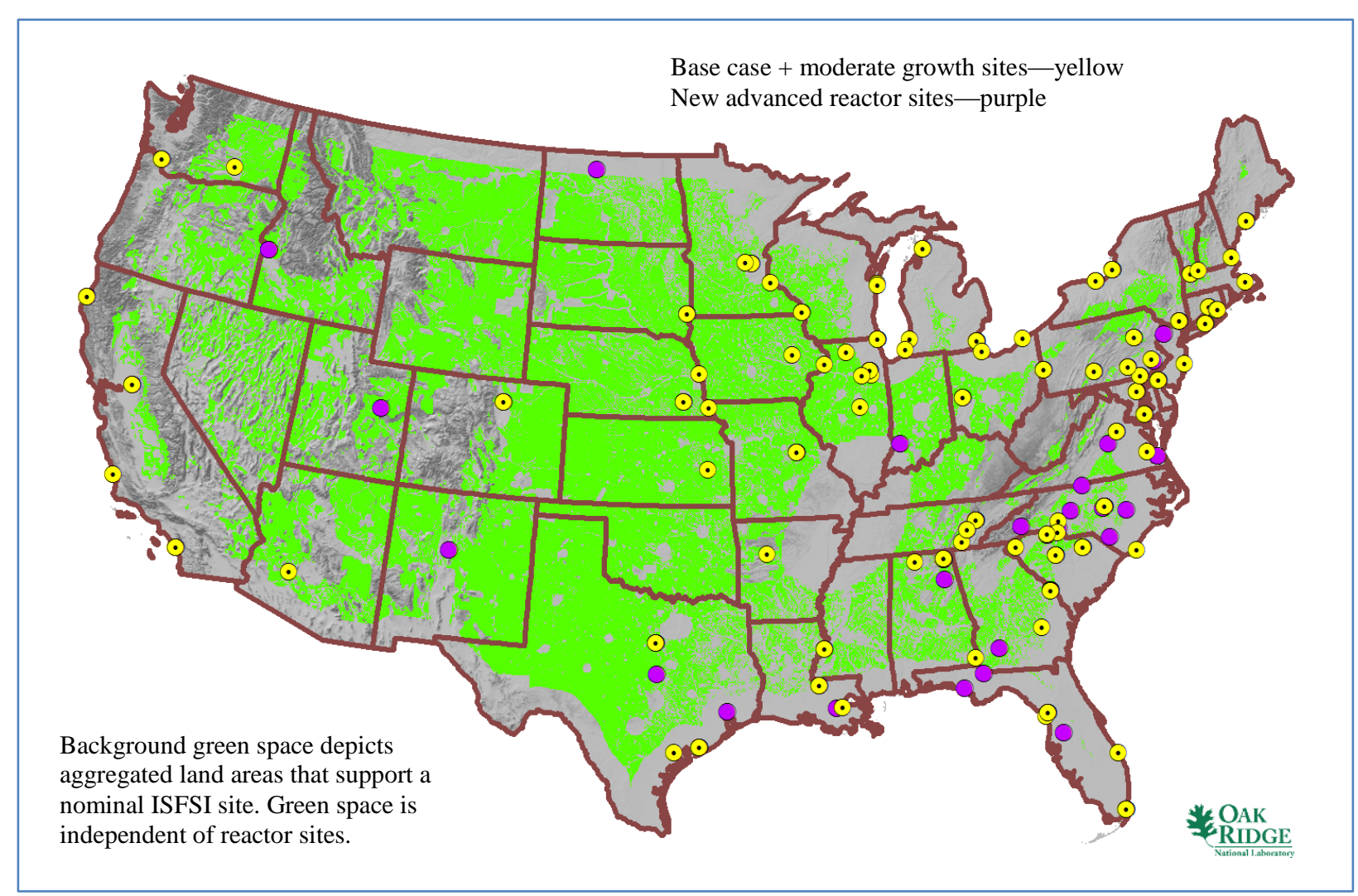

Fig. ES-6. Advanced reactor locations generated for the aggressive growth scenario.

The resulting five-site consolidated ISFSI solution, minimizing transportation distance, is shown in Fig. ES-7 and is based on the deployment of advanced reactors as just described and as depicted in Fig. ES-6. This can be compared to the similar five-site consolidated ISFSI solution, minimizing transportation distance, in Fig. ES-4. This case bounds the moderate growth scenario. In 2050, the selected locations for ISFSI siting continue to be dominated by the current fleet of operating reactors such that the forecast consolidated ISFSI locations change very little in either additional scenario. However, the network for transportation from the additional reactors is readily visible in Fig. ES-7. In short, the addition of new reactors and the limited time available by 2050 to accumulate SNF is small compared to the amount of SNF already generated by the current operating fleet as well as that which is expected to be generated by 2050 by the current fleet. 


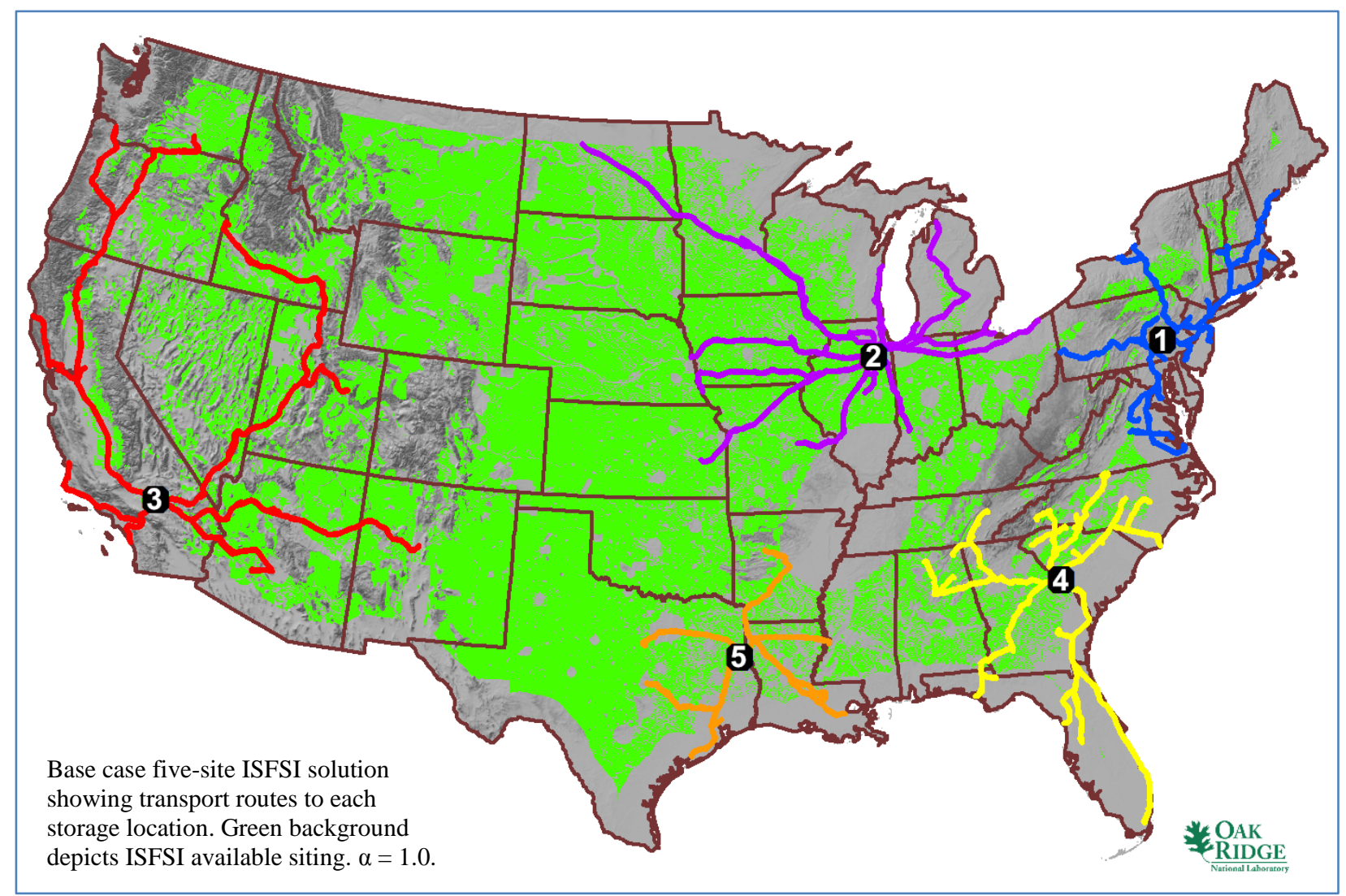

Fig. ES-7. Aggressive growth five-site ISFSI solution based on transportation distance.

The moderate reactor plant growth scenario increases the projected quantity of SNF in 2050 by just $29 \%$ over the base case scenario, and much of the additional SNF is stored at existing reactor sites as these sites expand. The aggressive reactor plant growth scenario increases the projected quantity of SNF in 2050 by just $31 \%$ over the base case scenario because the advanced reactors deployed in this scenario are small and arrive relatively late in the time sequence. Therefore, with the limits imposed by this study, the optimized $^{2}$ locations for consolidated ISFSI siting did not change significantly between each of the three main scenarios analyzed. In all calculations, the optimized ${ }^{2}$ ISFSI locations are visually sensible with regard to where the current reactors are located and the available area for ISFSI siting. Alternate restrictions, such as forcing a consolidated site to a specific location, as would be the case for a volunteer site, proved that the modeling is quite responsive.

As a totally separate analysis, the consolidated ISFSI site in Illinois is the single optimized ${ }^{2}$ site for an ISFSI solution when only SNF at orphaned reactors is considered relative to siting a consolidated ISFSI. 


\section{BACKGROUND, INTRODUCTION, AND METHODOLOGY}

\section{$1.1 \quad$ BACKGROUND}

A 2002 Electric Power Research Institute (EPRI) report ${ }^{5}$ on dry spent nuclear fuel (SNF) storage notes the following.

When the current operational nuclear power plants in the United States were designed, it was thought there was little need to store significant quantities of SNF on site. At the time, it was thought that SNF would be removed from the spent fuel pools after only a few years of cooling, and sent for reprocessing. Furthermore, it was understood that a long-term interim storage and/or a permanent disposal facility would be available by sometime in the 1980s. The subsequent elimination of the reprocessing option, along with significant delays in the availability of centralized interim storage or permanent disposal of SNF required nuclear utilities to expand their on-site SNF storage capabilities. Initially, utilities opted for re-racking their spent fuel pools to accommodate larger numbers of assemblies. By the early 1980s, as delays in the availability of centralized interim storage and disposal continued, it became apparent that some of the SNF inventory would have to be stored on site, but out of the spent fuel pools.

Starting in the early 1980s, the U.S. Department of Energy (DOE) and EPRI developed technology, and the utilities installed dry storage capabilities to alleviate SNF storage problems and maintain a full core reserve while DOE was preparing a disposal facility. At the same time, the U.S. Nuclear Regulatory Commission (NRC) developed regulations governing the development and operation of Independent Spent Fuel Storage Installations (ISFSIs), now codified in 10 CFR Part $72^{6}$ and associated review plans, regulatory guides, and interim guidance documents. While ISFSIs could also include wet storage facilities, all ISFSIs developed so far in the U.S. are dry storage systems.

Much effort and study has been expended evaluating the Yucca Mountain site in Nevada for a permanent repository. However, neither a consolidated interim storage nor a permanent disposal facility is currently available. This study is intended to use GIS tools available at Oak Ridge National Laboratory (ORNL) to evaluate optimized ${ }^{7}$ potential locations for aboveground, away-from-reactor, dry-storage ISFSIs.

The potential siting for aboveground ${ }^{8}$, away-from-reactor, consolidated dry-storage ISFSIs is based on a process developed for electric power plant siting as discussed in a 2011 ORNL report prepared for EPRI. ${ }^{9}$ The 2011 ORNL report notes that an examination of various generation sources, including nuclear power, indicates that $300 \mathrm{GW}(\mathrm{e})$ of new nuclear electrical generating capacity will be needed by 2050 . With that need identified, an initial, obvious question was whether $300 \mathrm{GW}(\mathrm{e})$ of nuclear capacity can be sited in the United States. In an attempt to address that question and others, ORNL initiated an internal National Electric Generation Siting Study, an ongoing multiphase study addressing several key questions related to

\footnotetext{
${ }_{6}^{5}$ J. Kessler, Technical Bases for Extended Dry Storage of Spent Nuclear Fuel, EPRI Technical Report 1003416, December 2002.

${ }^{6} 10$ CFR 72, Licensing Requirements for the Independent Storage of Spent Nuclear Fuel, High-Level Radioactive Waste, and Reactor-Related Greater than Class $C$ Waste.

${ }^{7}$ Two optimization factors, among multiple factors to consider, were used in the study; minimizing SNF quantity-transportation distance and minimizing population along the transportation route.

${ }^{8}$ Geology was not factored into site evaluation criteria. Therefore, dry storage systems designed for an underground configuration such as the Holtec HI-STORM 100U may not be appropriate for all sites.

${ }^{9}$ G. T. Mays, R. J. Belles, O. A. Omitaomu et al., Application of Spatial Data Modeling and Geographical Information Systems (GIS) for Identification of Potential Siting Options for Various Electrical Generation Sources, ORNL Technical Report ORNL/TM-2011/157 prepared for EPRI, December 2011.
} 
our national electrical energy supply. This effort has led to the development of a tool, OR-SAGE (Oak

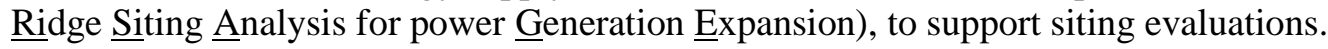

The objective in developing OR-SAGE was to use industry-accepted approaches and/or develop appropriate criteria for screening sites and employ an array of Geographic Information Systems (GIS) data sources at ORNL to identify candidate areas for a particular power generation technology application. As a guiding document, ORNL staff employed the general concepts presented in the 2002 EPRI Siting Guide ${ }^{10}$ methodology developed to support early site permit (ESP) applications. The concepts were used to develop exclusionary, avoidance, and suitability criteria for screening sites for nuclear power plants. For a given application, it is necessary to develop site evaluation criteria (SEC) that encompass a number of key screening criteria that essentially form the site environmental characterization for that application. These SEC might include population density, slope, seismic activity, proximity to cooling water sources, proximity to hazardous facilities, avoidance of protected lands and floodplains, susceptibility to landslide hazards, and others. OR-SAGE is a visual, relational database. The SEC are the fields of the database, and the GIS data for a given variable represent the values against which searches are performed. Figure 1 demonstrates the visual database concept. The database is tracking just under 700 million $100 \mathrm{~m}$ by $100 \mathrm{~m}(\sim 2.5$-acre $)$ cells.

The same principles that make the OR-SAGE tool useful in energy siting evaluations are applicable to other industrial concepts such as providing insight to siting consolidated ISFSIs. A waste storage and disposal solution for SNF is essential to the continued deployment of advanced reactors. This study provides insight into areas that can be used for consolidated ISFSI locations and subsequently demonstrating how an optimization methodology can be used for evaluating consolidated waste storage facility sites. This study does not include any evaluation of a waste disposal solution.

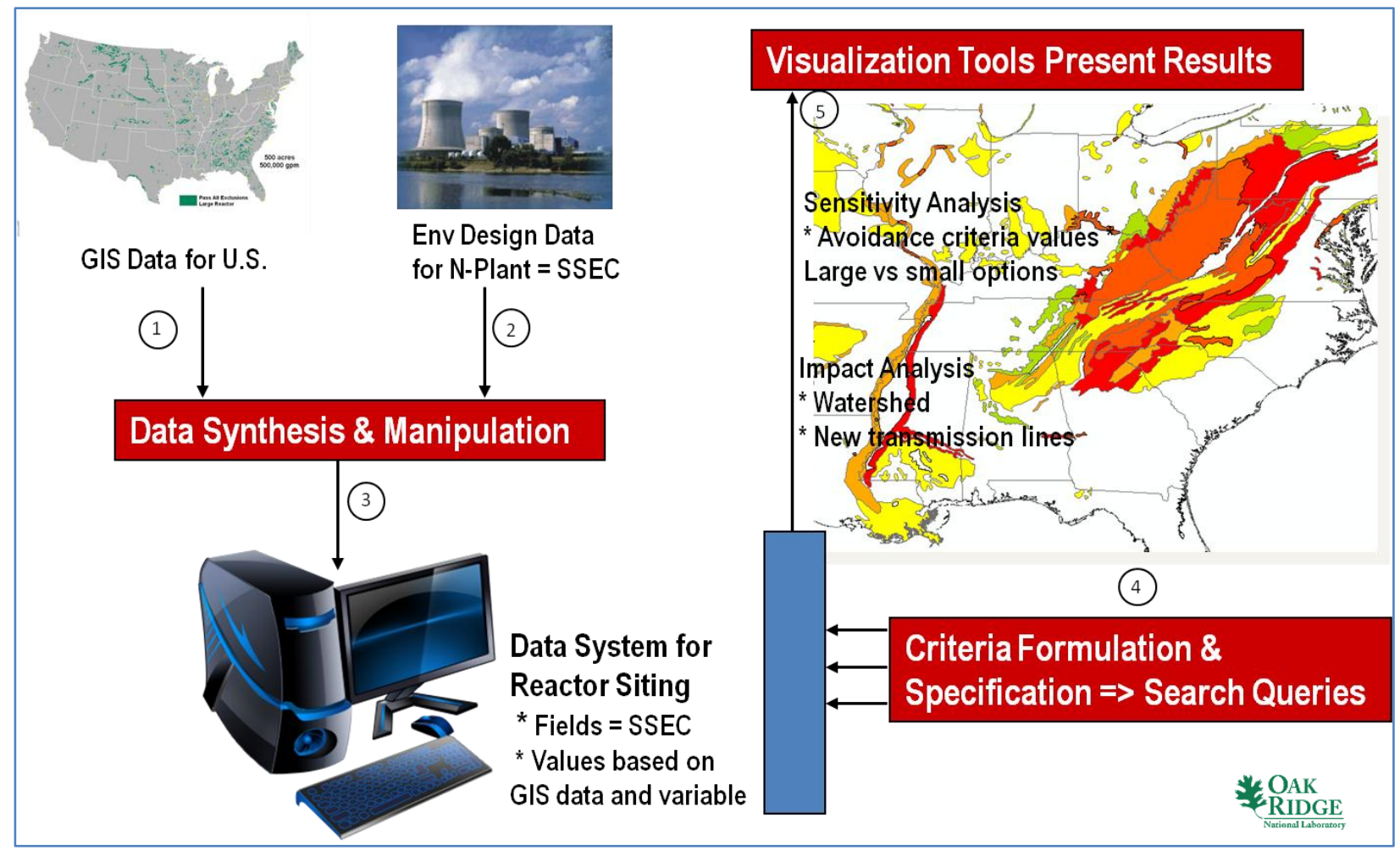

Fig. 1. OR-SAGE functions as a visual database.

\footnotetext{
${ }^{10}$ E. Rodwell (Project Manager), Siting Guide: Site Selection and Evaluation Criteria for An Early Site Permit Application, 1006878, Final Report, Electric Power Research Institute, March 2002.
} 


\section{$1.2 \quad$ INTRODUCTION}

The objective of this siting study work is to support DOE in evaluating integrated advanced nuclear plant and ISFSI deployment options in the future. This study looks at several nuclear power plant growth scenarios that consider the locations of existing and planned commercial nuclear power plants integrated with the establishment of consolidated ISFSIs. Using an appropriate optimization tool, a series of analyses were performed using the output from OR-SAGE for the sites of new nuclear power plants plus existing plants and the sites for interim waste storage facilities to provide an example of the methodology for optimizing the locations of the supporting ISFSI facilities.

This research project is aimed at providing methodologies, information, and insights that inform the process for determining and optimizing ${ }^{7}$ candidate areas for new advanced nuclear power generation plants and consolidated ISFSIs to meet projected US electric power demands for the future. This is accomplished using appropriate screening criteria and through the application of spatial modeling and GIS.

This report summarizes the approach that ORNL developed for screening and optimizing ${ }^{7}$ the ISFSI sites; forecasting advanced reactor sites; the methodology employed, including spatial modeling; and initial results for the contiguous United States. The objective in conducting this type of siting evaluation is to demonstrate the capability of the tool to perform early site characterization of the candidate areas to identify any particular issues for integrated advanced nuclear power plant and consolidated ISFSI siting; it is not intended to be a definitive assessment per se as to the overall suitability of any particular site. Furthermore, this study is not intended to preclude the utilization of volunteer sites. Rather, this study provides a tool to evaluate and rank proposed ISFSI sites against an example ISFSI site optimization plan. In other words, the optimized ISFSI results are intended to provide insight into the consolidated ISFSI storage issue and are not meant to imply an exact consolidated ISFSI siting answer.

\subsection{APPROACH AND METHODOLOGY}

The objective in structuring the approach for this study was to use industry-accepted practices in screening sites and then employ the proper array of data sources and identify candidate areas through the considerable computational capabilities of GIS technology available at ORNL. The methodology and results using the OR-SAGE tool documented in the 2011 ORNL study on potential siting options for various electrical generation sources ${ }^{9}$ were used to establish potential siting areas for consolidated ISFSIs, as well as scenarios involving reactor plant growth.

Essentially, the OR-SAGE tool (1) adapts and extends the 2002 EPRI Siting Guide ${ }^{5}$ methodology, developed to support ESP applications, for the purpose of screening sites and (2) employs three of the four steps in the Bechtel site evaluation process ${ }^{11}$ for nuclear plant siting. This same process is subsequently applied to consolidated ISFSIs. The screening process divides the contiguous United States into $100 \mathrm{~m}$ by $100 \mathrm{~m}$ (1-hectare) squares (cells), applying successive ISFSI suitability SEC to each cell. If a cell meets the requirements of each criterion, the cell is included as a candidate to be integrated in the possible siting of an ISFSI. Some SEC parameters preclude siting an ISFSI because of an environmental, regulatory, or land-use constraint. Other SEC assist in identifying less favorable areas such as proximity to saltwater. All of the selected SEC tend to recommend against sites. At this point, the suitability criteria are employed to assist in evaluating the acceptability of candidate areas and sites. The Bechtel evaluation process includes a successive four-step approach: (1) examining regions of the country, (2) examining regions of interest based on electricity and market projections, (3) identifying candidate areas, and (4) identifying candidate sites using various scoring and weighting factors.

\footnotetext{
${ }^{11}$ Dominion Energy, Inc., and Bechtel Power Corporation, Study of Potential Sites for the Deployment of New Nuclear Plants in the United States, prepared for the U.S. Department of Energy, September 2002.
} 
The focus of the ORNL screening and optimization of ISFSI study is on identifying and optimizing ${ }^{7}$ candidate areas from which potential sites might be selected, stopping short of performing any detailed site evaluations or comparisons. This approach is designed to quickly screen for and characterize candidate areas. In consideration of 10 CFR $72,{ }^{6}$ and the license application for the construction and operation of the ISFSI in Tooele County, Utah, ${ }^{12}$ a subset of SEC for ISFSI siting considered to have the most impact on the viability of any given site and directly amenable to application of GIS techniques was developed. Figure 2 provides an overview of the OR-SAGE tool application.

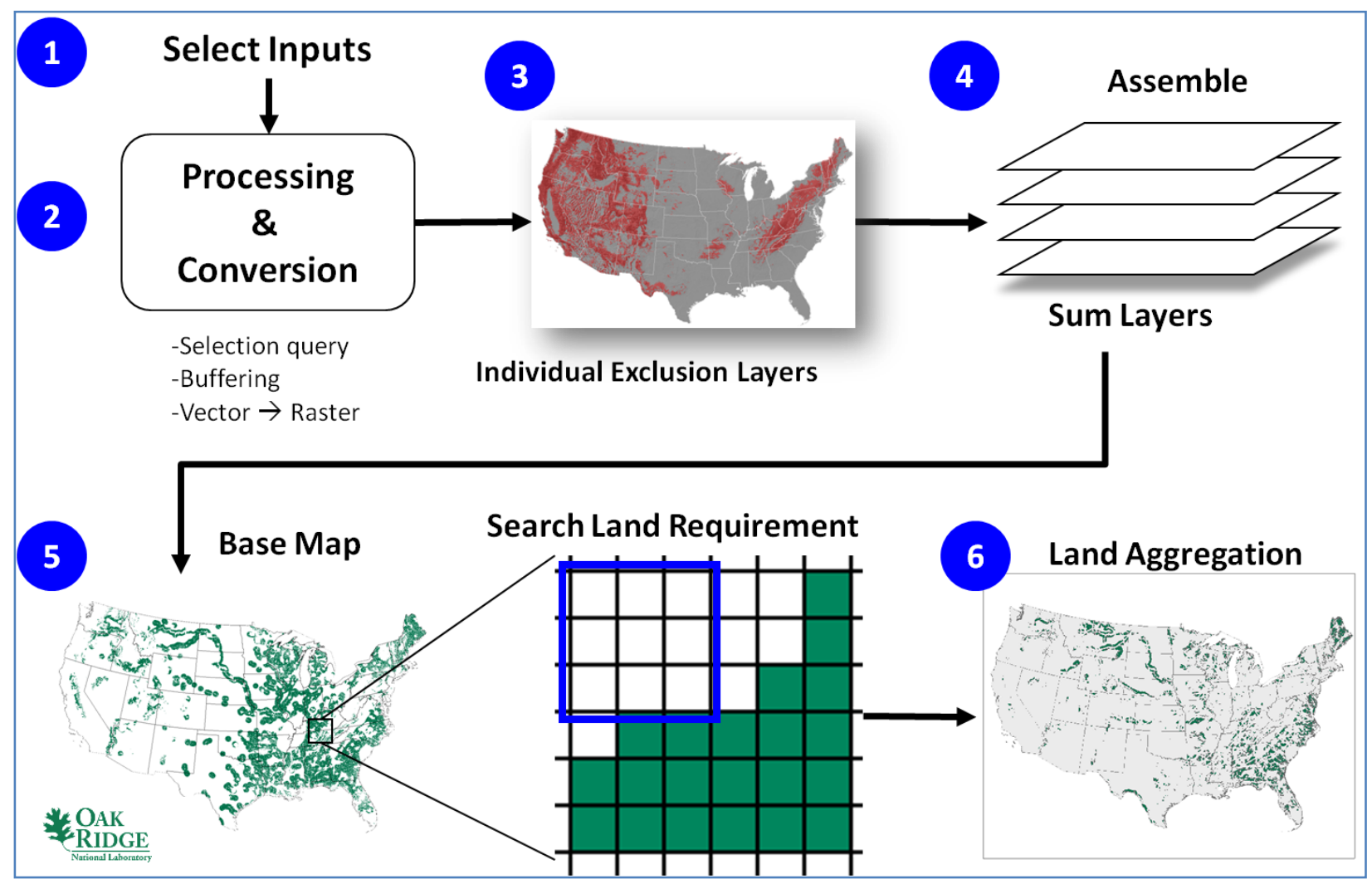

Fig. 2. Overview of the OR-SAGE tool process.

The first step shown in Fig. 2 is to select input datasets. Datasets that provide national or greater coverage with attributes matching the desired SEC are selected. The specific SEC identified for each power source are detailed as part of the results discussion for each individual power source. Greater than national coverage is preferred to prevent map "edge-effects." Appropriate scaling and resolution of each dataset must be considered before using a dataset in the study. There are 22 datasets in the nuclear portion of the OR-SAGE tool. The nuclear dataset sources include

- US Geological Survey (USGS),

- US National Park Service,

- US Forest Service,

- US Fish and Wildlife Service,

- Department of Transportation,

- Federal Emergency Management Agency,

\footnotetext{
${ }^{12}$ US Nuclear Regulatory Commission, Final Environmental Impact Statement for the Construction and Operation of an Independent Spent Fuel Storage Installation on the Reservation of the Skull Valley Band of Goshute Indians and the Related Transportation Facility in Tooele County, Utah, NUREG-1714, Vol. 1, Washington, DC, December, 2001.
} 
- Federal Aviation Administration (FAA),

- US Census Bureau,

- ORNL LandScan Data,

- ORNL 7-Day, 10-Year Low Flow Calculated Data, and

- other commercial sources.

The next step in Fig. 2 is to process and convert the input datasets. This involves vector-to-raster conversion and raster reclassification. The datasets are typically not to the same scale. The conversion process allows all the data sets to be represented to the same scale on a common map. In the GIS spatial modeling process, $100 \mathrm{~m}$ by $100 \mathrm{~m}$ cell sizes were created (approximately 2.5 acres per cell). For comparison, there are approximately 1.8 billion acres in the contiguous United States, which excludes Alaska and Hawaii. Figure 3 shows how a vector-based randomly shaped area is converted to raster and the effectiveness of the conversion based on the cell size.

This stage also involves generating an appropriate selection query and applying any required buffer zone. The application of the buffer zone can be a complex process. For example, one of the nuclear power plant SEC is population density of less than 500 people per square mile. Nuclear Regulatory Commission (NRC) Regulatory Guide $4.7^{13}$ indicates that "a reactor should preferably be located such that, at the time of initial site approval and within about 5 years thereafter, the population density, including weighted transient population, averaged over any radial distance out to 20 miles (cumulative population at a distance divided by the circular area at that distance), does not exceed 500 persons per square mile." To meet the guidance, each cell in the database is queried for ambient population, which considers the weighted transient population. If a cell is greater than 500 people per square mile, it is immediately excluded from the sample set. If a cell population is less than 500 people per square mile, the surrounding area is evaluated by calculating the population density in an expanding set of rings out to a maximum of 20 miles (in simple terms, a buffer zone). If any ring is calculated to have a population density above 500 people per square mile, then the center cell is excluded. If no ring around the central cell exceeds a population density of 500 people per square mile, then the cell remains viable with regard to population. Figure 4 shows a representative result of a population dataset query with a standoff distance considered. The maximum search radii can be set to any value to create alternate standoff distances. For other generation sources that do not require a "buffer" zone, no ring calculation is performed.

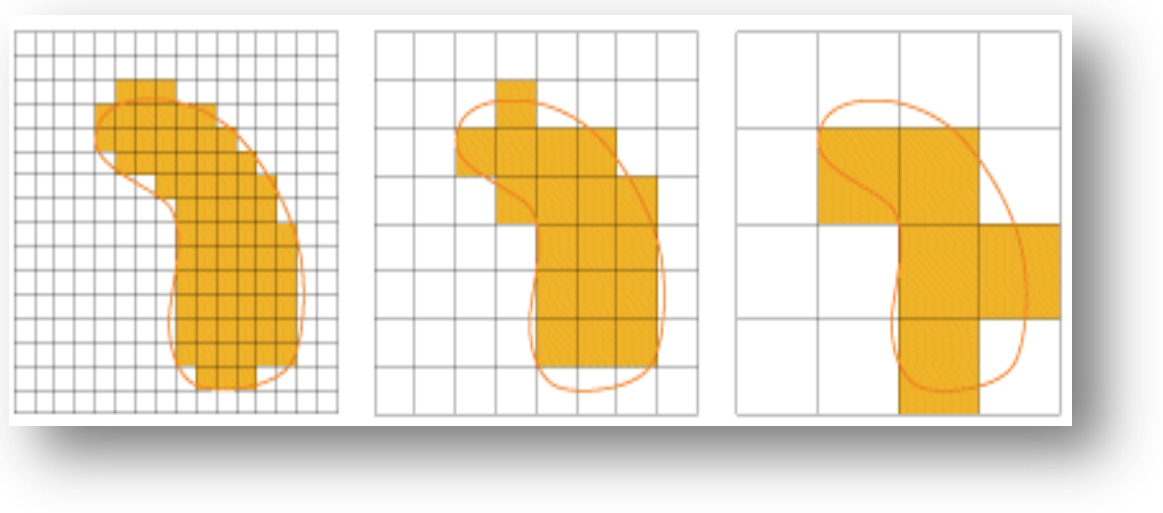

Fig. 3. Vector-to-raster conversion.

\footnotetext{
${ }^{13}$ US Nuclear Regulatory Commission, General Site Suitability Criteria for Nuclear Power Stations, Regulatory Guide 4.7, April 1998.
} 


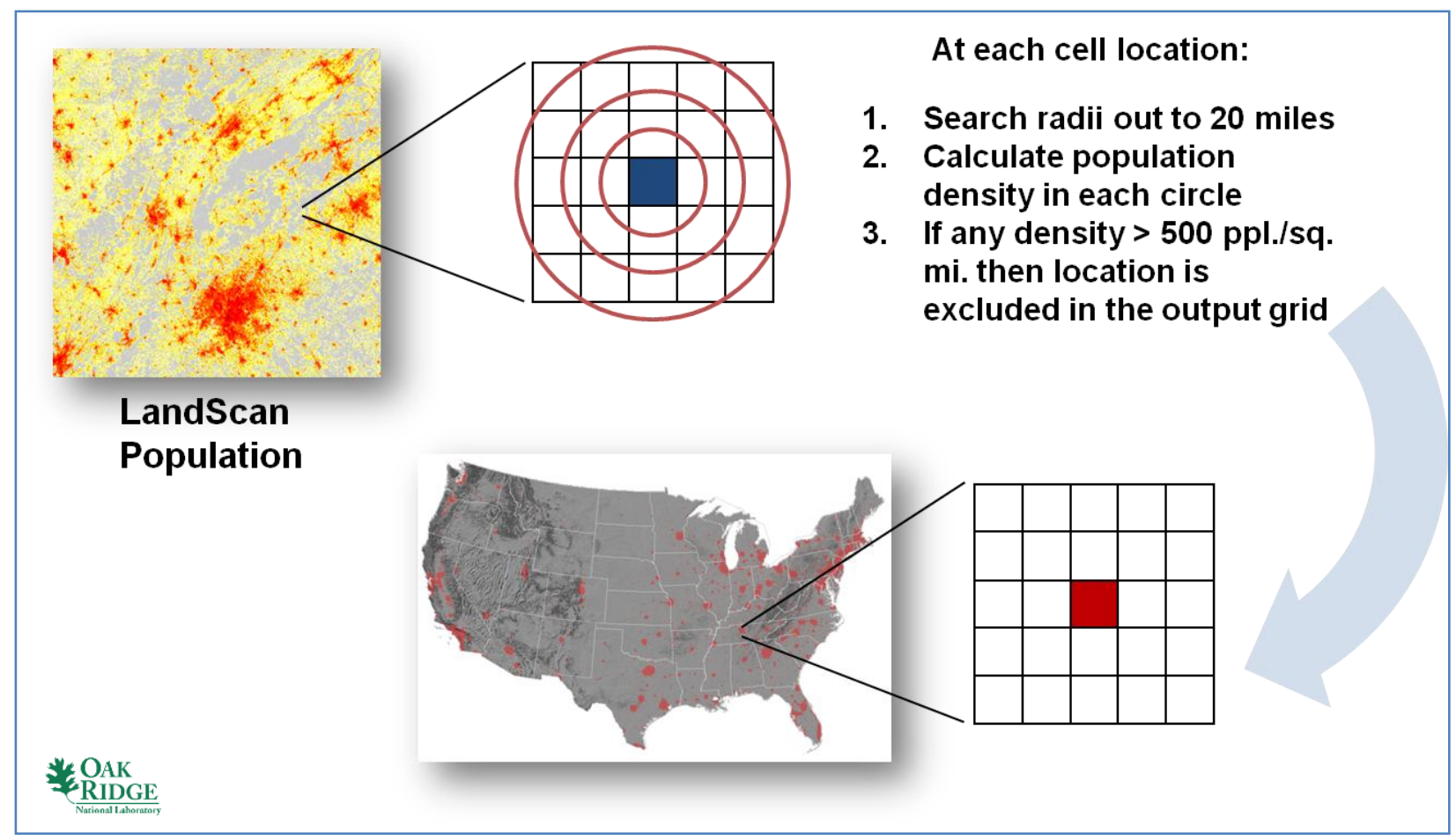

Fig. 4. Sample population calculation for each grid cell.

Buffering can also be a much simpler process, such as applying an area of land around a known geological feature. For example, Fig. 5 shows a stream segment and a 20-mile buffer zone to allow for pumping cooling water to a thermal power plant.

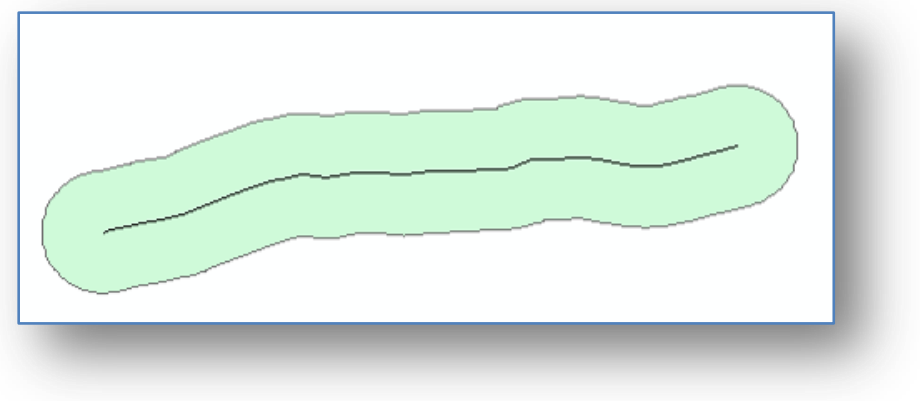

Fig. 5. Sample river and piping distance buffering.

The third step shown in Fig. 2 is to create the individual SEC layers for the ISFSI. Appropriate screening criteria are selected and the individual SEC layers are built based on available data. Some SEC layers are a direct representation of available data, and some are a composite of information from multiple sources. Areas that do not meet the specific criteria are typically highlighted in red on these individual SEC layer maps.

Next, in step four shown in Fig. 2, the individual SEC layers are assembled into a single output. Essentially, the applicable layers are summed cell by cell. The result is a highlighted US contiguous map of all the areas that do not pass one or more of the envelope criteria for a consolidated ISFSI. During this step, individual layers can be moved in and out of the study to conduct sensitivity analyses. The limits associated with any given SEC layer can also be adjusted to conduct sensitivity analyses. 
Since the desired result is to identify candidate areas where an ISFSI is viable, the highlighted portions of the map are "inverted" in step five of Fig. 2. The result is a highlighted US contiguous map of all the areas that have no siting challenges based on the chosen site selection and evaluation criterion. The result is considered to be the base map for consolidated ISFSIs. In effect, it is a static look in time at a set of criteria that are thought to bind the placement of an ISFSI. Each individual 100 by $100 \mathrm{~m}$ cell that passes every site SEC is typically highlighted in green on the base map. Figure 6 depicts the overall concept of the application of OR-SAGE in general by applying the individual SEC as GIS datasets to exclude areas (red map) leading to the identification of candidate areas (green map). Other considerations are available for map areas that have one or more siting challenges.

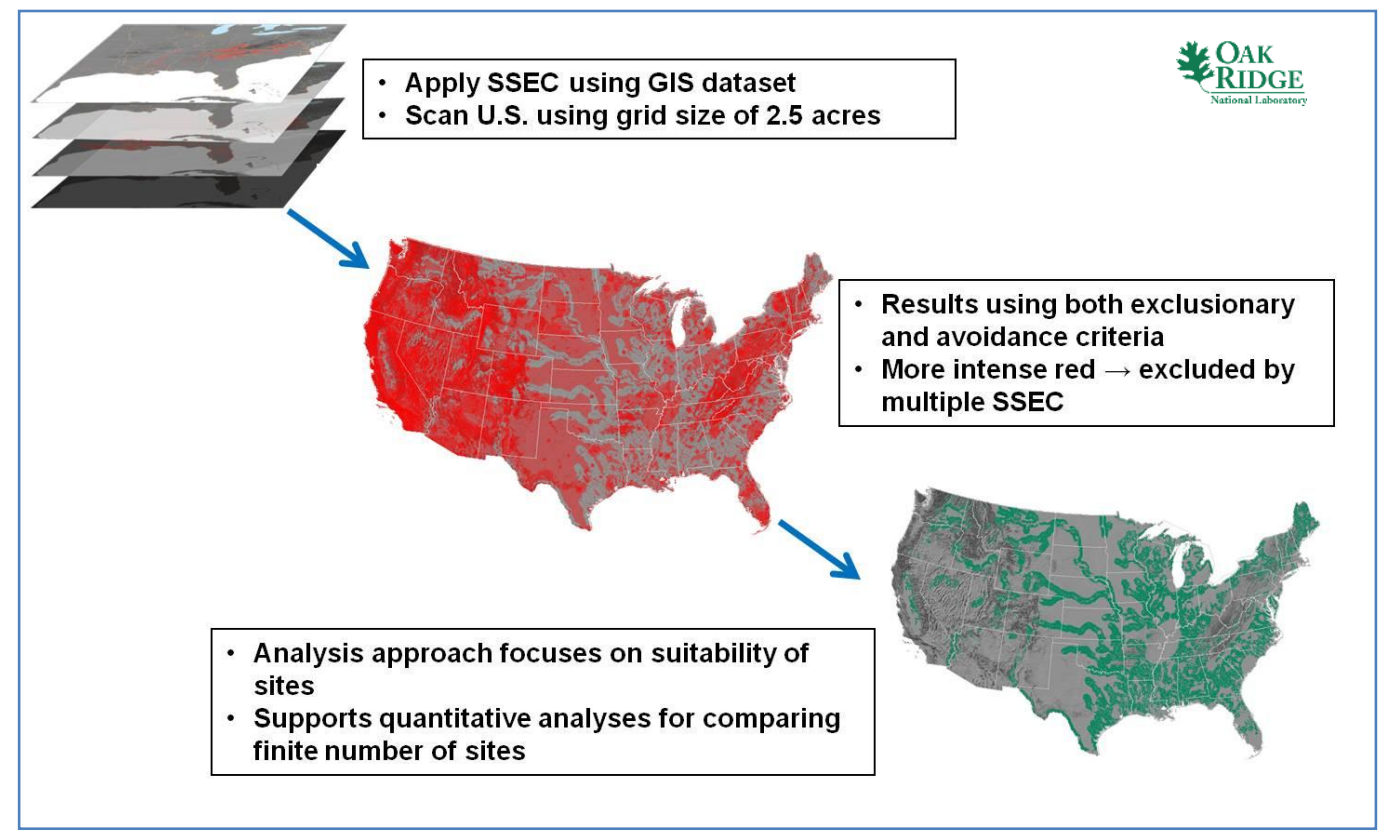

Fig. 6. Generating a base map with no siting challenges.

Given that a single cell represents approximately 2.5 acres of land, a land search must be conducted to identify realistically sized, connected plots of land that can support the typical size of a nominal ISFSI. The land aggregation process is considered to be the initial sensitivity study for an ISFSI. Cells that cannot be combined into a larger plot of land to support a representative storage facility are "turned off" in the output display. The result is a pared-down base map identifying candidate areas where the power source of interest could realistically be sited. This land aggregation process is discussed in Section 2.1, Methodology for Aggregating Land for the Typical ISFSI Size.

It must be stressed that the net result is a visualization of the candidate areas that could support an ISFSI. This is not meant to suggest an actual storage facility siting. Little is known of the underlying land ownership, except that the land is generally not in a high-population area, nor in most cases is the land situated on protected land such as a national park or forest. Furthermore, these results as presented from all the various siting analyses, reflect a set of technical assumptions, parameters, and constraints. There was no attempt to incorporate or reflect political factors, although that is certainly within the capability of the OR-SAGE tool.

It should also be noted that in many cases, the actual consolidated ISFSI sites selected by the government would likely be larger than 400 acres. However, not all the land supporting an ISFSI site needs to meet all SEC. 
When the area supporting potential consolidated ISFSI sites is established, calculations are made to forecast the most favorable or optimized ${ }^{7}$ locations for a waste storage facility based on selected optimization metrics. Reactor sites are linked to the nearest rail depot. In the example in this report, considerations are made for minimizing the overall transportation distance considering the amount of accumulated waste at any given reactor site and/or minimizing the dose risk to the population along the transportation corridor. A dedicated train algorithm, based on Dijkstra's shortest path algorithm, ${ }^{14}$ is used to find all possible routes from all reactor sites to all potential storage sites using up to five consolidated ISFSI locations. For each route, the summation of total travel distance and total population within a railroad buffer zone are calculated and minimized as appropriate.

Three possible reactor power plant growth scenarios for commercial nuclear power in the United States are considered in the consolidated ISFSI optimization ${ }^{7}$ analyses. The three commercial nuclear power scenarios are (1) a status quo scenario with no future commercial nuclear power growth, (2) a scenario with moderate commercial nuclear power growth, and (3) a scenario with aggressive commercial nuclear power growth that includes advanced reactor concepts. Appropriate assumptions for all the scenarios were made as described in Section 4 as to relicensing of existing commercial nuclear power plants,

development time frames for additional advanced reactors, and identification of suitable locations for these plants.

${ }^{14}$ E. W. Dijkstra, “A Note on Two Problems in Connexion with Graphs,” Numerische Mathematik 1(1), 269-271, 1959. 


\section{CRITICAL ASSUMPTIONS}

Critical assumptions supporting this work include a tool methodology to provide an adequate siting footprint for a typical storage facility; a methodology to account for operating cycles and the accumulation of SNF at individual reactor sites; a methodology to represent railroad access for shipping; and a methodology to account for population along various rail routes.

Additional study assumptions that were made to simplify the optimization analysis include the following.

1. The target year to optimize the storage of accumulated SNF is 2050.

2. All optimized interim storage facilities will exist simultaneously in 2050 .

3. Optimization at $99 \%$ confidence level is acceptable to save computational time.

4. Population is evaluated at 50\% day-50\% night levels along the shipping path within a $1600-\mathrm{m}-$ wide corridor.

5. SNF waste shipments will utilize dedicated DOE rail equipment that avoids train yard reconfiguration and transfer between various company-owned rail lines.

6. The time sequence of SNF relocation to an ISFSI is not considered in this initial waste storage study.

7. Stranded plant waste priority is not considered in the optimization strategy because time is not a factor.

8. The amount of accumulated waste at individual sites is not a prioritization factor in the optimization strategy because time is not a factor.

9. The total nuclear utility industry SNF calculation drives number of sites using an integer optimization.

10. To limit the overall data set size for the optimization routine, only acceptable ISFSI sites within 50 miles of existing rail lines are considered.

\subsection{METHODOLOGY FOR AGGREGATING LAND FOR THE TYPICAL ISFSI SIZE}

As stated previously, the GIS spatial modeling process reports results based on 100 by $100 \mathrm{~m}$ cell sizes, or approximately 2.5 acres per cell. This does not provide an adequate footprint for most siting applications. Thus, it was necessary to develop an algorithm to aggregate individual cells into a sufficient land size to support the core footprint for an ISFSI site. It was understood that an ISFSI operator may choose to purchase and provide a large land mass around a given ISFSI site. However, not all of the ISFSI-owned land would need to meet the specific SEC to support the ISFSI siting. An evaluation of the ISFSI licensed facility proposed for Skull Valley in Utah yielded a minimum ISFSI footprint of 400 acres. As a result, the land aggregation process is actually the first sensitivity study ISFSI siting, because the minimum footprint assessment is subjective.

\subsubsection{Basic Approach to Collect GIS Cells}

It was assumed that a square footprint was a reasonable footprint representation. This greatly simplified the algorithm and computation time required to aggregate the GIS cells into blocks of land that could support an ISFSI footprint. A 400-acre square consists of enough 100 by $100 \mathrm{~m}$ cells on a side to ensure that the minimum footprint size would be captured within the square. For example, a 400-acre square would be 13 GIS cells on a side and actually encompass approximately 418 acres of land.

Subsequently, all the cells inside the ISFSI core footprint square under evaluation must pass all of the SEC for all of the cells in the entire square to be considered available for the ISFSI site. Figure 7 shows two simple examples; one clearly fails because no cells in the red square (representing a core footprint for 
an ISFSI) under consideration pass all the SEC for that power supply. The second clearly passes because all the cells within the red square pass all the SEC. This process is repeated for the entire contiguous United States by moving the core footprint land-aggregation square one complete square length (i.e., nine cells in this simple example) to the right or one complete square height (i.e., 9 cells in this example) down and evaluating the GIS cells within the square.

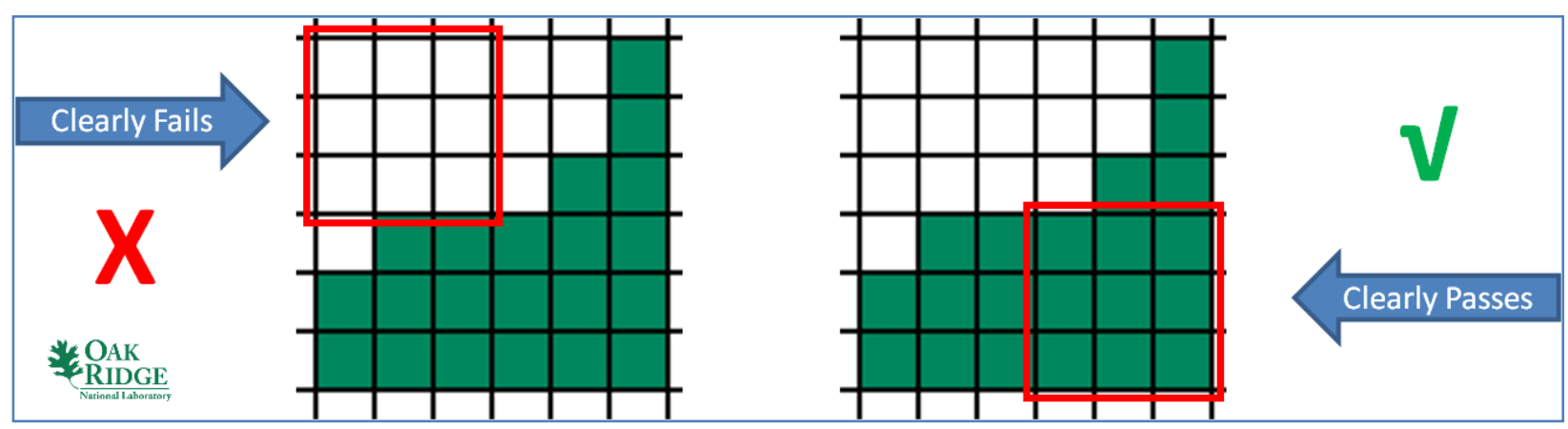

Fig. 7. Simple land aggregation process examples.

If any GIS cells within the land-aggregation square do not pass all of the SEC for the ISFSI siting, then all the GIS cells being evaluated are considered to fail the sensitivity analysis for land aggregation. This net result of the sample land aggregation process is shown in Fig. 8. The lower left corner (red square) land aggregation sensitivity evaluation fails because one of the nine cells in the sample case fails at least one SEC. The upper right corner (red square) land aggregation sensitivity evaluation fails because five of the nine cells in the sample case fail at least one SEC. The net effect of the land aggregation sensitivity analysis is shown in the lower right corner of Fig. 8. Based on how the land-aggregation square hits the region of land under consideration in the example case shown, only the nine GIS cells in the lower right corner of the region pass the land aggregation sensitivity study for the ISFSI criteria under consideration. Therefore, in this 36-cell GIS region, only the nine GIS cells shown in green would continue to be viable for placement of an ISFSI.

This process causes a very conservative estimation of the land available for the prospective placement of an ISFSI. Therefore, some less conservative alternatives were considered.

One approach is to move the land-aggregation square one row or one column at a time and repeat the aggregation evaluation. In the sample case shown in Fig. 8, this would result in an additional 6 GIS cells being included in the land aggregation study results. Although this would greatly increase the presumed accuracy of the results, the computational time associated with this approach would also increase substantially. The power of OR-SAGE is its ability to quickly adjust individual SEC layer limits and reevaluate the results. Despite the presumed increase in accuracy from using this approach, the substantial wait time between results would likely lead to less use of OR-SAGE for the intended purpose of identifying candidate ISFSI areas. 


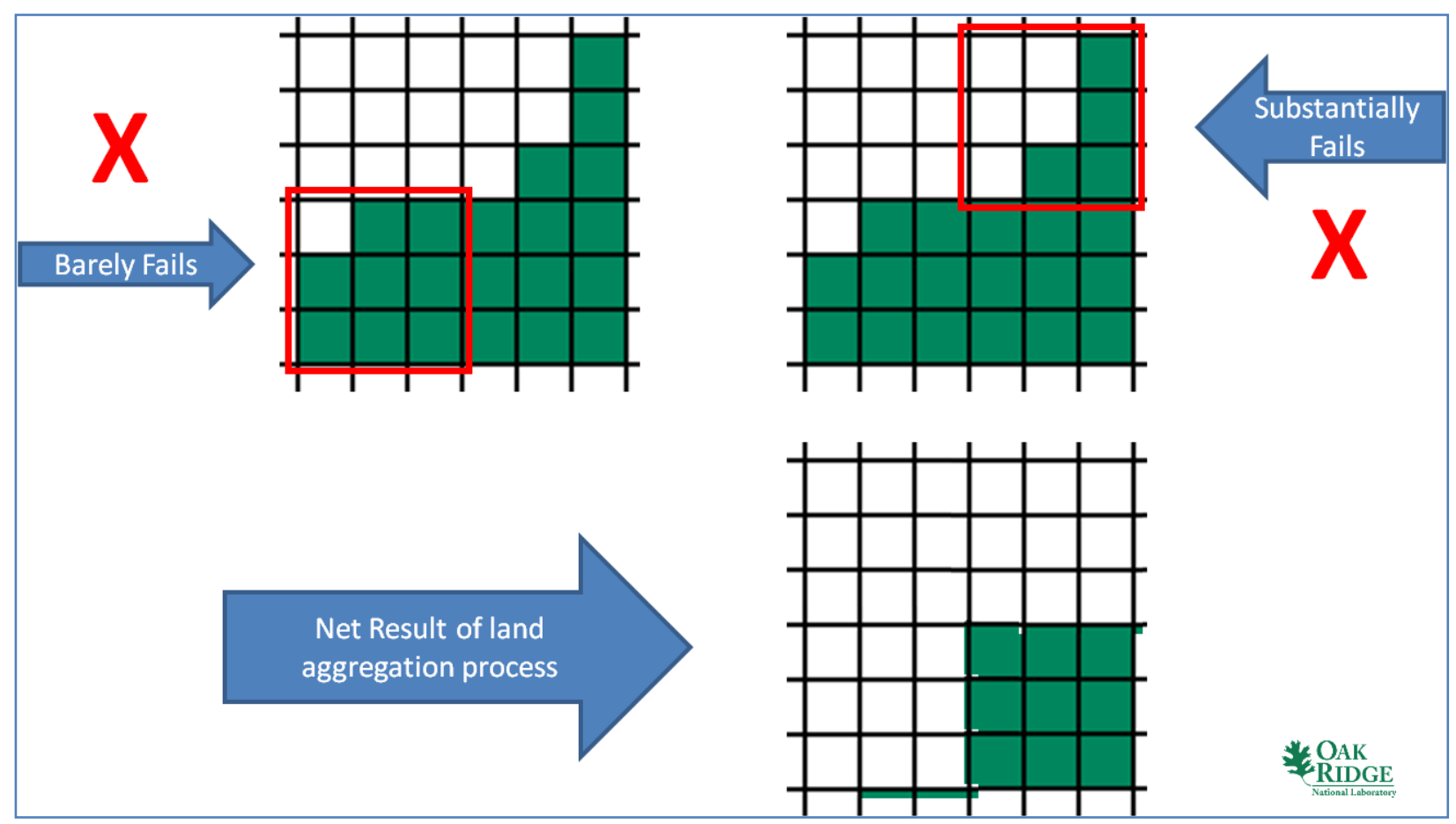

Fig. 8. Sample land aggregation process results over a larger area.

Another approach is to consider each individual GIS cell that passes and draw a different shape, such as a circle, around the cell that encompasses the exact acreage assumed for each power source. By evaluating whether each single cell could be a part of a reasonably shaped 400-acre footprint, fewer GIS cells would be eliminated in the aggregation process. The advantage of this approach would be that fewer near-miss GIS cell eliminations would occur, such as the upper left evaluation in Fig. 8. However, as with the previous approach, this would be computationally intense and, therefore, reduce the effectiveness and efficiency of the OR-SAGE tool.

A third approach was to reconsider the stringent requirements made on the simple square approach that required all GIS cells under consideration to pass in order for the GIS cells to be retained for consideration of an ISFSI location. This approach is discussed in the next section.

\subsubsection{Alternative Approach to Collect GIS Cells}

Though the examples shown in Figs. 7 and 8 are simplified and show only an evaluation of nine GIS cells at a time, it is not unreasonable to consider allowing a handful of failed GIS cells within the landaggregation evaluation square without failing the entire square. For example, if one square were allowed to fail the land aggregation screening process in the simplified case above without causing all the GIS cells under consideration to be failed, then the revised results would be as shown in Fig. 9. 


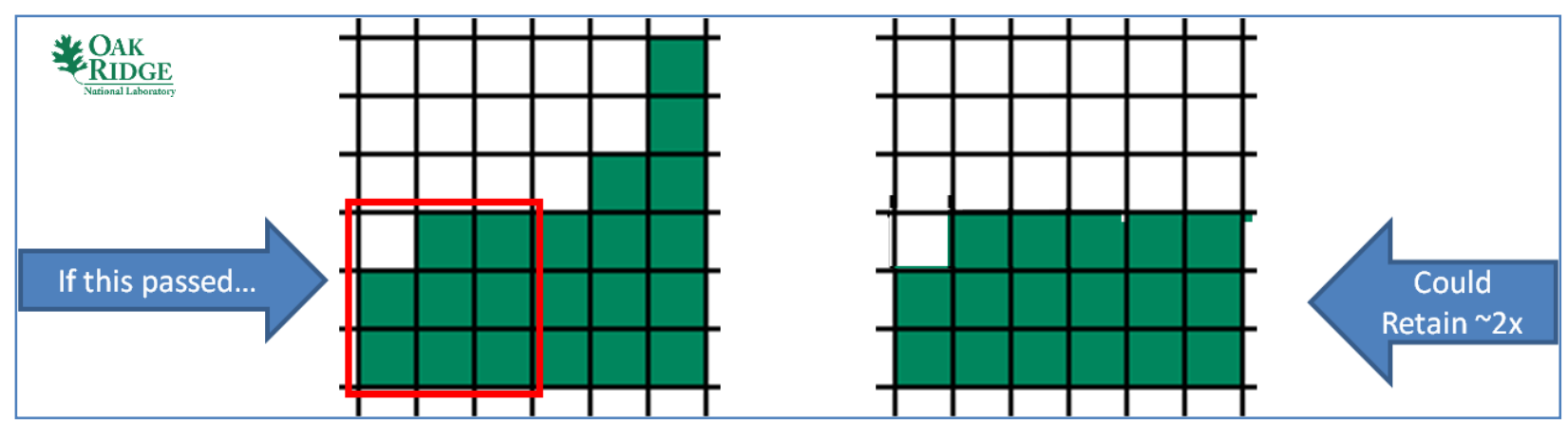

Fig. 9. Land aggregation example results with consideration for small flaws.

Only one cell fails in the left example shown in Fig. 9. Therefore, eight of the nine GIS cells are retained from this land-aggregation square and are added to the nine GIS cells previously retained. This results in a substantial increase in the number of GIS cells available for potential placement of an ISFSI. Note that the single GIS cell or "hole" that fails is not turned green in the land aggregation sensitivity result because it actually failed one or more SEC for that power source.

For the purposes of this study, it was assumed that if no more than $10 \%$ of the GIS cells failed within the aggregation square, then the GIS cells that did pass all SEC could be retained as part of the land aggregation sensitivity analysis. In the case of a 400 acre land requirement, 418 acres is actually analyzed with each land-aggregation square. If no more than $10 \%$ of this land mass is allowed to fail one or more SEC, then at least 376 acres is actually retained, albeit with a few holes. However, this allows a significant increase in the retained land for candidate power source areas. The nominal ISFSI analyzed is actually mapped at $4000 \mathrm{ft}$ by $4000 \mathrm{ft}$ or 367 acres. Therefore, this process matches well with the nominal plant size.

As an example of this process, Fig. 10 shows the results of a plant aggregation sensitivity analysis on a 500 acre power plant. The areas shown in dark green (solid, no white) are land-aggregation square blocks that contain GIS cells that have no siting challenges based on the selected SEC input parameters for the power plant. The lighter green areas with white spaces represent land-aggregation square blocks that failed the initial land aggregation screening based on one or more GIS cell SEC siting challenges within the power plant land aggregation square.

Figure 11 shows the added 500-acre land-aggregation square blocks that pass the land aggregation sensitivity analysis when up to $10 \%$ of the GIS cells within the land aggregation square are allowed to fail one or more SEC for that power source. The additional 500-acre power plant blocks identified in Fig. 11 are shown in solid light blue for illustration purposes. The individual GIS cells with one or more siting challenges in these light blue areas would actually be retained as failed and would ultimately be shown as white space. The light green areas in Fig. 11 with white space are those 500-acre blocks where more than $10 \%$ of the GIS cells had one or more siting challenges for that power source. 


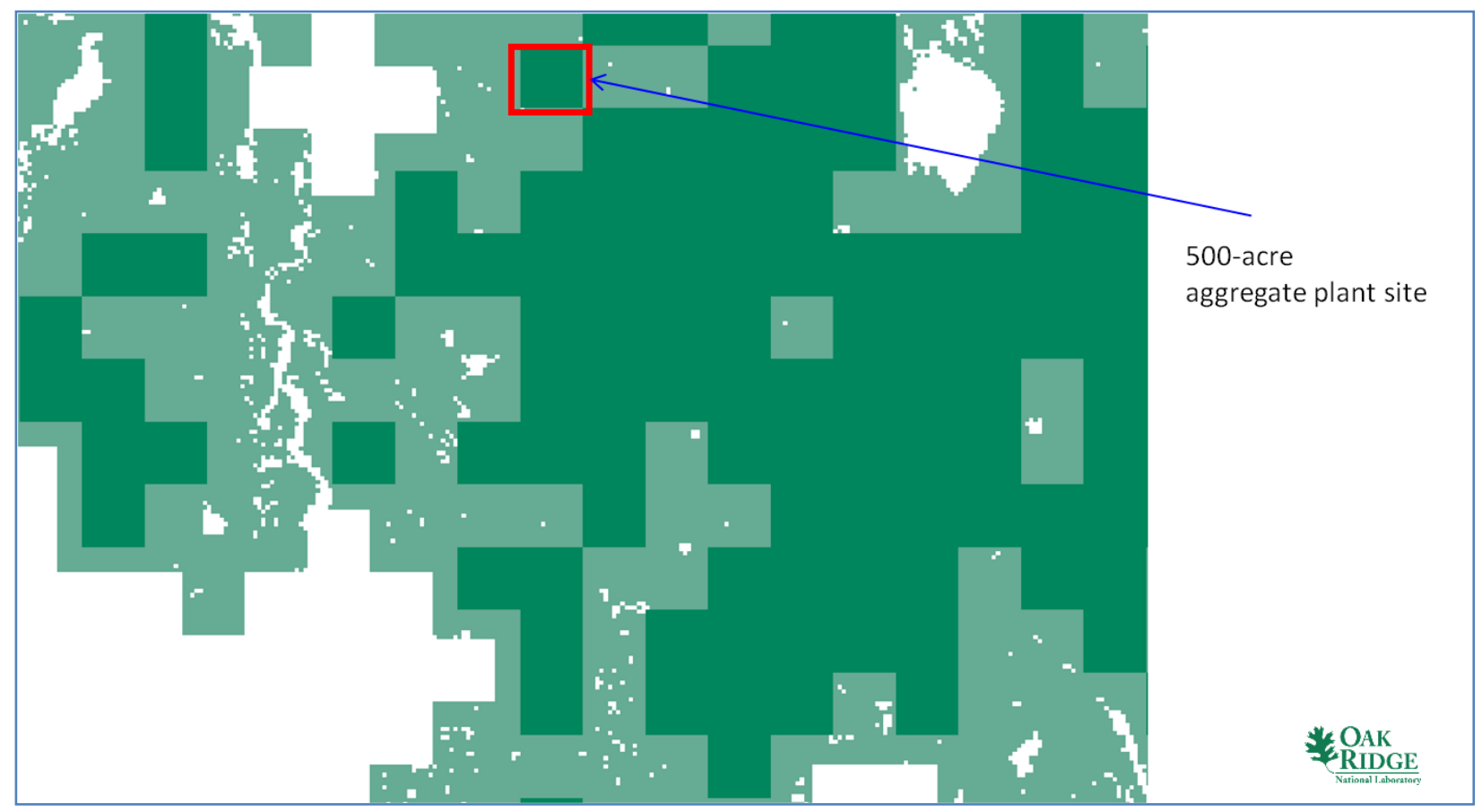

Fig. 10. Sample 500-acre power plant aggregation results with no cells with siting challenges.

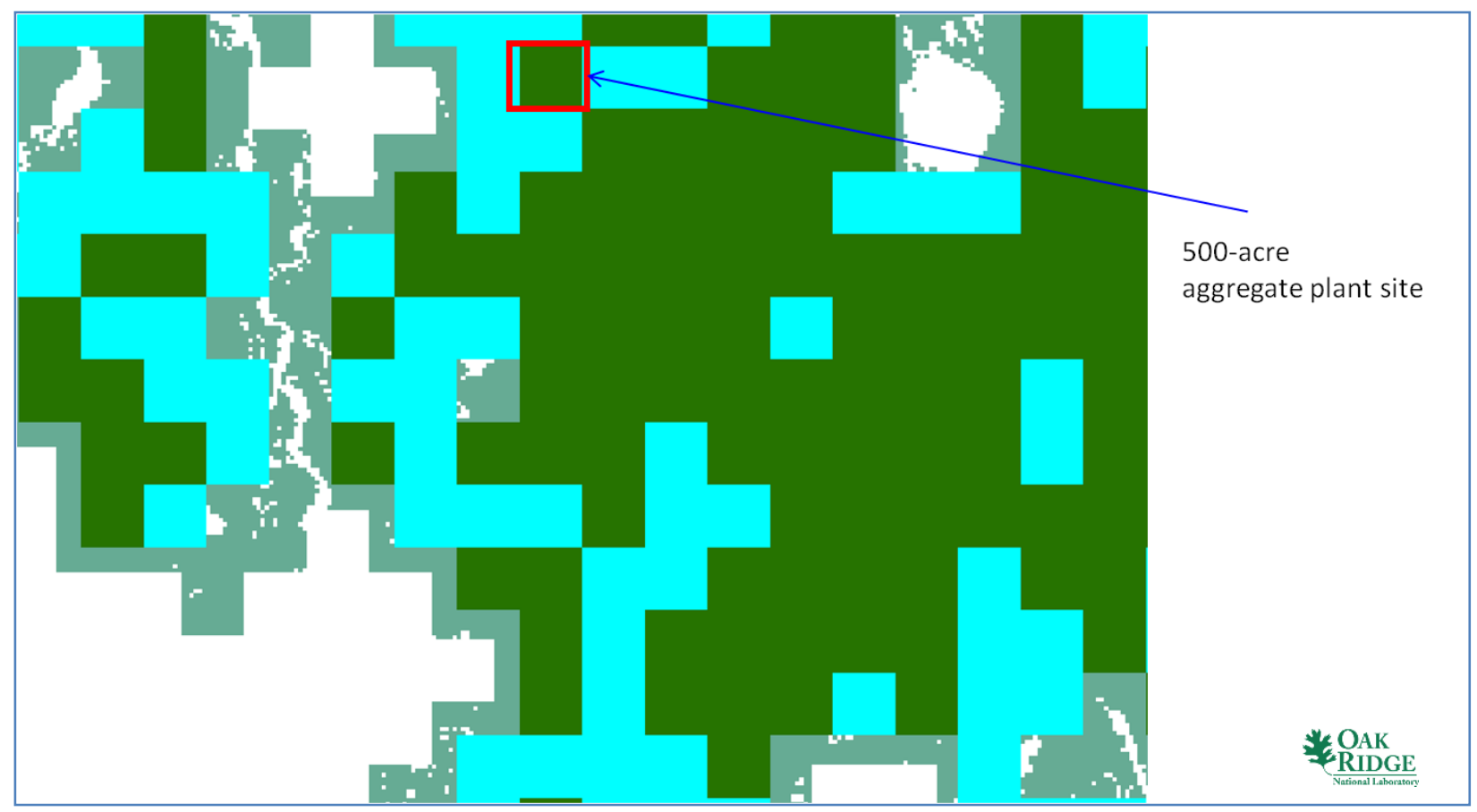

Fig. 11. Sample 500-acre power plant aggregation results with less than $10 \%$ cells with siting challenges.

This alternate land aggregation methodology strikes a reasonable balance between the very conservative requirement that all GIS cells within the land-aggregation square pass all SEC for the ISFSI site, and the more computationally intense alternatives. The results of using this approach are shown in Table 1. 
Table 1. Contiguous US land available for ISFSI siting

\begin{tabular}{lc}
\hline $\begin{array}{c}\text { Land available for ISFSI }(\% \\
\text { contiguous US land) }\end{array}$ & $\begin{array}{c}\text { 400-acre } \\
\text { ISFSI }\end{array}$ \\
\hline Initial base map & $48.3 \%$ \\
Aggregate map-100\% pass rate & $28.0 \%$ \\
Aggregate map-90\% pass rate & $42.3 \%$ \\
\hline
\end{tabular}

Table 1 shows that for ISFSI siting, more than $40 \%$ of the GIS cells initially identified as suitable are discarded in the aggregation sensitivity analysis with a requirement that $100 \%$ of the GIS cells within the land-aggregation square must pass all SEC. However, less than $15 \%$ of the ISFSI GIS cells are discarded in the sensitivity analysis where at least $90 \%$ of the GIS cells within the land-aggregation square must pass all SEC.

\subsection{METHODOLOGY TO ACCOUNT FOR OPERATING CYCLES AND THE ACCUMULATION OF SPENT NUCLEAR FUEL AT INDIVIDUAL REACTOR SITES}

The amount and point of origination of SNF that will be stored at the ISFSI sites are important considerations affecting ISFSI siting. In 2003, the US Department of Energy, through the Energy Information Administration, collected and distributed the RW-859 (2002) data, ${ }^{15}$ which includes detailed plant-specific SNF data through the end of 2002. The dataset includes, among other things, the initial uranium loading and final discharge dates for over 160,000 individual pressurized water reactor (PWR) and boiling water reactor (BWR) fuel assemblies. Unfortunately, more recent detailed data are not generally available. Consequently, the RW-859(2002) data was used to estimate the amount of fuel that will have accumulated at each plant by the year 2050 .

The estimates included the actual discharge information through 2002 supplemented with estimates for continued fuel discharges through the end of the license period, including currently approved license extensions, for each plant. The post-2002 estimates were based on the plant-specific average fuel assembly discharges over the last 5 years of the RW-859(2002) data (i.e., 1998 through 2002) applied from 2003 through the end of the license period and included a full-core offload in the final year of plant operation. These estimates do not include the effects of the gradual movement to higher initial fuel enrichments and higher final discharge burnups that should result in a reduction in the total amount of fuel that will be discharged by 2050 . The estimates also do not include anticipated license extensions or power uprates that have not yet been approved. Future work could include incorporation of more current SNF inventory data.

\subsection{METHODOLOGY TO REPRESENT RAILROAD ACCESS FOR SHIPPING AND POPULATION ALONG THE ROUTE}

In a 2006 report, ${ }^{16}$ the National Academy of Sciences, Committee on Transportation of Radioactive Waste, endorsed the DOE decision to ship SNF and high-level waste principally by rail using dedicated trains. The committee found that rail transportation of SNF is a "low radiological-risk activity with manageable safety, health, and environmental consequences when conducted with strict adherence to existing regulations." This formed the basis of the assumption in this study that all SNF transportation would take place by rail except for the transport of SNF from the point of origin at the nuclear power

\footnotetext{
${ }^{15}$ Energy Information Administration, Form RW-859, "Nuclear Fuel Data," US Department of Energy, 2002.

${ }^{16}$ National Academy of Sciences, Going the Distance? - The Safe Transport of Spent Nuclear Fuel and High-Level Radioactive Waste in the United States, Committee on Transportation of Radioactive Waste, 2006.
} 
plant to the railhead. This assumption fit well with the limited scope of this study. Furthermore, the Blue Ribbon Commission report ${ }^{17}$ indicates that the total number of shipments will be reduced by a factor of five by using a rail-only option. A rail spur line is assumed to be constructed for the transport of SNF from the railhead to the consolidated ISFSI.

\subsubsection{Data Resources: LandScan and TRAGIS}

This study uses two systems to estimate the transportation cost and population exposure risk during transport the nuclear waste materials. They are a high-resolution population distribution database, LandScan $^{\mathrm{TM}}$, and a transportation analysis tool, Transportation Routing Analysis Geographic Information System (TRAGIS). Both systems are developed by ORNL.

\subsubsection{LandScan ${ }^{\mathrm{TM}}$, A High Resolution Population Distribution System}

LandScan ${ }^{\mathrm{TM}}$ provides high-resolution global population distribution data representing an ambient population (average over 24 hours). The LandScan ${ }^{\mathrm{TM}}$ algorithm uses spatial data and imagery analysis technologies and a multi-variable dasymetric modeling approach to disaggregate census counts within an administrative boundary. LandScan ${ }^{\mathrm{TM}}$ is readily adaptable to various socio-environmental studies, including exposure/heath risk assessment, urban sprawl estimation, and estimating population at risk from natural and anthropogenic disasters. It uses an innovative approach with GIS and remote sensing technologies with various spatial information sources to reconstruct synthetic population distribution databases. LandScan ${ }^{\mathrm{TM}}$ has two databases, the LandScan Global and LandScan USA. The LandScan Global covers the entire world with a special resolution of 30 arc second $(\sim 1 \mathrm{~km})$. The LandScan USA has a spatial resolution of 3 arc seconds ( $\sim 90 \mathrm{~m}$ ) that covers the continental United States (CONUS), Alaska, and Hawaii. Each database has two layers, a nighttime and a daytime population distribution.

\subsubsection{TRAGIS, A Transportation Analysis Tool}

The TRAGIS model is designed for modeling transportation routing. TRAGIS was originally built for DOE for routing high-visibility shipments of spent nuclear fuel and nuclear waste. Currently, TRAGIS is used for routing, alternative route analysis, and transportation infrastructure assurance analysis. TRAGIS offers numerous options for route calculation utilizing unique value-added network databases for highway, rail, and waterway infrastructures in the continental United States. The model also provides estimates of population at risk for all transportation segments through integration with the LandScan USA model. It has two major components, a national multi-modal network database (highway, railway, waterway, and transshipment points among different modes) and various transportation algorithms. The national multi-modal network database is 1:100,000-scale routing networks developed from the US Geological Survey (USGS) Digital Line Graphs (DLG) and the US Bureau of Census Topologically Integrated Geographic Encoding and Referencing (TIGER) system.

An important aspect of TRAGIS is the need to continually review and update the routing networks. Infrastructure changes occur with new road construction, highway renumbering, rail abandonment, and changes of rail ownership. The routing networks in the TRAGIS model undergo a scheduled maintenance to ensure that the quality of the databases is as accurate as possible. An updated new national railway network co-developed by the Federal Railway Administration (FRA) and ORNL will be incorporated into the TRAGIS network database in the summer of 2012. The updated national highway and waterway networks are currently under way.

The transportation algorithms for highway in TRAGIS include quickest route, shortest route, and commercial route. The additional highway route type, HRCQ, is based on Department of Transportation (DOT) routing regulation (49 CFR 297.101) in the Code of Federal Regulations. The transportation algorithms for railroads include commercial and dedicated train algorithms. The commercial algorithm

${ }^{17}$ Blue Ribbon Commission on America's Nuclear Future, Report to the Secretary of Energy, January 2012. 
observes the track ownership and transshipment yards among rail companies. The dedicated train algorithm ignores the track ownership and will travel by direct routing with no transshipment delays. While an expanded transportation optimization study could incorporate all modes of transportation available in TRAGIS, for the limited scope study presented here, the dedicated train algorithm was used.

A combined sample of the LandScan and TRAGIS data is provided Fig. 12 depicting the population and railway network around the Knoxville, Tennessee, area.

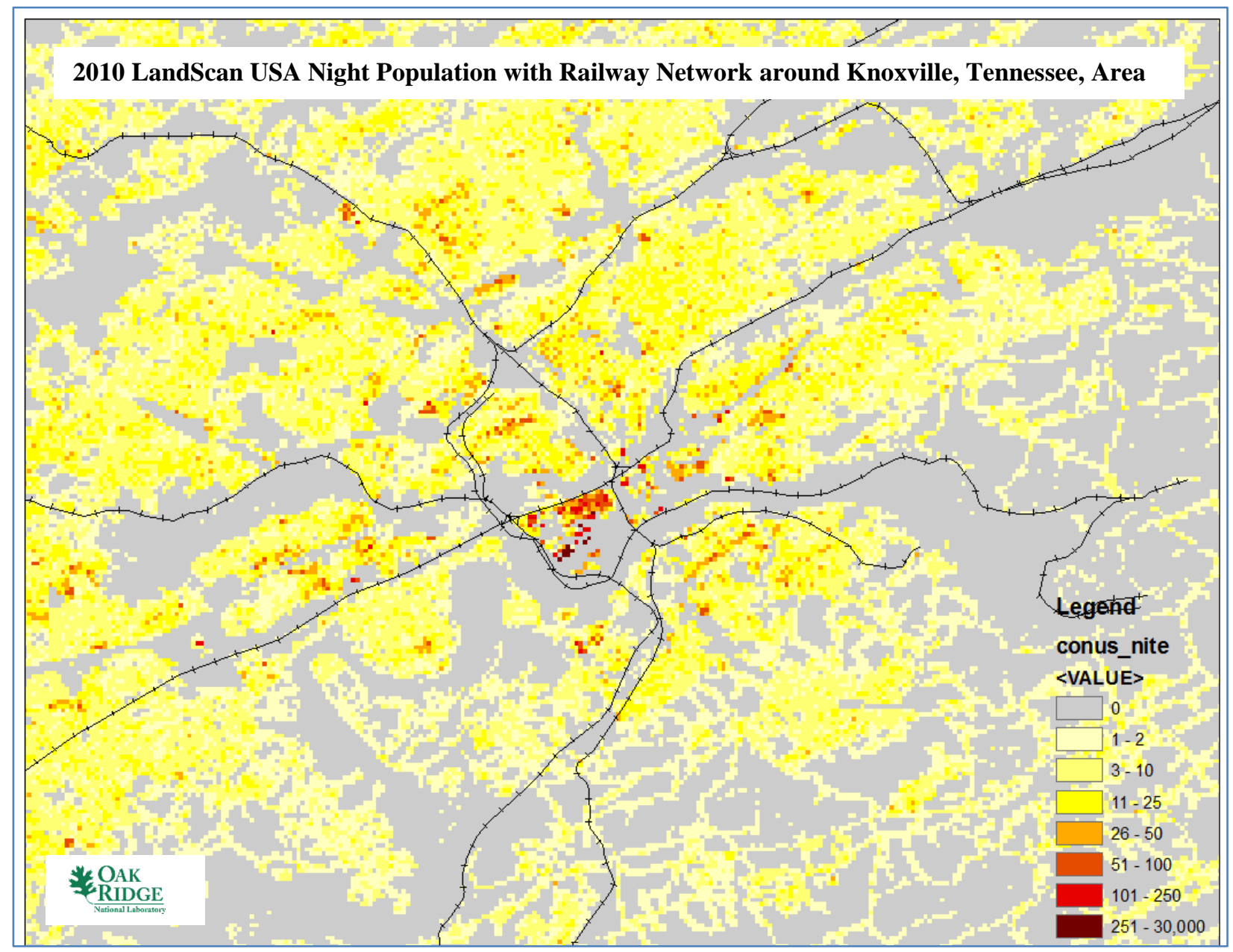

Fig. 12. 2010 LandScanUSA and National Railway Network around Knoxville, Tennessee.

\subsubsection{Population along the Rail Corridors}

Population along the rail corridors is one of the main features of the TRAGIS. In this study, the year 2010 LandScan USA population distribution databases both nighttime and daytime are used. This study creates an average 3 arc second LandScan USA population distribution database where each cell is the average of the same cell in the nighttime and daytime population. This database indicates that the possibility of a nuclear waste shipment through a cell will be $50 \%$ at daytime and $50 \%$ at nighttime.

The methodology for creating the population buffer along a single rail link is shown in Fig. 13. The buffer distance is $800 \mathrm{~m}$ on each side of the track along the railway center lines based on risk assumptions made in the Blue Ribbon Commission report. ${ }^{17}$ The blue line in Fig. 13 represents the railway center line. The green lines in Fig. 13 are the perpendicular lines to the railway center line and are reproduced with each change in direction of the track, as shown in Fig. 13. The tips of these green lines subsequently sweep out 
the 1600-m corridor for the population calculation. Population in TRAGIS and LandScan USA is counted by cells; in this case, each cell is approximately $90 \mathrm{~m}$ by $90 \mathrm{~m}$ or roughly 2.0 acres. The red dots shown in Fig. 13 depict all cells with a nonzero population. The population in each cell shown in red is not necessarily equal. Therefore, the total population for this particular link is simply the summation of the population of all the red colored cells. This procedure is repeated for all links in the national railway network.

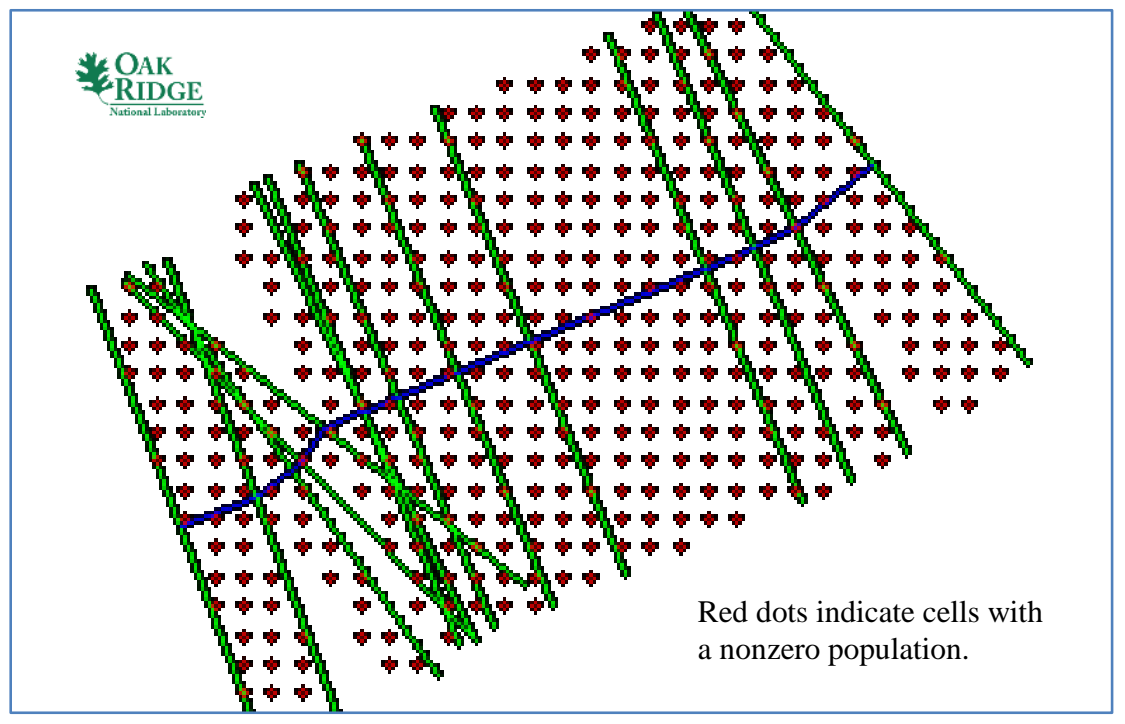

Fig. 13. Population buffering for a single rail link using TRAGIS and LandScan.

Calculations similar to that shown in Fig. 13 for a single rail link are repeated for the entire national railway network for the contiguous United States. The result of establishing an $800 \mathrm{~m}$ track buffer (1600-m corridor) nationwide is shown in Fig. 14. The population residing in areas displayed in yellow in Fig. 14 is the population residing within the buffer nationwide as a result of SNF transportation to a consolidated ISFSI. Even with consideration for the scaling of the map in Fig. 14, it can be observed that a more significant portion of the population in the eastern half of the United States lies within a track buffer zone compared to the population in the western half of the country. A more localized depiction of an 800-m track buffer is shown in Fig. 15. 


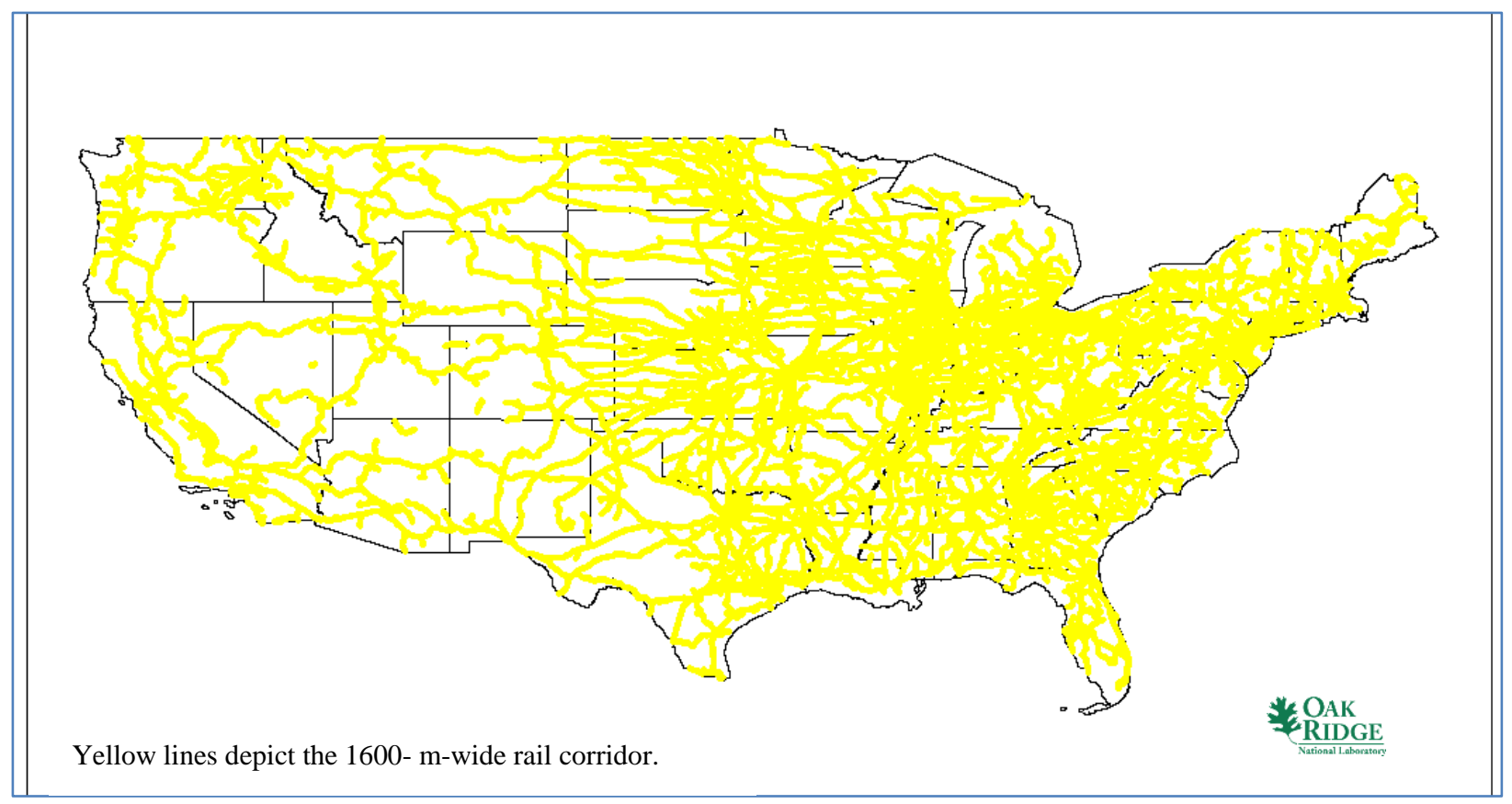

Fig. 14. The 800-m population buffers for the contiguous United States.

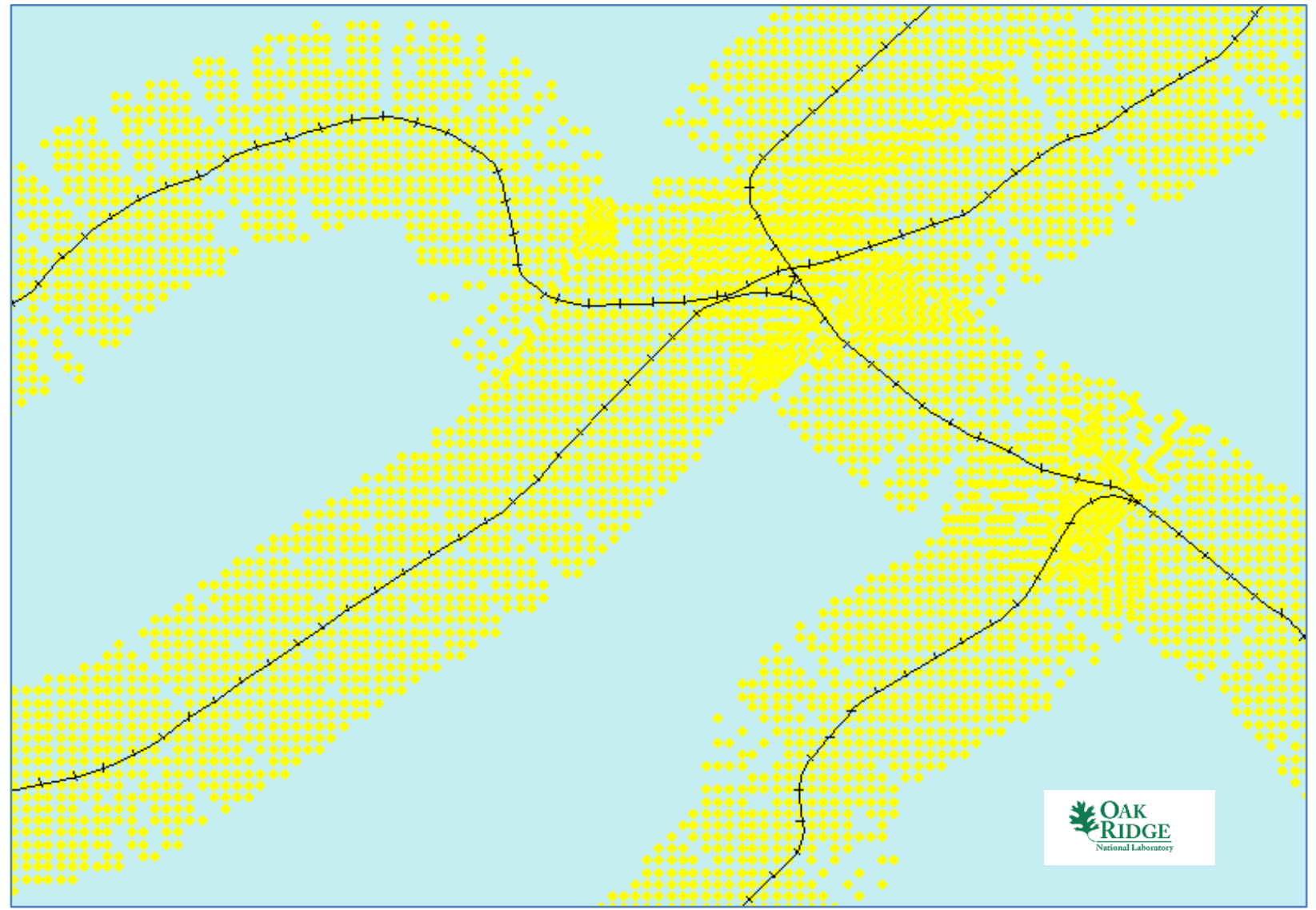

Fig. 15. The 800-m population buffer at a local level. 


\subsubsection{Mapping the Reactors and Potential Storage Sites to the Railway Network}

This study considers only railway transportation using dedicated trains. However, not all nuclear reactors or the potential waste storage sites are located on the railway network. Therefore, it is necessary to map the reactors or the potential storage sites to the railway network nodes in order to construct the complete transportation route. For each reactor site considered in this study, the nearest railroad node by straightline calculation is identified. A railroad node is any siding, depot, or rail yard where cargo can be transferred from truck to rail. A sample map showing the truck transport link between several reactor sites and the nearest railroad node is provided in Fig. 16. The red lines in the map show the straight-line mapping between the reactor sites and the nearest railroad nodes. Railroad nodes are identified by the red dots on the black rail lines. The reactor sites are identified by a green dot. This waste transport would be accomplished by truck.

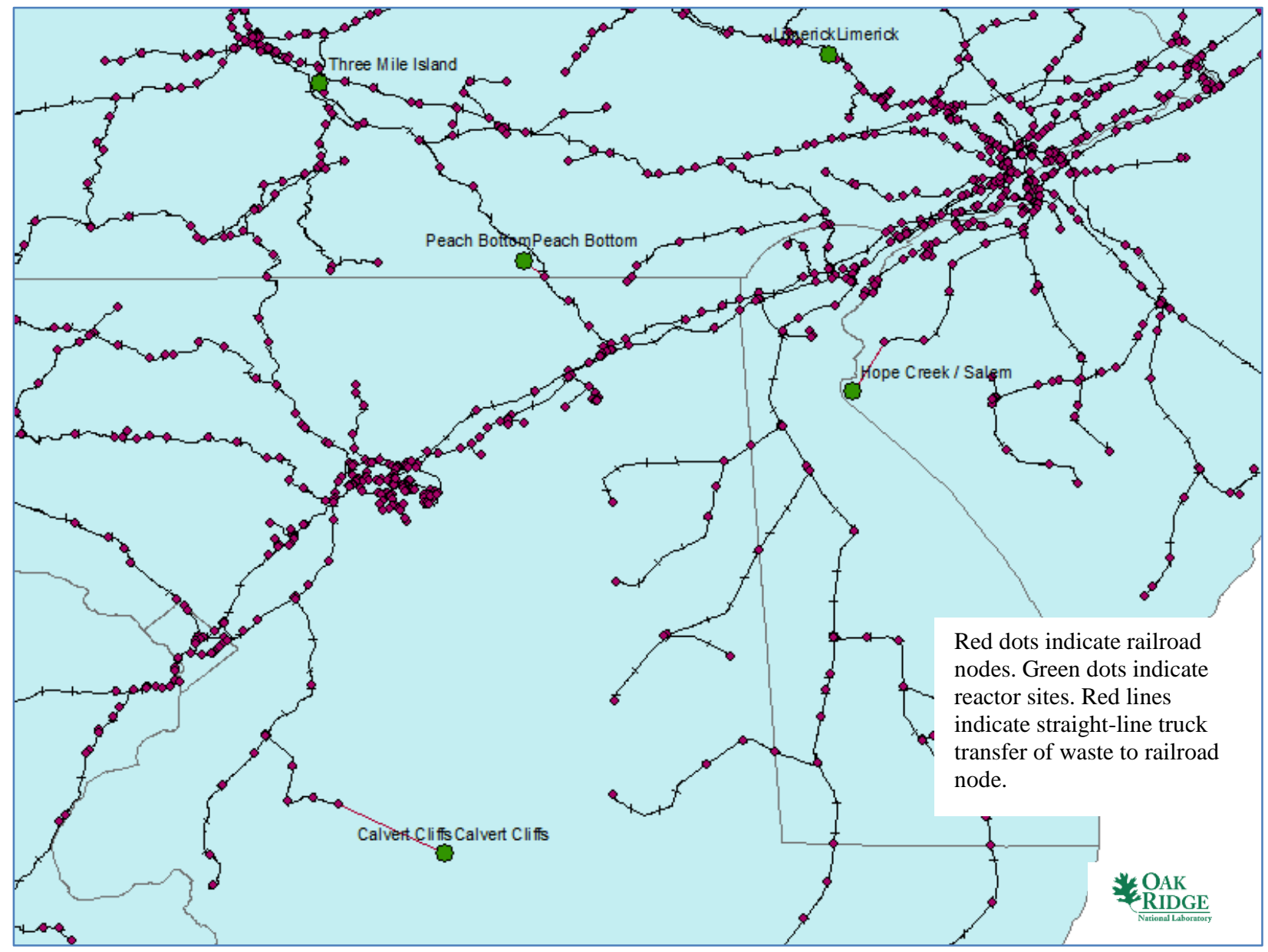

Fig. 16. Representative calculation of transfer link between reactor sites and nearest railroad node.

The potential waste storage mapping is the same as the reactor mapping except that the distance between the nearest railway node and a potential storage site is limited to 50 miles of great circle distance. It is expected that this distance would be covered by a new railroad spur line to the waste facility. Obtaining right-of-way for such a spur line is anticipated to be difficult; therefore, for this study the spur line length was limited to 50 miles. The 50-mile spur line range is based on the failed attempt of the Skull Valley, Utah, volunteer ISFSI site to gain right-of-way for a 32-mile spur line to the licensed facility. Therefore, a 50-mile limit on a spur line to a consolidated ISFSI is considered reasonable. All nominal waste storage sites that meet the criteria described in Section 3 of this report within the 50-mile radius of a railroad node 
would be considered acceptable. This provides greater ISFSI siting flexibility and does not result in a single point location being recommended as a result of this study. Vectors up to 50 miles in length between a railroad node and potential ISFSI sites meeting criterion provided in Section 3 are shown in Fig. 17. A larger scale, national view of available space is provided in Fig. 18.

In summary, the mapping process links all reactors and potential waste storage sites to railway nodes on the national railway network. A dedicated train algorithm, based on Dijkstra's shortest path algorithm, ${ }^{14}$ is used to find all possible routes from all reactor sites to all potential storage sites. For each route, the summation of total travel time and total population within $800-\mathrm{m}$ buffer are calculated. This information is the input for the optimization study as discussed in Sections 5 and 6 of this report.

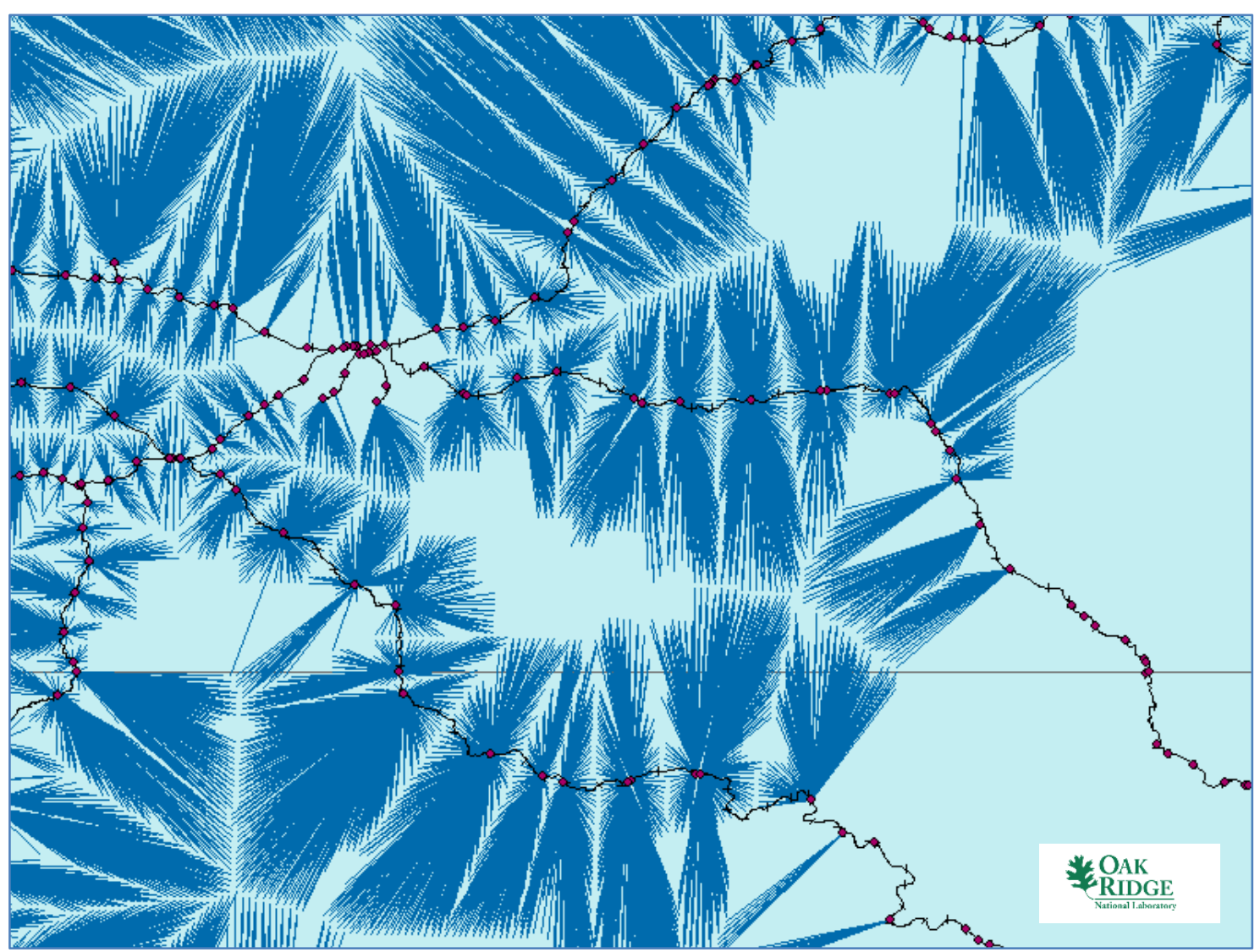

Fig. 17. Vectors limited to 50 miles in length between potential ISFSI sites and nearest railroad node. 


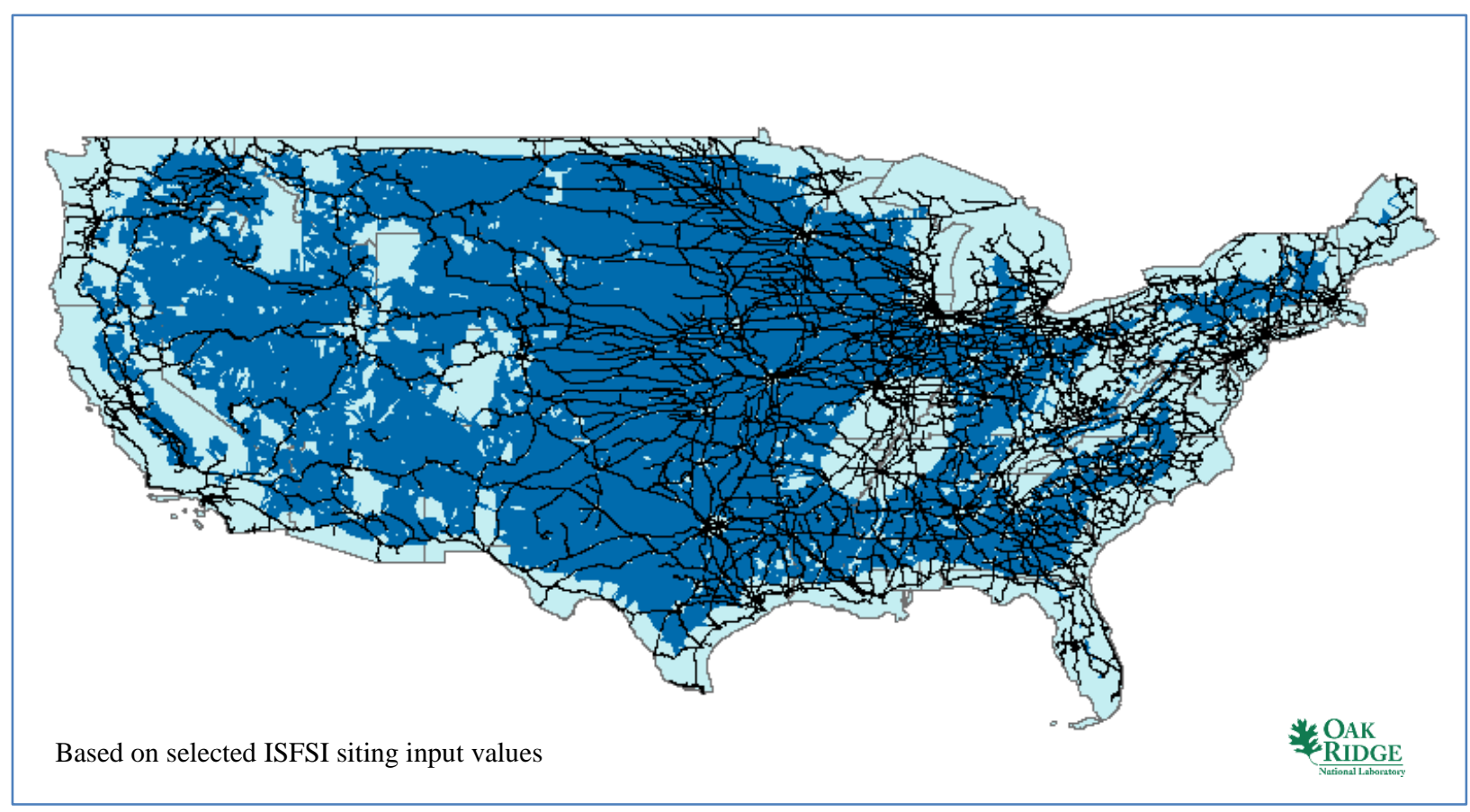

Fig. 18. National view of area available for ISFSI optimization using railroad network. 


\section{INTERIM SPENT FUEL STORAGE INSTALLATION EVALUATION}

\subsection{NOMINAL INTERIM SPENT FUEL STORAGE INSTALLATION DESCRIPTION}

This analysis characterizes suitable area for an ISFSI based on selected evaluation criteria. For the purposes of this study, an ISFSI stores SNF in a monitored, consolidated, dry-storage facility with a nominal maximum storage capacity of 70,000 metric tons of heavy metal based on the current limits in 10 CFR 72. While the maximum stated storage capacity influenced the footprint of the nominal facility, the optimization results detailed in Section 6 were not specifically limited by this capacity. The ISFSI siting evaluation is influenced by the private storage facility proposed by the Skull Valley Band of the Goshute Indian Tribe in Utah. ${ }^{18}$

\subsubsection{Site Evaluation Criteria}

There is well-defined regulatory guidance for siting an ISFSI in the United States. ${ }^{19}$ Numerous potential SEC were identified in various sources related to health and safety, environment, socioeconomic, and engineering factors. The selected SEC are based on providing a high level of discrimination using readily available data. A summary of the SEC selected for consolidated ISFSI siting is provided here and a more detailed discussion of each individual SEC follows below.

- Land with a population density greater than 500 people per square mile (including a 20-mile buffer) is excluded.

- Protected lands (e.g., national parks, historic areas, wildlife refuges) are excluded. However, Indian lands are specifically included based on recent volunteers to host an ISFSI.

- Land with safe shutdown earthquake (SSE) peak ground acceleration (2\% chance in a 50 -year return period) greater than $0.2 \mathrm{~g}$ is excluded east of $104^{\circ} \mathrm{W}$ longitude (Rocky Mountain Front). Land with SSE peak ground acceleration greater than $0.4 \mathrm{~g}$ is excluded west of $104^{\circ} \mathrm{W}$ longitude.

- Land too close to identified fault lines (length determines standoff distance) is excluded.

- Land with a moderate or high landslide hazard susceptibility as defined by the USGS is excluded.

- Wetlands and open water are excluded.

- Land that lies within a 100-year floodplain is excluded.

- Land that lies within 50 miles of seawater or Great Lakes coast is avoided based on concerns regarding environmental corrosion, tsunamis, hurricanes, typhoons, seiches, and sea level changes.

- Land that lies within 50 miles of the US border is avoided based on security concerns.

- Land located in proximity to hazardous facilities is avoided.

Based on knowledge of a proposed private ISFSI on Goshute Indian land and expert judgment, it is assumed that a nominal ISFSI can be accommodated on a 400 -acre structural footprint meeting the above criteria, exclusive of additional owner-controlled land.

\footnotetext{
${ }^{18}$ US Nuclear Regulatory Commission, Final Environmental Impact Statement for the Construction and Operation of an Independent Spent Fuel Storage Installation on the Reservation of the Skull Valley Band of Goshute Indians and the Related Transportation Facility in Tooele County, Utah, NUREG-1714, December 2001.

1910 CFR 72, Licensing Requirements for the Independent Storage of Spent Nuclear Fuel, High-Level Radioactive Waste, and Reactor-Related Greater than Class $C$ Waste, Subpart E, Siting Evaluation Factors.
} 
Population densities of greater than 500 people per square mile begin to transition into an urban setting. NRC nuclear power plant siting guidance ${ }^{20}$ recommends calculating the population density within 20 miles of the site and excluding population densities of greater than 500 people per square mile for health and safety concerns. Small operational ISFSIs are currently collocated at various nuclear power plants. Therefore, by engineering judgment, the population guidance regarding nuclear power plant siting was deemed appropriate for ISFSI siting as well. In addition, other protected lands are also excluded for health and safety purposes. These restrictions include national parks, national monuments, national forests, wilderness areas, state parks, wild or scenic rivers, wildlife refuges, hospitals, correctional facilities, schools, colleges, inventoried roadless areas, and areas of critical environmental concern. There is no buffer on protected lands; this would be a secondary siting evaluation. Indian land is not excluded because several Indian nations have volunteered to host an ISFSI.

Based on requirements detailed in 10 CFR $72.103,{ }^{19}$ areas of known seismic activity east of the Rocky Mountain Front impose a limit on the appropriate response spectrum anchored at $0.2 \mathrm{~g}$ if the results of site analyses show no unstable geological characteristics or soil stability problems. In areas east of the Rocky Mountain Front without known seismic activity, an appropriate response spectrum anchored at $0.25 \mathrm{~g}$ may be used. For the purposes of the GIS study, the more restrictive $0.2 \mathrm{~g}$ limit is used east of the Rocky Mountain Front. West of the Rocky Mountain Front, 10 CFR 72.103 requires that individual site analyses be performed to estimate the earthquake ground motion and to permit adequate engineering solutions to geologic or seismic effects. The Skull Valley site in Utah is evaluated at just under $0.4 \mathrm{~g}$. Therefore, the maximum ground acceleration west of the Rocky Mountain Front was set to a less conservative $0.4 \mathrm{~g}$ for the GIS study. However, this GIS acceleration layer is in addition to a fault line layer with varying standoff distances from the fault depending on fault length that is most limiting in the western portion of the United States. ${ }^{10}$ Also, land with high or medium landslide hazard susceptibility is excluded, which encompasses significant area around the Rocky Mountains. The combination of the GIS acceleration layer, the fault layer, and the landslide layer impose conservative seismic restrictions west of the Rocky Mountain Front.

External flooding could affect the safe operation of an ISFSI. Therefore, simple land exclusions to protect proposed ISFSI siting from general flooding include avoiding land categorized as part of a 100-year floodplain, avoiding wetlands, and avoiding open water and the Great Salt Lake. In addition, the threat from specific external natural events such as tsunamis, hurricanes, typhoons, seiches, and sea level changes are avoided by imposing a standoff distance of 50 miles from the sea coast and the Great Lakes. This has the added benefit of avoiding an environmental concern related to salt water corrosion.

Man-made hazards are avoided by imposing a buffer around certain hazardous facilities. Commercial airports, including a 10-mile buffer, are excluded to reduce intentional or accidental aircraft interactions. Military installations, including a 1-mile buffer, are excluded to reduce intentional or accidental aircraft interactions, and potential ordnance interactions. Oil refineries, including a 1-mile buffer, are excluded based on potential explosive hazard.

Any national ISFSI will include hardened site security structures, administrative security procedures, and guards. However, additional security is considered by including a 50-mile GIS buffer layer from the United States borders. Part of this buffer layer is already defined by the 50-mile stand-off distance described above for specific flooding threats.

The following figures (Figs. 19 through 27) show the individual SEC layers for the nominal ISFSI based on the values provided in the above list. Areas shown in red are excluded based on the selected input parameter value. Excluded areas in each individual layer can be modified based on different assumptions or requirements for the SEC.

\footnotetext{
${ }^{20}$ US Nuclear Regulatory Commission, General Site Suitability Criteria for Nuclear Power Stations, Regulatory Guide 4.7, April 1998.
} 


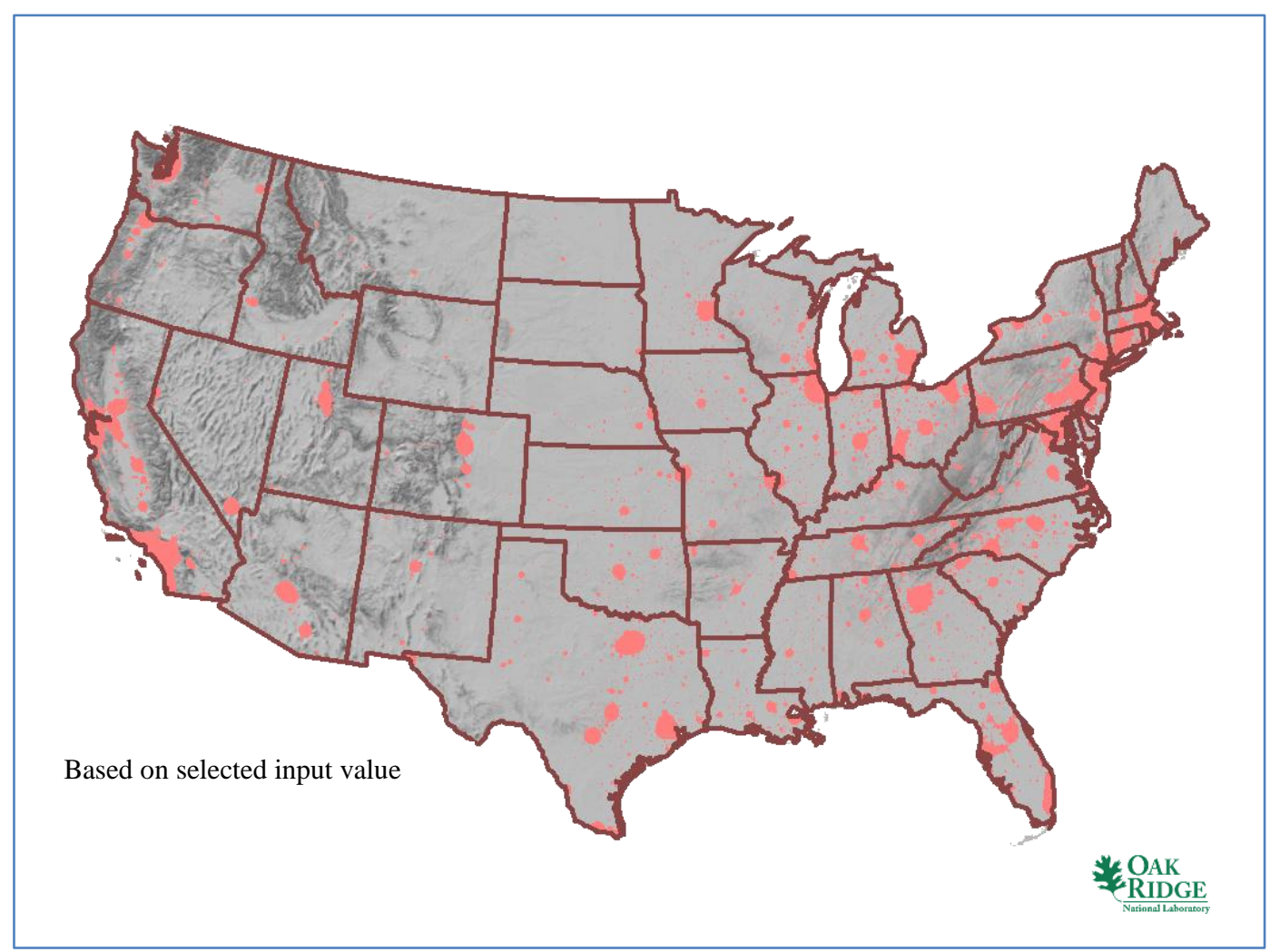

Fig. 19. ISFSI high population SEC layer.

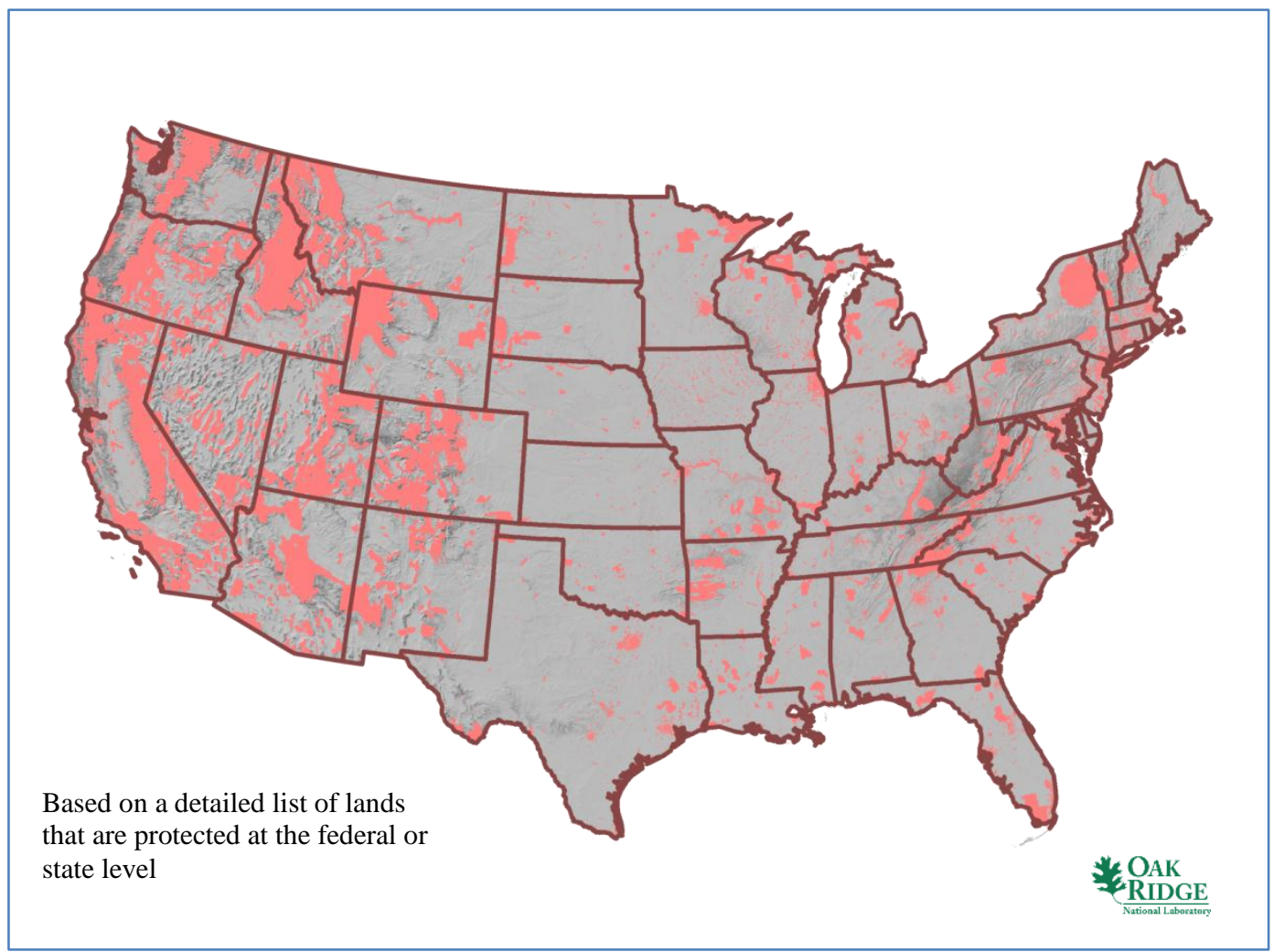

Fig. 20. ISFSI protected lands SEC layer. 


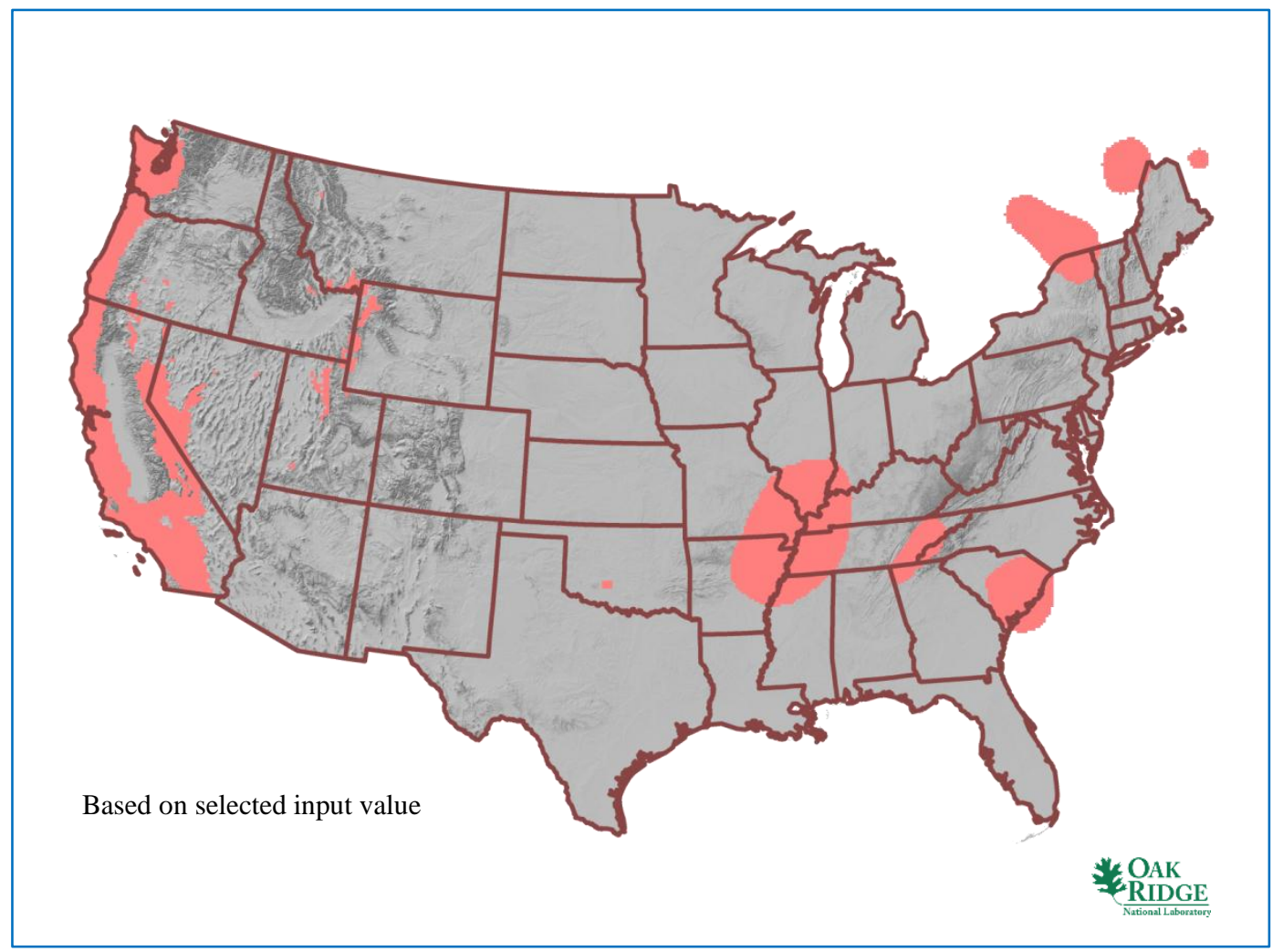

Fig. 21. ISFSI composite safe shutdown earthquake SEC layer.

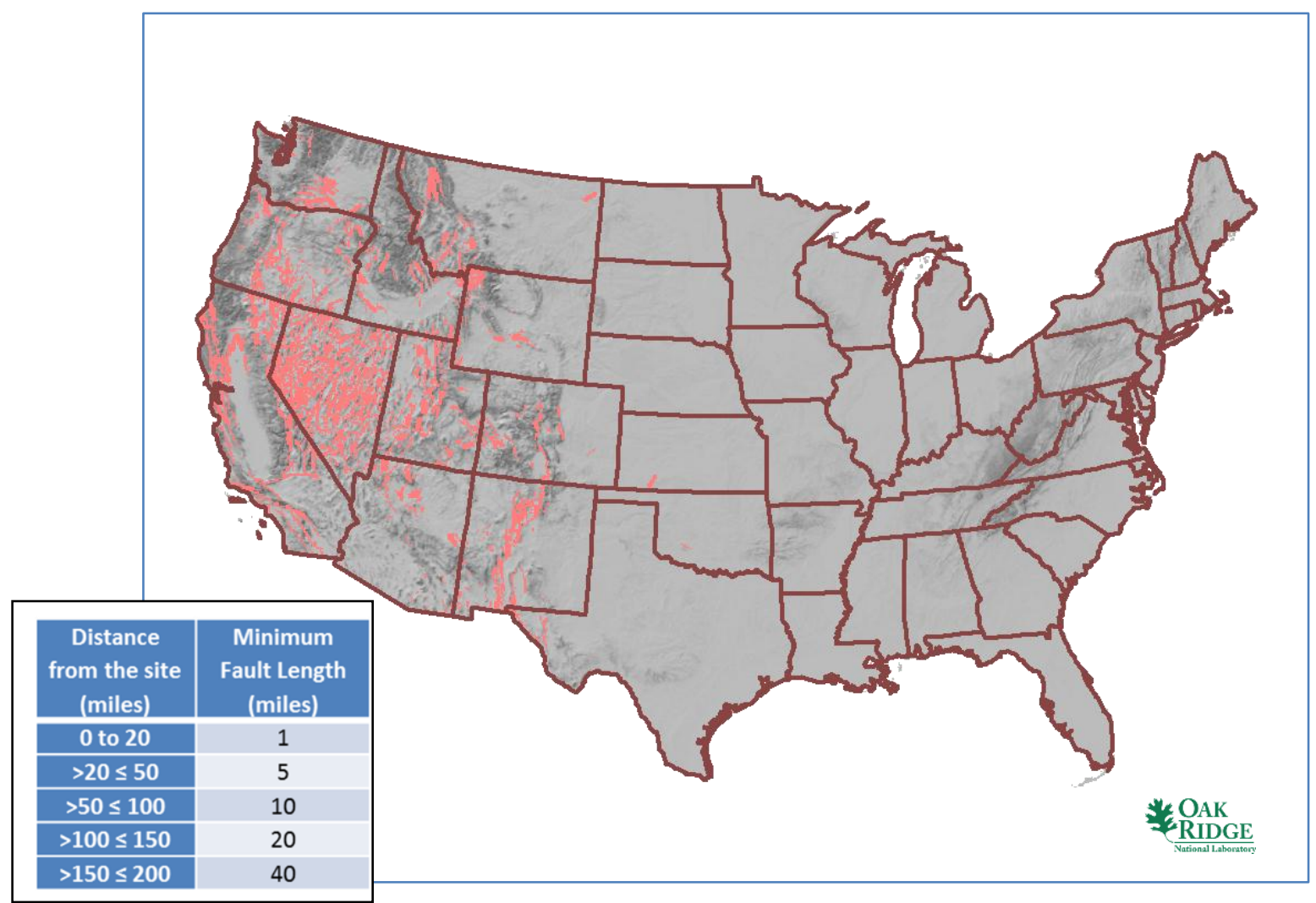

Fig. 22. ISFSI proximity to fault lines SEC layer. 


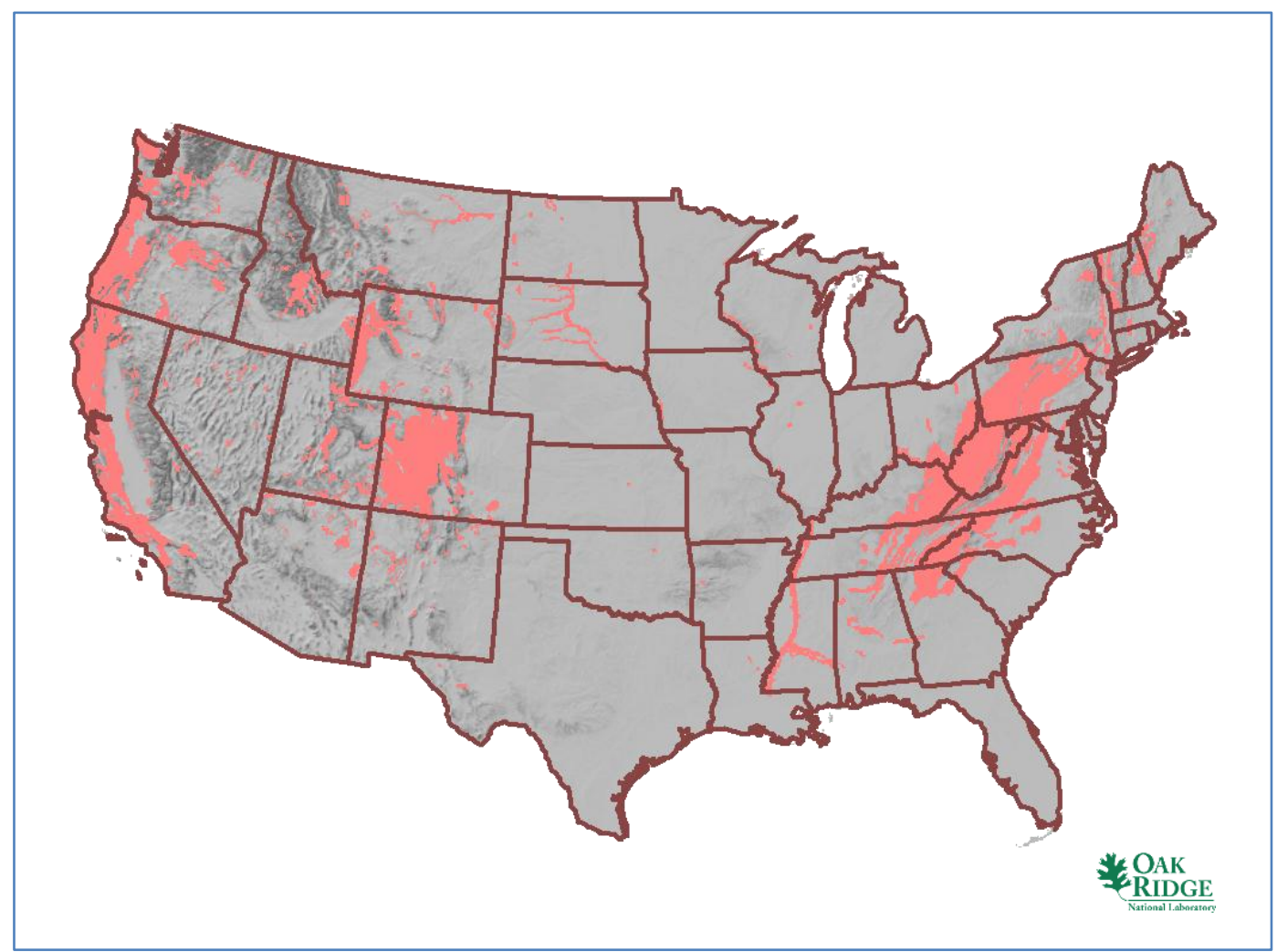

Fig. 23. ISFSI landslide hazards SEC layer.

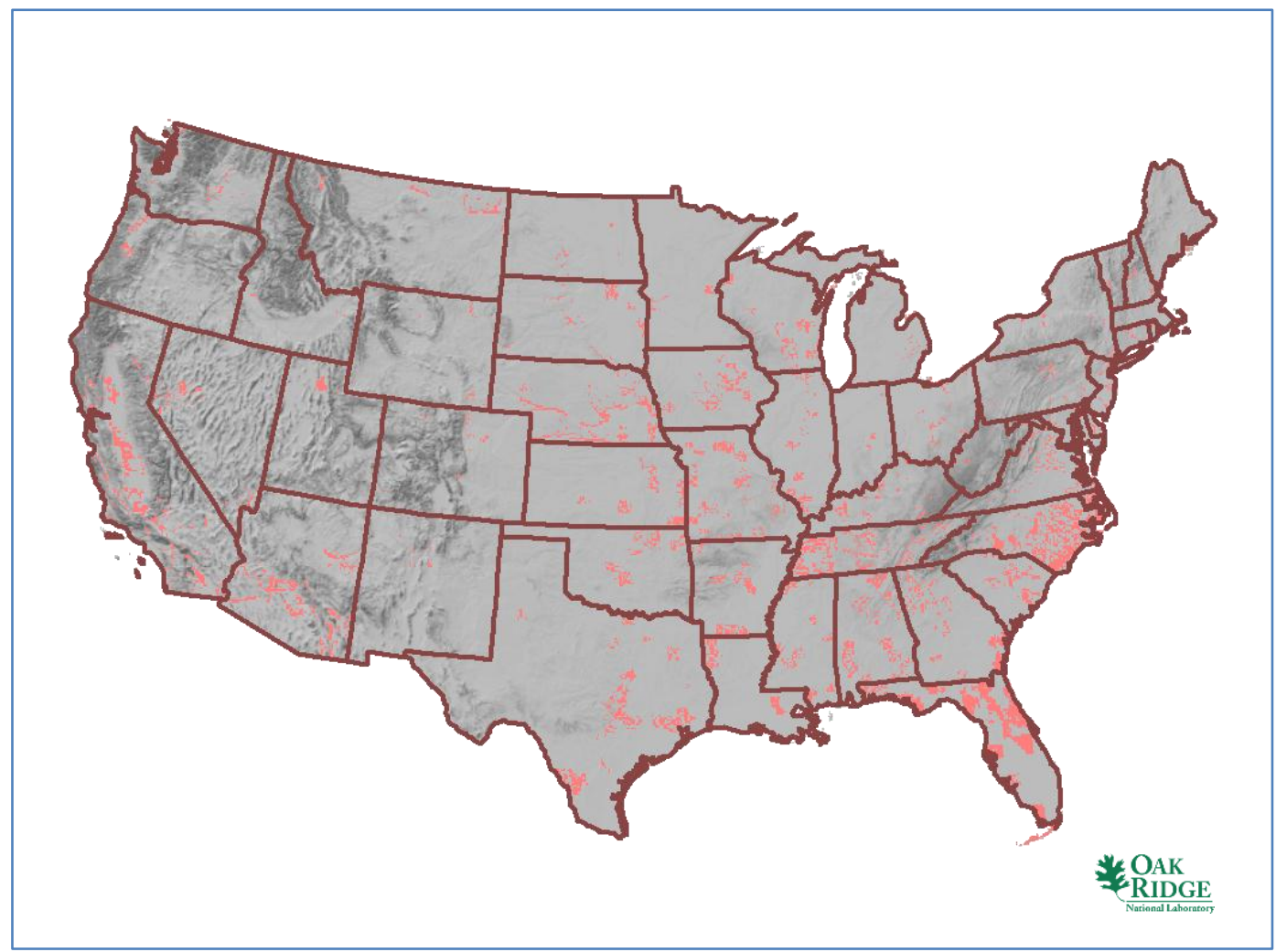

Fig. 24. ISFSI 100-year floodplain SEC layer. 


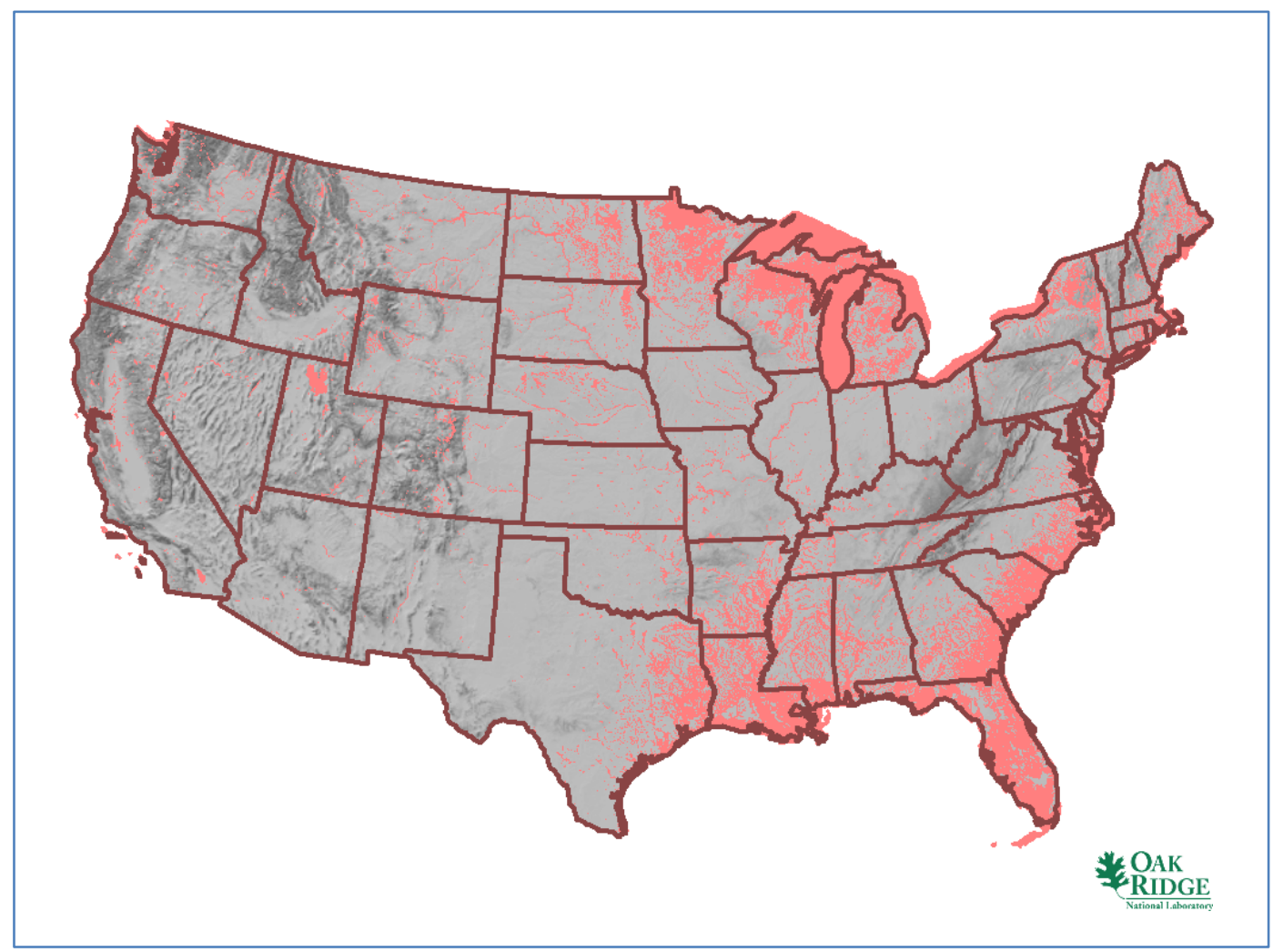

Fig. 25. ISFSI wetlands and open water SEC layer.

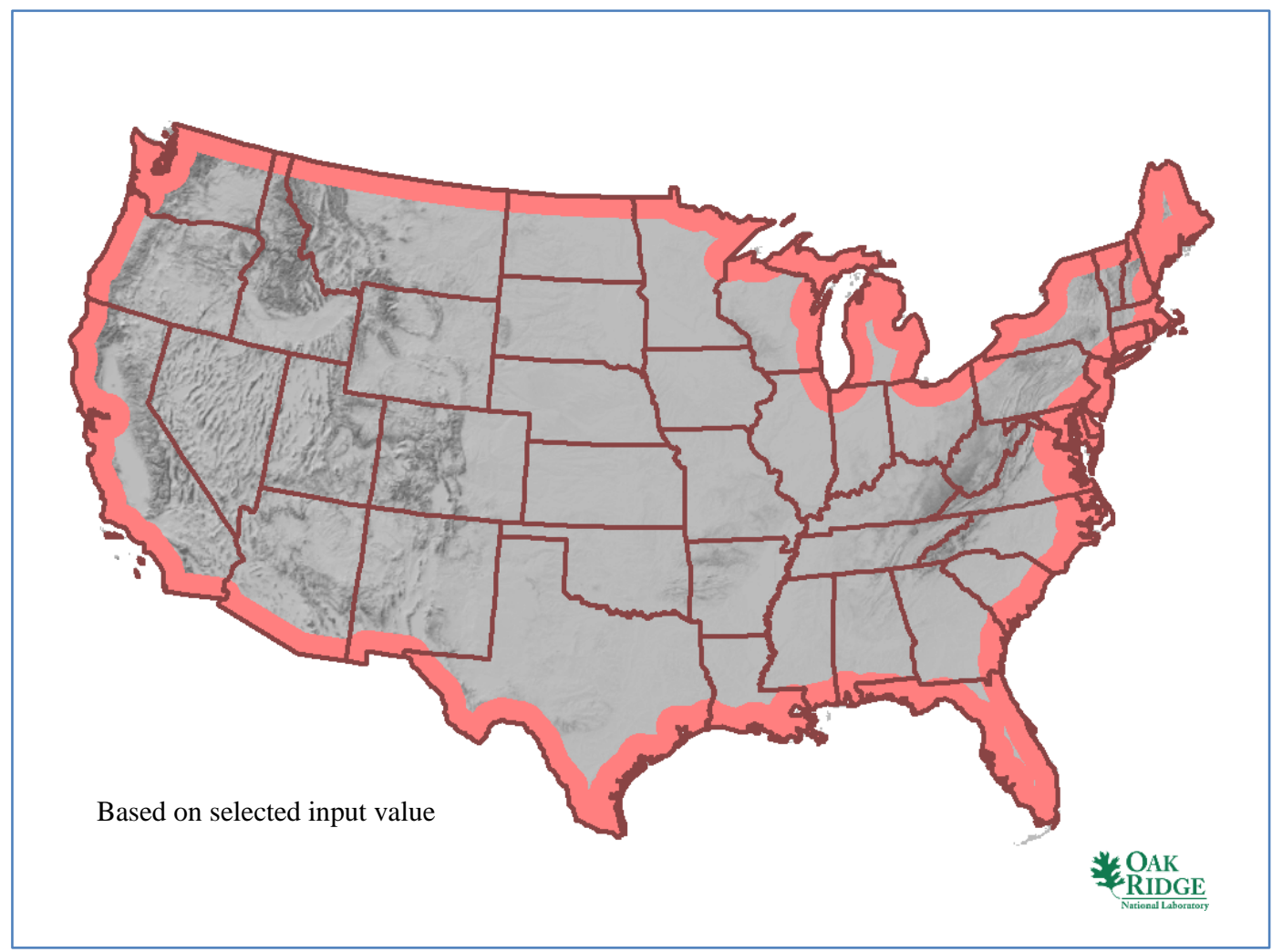

Fig. 26. ISFSI coastal flooding, environmental corrosion, and security SEC layer. 


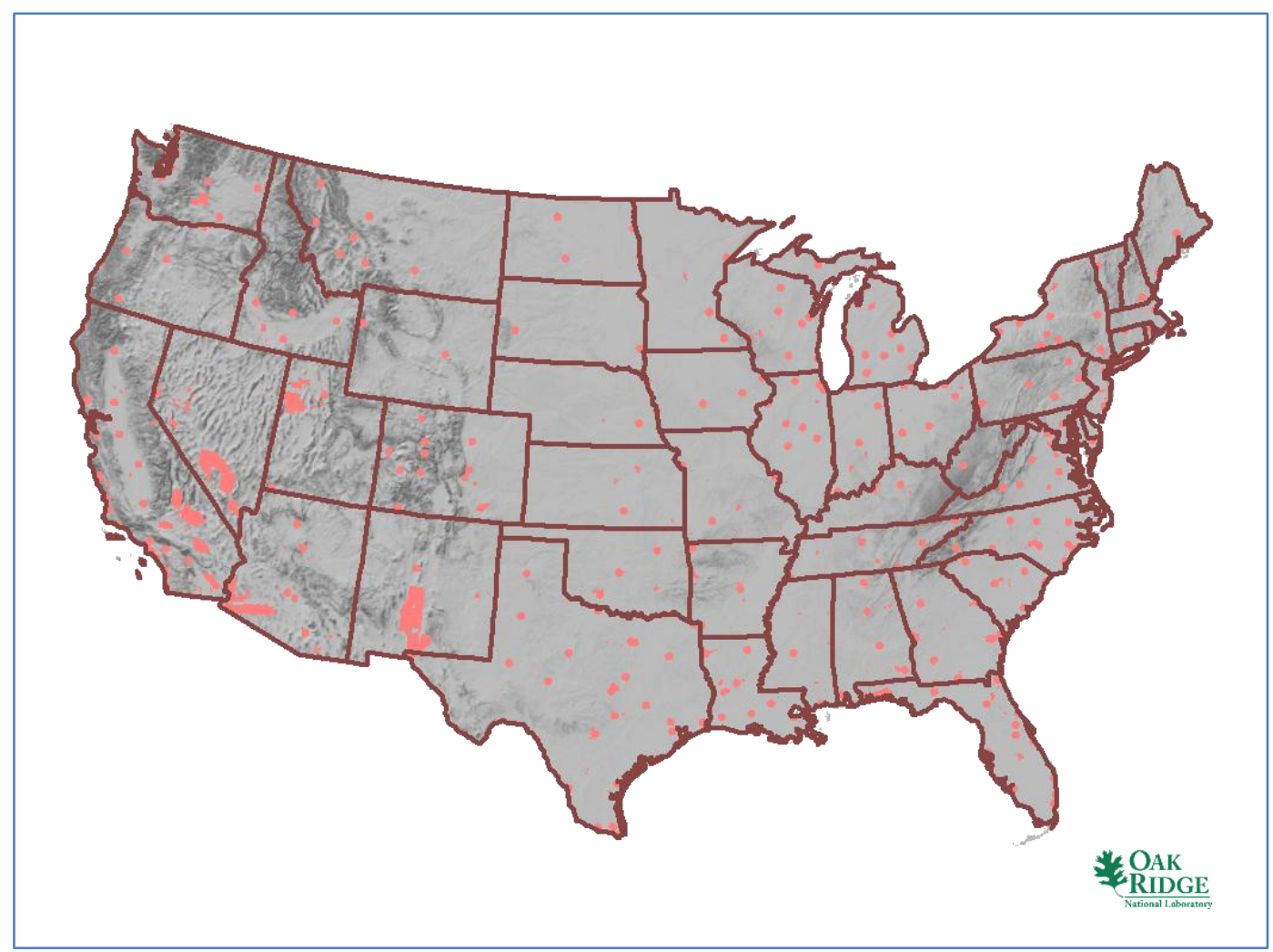

Fig. 27. ISFSI proximity to hazards SEC layer.

The successive application of each ISFSI SEC layer to the overall available land in the contiguous United States can be captured as a step-down histogram as shown in Fig. 28. Since the SEC layers are independent, the shape of the cumulative histogram is strictly determined by the order in which the SEC layers (steps) are applied. However, the end result at step 9 is the same no matter the SEC layer application order.

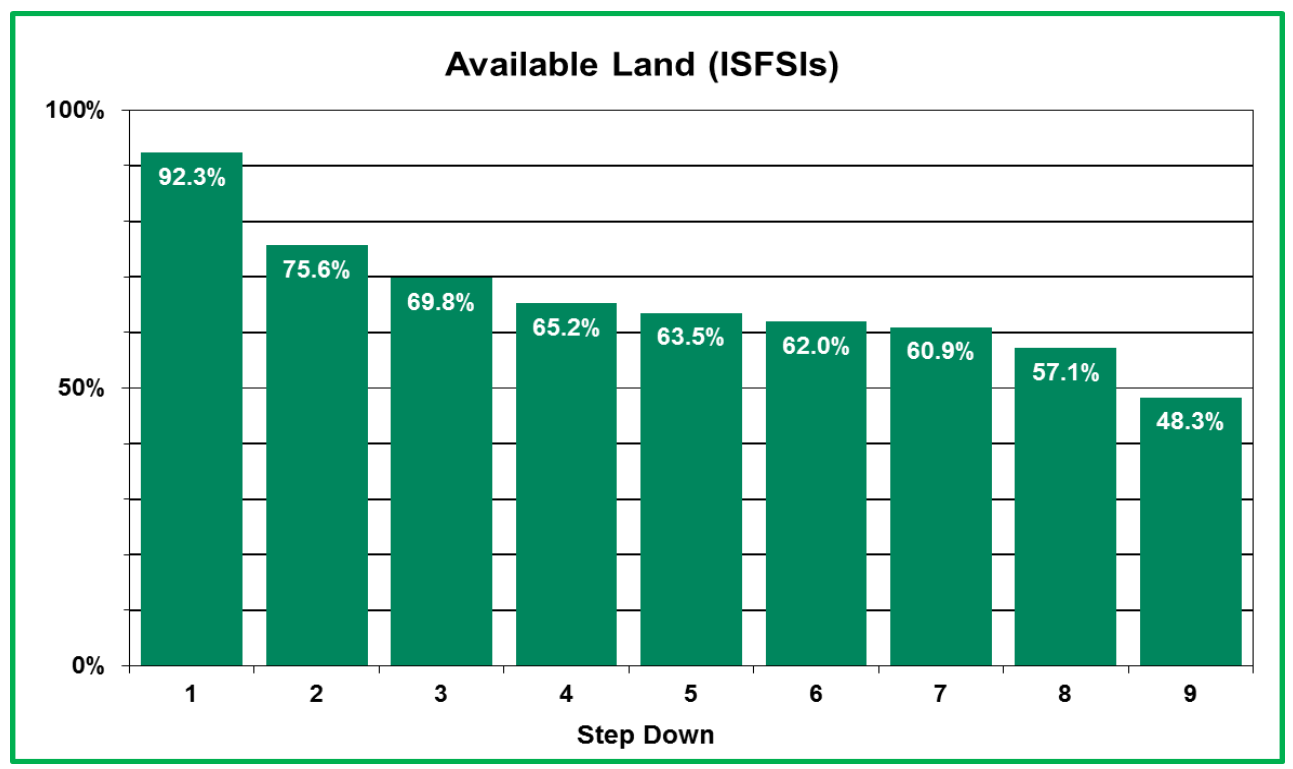

Order of Exclusion Layers

1. Population

2. Protected Lands

3. Safe Shutdown Earthquake

4. Landslide

5. Fault Lines

6. Hazardous Operations

7. 100-yr Floodplain

8. Wetlands/Open Water

9. Sea-level Change and Border Security Buffer

Fig. 28. ISFSI step-down histogram. 
A review of the individual SEC layers and the histogram provides the following insights.

- Population is a significant factor in the Northeast and in many coastal areas.

- Protected lands and the sea-level change and border security buffer are the most significant SEC in terms of total land affected.

- Protected lands and fault lines have a greater impact on the west.

- Coastal and security concerns almost completely eliminate Florida from consideration for a consolidated ISFSI.

- Floodplains, wetlands, and open water have a greater impact on the central and eastern portion of the country.

The OR-SAGE tool tracks the parameters for each individual 100 by $100 \mathrm{~m}$ cell. As a result, not only can the cells that are clear of all the SEC layer exclusions be displayed visually but also cells that are tripped by one, two, or three or more exclusions can be tracked and displayed. This is known as the "ISFSI composite map," as shown in Fig. 29. This is a powerful aspect to the OR-SAGE tool, because it allows areas with a limited number of siting challenges to also be identified. Engineering solutions to areas with limited siting challenges may be available. The areas in green in Fig. 29 have no siting challenges based on the selected values for the ISFSI SEC layers. However, the areas in yellow also include a significant land area and have just a single siting challenge.

In addition, political restrictions against nuclear power and ISFSIs are not considered. For example, some states have laws prohibiting the use of nuclear power to generate electricity, and other states have nuclear bans until trigger events are reached, such as a SNF repository. Likewise, those states with negative public opinion toward nuclear power are not factored into the results.

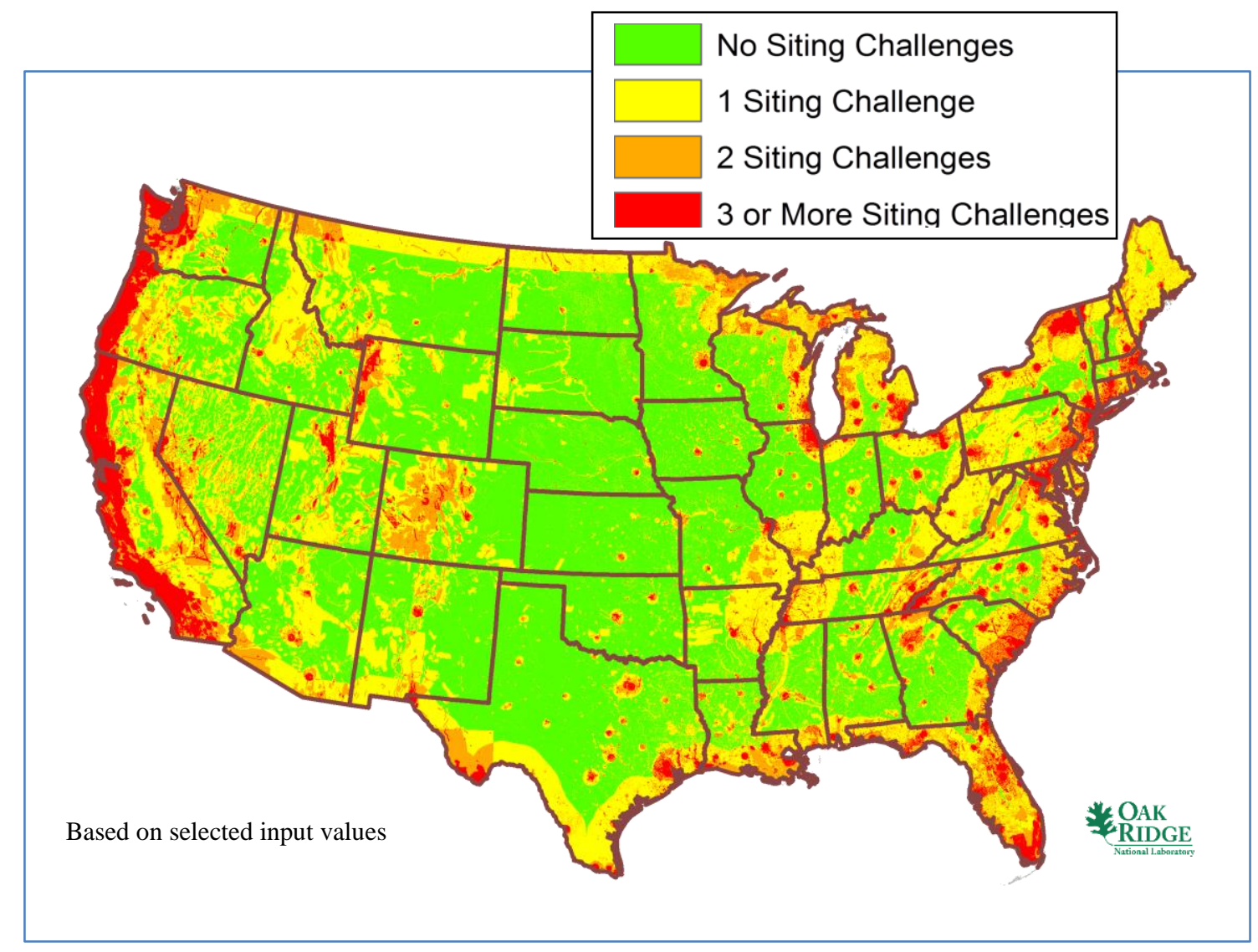

Fig. 29. ISFSI composite map detailing siting challenges. 


\subsubsection{Base Map}

Section 1.3, Approach and Methodology, describes the process of developing a base map. A base map is created to reflect one set of values based on the stated assumptions and ISFSI SEC. The base map shows where all SEC criteria are met. The areas depicted in green from the ISFSI composite map shown in Fig. 29 are used to develop the ISFSI base map.

The ISFSI base map, depicting only the areas that have no siting challenges based on the entire set of ISFSI SEC, is shown in Fig. 30. The area in green represents $48.3 \%$ of the contiguous United States or 827 million acres, but it has not been aggregated for 400 -acre ISFSI sites. Figure 30 shows that the central United States has strong siting potential for a consolidated ISFSI site. The southeastern and western states also have fair siting potential. The far West, Northeast, and Florida generate the most exclusions.

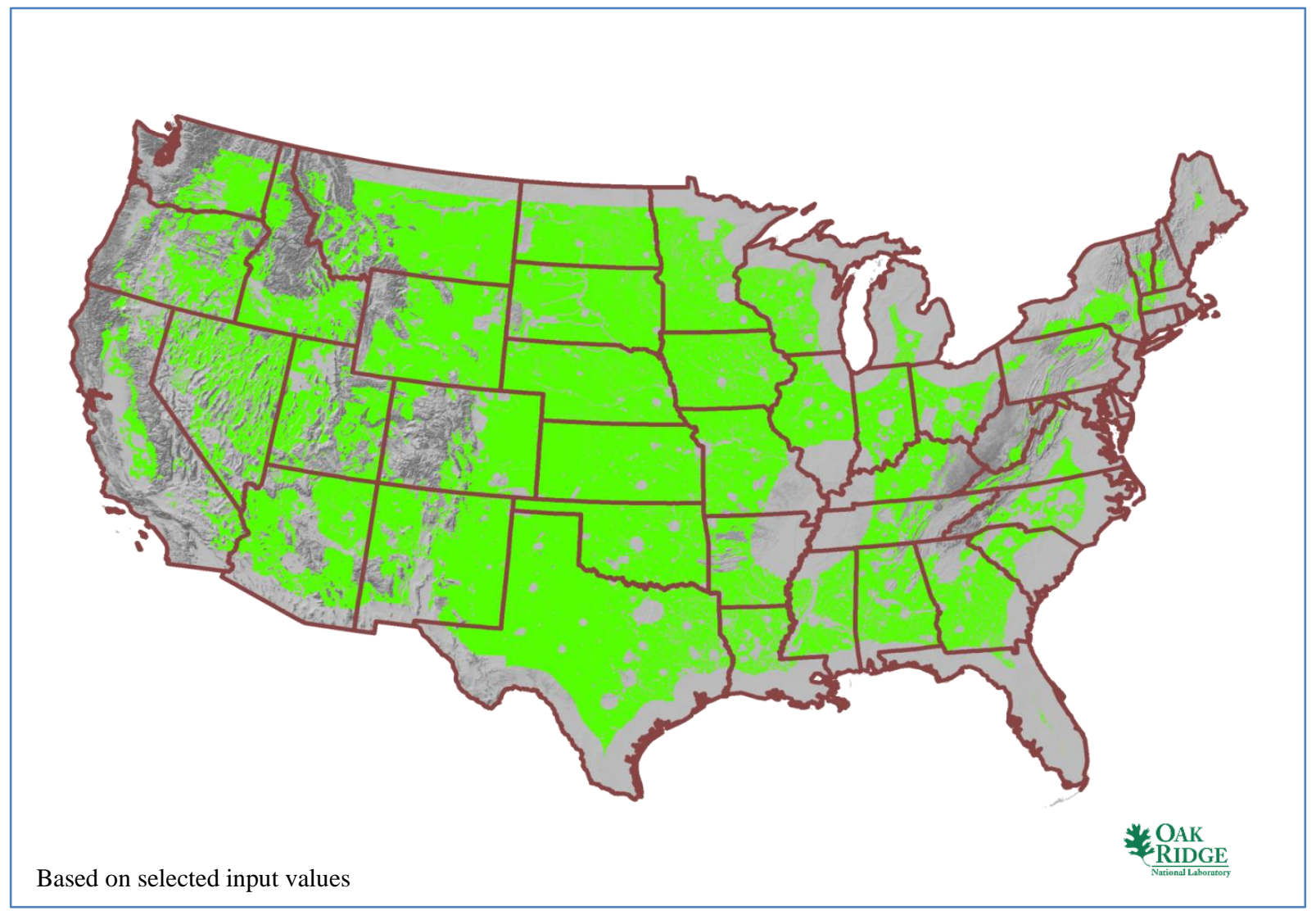

Fig. 30. ISFSI base map.

Figure 31 shows the effect of aggregating the available land from the ISFSI base map into 400 -acre tracts at a 90\% aggregation rate. The available aggregated land with no siting challenges for ISFSI facilities is reduced from $48.3 \%$ (Fig. 30) to $42.3 \%$ of the contiguous United States, or 724 million acres, based on the stated assumptions and selected values for the ISFSI plant SEC. This represents more than 1.7 million individual 400-acre nominal ISFSI sites with no siting issues based on the selected ISFSI SEC and values. Figure 31 shows that all regions of the country have numerous suitable locations for a monitored, consolidated, dry-storage facility with a nominal maximum storage capacity of 70,000 metric tons of heavy metal. 


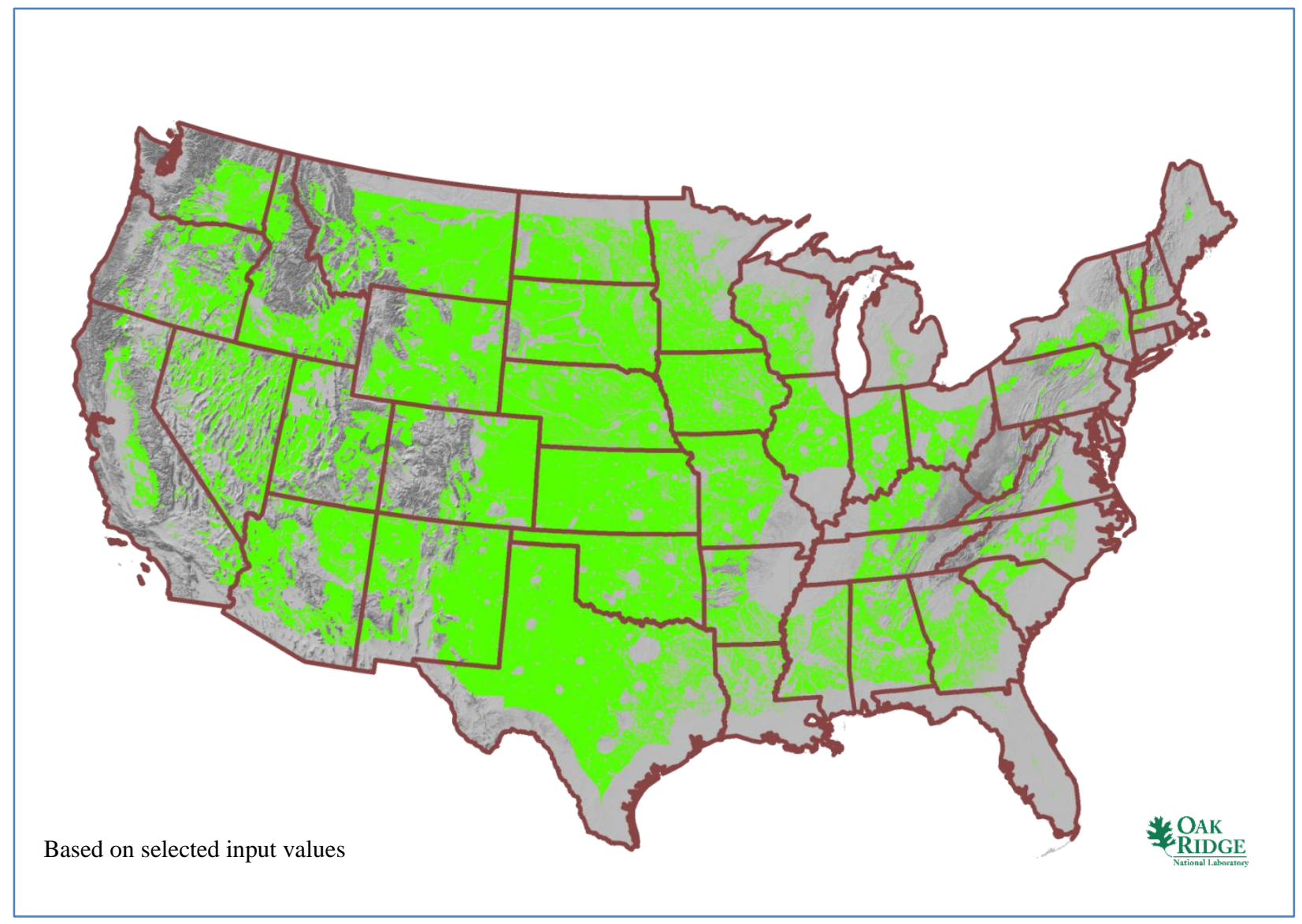

Fig. 31. ISFSI base map aggregated for 400 -acre sites.

\subsubsection{Utah Case Study}

The nominal ISFSI facility is derived from the private storage facility proposed by the Skull Valley Band of the Goshute Indian Tribe in Utah. Therefore a closer look at the evaluation results for the state of Utah and specifically the land controlled by the Skull Valley Band of the Goshute Indian Tribe is appropriate to provide some validation of the evaluation criteria. The Goshute Reservation is located within Tooele County, Utah, and the storage facility is approximately 27 miles west-southwest of the city of Tooele, Utah. The proposed ISFSI would be built on an 820-acre site (including owner-controlled land) about 3.5 miles from the Skull Valley Band's village in the northwest corner of the Reservation. In addition to the proposed ISFSI, the facility owner-operators propose to construct and operate a 32-mile rail line on public land administered by the US Department of Interior's Bureau of Land Management (BLM). The proposed rail line is needed to transport SNF from the nearest main rail line to the proposed ISFSI. ${ }^{18}$ The facility owner-operators were unable to secure the necessary track right-of-way from the government and the plans for the facility have not progressed.

Figure 32 is a replication of Fig. 29 with the state of Utah outlined in blue and the Skull Valley site shown in the northwest part of Utah as a red box. As before, areas in green have no siting issues relative to the selected ISFSI evaluation criteria and values. Areas in yellow have one siting issue relative to the selected ISFSI evaluation criteria and values. A detail map of Utah is provided in Fig. 33. 


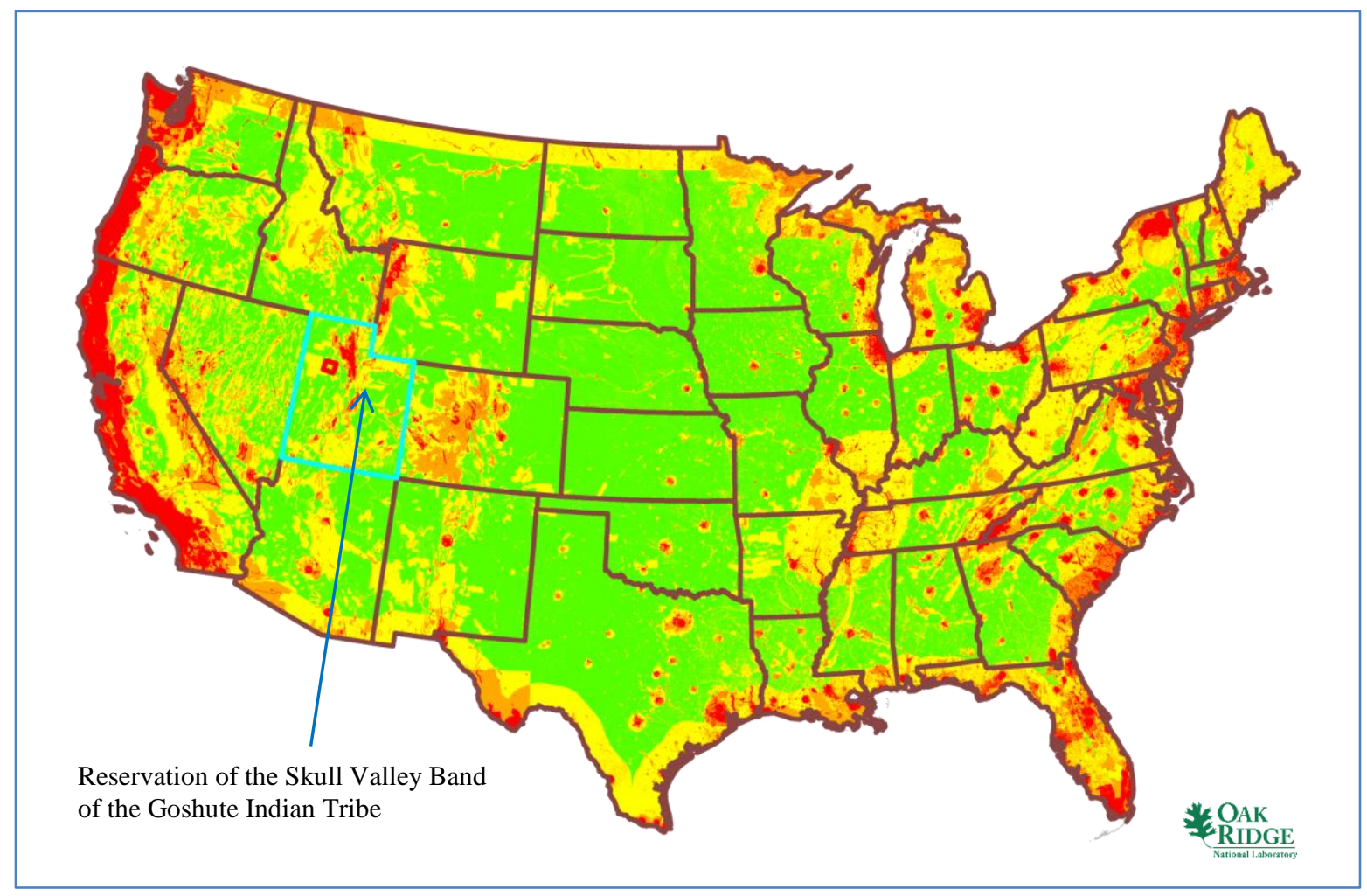

Fig. 32. ISFSI composite map with state of Utah outlined in blue.

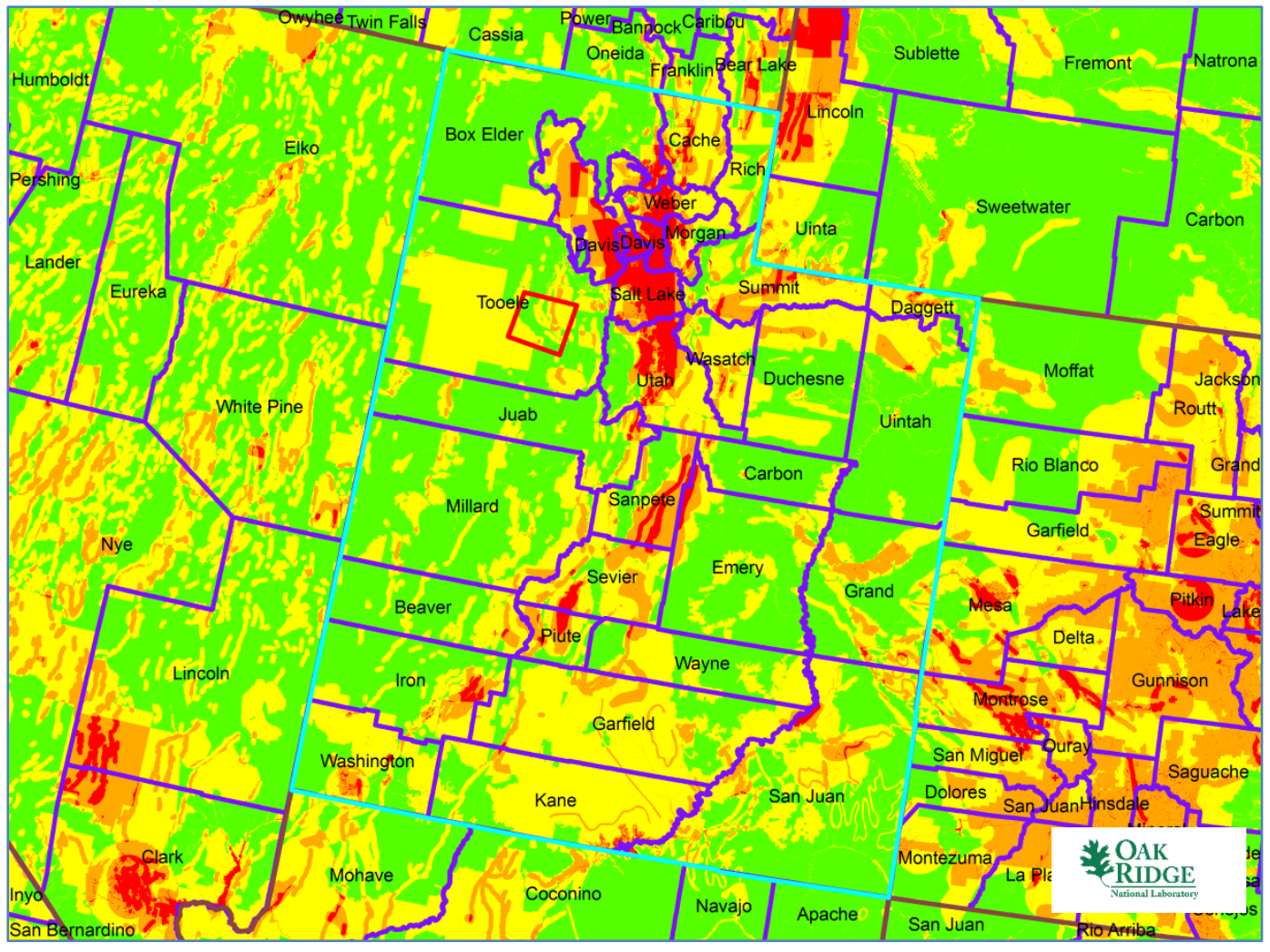

Fig. 33. ISFSI composite map showing Goshute Indian Reservation in red box (Tooele County). 
The areas within Utah and within the Reservation of the Skull Valley Band of the Goshute Indian Tribe (red box) that satisfy all of the ISFSI siting criteria with the selected criteria values are identified in Fig. 34. These areas are depicted in green. Note that the proposed Skull Valley site is in the northwest corner of the Reservation and is on area that is highlighted in green.

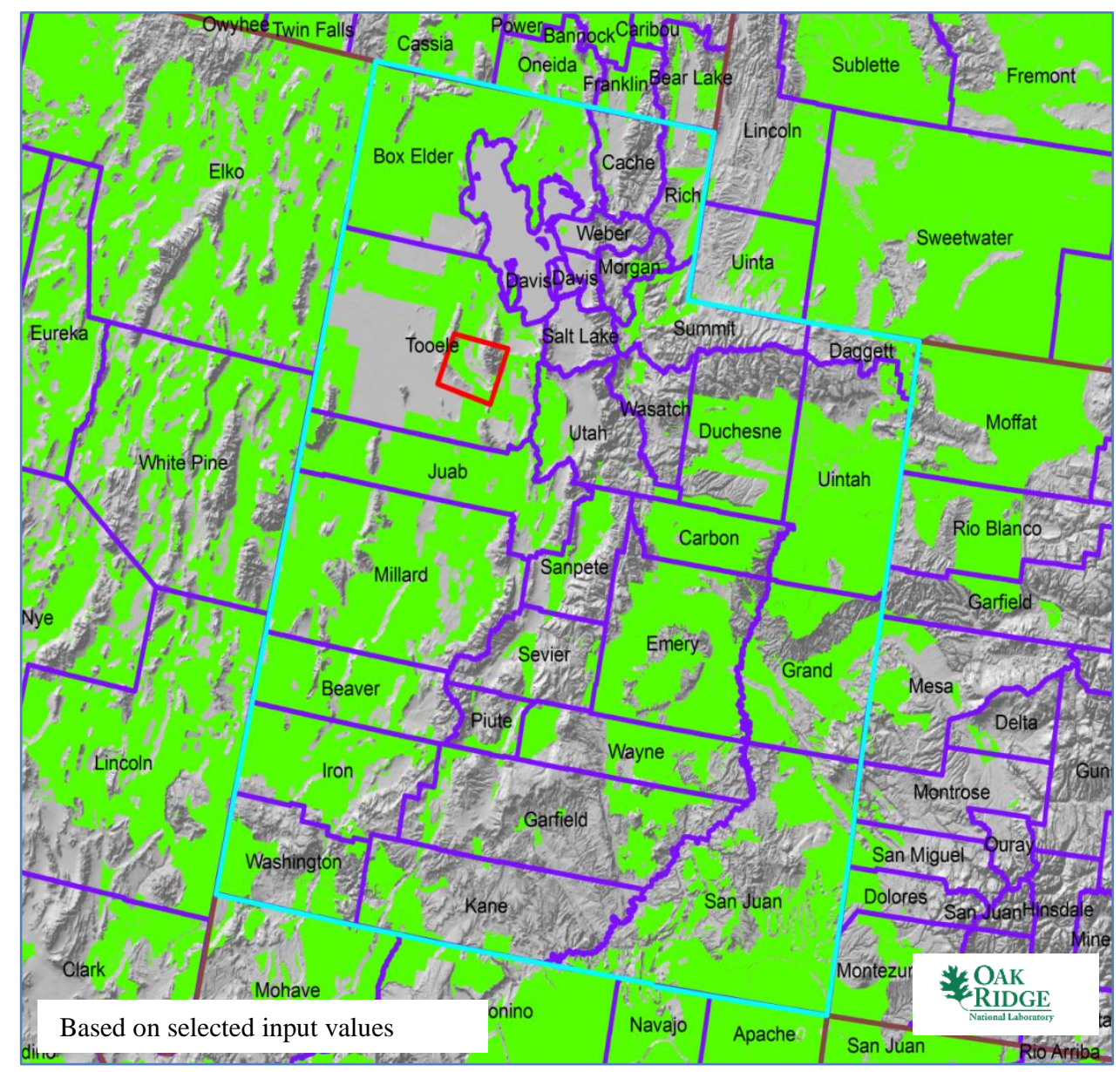

Fig. 34. Utah base map and Goshute Indian Reservation.

Areas to the east of the proposed ISFSI site on the Skull Valley Indian Reservation have SEC siting issues related to existing fault lines with appropriate standoff distances and the Wasatch-Cache National Forest, which is protected land. The area to the west and southwest of the of the proposed ISFSI site on the Skull Valley Indian Reservation has an SEC siting issue with hazardous facilities, which include the Dugway Proving Grounds, the Wendover Range, and the Deseret Test Center. Of these, only the Dugway Proving Grounds are currently in operation on over 800,000 acres. For siting purposes, hazardous military facilities include a 1-mile buffer. Figures 35-37 depict the individual SEC layers that actually intersect the Skull Valley Indian Reservation. None of these siting issues poses a threat to the proposed ISFSI site on the Skull Valley Indian Reservation, which passes all of the established ISFSI siting criteria. None of the remaining ISFSI SEC criteria intersects the Skull Valley Indian Reservation. Therefore, the proposed ISFSI site on the Skull Valley Indian Reservation passes the ISFSI siting criteria established for the purposes of this siting study. 


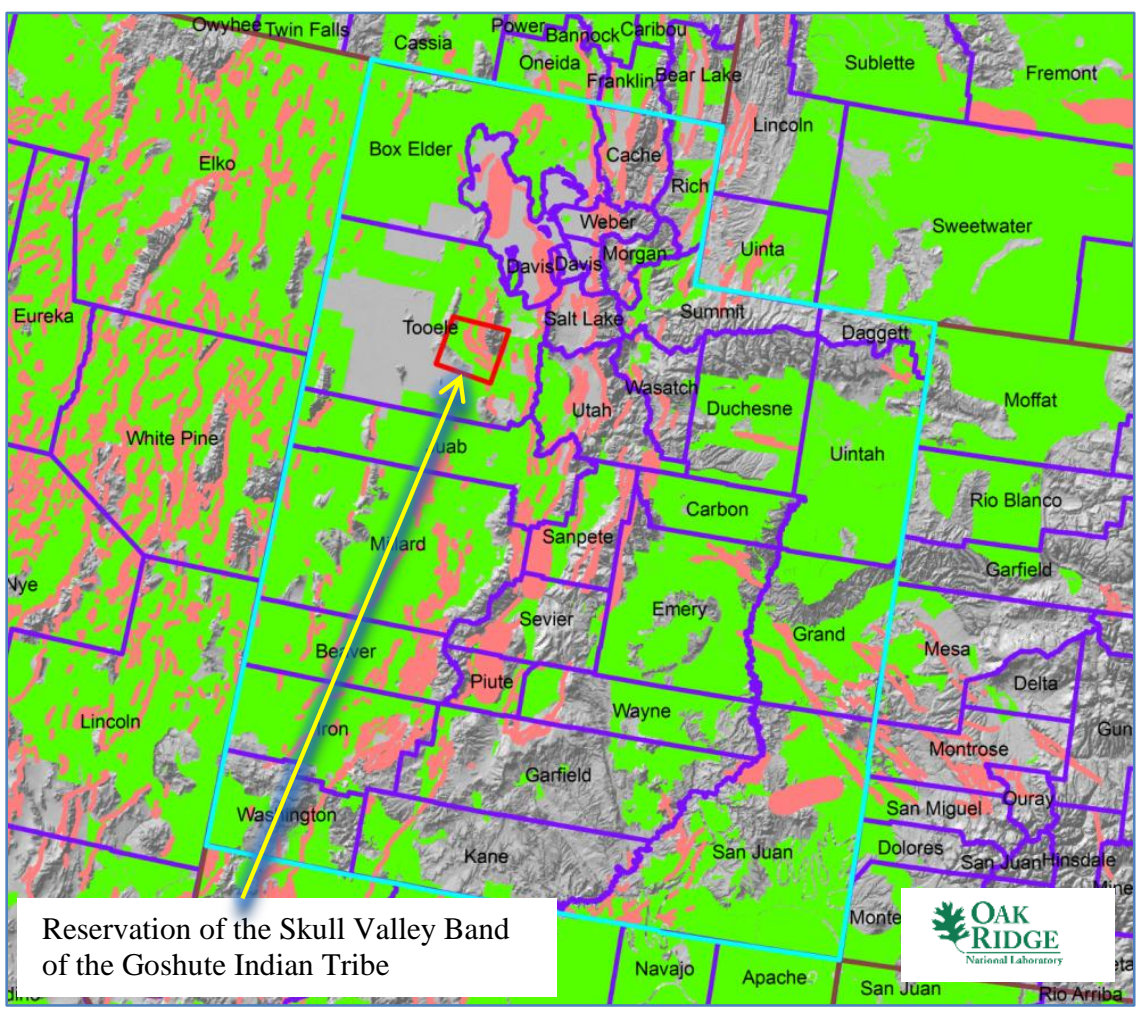

Fig. 35. ISFSI base map highlighting fault line SEC with standoff distances in red.

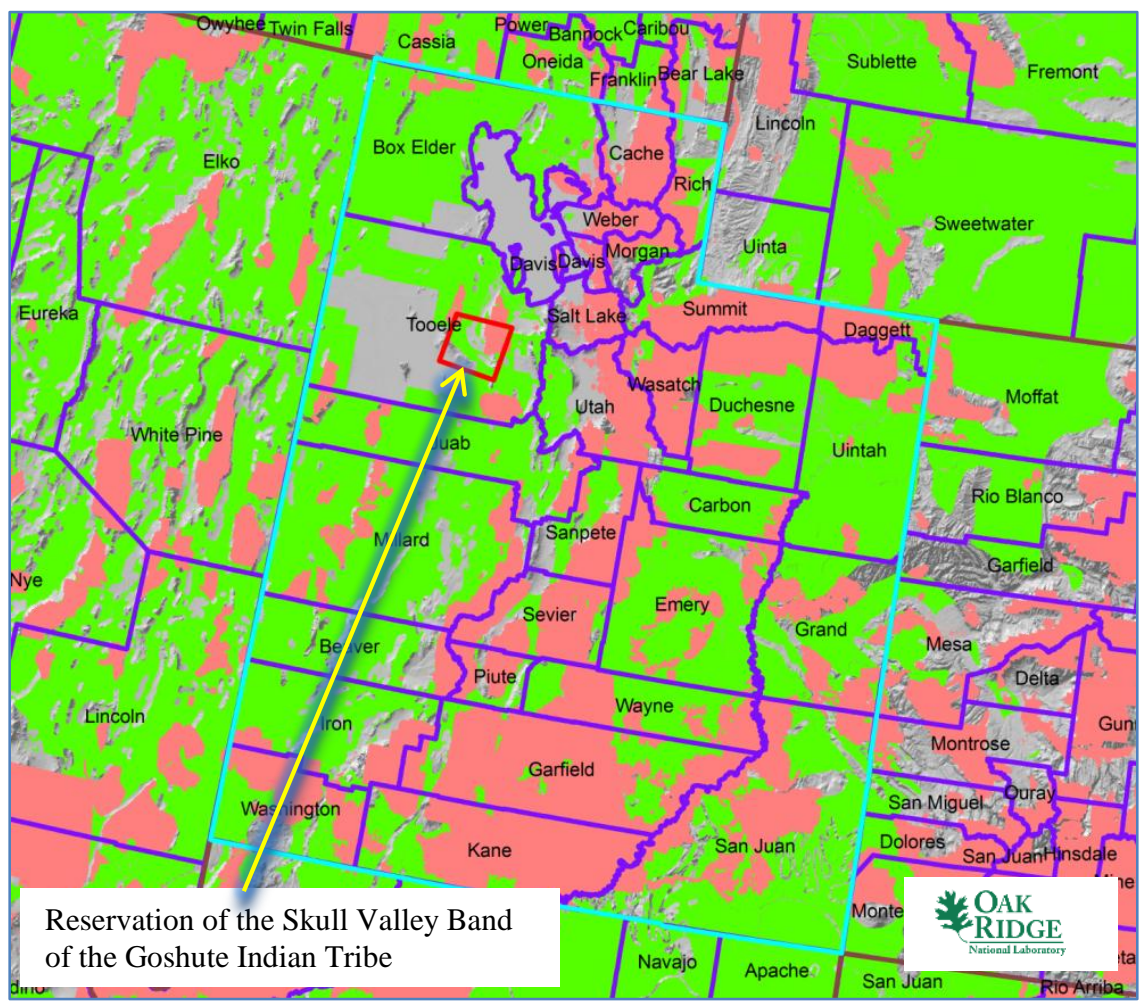

Fig. 36. ISFSI base map highlighting protected land SEC in red. 


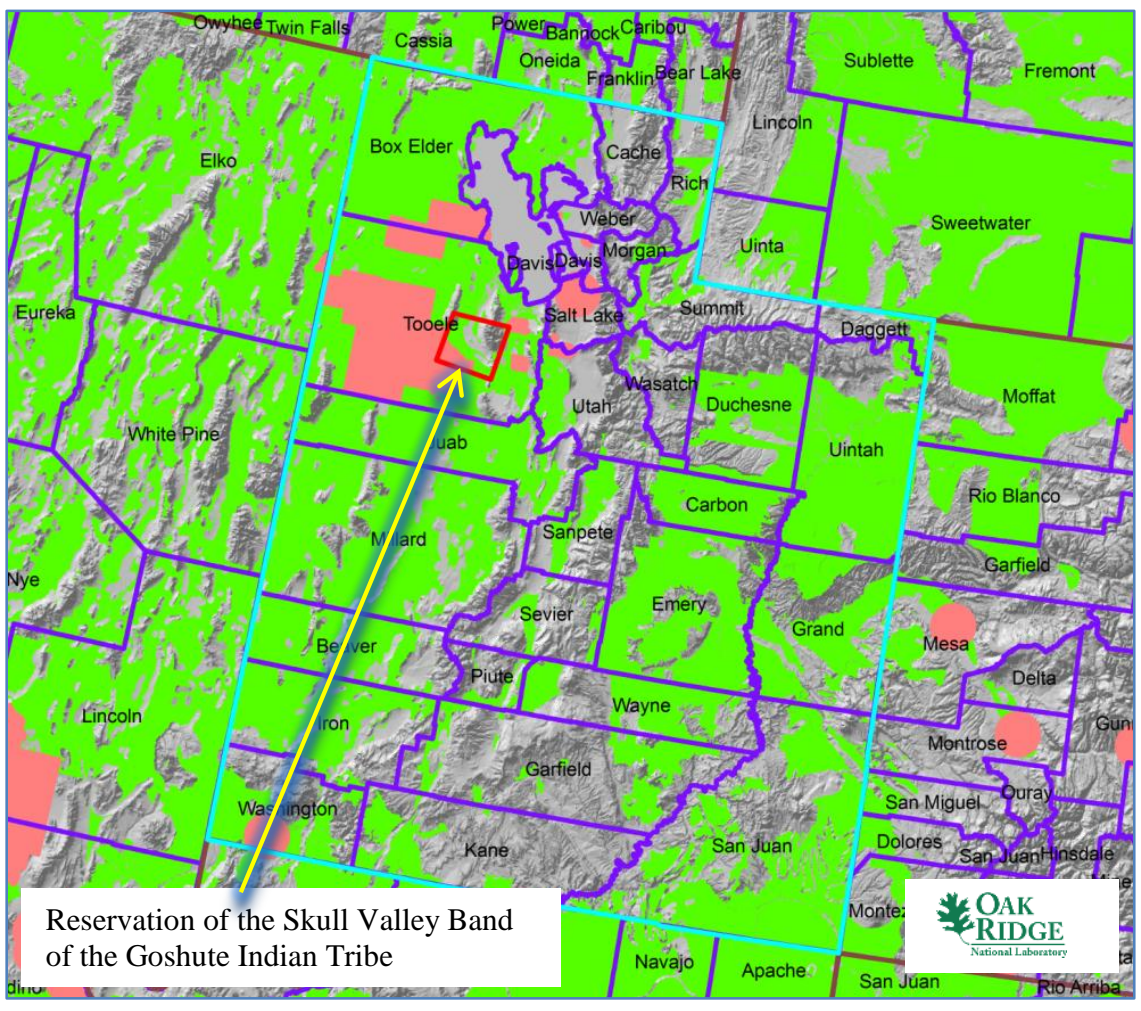

Fig. 37. ISFSI base map highlighting proximity to hazards SEC with buffer in red. 


\section{EVALUATION SCENARIOS}

Over 1.7 million potential 400-acre sites were generated by the ISFSI siting process described in Section 3 of this report based on the selected ISFSI SEC and values. Three possible scenarios for commercial nuclear power growth in the United States were evaluated relative to the best or optimized location(s) for a consolidated interim storage facility based on selected optimization criteria. The three commercial nuclear power scenarios are (1) the status quo scenario with no future commercial nuclear power growth, (2) a scenario with moderate commercial nuclear power growth, and (3) a scenario with aggressive commercial nuclear power growth that includes advanced reactor concepts.

\subsection{NO NUCLEAR GROWTH (STATUS QUO) SCENARIO}

A scenario that envisions no future commercial nuclear power growth was established as the base case scenario. For purposes of calculating SNF generation until 2050, nuclear power plants that have been granted a license extension were assumed to shut down when their 60-year amended license expired. Likewise, plants that have not yet been granted a license extension were assumed to shut down when their 40-year initial license expired. The completion of Watts Bar 2, Summer $2 \& 3$, and Vogtle $3 \& 4$ were not included in the status quo evaluation. The reactor sites are shown as yellow dots in Fig. 38.

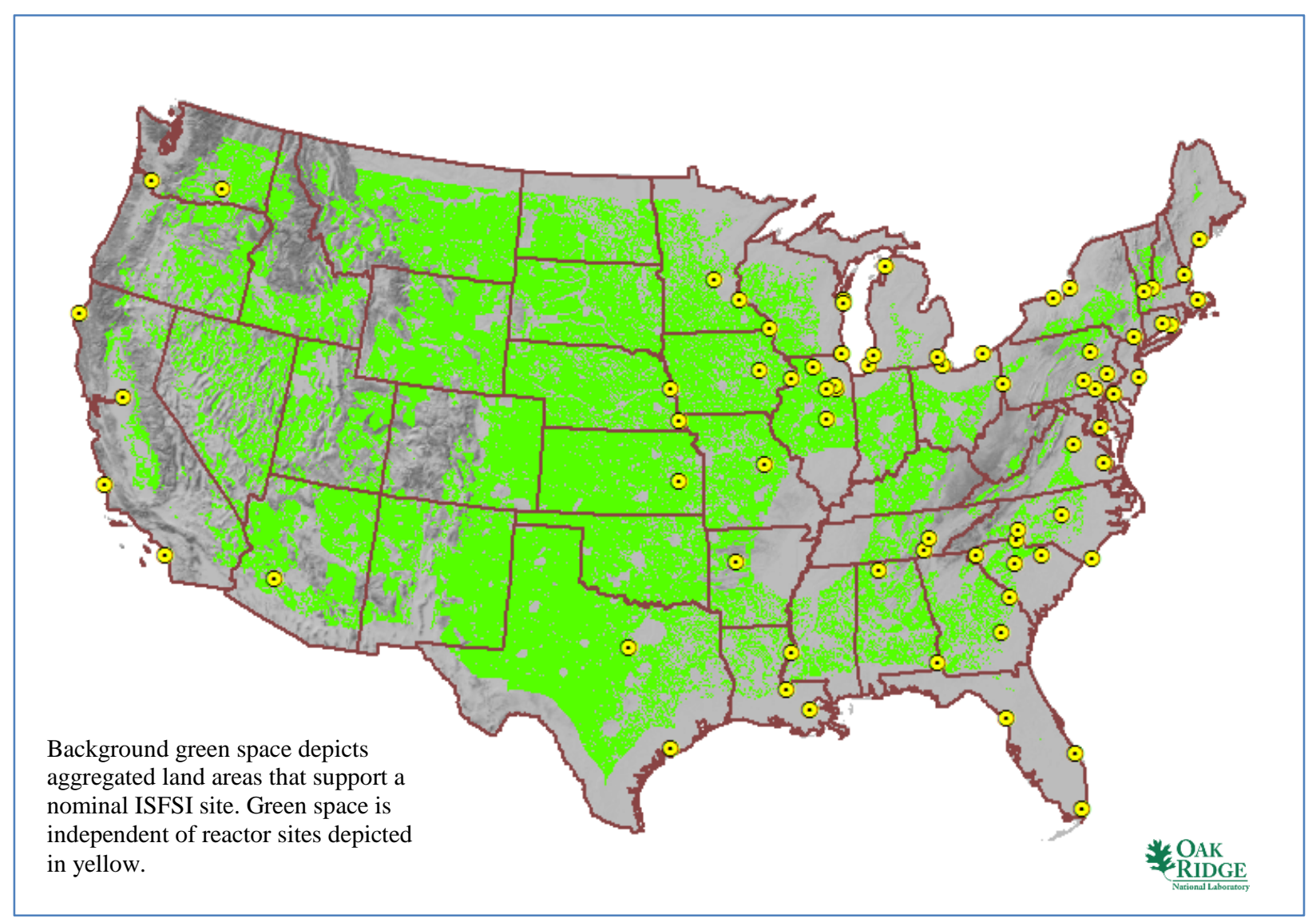

Fig. 38. Base case reactor locations. 
Table 2 lists the plants, license expiration date, and generated SNF calculated for 2050 considered for the status quo scenario. The base case generation capacity is $1,025 \mathrm{GW}(\mathrm{e}) .{ }^{21} \mathrm{~A}$ " $\mathrm{D}$ " following the plant name indicates that the plant has been decommissioned. The optimization results for this scenario are discussed in Section 6.1 of this report. The SNF generated is based on the methodology described in Section 2.2 of this report.

Table 2. Base case scenario nuclear power plants and SNF

\begin{tabular}{|l|c|c|}
\hline \multicolumn{1}{|c|}{ Facility } & $\begin{array}{c}\text { License } \\
\text { expiration }\end{array}$ & $\begin{array}{c}\text { SNF generated } \\
\text { by 2050 } \\
\text { (MTHM) }\end{array}$ \\
\hline Arkansas Nuclear One 1 & 2034 & 1244.8 \\
\hline Arkansas Nuclear One 2 & 2038 & 1195.5 \\
\hline Beaver Valley 1 & 2036 & 879.3 \\
\hline Beaver Valley 2 & 2047 & 1120.2 \\
\hline Big Rock Point (D) & 1997 & 59.0 \\
\hline Braidwood 1 & 2026 & 949.0 \\
\hline Braidwood 2 & 2027 & 955.4 \\
\hline Browns Ferry 1 & 2033 & 1327.5 \\
\hline Browns Ferry 2 & 2034 & 1324.0 \\
\hline Browns Ferry 3 & 2036 & 1682.3 \\
\hline Brunswick 1 & 2036 & 1353.3 \\
\hline Brunswick 2 & 2034 & 1026.7 \\
\hline Byron 1 & 2024 & 951.2 \\
\hline Byron 2 & 2026 & 1129.2 \\
\hline Callaway & 2024 & 1346.9 \\
\hline Calvert Cliffs 1 & 2034 & 1270.2 \\
\hline Calvert Cliffs 2 & 2036 & 1003.1 \\
\hline Catawba 1 & 2043 & 1333.2 \\
\hline Catawba 2 & 2043 & 1287.3 \\
\hline Clinton 1 & 2026 & 794.9 \\
\hline Columbia & 2023 & 1008.1 \\
\hline Comanche Peak 1 & 2030 & 1319.5 \\
\hline Comanche Peak 2 & 2033 & 1000.0 \\
\hline Cook 1 & 2034 & 860.8 \\
\hline Cook 2 & 2037 & 811.9 \\
\hline Cooper Station & 2034 & 1119.9 \\
\hline Crystal River 3 & 2016 & 652.9 \\
\hline Davis-Besse & 2017 & 768.5 \\
\hline Diablo Canyon 1 & 2024 & 1037.8 \\
\hline Diablo Canyon 2 & 2025 & 920.1 \\
\hline Dresden 1 (D) & 1978 & 91.0 \\
\hline Dresden 2 & & 1493.4 \\
\hline Dresden 3 & 2029.5 \\
\hline Duane Arnold & \\
\hline
\end{tabular}

${ }^{21}$ US NRC 2011-2012 Information Digest, value is based on 2009 data. 
Table 2. Base case scenario nuclear power plants and SNF (cont'd)

\begin{tabular}{|c|c|c|}
\hline Facility & $\begin{array}{c}\text { License } \\
\text { expiration }\end{array}$ & $\begin{array}{l}\text { SNF generated } \\
\text { by } 2050 \\
\text { (MTHM) }\end{array}$ \\
\hline Enrico Fermi 2 & 2025 & 964.9 \\
\hline Farley 1 & 2037 & 1209.5 \\
\hline Farley 2 & 2041 & 1347.3 \\
\hline Fitzpatrick & 2034 & 1336.7 \\
\hline Fort Calhoun & 2033 & 870.8 \\
\hline Grand Gulf 1 & 2024 & 1395.5 \\
\hline Haddam Neck (D) & 1996 & 462.8 \\
\hline Harris 1 & 2046 & 1097.0 \\
\hline Hatch 1 & 2034 & 1383.5 \\
\hline Hatch 2 & 2038 & 1337.9 \\
\hline HB Robinson 2 & 2030 & 1174.2 \\
\hline Hope Creek & 2046 & 1638.9 \\
\hline Humboldt Bay (D) & 1976 & 296.4 \\
\hline Indian Point 1 (D) & 1974 & 31.2 \\
\hline Indian Point 2 & 2013 & 723.9 \\
\hline Indian Point 3 & 2015 & 643.0 \\
\hline Kewaunee & 2033 & 706.5 \\
\hline La Crosse (D) & 1987 & 40.1 \\
\hline LaSalle County 1 & 2022 & 1010.2 \\
\hline LaSalle County 2 & 2023 & 742.2 \\
\hline Limerick 1 & 2024 & 1109.0 \\
\hline Limerick 2 & 2029 & 1430.0 \\
\hline Maine Yankee (D) & 1996 & 544.9 \\
\hline McGuire 1 & 2041 & 1683.1 \\
\hline McGuire 2 & 2043 & 1461.9 \\
\hline Millstone 1 (D) & 1998 & 565.3 \\
\hline Millstone 2 & 2035 & 882.7 \\
\hline Millstone 3 & 2045 & 1297.7 \\
\hline Monticello & 2030 & 947.4 \\
\hline Nine Mile Point 1 & 2029 & 915.7 \\
\hline Nine Mile Point 2 & 2046 & 1771.2 \\
\hline North Anna 1 & 2038 & 1158.3 \\
\hline North Anna 2 & 2040 & 1451.8 \\
\hline Oconee 1 & 2033 & 1157.4 \\
\hline Oconee 2 & 2033 & 1289.4 \\
\hline Oconee 3 & 2034 & 1095.0 \\
\hline Oyster Creek & 2029 & 1074.0 \\
\hline Palisades & 2031 & 944.7 \\
\hline Palo Verde 1 & 2044 & 1899.3 \\
\hline Palo Verde 2 & 2046 & 1711.2 \\
\hline
\end{tabular}


Table 2. Base case scenario nuclear power plants and SNF (cont'd)

\begin{tabular}{|c|c|c|}
\hline Facility & $\begin{array}{c}\text { License } \\
\text { expiration }\end{array}$ & $\begin{array}{l}\text { SNF generated } \\
\text { by } 2050 \\
\text { (MTHM) }\end{array}$ \\
\hline Peach Bottom 2 & 2033 & 1777.5 \\
\hline Peach Bottom 3 & 2034 & 1402.1 \\
\hline Perry 1 & 2026 & 979.7 \\
\hline Pilgrim 1 & 2012 & 646.4 \\
\hline Point Beach 1 & 2030 & 758.2 \\
\hline Point Beach 2 & 2033 & 670.9 \\
\hline Prairie Island 1 & 2033 & 782.0 \\
\hline Prairie Island 2 & 2034 & 793.2 \\
\hline Quad Cities 1 & 2032 & 1583.2 \\
\hline Quad Cities 2 & 2032 & 1288.6 \\
\hline R. E. Ginna & 2029 & 709.0 \\
\hline Rancho Seco (D) & 1989 & 227.3 \\
\hline River Bend 1 & 2025 & 1203.0 \\
\hline Salem 1 & 2036 & 1273.7 \\
\hline Salem 2 & 2040 & 1245.2 \\
\hline San Onofre 1 (D) & 1992 & 243.4 \\
\hline San Onofre 2 & 2022 & 1039.3 \\
\hline San Onofre 3 & 2022 & 837.6 \\
\hline Seabrook & 2030 & 1071.3 \\
\hline Sequoyah 1 & 2020 & 823.4 \\
\hline Sequoyah 2 & 2021 & 930.2 \\
\hline South Texas 1 & 2027 & 1105.8 \\
\hline South Texas 2 & 2028 & 1322.7 \\
\hline St. Lucie 1 & 2036 & 1314.2 \\
\hline St. Lucie 2 & 2043 & 1115.6 \\
\hline Surry 1 & 2032 & 940.2 \\
\hline Surry 2 & 2033 & 1000.5 \\
\hline Susquehanna 1 & 2042 & 1851.3 \\
\hline Susquehanna 2 & 2044 & 1410.1 \\
\hline Three Mile Island 1 & 2034 & 932.3 \\
\hline Trojan (D) & 1992 & 357.2 \\
\hline Turkey Point 3 & 2032 & 930.9 \\
\hline Turkey Point 4 & 2033 & 947.0 \\
\hline V C Summer & 2042 & 1104.7 \\
\hline Vermont Yankee & 2012 & 731.3 \\
\hline Vogtle 1 & 2047 & 1735.8 \\
\hline Vogtle 2 & 2049 & 1920.3 \\
\hline Waterford 3 & 2024 & 971.1 \\
\hline Watts Bar 1 & 2035 & 887.8 \\
\hline
\end{tabular}


Table 2. Base case scenario nuclear power plants and SNF (cont'd)

\begin{tabular}{|l|c|c|}
\hline \multicolumn{1}{|c|}{ Facility } & $\begin{array}{c}\text { License } \\
\text { expiration }\end{array}$ & $\begin{array}{c}\text { SNF generated } \\
\text { by 2050 } \\
\text { (MTHM) }\end{array}$ \\
\hline Wolf Creek 1 & 2045 & 1518.9 \\
\hline Yankee Rowe (D) & 1991 & 145.5 \\
\hline Zion 1 (D) & 1997 & 518.9 \\
\hline Zion 2 (D) & 1996 & 490.6 \\
\hline TOTAL & 2050 & $123,720.0$ \\
\hline
\end{tabular}

\subsection{MODERATE NUCLEAR GROWTH SCENARIO}

The moderate growth scenario assumes that all of the reactors considered in the base case remain available in a growth scenario. In addition, all the base case plants that have not yet been granted a license extension are assumed to eventually be granted a 20 -year license extension. Therefore, all of the base case plants considered in this moderate growth scenario are assumed to generate SNF until their 60-year amended licenses expire. The calculation for SNF generated based on the methodology described in Section 2.2 of this report was revised to account for later license expiration for those current plants that have not previously been granted a license extension.

In addition, at the time of this report, the NRC has received 18 combined license (COL) applications to build 28 new reactors in the United States. Some of these COL applications have subsequently been put on hold by the respective utilities. However, the moderate commercial nuclear power growth scenario assumes that all of these COL applications eventually result in a license and are subsequently built. Watts Bar 2, under a part 50 license application, is also assumed to be completed. The calculation for SNF generation for these new reactors is based on publically available reactor design details and forecast refueling cycles and capacity factors since a calculation based on RW-859 data is not available.

Several reactors included in the moderate growth scenario are already under construction. These reactors are Watts Bar 2, Summer $2 \& 3$, and Vogtle $3 \& 4$. Completion dates were assumed for these reactors based on current trade literature. Watts Bar 2 is expected to be complete in 2015. Summer $2 \& 3$ are expected to come online in 2017 and 2018, respectively. Vogtle $3 \& 4$ are expected to come online in 2016 and 2017, respectively. The remaining COL application plants are assumed to observe some schedule and cost success among the initial new nuclear plant builds and subsequently come online in mass by 2025. All these plants are assumed to have a 60-year life (40-year initial license and 20-year license amendment), which extends beyond the 2050 SNF calculation window for this report.

Finally, there are two small modular reactor (SMR) concepts under consideration by two utilities. The Tennessee valley Authority (TVA) is considering building six B\&W mPower ${ }^{\mathrm{TM}}$ integral pressurized water reactors (iPWRs) at the Clinch River site near Oak Ridge, Tennessee. The mPower ${ }^{\mathrm{TM}}$ reactors are built in pairs. These mPower ${ }^{\mathrm{TM}}$ pairs are assumed to come online at the Clinch River site in 2020, 2022, and 2024. The utility, AmerenUE, is considering building a Westinghouse iPWR at its Callaway reactor site in Missouri. This reactor is assumed to come online in 2022. Both these SMR concepts are assumed to have a 60-year life, which extends beyond the $2050 \mathrm{SNF}$ calculation window for this report. The calculation for SNF generation for these small reactors is based on preliminary reactor design details and forecast refueling cycles and capacity factors since these reactors are still in the design process and a calculation based on RW-859 data is not practical.

The base case reactor sites are shown as yellow dots in Fig. 39. New reactor sites and base case reactor sites that subsequently receive license renewals per the assumptions of the moderate growth scenario are shown as blue dots or yellow dots with a blue ring in Fig. 39. Many of the new reactor sites in the 
moderate growth case are at existing reactor locations. The moderate growth scenario adds approximately $36.6 \mathrm{GW}(\mathrm{e})$ of new generation to the base case by 2025 (4\% increase). Of course, without further life extensions beyond 60 years, the current fleet of reactors begins large scale retirement in the 2030s and 2040s and is substantially retired by 2050 .

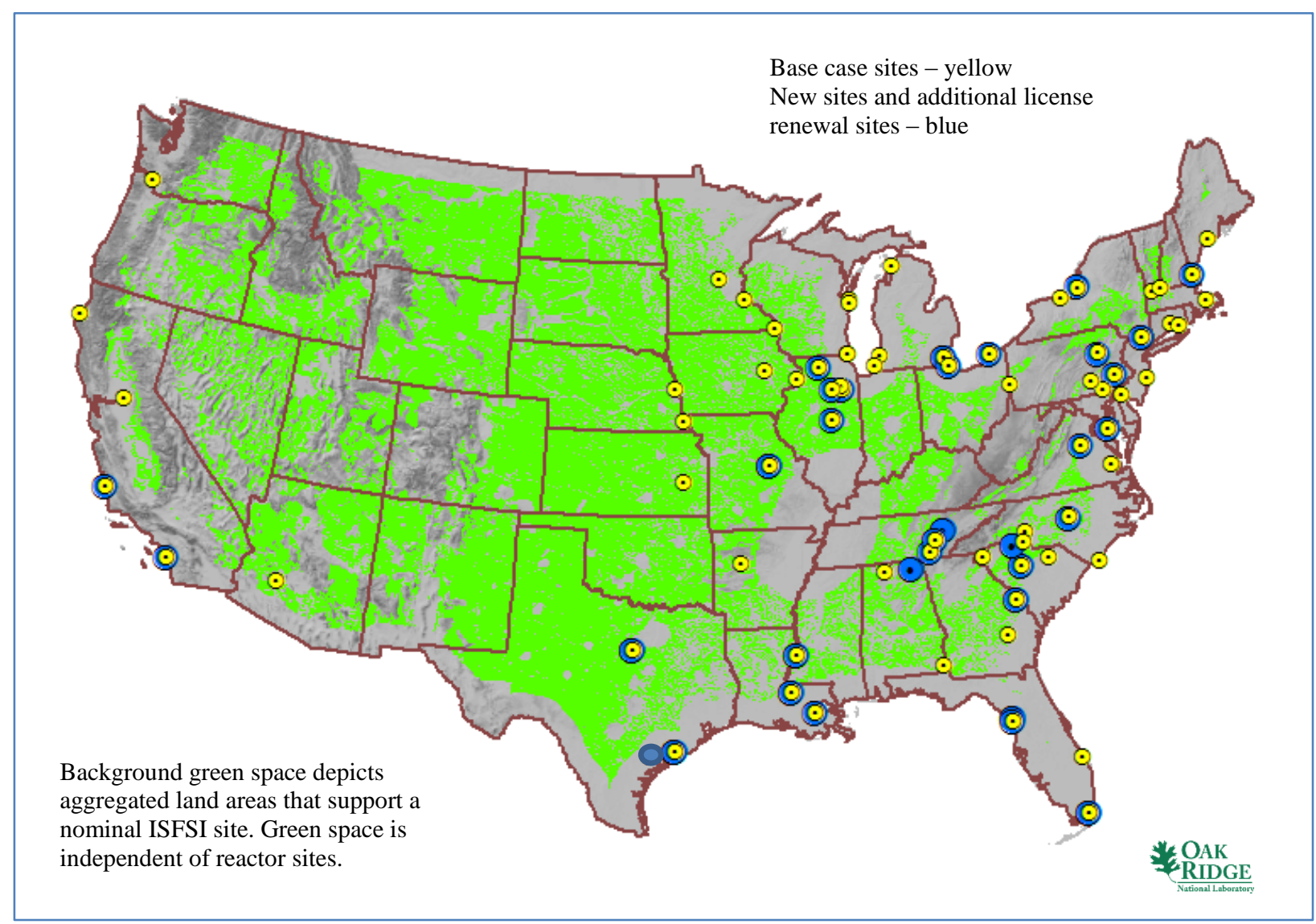

Fig. 39. Moderate growth case reactor locations.

Table 3 lists the additional plants, reactor startup date, and generated SNF calculated for 2050 considered for the moderate growth scenario. Table 4 lists the base case plants that are assumed to subsequently be granted a license extension, revised license expiration date, and generated SNF calculated for 2050. The optimization results for this scenario are discussed in Section 6.2 of this report. 
Table 3. Additional reactors and SNF for moderate growth scenario

\begin{tabular}{|l|c|c|}
\hline \multicolumn{1}{|c|}{ Facility } & Startup & $\begin{array}{c}\text { SNF generated } \\
\text { by 2050 } \\
\text { (MTHM) }\end{array}$ \\
\hline Bell Bend & 2025 & 819.4 \\
\hline Bellefonte 3 & 2025 & 528.9 \\
\hline Bellefonte 4 & 2025 & 528.9 \\
\hline Callaway 2 & 2025 & 819.4 \\
\hline Callaway 3 W-SMR & 2020 & 160.2 \\
\hline Calvert Cliffs 3 & 2025 & 819.4 \\
\hline Comanche Peak 3 & 2025 & 866.3 \\
\hline Comanche Peak 4 & 2025 & 866.3 \\
\hline Fermi 3 & 2025 & 858.0 \\
\hline Grand Gulf 3 & 2025 & 858.0 \\
\hline Harris 2 & 2025 & 528.9 \\
\hline Harris 3 & 2025 & 528.9 \\
\hline Levy County 1 & 2025 & 528.9 \\
\hline Levy County 2 & 2025 & 528.9 \\
\hline Nine Mile Point 3 & 2025 & 819.4 \\
\hline North Anna 3 & 2025 & 644.5 \\
\hline River Bend Station 3 & 2025 & 858.0 \\
\hline South Texas Project 3 & 2025 & 1553.0 \\
\hline South Texas Project 4 & 2025 & 1553.0 \\
\hline Summer 2 & 2017 & 698.1 \\
\hline Summer 3 & 2018 & 677.0 \\
\hline Turkey Point 6 & 2025 & 528.9 \\
\hline Turkey Point 7 & 2025 & 528.9 \\
\hline TVA mPower ${ }^{\mathrm{TM}}$ Unit 1-2 & 2020 & 150.0 \\
\hline TVA mPower ${ }^{\mathrm{TM}}$ Unit 3-4 & 2022 & 140.0 \\
\hline TVA mPower ${ }^{\mathrm{TM}}$ Unit 5-6 & 2024 & 130.0 \\
\hline Vogtle 3 & 2016 & 719.3 \\
\hline Vogtle 4 & 2017 & 698.1 \\
\hline Watts Bar 2 & 2015 & 776.8 \\
\hline William States Lee 1 & 2025 & 528.9 \\
\hline William States Lee 2 & 2025 & \\
\hline & & 528.9 \\
\hline
\end{tabular}


Table 4. Base case plants with license extension for moderate growth scenario

\begin{tabular}{|l|c|c|}
\hline \multicolumn{1}{|c|}{ Facility } & $\begin{array}{c}\text { License } \\
\text { expiration }\end{array}$ & $\begin{array}{c}\text { SNF generated by } \\
\mathbf{2 0 5 0} \\
\text { (MTHM) }\end{array}$ \\
\hline Braidwood 1 & 2046 & 1430.6 \\
\hline Braidwood 2 & 2047 & 1414.4 \\
\hline Byron 1 & 2044 & 1401.7 \\
\hline Byron 2 & 2046 & 1724.2 \\
\hline Callaway & 2044 & 2055.3 \\
\hline Clinton 1 & 2046 & 1131.6 \\
\hline Columbia* & 2043 & 1486.8 \\
\hline Comanche Peak 1 & 2050 & 1923.6 \\
\hline Comanche Peak 2 & 2053 & 1332.7 \\
\hline Crystal River 3 & 2036 & 941.2 \\
\hline Davis-Besse & 2037 & 1199.0 \\
\hline Diablo Canyon 1 & 2044 & 1543.8 \\
\hline Diablo Canyon 2 & 2045 & 1362.1 \\
\hline Grand Gulf 1 & 2044 & 2060.8 \\
\hline Indian Point 2 & 2033 & 1015.1 \\
\hline Indian Point 3 & 2035 & 934.8 \\
\hline LaSalle County 1 & 2042 & 1519.2 \\
\hline LaSalle County 2 & 2043 & 994.8 \\
\hline Limerick 1 & 2044 & 1625.0 \\
\hline Limerick 2 & 2049 & 2103.4 \\
\hline Perry 1 & 2046 & 1392.7 \\
\hline Pilgrim 1 & 2032 & 881.6 \\
\hline River Bend 1 & 2045 & 1828.0 \\
\hline San Onofre 2 & 2042 & 1543.2 \\
\hline San Onofre 3 & 2042 & 1171.4 \\
\hline Seabrook & 2050 & 1523.5 \\
\hline Sequoyah 1 & 1246.6 \\
\hline Sequoyah 2 & 2040 & 1415.7 \\
\hline South Texas 1 & 2041 & 1657.6 \\
\hline South Texas 2 & 2047 & 2026.0 \\
\hline Vermont Yankee & 2048 & 1073.3 \\
\hline Watts Bar 1 & 2032 & 1130.2 \\
\hline 'L5 & \\
\hline
\end{tabular}

${ }^{a}$ License renewal has been granted to these reactors after calculations were made for this report. 


\subsection{AGGRESSIVE NUCLEAR GROWTH WITH ADVANCED TECHNOLOGIES}

\subsubsection{Small Modular Reactors (SMRs)}

The starting point for the aggressive growth scenario is the moderate growth scenario considerations outlined above. Based on the assumed success of the SMR designs, an aggressive growth scenario was developed utilizing near-term SMR designs to replace aging coal plants, help several military installations achieve a more green power footprint, and provide process heat to the chemical industry.

The military has shown a mild interest in using reactors to provide the power needs at various military installations. Four military bases were selected based solely on providing a reasonable geographic spread of SMRs for military use, as well as a variety of military services (Air Force, Army, and Navy). SMRs have a relatively small footprint and deliver an electrical output that is well suited to a military installation; the iPWR designs are largely underground, which supports security needs as well. Therefore, iPWR designs were proposed for the selected military installations coming online between 2026 and 2029.

Nuclear utilities with aging coal plants were assumed to be the most likely to consider replacing a coal plant with an SMR installation. More than 50\% of the United States nuclear generating capacity is owned by seven nuclear utilities. ${ }^{22}$ Active and retired coal plants from Exelon Generation, Entergy, Southern Company, TVA, Duke Power Company, Progress Energy, and Dominion Generation were considered. The primary consideration for site selection was based on the electrical output of the coal plant to be replaced and the current rated power outputs of two iPWR designs under consideration: the B\&W mPower ${ }^{\mathrm{TM}}$ iPWR design and the Westinghouse iPWR design. These SMR designs were selected based on industry support for these designs as discussed in the moderate growth scenario above. These SMRs were assigned phased-in startup dates following the predicted startup date for the TVA Clinch River mPower ${ }^{\mathrm{TM}}$ site.

Additionally, the Blue Castle site in Utah and the Payette site in Idaho have been mentioned in the trade press as possible sites for a nuclear power plant. Under the aggressive growth scenario, it was assumed that these sites proceed with nuclear generation based on an SMR design. A third iPWR design, the NUSCALE iPWR, is currently in pre-application review with the NRC. No utility has announced intent to partner with the NUSCALE group. However, this design was assigned to the Blue Castle site based on the ongoing NRC interaction for design certification. A 12-unit NUSCALE plant [540 MW(e)] is proposed in this scenario to startup in 2035. A 2-unit $\mathrm{mPower}^{\mathrm{TM}}{ }_{\mathrm{iPWR}}$ was assigned to the Payette site.

\subsubsection{Advanced Reactors}

Advanced reactors are the emerging class of reactors that, generally speaking, employ a non-water coolant in the primary heat transport system. Various terms are used-sometimes interchangeably-to describe advanced reactor designs, including evolutionary designs, passive designs, and innovative designs. An IAEA terminology document ${ }^{23}$ describes "advanced reactor" term as follows:

An advanced plant design is a design of current interest for which improvement over its predecessors and/or existing designs is expected. Advanced designs consist of evolutionary designs and designs requiring substantial development efforts. The latter can range from moderate modifications of existing designs to entirely new design concepts. They

\footnotetext{
${ }^{22}$ T. J. Harrison, G. T. Mays, B. R. Blevins, "Preliminary Report on Evaluating Selected Coal Plant Sites for Repowering with Small Modular Reactors,” ORNL Letter Report LTR/DOE-NE/Siting-2011/001 prepared for DOE, Office of Nuclear Energy, February 2011.

${ }^{23}$ International Atomic Energy Agency (IAEA), Terms for Describing New, Advanced Nuclear Power Plants, IAEA-TECDOC936, Vienna, 1997.
} 
differ from evolutionary designs in that a prototype or a demonstration

plant is required, or that not sufficient work has been done to establish

whether such a plant is required.

Advanced designs vary dramatically in terms of types of coolants used, power-conversion system technologies, etc., but they generally offer improved safety, reliability, and dependability with highdegree of passive safety features, and typically enjoy less dependence on external power sources during an anticipated transient or an accident condition.

Much of the existing advanced reactor designs generally offer higher reactor outlet temperatures compared to the conventional light-water reactors (LWRs), which make them attractive power generation sources for hybrid electricity-generation and process-heat applications.

The advanced reactor designs that were taken into consideration for this project include the following:

1. high-temperature gas reactor (HTGR),

2. advanced high-temperature reactor (AHTR), and

3. sodium-cooled fast reactor (SFR).

Next-Generation Nuclear Plant (NGNP) developed by US DOE is a design variant of the HTGR class. The most recent NGNP point design is based on General Atomics Modular High-Temperature GasCooled Reactor (MHTGR). NGNP and AHTR are thermal-spectrum reactors, while SFR is a fastspectrum reactor.

Other design concepts were not taken into consideration due to their relatively low maturity levels compared to the ones considered in Scenario 3. SFR was later eliminated because of its primary mission: fast reactors are generally interpreted as "fuel cycle optimizers," in that (1) they can accept used LWR fuel and (2) they can significantly reduce the minor actinide content in the SNF through transmutation because of the hard neutron spectrum. However, the latter mission requires a comprehensive fuel cycle planning, and outcomes - that is, the final waste inventory as a result of this planning - may vary substantially. Because of these complications, ORNL focused on only thermal-spectrum reactors, which included only HTGR and AHTR.

It should be pointed out that elimination of this technology should not be construed with a negative connotation: fast-spectrum reactors should be considered as important actors of the future US energy portfolio. The most important advantage of employing fast-spectrum reactors is significant reduction of waste volume and thermal loading. The most problematic components in LWR SNF are the transuranics, and particularly the minor actinides. Minor actinides generally take up about 5\% of the entire SNF volume but cause about $99 \%$ of the problems, such as long-term radioactivity and decay heat.

Identifying candidate sites for advanced reactors is a challenge primarily because there is not yet an established domestic customer base for these technologies. International efforts are ongoing primarily to (1) demonstrate the safe and reliable operation of these technologies, (2) improve the technology readiness levels, and (3) to expedite the licensing path by providing necessary operational data.

Because of a lack of customer base for these technologies, ORNL focused on potential future customers by analyzing the current industry landscape, particularly placing emphasis on the industries that might be served by high-temperature process heat. In order to determine the spatial distribution of these industries, one needs to identify the subcategories of commercial industries that use energy-intensive hightemperature processes for manufacturing.

A recent analysis of the US industry by MPR Associates for the NGNP program ${ }^{24}$ tried to identify

\footnotetext{
${ }^{24}$ J. Konefal and D. Rackiewicz, Survey of HTGR Process Energy Applications, MPR-3181 Rev. 0, MPR Associates Inc., prepared for NGNP Project—Battelle Energy Alliance, May 2008.
} 
potential customers for this technology. The analysis categorized various industries with respect to temperature range of the processes: (1) $250-500^{\circ} \mathrm{C}$, (2) $500-700^{\circ} \mathrm{C}$, and (3) $700-950^{\circ} \mathrm{C}$. Based on these temperature ranges, major commercial products and manufacturers were identified. A list of potential products and associated chemical processes is shown in Table 5. The current US demand-an indication of the potential market size-for process heat is shown in Fig. 40.

Table 5. Products, processes, and temperature ranges applicable to high-temperature reactors ${ }^{24}$

\begin{tabular}{|c|c|c|c|c|c|}
\hline \multicolumn{2}{|c|}{$200-500^{\circ} \mathrm{C}$} & \multicolumn{2}{|c|}{$500-700^{\circ} \mathrm{C}$} & \multicolumn{2}{|c|}{$700-950^{\circ} \mathrm{C}$} \\
\hline Product & Process & Product & Process & Product & Process \\
\hline \multirow{4}{*}{ Refinery Products } & $\begin{array}{l}\text { Atmospheric } \\
\text { Distillation }\end{array}$ & Petroleum Coke & Coking & Ethylene & \multirow{2}{*}{ Steam Cracking } \\
\hline & $\begin{array}{l}\text { Vacuum } \\
\text { Distillation }\end{array}$ & Refinery Products & Catalytic Cracking & Propylene & \\
\hline & $\begin{array}{l}\text { Catalytic Hydro } \\
\text { Cracking }\end{array}$ & \multirow[t]{2}{*}{ Refinery Products } & \multirow{4}{*}{$\begin{array}{l}\text { Catalytic } \\
\text { Reforming }\end{array}$} & Hydrogen & \multirow{2}{*}{$\begin{array}{l}\text { Steam Methane } \\
\text { Reforming }\end{array}$} \\
\hline & Hydro-Treating & & & Carbon Dioxide & \\
\hline Bitumen & $\begin{array}{l}\text { In-Situ Bitumen } \\
\text { Extraction }\end{array}$ & Toluene & & Hydrogen & $\begin{array}{l}\text { High-Temperature } \\
\text { Steam } \\
\text { Electrolysis, } \\
\text { Sulphur-Iodine, } \\
\text { HyS }\end{array}$ \\
\hline Acetone & $\begin{array}{l}\text { Rearrangement of } \\
\text { Cumene } \\
\text { Hydroperoxide }\end{array}$ & P-Xylene & & $\begin{array}{l}\text { Cement (with } \\
\text { catalyst) }\end{array}$ & Calcination \\
\hline Acrylonitrile & Ammoxidation & $\begin{array}{l}\text { Synthetic Crude } \\
\text { Oil }\end{array}$ & $\begin{array}{l}\text { Bitumen } \\
\text { Upgrading }\end{array}$ & Syngas & Gasification \\
\hline Ethylbenzene & $\begin{array}{l}\text { Friedel-Crafts } \\
\text { Alkylation }\end{array}$ & Styrene & Dehydrogenation & $\begin{array}{l}\text { Direct Reduced } \\
\text { Iron }\end{array}$ & \\
\hline Ethylene Oxide & Air Epoxidation & $\begin{array}{l}\text { Hot Briquetted } \\
\text { Iron }\end{array}$ & Gasification & & \\
\hline Acetic Acid & Multiple & \multirow{9}{*}{\multicolumn{2}{|c|}{ * Shaded cells indicate far-term applicatic }} & & \\
\hline Cumene & $\begin{array}{l}\text { Friedel-Crafts } \\
\text { Alkylation }\end{array}$ & & & & \\
\hline Cyclohexane & $\begin{array}{l}\text { Transformation of } \\
\text { Benzene }\end{array}$ & & & & \\
\hline Terephthalic Acid & Amoco Process & & & & \\
\hline Ammonia & Haber Process & & & & \\
\hline $\begin{array}{l}\text { Low-Density } \\
\text { Polyethylene }\end{array}$ & \multirow{3}{*}{ Polymerization } & & & & \\
\hline $\begin{array}{l}\text { Nylon } 6 \text { and } \\
\text { Nylon } 6.6\end{array}$ & & & & & \\
\hline Polyester & & & & & \\
\hline Liquid Fuels & Fischer-Tropsch & & & & \\
\hline
\end{tabular}




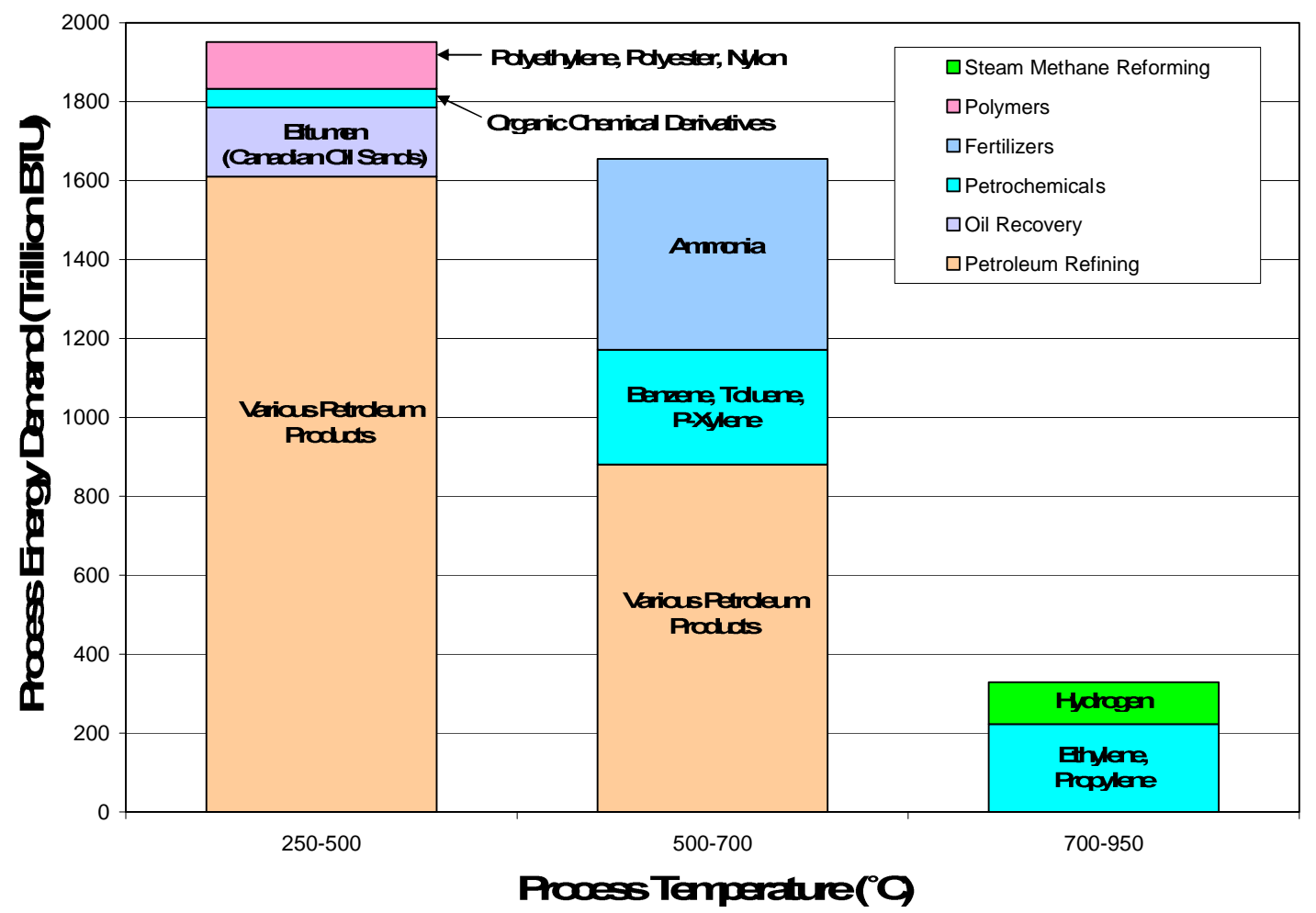

Fig. 40. Current US demand for high-temperature process heat across various industries. ${ }^{24}$

Using the results of this analysis, ORNL narrowed the chemical and petrochemical industry in the United States into key subcategories.

Primary Subtype Description:

- amines, acids, salts, esters;

- ammonia and ammonium salts;

- ammonium salts and compounds;

- ammonium (except for small arms);

- chemicals and allied products;

- petroleum refining;

- petroleum products;

- petroleum, mining, and chemical engineering; and

- phosphates.

The distribution of the chemical plants that fall into these categories is shown in Fig. 41. Looking at the geographical distribution, a number of locations seem to have increased density of chemical and petrochemical plants and were considered suitable candidates for siting high-temperature reactors:

1. Wisconsin-Illinois border toward Lake Michigan (2 HTGRs),

2. northern part of New Jersey (1 HTGR),

3. mid-western side of Florida (1 AHTR),

4. eastern tip of Louisiana toward Lake Pontchartrain (1 AHTR), and

5. southeastern strip of Texas toward Trinity Bay (1 AHTR). 


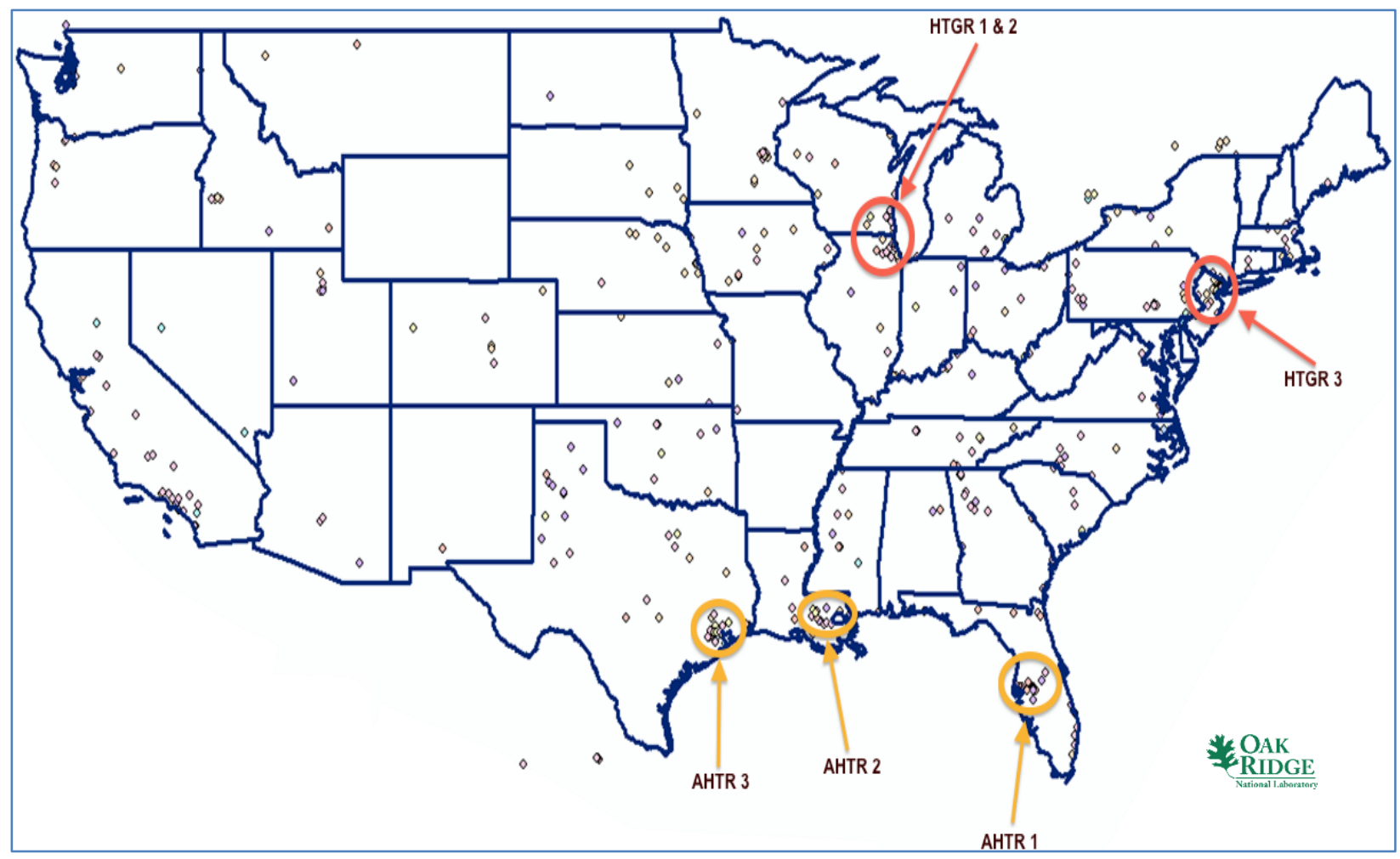

Fig. 41. Selected sites for high-temperature reactors.

What is presented here for advanced reactor siting is not an extensive analysis for power plant siting. This rough study was only intended to offer some technical basis for siting the selected advanced reactors across the nation. Selection and distribution of the reactor types (HTGR vs AHTR) were also made arbitrarily.

ORNL recognizes that the prospect of high-temperature process heat is not the only reason for moving to advanced reactor designs, but we also acknowledge that this capability will be a major driving force to catapult US manufacturing by providing cheap and clean energy — both electricity and heat - to become more competitive in the global markets.

The moderate growth reactor sites are shown as yellow dots in Fig. 42. New reactor sites per the assumptions of the aggressive growth scenario are shown as purple dots in Fig. 42. The aggressive growth scenario adds approximately $19 \mathrm{GW}(\mathrm{e})$ of new generation to the moderate growth case by 2035 . This represents an increase of approximately $55.6 \mathrm{GW}(\mathrm{e})$ in new generation over the base case scenario (5\% increase). 


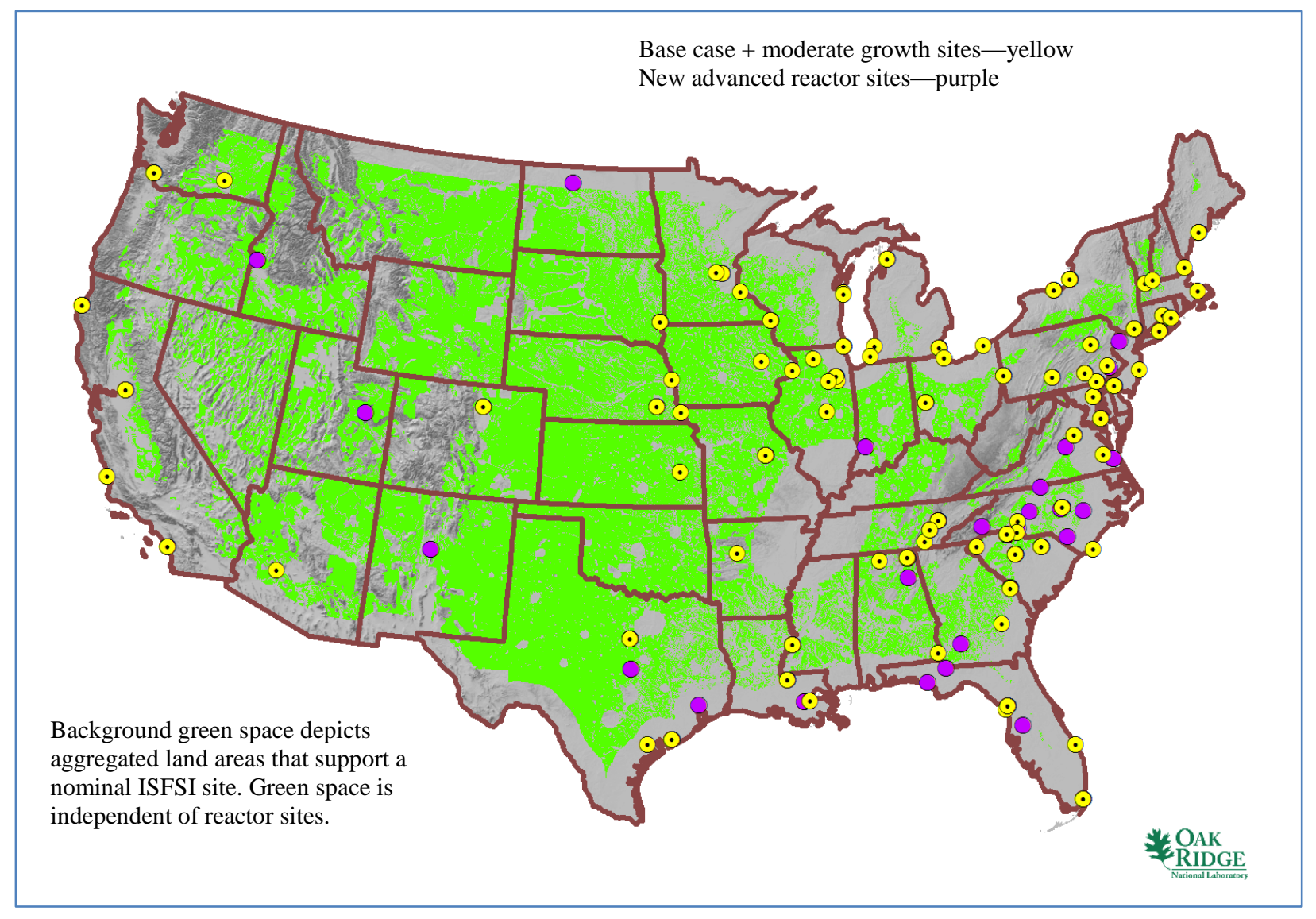

Fig. 42. Aggressive growth case reactor locations.

Table 6 lists the additional plants, reactor type, reactor startup date, and generated SNF calculated for 2050 considered for the aggressive growth scenario. The calculation for SNF generation for these advanced reactors is based on preliminary reactor design details and forecast refueling cycles and capacity factors since many of these reactors are still in the concept phase and a calculation based on RW-859 data is not practical. The optimization results for this scenario are discussed in Section 6.3 of this report. 
Table 6. Additional reactors and SNF for aggressive growth scenario

\begin{tabular}{|c|c|c|c|}
\hline Facility & Reactor & Startup & $\begin{array}{c}\text { SNF generated } \\
\text { by } 2050 \\
\text { (MTHM) }\end{array}$ \\
\hline Norfolk Naval Station 1-2 & mPower $^{\mathrm{TM}}$ & 2026 & 120.1 \\
\hline Minot Air Force Base 1-2 & mPower $^{\mathrm{TM}}$ & 2028 & 110.1 \\
\hline Payette, ID 1-2 & mPower $^{\mathrm{TM}}$ & 2032 & 90.0 \\
\hline Payette, ID 3-4 & mPower $^{\mathrm{TM}}$ & 2034 & 80.0 \\
\hline Lansing Smith 1-2 & mPower $^{\mathrm{TM}}$ & 2025 & 125.1 \\
\hline Buck 1-2 & mPower $^{\mathrm{TM}}$ & 2026 & 120.1 \\
\hline Dan River 1-2 & mPower $^{\mathrm{TM}}$ & 2027 & 115.1 \\
\hline Cape Fear 1-2 & mPower $^{\mathrm{TM}}$ & 2028 & 110.1 \\
\hline H.B. Robinson 1-2 & mPower $^{\mathrm{TM}}$ & 2029 & 105.1 \\
\hline Bremo Bluff 1-2 & mPower $^{\mathrm{TM}}$ & 2030 & 100.1 \\
\hline H.P. Lee 1-4 & mPower $^{\mathrm{TM}}$ & 2032 & 90.0 \\
\hline Fort Hood Texas 1 & Westinghouse SMR & 2027 & 122.8 \\
\hline Kirtland Air Force Base 1 & Westinghouse SMR & 2029 & 112.1 \\
\hline Cromby Generating 1 Station & Westinghouse SMR & 2026 & 128.2 \\
\hline Gadsden 1 & Westinghouse SMR & 2027 & 122.8 \\
\hline Scholz 1 & Westinghouse SMR & 2028 & 117.5 \\
\hline Mitchell 1 & Westinghouse SMR & 2029 & 112.1 \\
\hline Edwardsport 1 & Westinghouse SMR & 2030 & 106.8 \\
\hline Riverbend 1-2 & Westinghouse SMR & 2032 & 96.1 \\
\hline Weatherspoon 1 & Westinghouse SMR & 2033 & 90.8 \\
\hline Asheville 1 & Westinghouse SMR & 2035 & 80.1 \\
\hline Blue Castle 1-12 & NUSCALE & 2035 & 344.3 \\
\hline Florida & AHTR & 2035 & 224.4 \\
\hline Louisiana & AHTR & 2035 & 224.4 \\
\hline Texas & AHTR & 2035 & 224.4 \\
\hline Wisconsin-Illinois 1 & HTGR & 2035 & 143.7 \\
\hline Wisconsin-Illinois 2 & HTGR & 2035 & 143.7 \\
\hline New Jersey & HTGR & 2035 & 143.7 \\
\hline
\end{tabular}

\subsection{NUCLEAR GROWTH PREDICTION}

The nuclear plant generation capacity growth scenarios identified in this report were primarily based on current COL applications to the NRC and the possibility of using SMRs to replace a portion of the electrical power provided by aging coal plants. There are other more sophisticated methods to predict future energy demand based on population growth and plant retirements and the share of that demand provided by new nuclear plant generation.

Future nuclear plant development can be influenced by energy economic projections. The projections produced with the DOE Energy Information Administration's (EIA) National Energy Modeling System (NEMS) provide forecasts of domestic energy-economy markets in the long term and perform energy policy analyses. The projections in NEMS are developed with the use of a market-based approach to energy analysis over a time horizon of approximately 25 years. For each fuel and consuming sector, 
NEMS balances the energy supply and demand, accounting for the economic competition between the various energy fuels and sources. NEMS modules represent each of the fuel supply markets, conversion sectors, and end-use consumption sectors of the energy system. NEMS also accounts for the impacts and costs of legislation and environmental regulations that affect that an energy sector. Finally, NEMS tallies all combustion-related carbon dioxide $\left(\mathrm{CO}_{2}\right)$ emissions, as well as emissions of sulfur dioxide $\left(\mathrm{SO}_{2}\right)$, nitrogen oxides $\left(\mathrm{NO}_{x}\right)$, and mercury from the electricity generation sector. ${ }^{25}$

ORNL has developed the capability to couple NEMS energy projections with the screening process provided by OR-SAGE in a modeling process known as energy visualization (EnVISion). EnVISion is a decision-support system to provide national-level energy policy makers the capability to evaluate the impacts of policy options for addressing future US electrical generation needs. EnVISion employs spatial modeling and simulation applications including geographical information systems (GIS) to enhance the understanding, implications, and viability of potential energy policies and plans.

Presently EnVISION couples the GIS-based siting tool, OR-SAGE, and NEMS as the economic model for input to OR-SAGE. However, any energy demand prediction model could potentially be coupled to OR-SAGE. EnVISion evaluates potential energy policies and electricity market factors as represented by NEMS in terms of visualizing what is potentially possible and potentially not possible in terms of deploying a wide array of electrical generation resources (nuclear, clean coal, wind, solar, biomass, geothermal, etc.) nationally and/or regionally to meet the power demand and power mix associated with the particular case examined. Therefore, for future ISFSI siting optimization work, EnVision could be utilized to provide input into a variety of future nuclear plant capacity growth scenarios. This would have the added benefit of accounting for resources such as water usage in future thermoelectric plant growth.

${ }^{25}$ EIA Annual Energy Outlook 2011. 


\section{OPTIMIZATION APPLICATION}

Optimizing the locations of potential storage facilities utilizes a classical location problem commonly referred to as the p-median problem. The problem is one of locating set number of facilities (p-medians) on a network relative to a set of customers such that the sum of the shortest demand weighted distance between customers and facilities is minimized. In this case, the facilities are the consolidated ISFSI sites and the customers are the reactor sites with SNF awaiting disposal. The typical p-median problem can be stated as follows:

\section{Given a set of customers with known amounts of demand, a set of candidate locations for warehouses, and the distance between each pair of customer-warehouse, choose P warehouses that would minimize the demand-weighted distance of serving all customers from those $P$ warehouses.}

Of course, in this study the customers are not demanding material from the warehouse; instead the customers are delivering material to the warehouse. However, the same p-median concept applies. The generic objective is to find a set number of interim SNF storage sites that would minimize a "cost" function using a set of constraints. Cost can include monetary limitations, time, population dose, and socio-political issues, such as willingness to participate by local population in a proposed siting of a facility, or laws banning nuclear facilities, or transporting the material through state and local land. The significance of the socio-political dimension of this long-standing problem remains an important consideration for future review. Obviously, implementation of social aspects in a geo-spatial mathematical model requires creation of data sets that quantify these social attributes with a credible metric in a consistent fashion.

It should be noted that this particular project was embarked on as a proof-of-principle application that would (1) define a reasonable "cost" structure, (2) introduce an agreeable set of generic constraints against identifying potential sites, and (3) propose a link that would connect a potential site with a reactor site. Objectives, costs, and constraints are based on realistic assumptions and the most up-to-date data available at the time of this study. However, in order to present the capabilities within the limited scope of the project, only technical aspects of the problem were formulated into the simulation. The "cost" factors consider in this p-median optimization are (1) minimizing transportation distance per quantity of SNF and (2) minimizing population dose along the transportation route. Prioritized SNF shipments could impact the optimized location of consolidated ISFSIs. However, no consideration of time sequencing relative to the SNF shipments was reflected in this optimization study.

Locating single and multi-medians was first formulated by Hakimi. ${ }^{26,27} \mathrm{He}$ also proposed a simple enumeration procedure to solve the problem. The problem is well known to be NP-hard (nondeterministic, polynomial-time hard). ${ }^{28}$ Several heuristics have been developed for p-median problems. Some of them are used to obtain good initial solutions or to calculate intermediate solutions on search tree nodes.

ORNL staff employed a number of computational tools during the execution of the project, including data processing tools implemented specifically for this project, mixed-integer linear programming (MILP) solvers, and data display software. MILP solvers included the open-source SYMPHONY framework and the commercial GUROBI package. SYMPHONY software was installed on ORNL's Institutional Clusters (OIC) to take advantage of parallel computing capability of the tool using the Parallel Virtual

\footnotetext{
${ }^{26}$ S. L. Hakimi, "Optimum Location of Switching Centers and the Absolute Centers and the Medians of a Graph," Operations Research 12, 450-459 (1964).

${ }^{27}$ S. L. Hakimi, "Optimum Distribution of Switching Centers in a Communication Network and Some Related Graph Theoretic Problems," Operations Research 13, 462-475 (1965).

${ }^{28}$ M. R. Garey and D. S. Johnson, Computers and Intractability: A Guide to the Theory of NP-Completeness, W. H. Freeman and Co., San Francisco, 1979.
} 
Machine (PVM) architecture. GUROBI, on the other hand, was installed on a single-node computer. It was observed that GUROBI outperformed SYMPHONY by orders of magnitude.

\subsection{MATHEMATICAL BACKGROUND}

The optimization objective of minimizing transportation distance and minimizing population dose is expressed mathematically by the minimum of the following expression:

$$
\min \left\{\sum_{i \in\{1, \ldots, I\}} \sum_{j \in\{1, \ldots, J\}} C_{i j} x_{i j}\right\}
$$

where $C_{i j}$ is the combined "cost" associated with transporting a certain quantity of spent nuclear fuel, that is, the total distance traversed and total population exposed between the origin and destination; $i \in\{1, \ldots, I\}$ index represents each reactor out of a total of $I$ reactors; and $j \in\{1, \ldots, J\}$ index represents each potential storage site out of a total of $J$ potential storage sites.

\subsubsection{Optimization Cost Function}

The cost variable $C_{i j}$ inherently includes the quantity of spent nuclear fuel associated with each reactor site; that is,

$$
C_{i j}=\omega_{i} \vartheta_{i j},
$$

where $\omega_{i}$ is the amount of spent nuclear fuel (in MTHM) to be discharged from reactor site $i$ in year 2050 and $\vartheta_{i j}$ is the combined cost of distance and population exposure between reactor site $i$ and interim SNF storage site $j$.

In ORNL's formulation, the cost function $\vartheta_{i j}$ was defined as follows:

$$
\vartheta_{i j}=\alpha \delta_{i j}+(1-\alpha) \psi_{i j}
$$

where $\delta_{i j}$ is the normalized pure transportation cost, $\psi_{i j}$ is the normalized pure population exposure between reactor site $i$ and interim storage facility $j$, and $\alpha \in[0,1]$ is a weighting factor that determines the relative importance of transportation distance and associated population exposure risk.

The transportation distance, $\Delta_{i j}$, and the number of populace along the transportation route, $\Psi_{i j}$, are normalized by their respective segment-wise maximum values between reactor site $i$ and interim SNF storage site $j$; that is,

$$
\begin{aligned}
\psi_{i j} & =\frac{\Psi_{i j}}{\max \Psi_{i j}} \\
\delta_{i j} & =\frac{\Delta_{i j}}{\max \Delta_{i j}} .
\end{aligned}
$$

With this operation, both $\delta_{i j}$ and $\psi_{i j}$ variables are bounded within the same domain; that is

$$
\begin{gathered}
\psi_{i j} \in[0,1] \\
\delta_{i j} \in[0,1] .
\end{gathered}
$$


The rationale behind this normalization is that the transportation distance and the population within $800 \mathrm{~m}$ ( 0.5 mile) of each side of the railroad along the transportation route are not of comparable magnitude, which would have created an unsteady bias towards the variable with larger compound value-generally speaking transportation distance - during the computation of the overall cost. Normalization of variables avoids this potential anomaly.

The population that fall within $800 \mathrm{~m}$ of each side of the railroad along the transportation path is calculated using ORNL's LandScan ${ }^{\mathrm{TM}}$ capability. The LandScan algorithm, an R\&D 100 Award Winner, uses spatial data and imagery analysis technologies and a multi-variable dasymetric modeling approach (a method for mapping population density) to disaggregate census counts within an administrative boundary. ${ }^{29}$ Figure 43 depicts the mathematical algorithm developed for this purpose to determine the population subject to exposure risk by adding the number of people in cells within an 800-m buffer along either side of the transportation route. The green lines in Fig. 43 represent the 1600-m-long sweep lines perpendicular to the rail track that integrate the population data along the transportation route. The complete algorithm is discussed in Section 2.3.

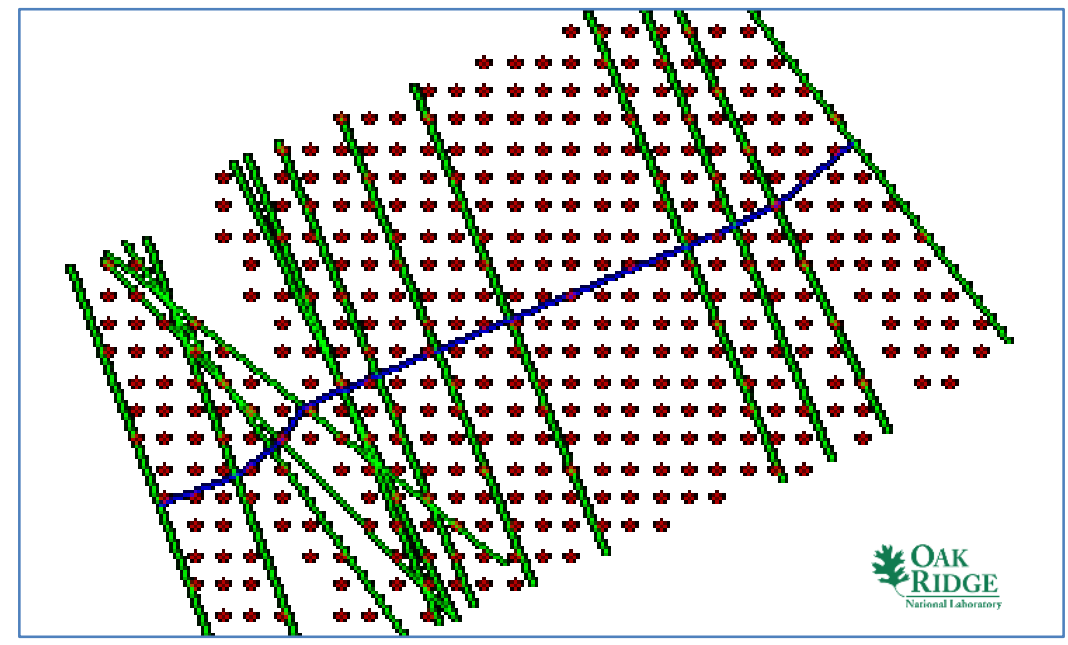

Fig. 43. Calculation of the population that live within $800 \mathrm{~m}$ on each side of the railroad.

Having formulated the cost function in this fashion creates an additional degree of freedom in defining the cost variable used in the optimization calculation; that is, choosing an $\alpha$ value between 0 and 1 , one can easily observe how recommended storage sites, as well as reactors served by these storage facilities, move across available land. The weighting factor is discussed further in Section 5.2.

\subsubsection{Optimization Constraints}

Generically, p-median problems contain three constraints: supply constraint, logic constraint, and location constraint. The supply constraint can be expressed mathematically as below:

$$
\sum_{j \in J} x_{i j} \geq 1, \forall i \in\{1, \ldots, I\},
$$

which states that each reactor site is served by at least one interim storage facility.

\footnotetext{
${ }^{29}$ http://www.ornl.gov/sci/landscan/index.shtml
} 
The logic constraint is expressed mathematically as

$$
x_{i j} \leq y_{j}, \forall i \in\{1, \ldots, I\}, j \in\{1, \ldots, J\},
$$

which states that a reactor site cannot be served by an unopened interim storage facility.

The location constraint is expressed mathematically as:

$$
\sum_{j \in J} y_{j} \leq P,
$$

which states that at least $P$ interim SNF storage facilities are built.

In the p-median formulation, $x_{i j}$ and $y_{j}$ are called binary decision variables; that is, they take values either 0 or 1 , where

$$
x_{i j}= \begin{cases}1, & \text { if reactor site } i \text { is served by candidate storage site } j \\ 0, & \text { otherwise }\end{cases}
$$

and

$$
y_{j}= \begin{cases}1, & \text { if candidate storage site } j \text { is used } \\ 0, & \text { otherwise }\end{cases}
$$

\subsection{WEIGHTING FACTOR}

The weighting factor, $\alpha$, was introduced to support optimization simulations with varying weights for distance and population exposure. When $\alpha=1$, the cost function becomes purely dependent on transportation distance, whereas $\alpha=0$ means the cost function depends purely on integrated population exposure between reactor site $i$ and interim SNF storage site $j$.

The concept of population exposure should be clarified. There are two potential sources of radiological exposures from transporting SNF and high-level waste (HLW): (1) radiation shine - that is, radiation emitted from a transportation package containing SNF or HLW, and (2) potential increases in radiation shine and potential release of radioactive materials from transport packages under accident conditions that are severe enough to compromise fuel element and package integrity. ${ }^{30}$ The radiological risks associated with the transportation of SNF and HLW are well understood.

The first analytical study of the health effects of SNF transportation in the United States was undertaken by the Atomic Energy Commission (AEC) in 1972, which was later known to be as the WASH-1238 study after its report identification number. ${ }^{31}$ This study estimated doses to workers and the general public from nuclear fuel and solid radioactive waste transport both under normal transport conditions and for severe accidents. WASH-1238 study has limited applicability to modern-day SNF transport programs: It examined highway transport of SNF along routes with very different population densities than presentday routes using transportation packages that do meet current regulatory requirements. ${ }^{30}$

\footnotetext{
${ }^{30}$ National Research Council, Nuclear and Radiation Studies Board/Transportation Research Board, Going the Distance: The Safe Transport of Spent Nuclear Fuel and High-Level Waste in the United States, August 2006.

${ }^{31}$ Atomic Energy Commission (AEC), Environmental Survey of Transportation of Radioactive Materials to and from Nuclear Power Plants, WASH-1238, Washington, DC, 1972.
} 
In 1977, the US NRC embarked on a comprehensive analysis of potential risks of incident-free transportation of SNF by various modes, which was released as the Transportation Environmental Impact Statement (EIS). ${ }^{32}$ This EIS provided a more complete analysis of the radiological consequences for land, water, and air transport of radioactive materials than WASH-1238 and has become the baseline analysis for assessing radioactive transportation risks in the United States.

The 1977 transportation EIS characterized environmental impacts in terms of fatalities, expressed as an annual probability of occurrence for two types of transport: (1) incident-free transport, where the main health impact is expected to be cancer fatalities due to exposure of workers and the general public to small doses of radiation from the shipping containers, and (2) accidents that produce either conventional traffic fatalities or, for more severe conditions, latent cancer fatalities resulting from the release of radioactive materials from a damaged transport package. ${ }^{30}$

Collective dose is defined as the sum of all radiation doses received by all members of a population at risk. ${ }^{33,34}$ The use of collective dose for radiation protection purposes assumes the following.

1. There is a direct proportionality between radiation dose and risk over their respective ranges of concern.

2. Risk is independent of dose rate.

3. A radiation dose leads to an identical risk whether it is administered to a single individual or to a population.

The National Council on Radiation Protection and Measurements (NCRP) notes that "[w]hile these assumptions may or may not be valid, they are considered to be conservative and have been generally accepted by the scientific community concerned with radiation protection., ${ }^{, 4}$

Based on NCRP's recommendation on estimating risk to populace, the exposure risk is directly proportional to the number of people who fall within a certain buffer region of the radioactive material being transported. The 800-m buffer on each side of the transported package originates from a conservative estimate of exposure to a single person standing at the buffer boundary based on the maximum measurable dose rate of the dry cask surface.

However, this methodology does not take into account a moving source term. While collective dose is still directly proportional to population density, the exposure risk is also proportional to the transportation distance - that is, the longer the transportation distance, the higher the risk. This is especially the case for probabilistic risk assessments where risk from potential accidents is considered quantitatively.

Furthermore, highway routes for shipment of SNF are dictated by DOT regulations. ${ }^{35}$ The regulations specify that shipments normally must travel by the fastest route using highways designated by the states or the federal government. ${ }^{30}$ While there is not a specific regulation on route selection that addresses SNF shipments by rail, one of the Blue Ribbon Commission (BRC) recommendations states that the fastest route approach also be implemented for rail transportation. ${ }^{3}$

ORNL's implementation for optimization based on minimizing transportation distance is based on this particular BRC recommendation, ${ }^{3}$ which was also included in the recommendations by the National Research Council. ${ }^{30}$

The selection of routes that minimize the number of people along the transportation corridor and the routes that provide the fastest delivery - that is, the shortest path since hazardous material shipment is

\footnotetext{
${ }^{32}$ US Nuclear Regulatory Commission, Final Environmental Statement on the Transportation of Radioactive Material by Air and Other Modes, NUREG-0170, Washington, DC, 1977.

${ }^{33}$ National Council on Radiation Protection and Measurements (NCRP), Ionizing Radiation Exposure of the Population of the United States, NCRP Report 93, Bethesda, MD (1987).

${ }^{34}$ NCRP, Principles and Application of Collective Dose in Radiation Protection, NCRP Report 121, Bethesda, MD (1995).

3549 CFR Part 397.
} 
generally done at a constant speed - is clearly open to scientific debate. Besides, the route selection approaches have political and operational implications. Finding an optimal route is not just a matter of minimizing the financial burden of transporting SNF from an origin to destination.

This is why incorporating the weighting factor $\alpha$ becomes highly valuable: by varying this parameter, it is possible to identify routes that meet certain regulatory, political or operational requirements. The essential step, which remains to be done, is identification of the weighting factor based on more comprehensive risk assessments.

\subsection{COMPUTATIONAL CHALLENGES}

The solution of the optimization problem is not trivial. The very high resolution of the available GIS data sources used for this project offers realistic, high-fidelity simulation capability but, at the same time, creates considerable computational complexity. For instance, the MILP calculation for Scenario 3 resulted in a matrix with 1,608,552 rows and 1,624,064 columns, that is, a matrix with over $2.6 \times 10^{12}$ elements, of which 4,840,960 are nonzero. Any future addition of more optimization factors will increase the complexity of the computational solution. 


\section{COMPUTATIONAL ANALYSES RESULTS}

Optimized $^{7}$ ISFSI placements within a 50-mile radius of a railroad transfer node were made for each of the reactor power plant scenarios. Results were calculated for up to five ISFSI facilities based on transport distance by railroad, risk to the population along the route, and a combination of these factors. The optimization routine was responsive to changes in the number of ISFSI sites and changes in the weighting of the optimization parameters. The three commercial nuclear power scenarios, as described in Section 4, are (1) the status quo scenario with no future commercial nuclear power growth, (2) a scenario with moderate commercial nuclear power growth, and (3) a scenario with aggressive commercial nuclear power growth that includes advanced reactor concepts. All results depict a large dot centered on the resulting railroad node. The associated ISFSI could be on any acceptable land within 50 miles of the node.

The objective in conducting this type of siting evaluation is to demonstrate the capability to perform early site characterization of candidate areas to identify any particular issues for integrated advanced nuclear power plant and consolidated ISFSI siting; it is not intended to be a definitive assessment per se as to the overall suitability of any particular site. Furthermore, this study is not intended to preclude the utilization of volunteer sites. Rather, this study provides a tool to evaluate and rank proposed ISFSI sites against an example ISFSI site optimization plan. In other words, the optimized ISFSI results are intended to provide insight to the consolidated ISFSI storage issue and are not meant to imply an exact consolidated ISFSI siting answer.

A series of computational analyses was performed for each major nuclear power growth scenario varying the key simulation parameters as explained in Section 5.1, that is, number of storage facilities, $p$, and the weighting factor, $\alpha$. The following sections present the results obtained from the different optimization simulations with various parameters. For the base case, the number of storage facilities is varied between 1 and 5, which is intended to demonstrate a number of options. As indicated in Section 6.1, even for the base case scenario, two is the minimum number of interim storage facilities needed such that the federal government can deliver its legal responsibilities within the constraints of the law as currently written. However, it should also be noted that no waste disposal facility is forecast in this report that would ultimately affect the throughput of waste at an interim storage facility and potentially affect the number of consolidated ISFSI sites that may be required.

Varying the number of available consolidated ISFSI sites demonstrates that certain geographic locations are found to be favorable for a multitude of parameter values. This can provide a sense of time sequencing for building up the ISFSI capabilities. It should be noted that ORNL did not perform a time series analysis for this project, primarily because it was not part of the scope, and is complex relative to the analyses that were performed. However, a time series analysis should be considered an essential task to be implemented in the future. A dynamic analysis can shed some light into one of the BRC's key recommendations, which states that the spent fuel storage campaign should give priority to the oldest spent fuel assemblies discharged from operating reactors as well as those stored at certain shutdown reactor sites. This approach has multiple advantages: (1) older fuel assemblies have significantly lower radioactivity, reducing the population exposure risk, and (2) they have lower thermal output, potentially relaxing some of the mechanical design requirements of storage casks.

\subsection{SCENARIO 1: BASE CASE}

As presented in Section 4.1, the base case considered in this work includes SNF stored currently at certain shutdown reactor sites, and SNF to be generated by 2050 by currently operating reactors. This scenario, which this report refers to as the base case, considers that (1) no new reactors are built and (2) none of the operating reactors that have not yet received a license extension get license renewal approvals; that is, 
they retire at the end of their license window. Clearly, the base case establishes the very minimum amount of SNF at 2050. It should also be noted that no waste disposal facility is forecast in this report that would ultimately affect the throughput of waste at an interim storage facility.

Based on these assumptions, the total amount of projected SNF by 2050 was calculated to be 123,720 MTHM. 10 CFR Part 72.96 , "Siting Limitations," prohibits the storage of a quantity of SNF containing in excess of 70,000 metric tons of heavy metal. This limit requires that a minimum of two SNF storage facilities be built by 2050 to meet the baseline storage requirements provided no disposal capability has been invoked. The combined capacity of two storage facilities would be $88 \%$ utilized in 2050 .

\subsubsection{Five Interim Storage Facilities}

Based on engineering judgment, ORNL selected five interim storage facilities as the upper limit for consideration of the number of ISFSI sites, even though two is the minimum number of facilities necessary to meet the baseline SNF storage requirements in the year 2050. This number was arbitrarily selected and is not based on detailed technical insight. However, it was felt that this was a reasonable bounding solution for other scenarios where more SNF is generated by 2050 . Thus, five consolidated ISFSIs serves as a reasonable comparison between scenarios. A solution with five storage facilities also forces the most diverse location solution for consideration.

Optimization simulations were executed with five ISFSI facilities varying the weighting factor, $\alpha$, between 0 and 1: $\alpha=1.0$ corresponds to optimization based on pure transportation distance, and $\alpha=0.0$ corresponds to optimization based on the number of populace along the rail route within a 1.6-km corridor. The weight factor $\alpha=0.5$ was selected as the value that combines both cost variables with approximately equal weight. It should be noted that mathematically, $\alpha=0.5$ does not essentially put equal emphasis on the cost variables transportation distance and population along the transportation corridor.

Graphical results are presented only for weight factors $\alpha=0.0, \alpha=0.5$, and $\alpha=1.0$ to avoid populating the report with too many maps. Variation of the cost, in units of transportation distance times the amount of SNF transported as a function of the weighting factor, $\alpha$, is also plotted for the simulation.

\section{Optimization by Transportation Distance}

The results of the calculations for Scenario 1 based on optimization for transportation distance only are shown in Fig. 44. As indicated earlier, this optimization calculation generates the rail routes that are the most direct, and consequently the fastest routes (if constant speed of transportation is to be assumed).

The results clearly reflect the high nuclear generating capacity in the eastern United States, particularly the southeastern and northeastern United States, where four out of the five ISFSI facilities are sited. The ISFSI site in California only serves the reactors in California and a handful of neighboring states.

The amount of SNF stored at each ISFSI site and the corresponding utilization factors based on simulation results is listed in Table 7. Only two of the five ISFSI sites show utilization over 50\%. ISFSI Site \#3 in California generally gets a low utilization in all the base case simulations with various weighting factor values, typically below $20 \%$. If this site is to be selected with the potential customers as indicated by the simulation, it can be easily suggested that this site can be built with a much lower capacity instead of the full capacity allowed by law.

The ISFSI site numbers listed in Table 7 correspond to the site numbers shown in Fig. 44. For the base case scenario, five interim storage facilities seem to be too many considering the capacity utilization of the facilities. Clearly, this is not a technical evaluation but merely an observation based on the results. A decision on the number of facilities should be based on a coordinated effort that takes into account 
multitude of dimensions of the problem, as briefly presented in previous sections, from transportation safety, package security, population exposure risk, to estimated financial burden of the campaign.

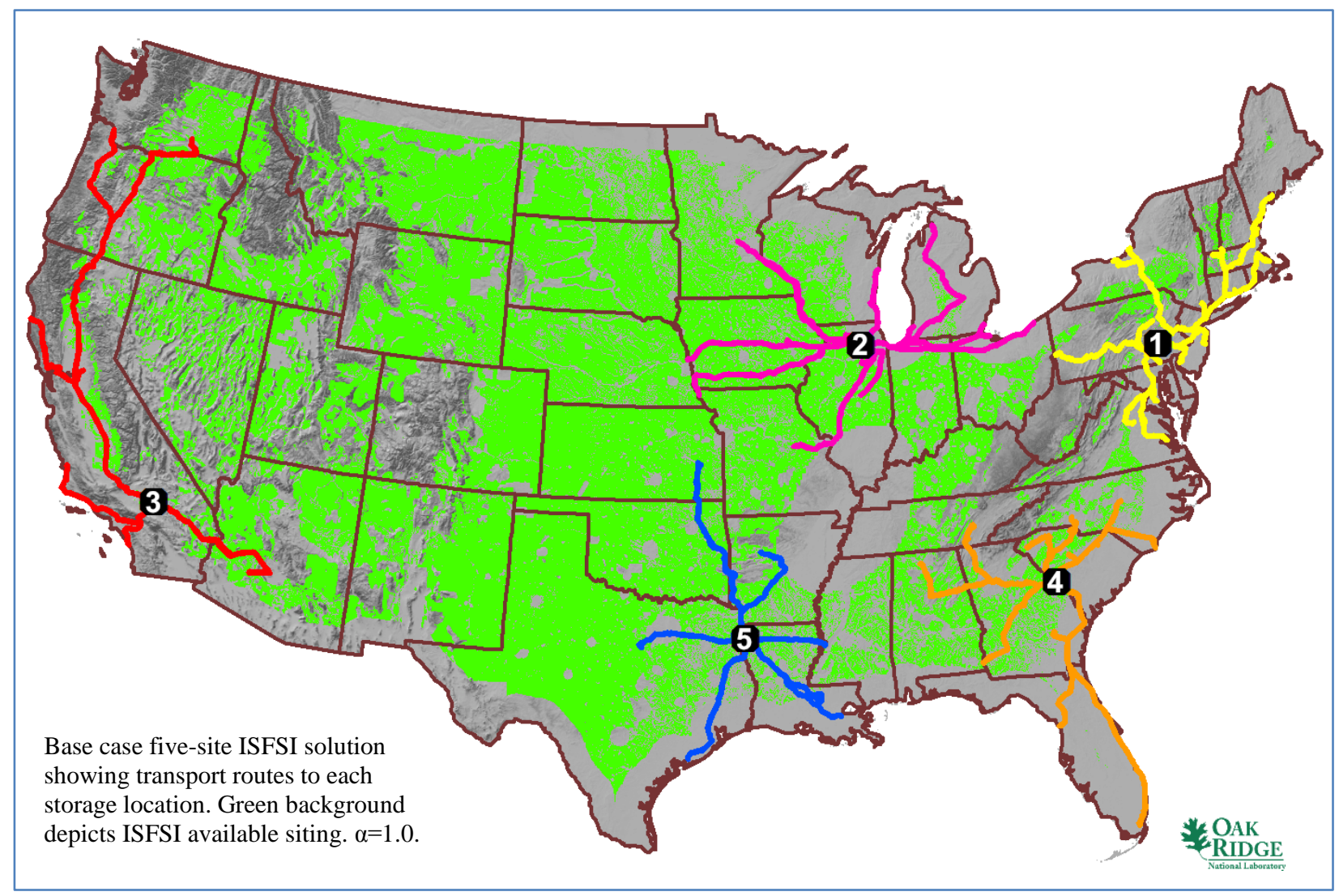

Fig. 44. Base case five-site ISFSI solution based on transportation distance $(\alpha=1.0)$.

Table 7. Base case SNF inventory and capacity factors for each storage site with five ISFSIs $(\alpha=1.0)$

\begin{tabular}{ccc}
\hline ISFSI site & $\begin{array}{c}\text { Stored SNF inventory } \\
\text { (MTHM) }\end{array}$ & $\begin{array}{c}\text { Used capacity } \\
(\mathbf{\%})\end{array}$ \\
\hline 1 & $36,446.18$ & 52.07 \\
\hline 2 & $27,870.22$ & 39.81 \\
\hline 3 & $11,193.11$ & 15.99 \\
\hline 4 & $35,933.46$ & 51.33 \\
\hline 5 & $12,277.01$ & 17.54 \\
\hline
\end{tabular}

Optimization by Population Radiation Exposure Risk

This optimization scheme aims to minimize the number of populace within the transportation corridor in finding the location of the storage facilities as well as the reactors that will be served by each facility. The 
map that shows the results of this optimization simulation is shown in Fig. 45. Note that while the ISFSI sites remain roughly in the same geographic areas, the affiliated reactor sites shift alignment.

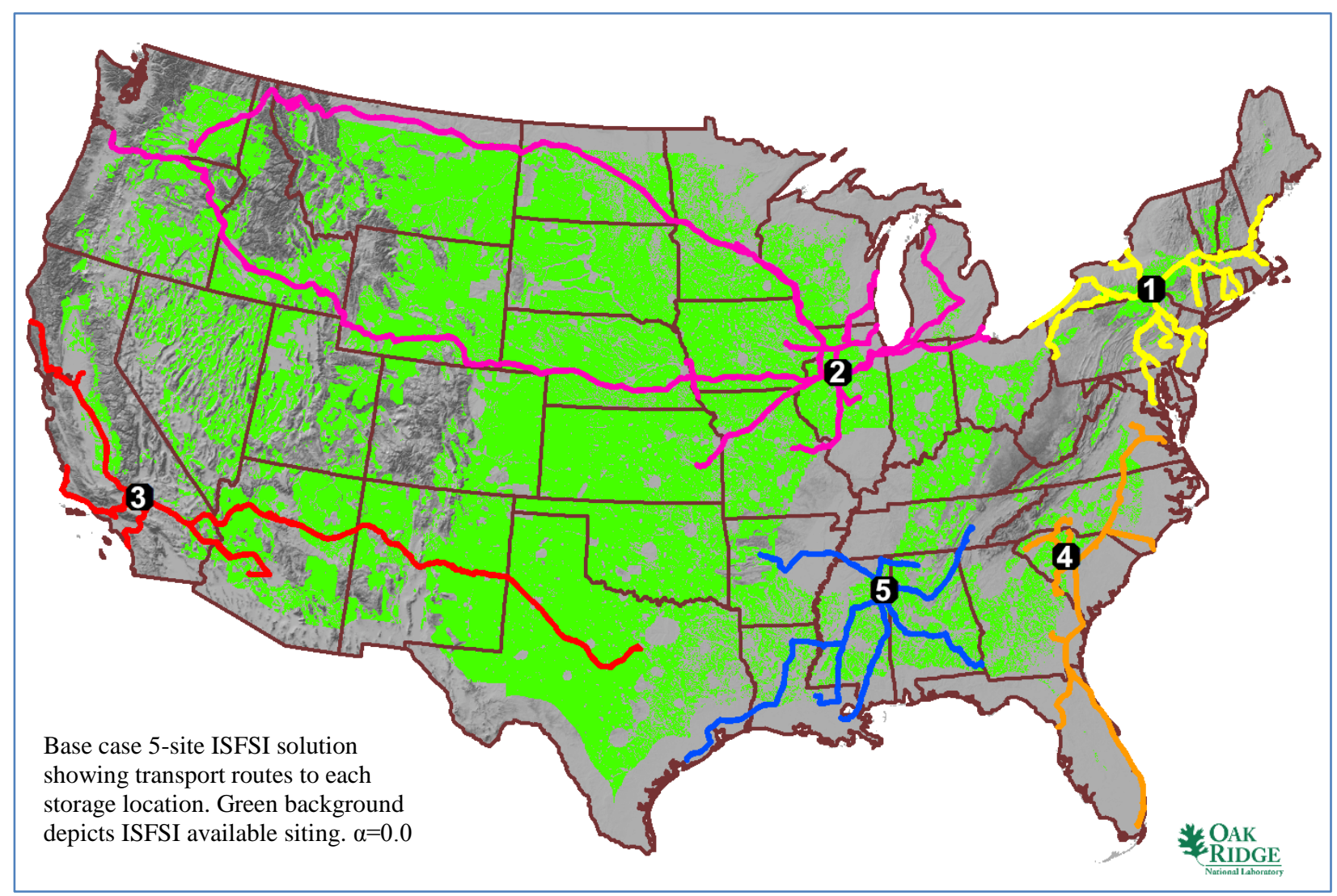

Fig. 45. Base case five-site ISFSI solution based on population along the transportation corridor $(\alpha=0.0)$.

As the optimization scheme is moved from minimizing the distance towards minimizing the number of people along the transportation corridor, the ISFSI sites and the reactors served by these sites shift considerably, which is an indication of the model's responsiveness to model parameters. The amount of SNF stored at each ISFSI site and the corresponding utilization factors are shown in Table 8.

Table 8. Base case SNF inventory and capacity factors for each storage site with five ISFSIs $(\alpha=0.0)$

\begin{tabular}{ccc}
\hline ISFSI site & $\begin{array}{c}\text { Stored SNF inventory } \\
\text { (MTHM) }\end{array}$ & $\begin{array}{c}\text { Used capacity } \\
(\boldsymbol{\%})\end{array}$ \\
\hline 1 & $32,875.13$ & 46.96 \\
\hline 2 & $29,774.80$ & 42.54 \\
\hline 3 & $12,147.27$ & 17.35 \\
\hline 4 & $30,952.30$ & 44.22 \\
\hline 5 & $17,970.49$ & 25.67 \\
\hline
\end{tabular}

The results as shown in Fig. 45 indicate clear contrast with the results from the optimization based purely on transportation distance, that is, shortest path or fastest route. As the emphasis moves towards 
minimizing the population exposure risk, that is, the population along the transportation corridor, ISFSI Site \#3 loses its customers from the northwestern United States because of higher population density along the rail route to California while the ISFSI Site \#3 location remains almost the same. Other ISFSI sites, on the other hand, shift geographic locations. The geographic shift is particularly apparent in ISFSI Sites \#5 and \#1 where the facility location changes to another state. ISFSI sites \#2 and \#4 move but still remain within the same states as the locations from simulation based on transportation distance.

\section{Optimization by Mixed Transportation Distance/Population Exposure Risk of Equal Weight}

This optimization scheme puts approximately equal emphasis on objectives for minimizing the transportation distance and the number of populace along the transportation corridor between a particular reactor site and the ISFSI site, which accepts the SNF from that site. The map for the simulation results is shown in Fig. 46. Again, while the ISFSI sites remain roughly in the same geographic areas, the affiliated reactor sites shift alignment. The amount of SNF stored at each ISFSI site and corresponding utilization factors are listed in Table 9.

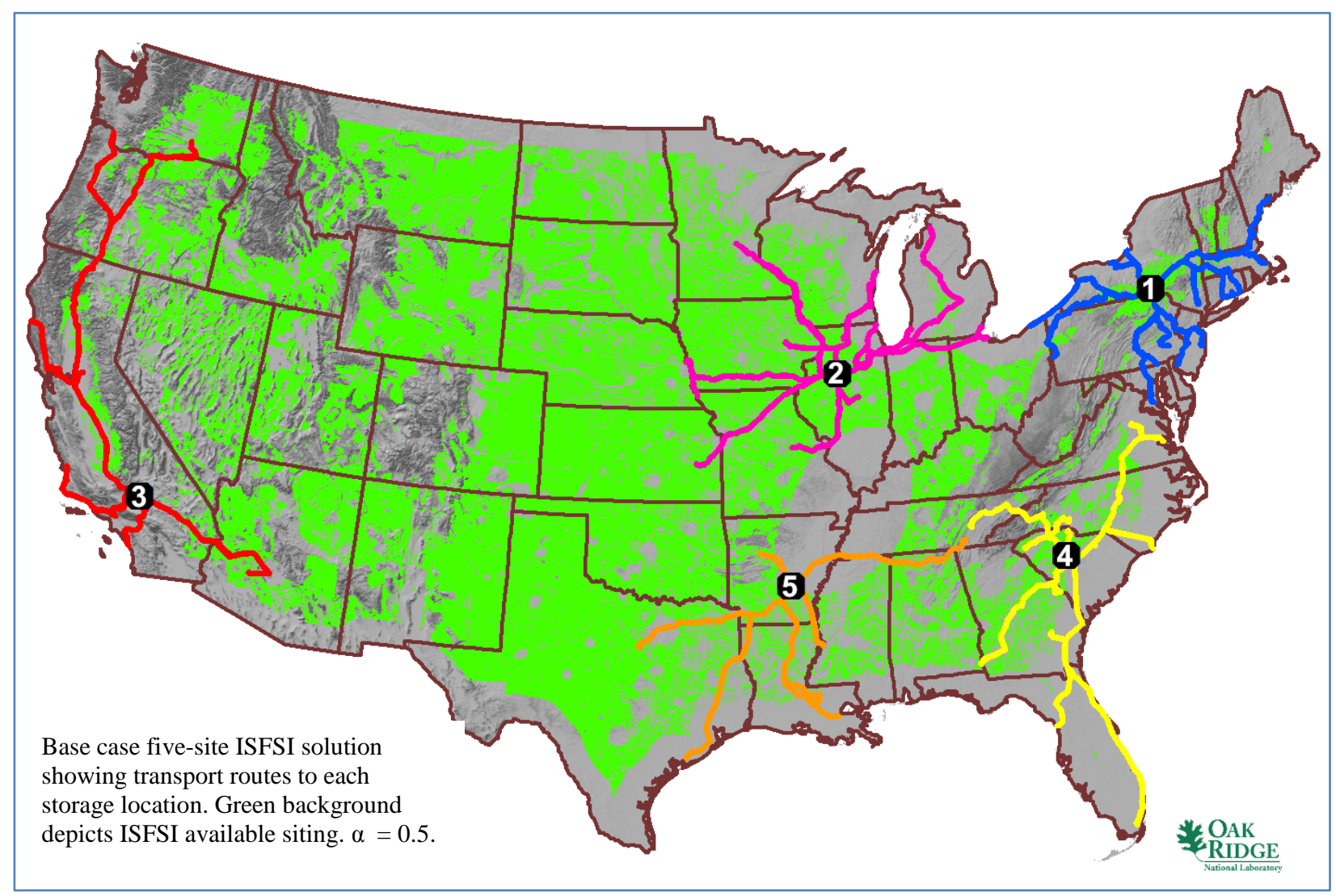

Fig. 46. Base case five-site ISFSI solution based on mixed factors with equal weights $(\alpha=0.5)$. 
Table 9. Base case SNF inventory and capacity factors for each storage site with five ISFSIs $(\alpha=0.5)$

\begin{tabular}{ccc}
\hline ISFSI site & $\begin{array}{c}\text { Stored SNF inventory } \\
(\mathbf{M T H M})\end{array}$ & $\begin{array}{c}\text { Used capacity } \\
(\boldsymbol{\%})\end{array}$ \\
\hline 1 & $32,875.13$ & 46.96 \\
\hline 2 & $28,409.43$ & 40.58 \\
\hline 3 & $11,193.11$ & 15.99 \\
\hline 4 & $34,396.82$ & 49.14 \\
\hline 5 & $16,845.50$ & 24.07 \\
\hline
\end{tabular}

This particular selection of the weighting factor $\alpha$ generates a compromise result where the shift of ISFSI sites is less obvious: Only ISFSI Site \#5 crosses into another state, while Site \#1 moves to a state boundary. As listed in Table 7 and Table 9, ISFSI Site \#3 has the same customers and hence gets the exact same utilization as in the case with $\alpha=1.0$. The most obvious exchange is between the northeastern and the southeastern facilities, where in this case the southeastern facility picks up customers from the northeastern facility.

\subsubsection{Four Interim Storage Facilities}

As presented in the previous section, the selection of five ISFSI sites resulted in significant underutilization of the capacity of each ISFSI. While one viable option is to build interim storage facilities with reduced capacity, the more cost-effective viable option would be to build fewer facilities. This subsection and the subsequent subsections evaluate these options. As discussed in Section 7.2.6, Future Work, the rational approach would be to introduce realistic cost figures, in terms of financial cost, of different cost variables used in the optimization, which would open up the possibility of making a more logical evaluation of various options. For instance, having a financial figure for the cost of transporting a given amount of radioactive package for a calculated distance from a reactor site to an interim storage facility would allow evaluating options for identifying the required number of facilities as well as the storage capacity of each facility. Without at least rudimentary cost figures, these evaluations are merely parametric search studies that do not lend themselves to comparison outside their bounds, for example, comparison between the number of facilities and the integrated quantity of radioactive material times the transported distance. Such cost figures are available and should be factored into a future study.

The national map in Fig. 47 shows four ISFSI sites and preferred rail routes connecting each reactor site to its associated interim storage facility for optimization simulation based on transportation distance; that is, the weighting factor $\alpha=1.0$. The SNF inventory stored at each ISFSI site and the site's anticipated utilization factor is listed in Table 10. Also listed in Table 10 are the estimated inventory and utilization factors for the weighting factor values of 0.0 (minimizing population dose only) and 0.5 (approximately equal weight between minimizing population dose and minimizing transportation distance) which are not shown graphically. The ISFSI locations vary under the different weighting factors, but remain in the same geographic areas.

When the emphasis is only on minimizing transportation distance, $\alpha=1.0$, imposing 4 interim storage facilities in the optimization algorithm largely results in the combination of two sites in the southern United States; ISFSI Sites \#4 and \#5 from Fig. 44 are combined into a more geographically compromised single facility at the new ISFSI Site \#4. ISFSI Sites \#1 and \#3 retain their customer base and the preferred routes. There is a slight exchange of customers between ISFSI Sites \#2 and \#4. Note that ISFSI site \#4 in the southern United States is the most utilized facility when the emphasis is only on minimizing transportation distance, $\alpha=1.0$. However, as the weighting factor is shifted toward minimizing population exposure, $\alpha<1.0$, ISFSI site \#2 near the Great Lakes becomes the most utilized facility. 


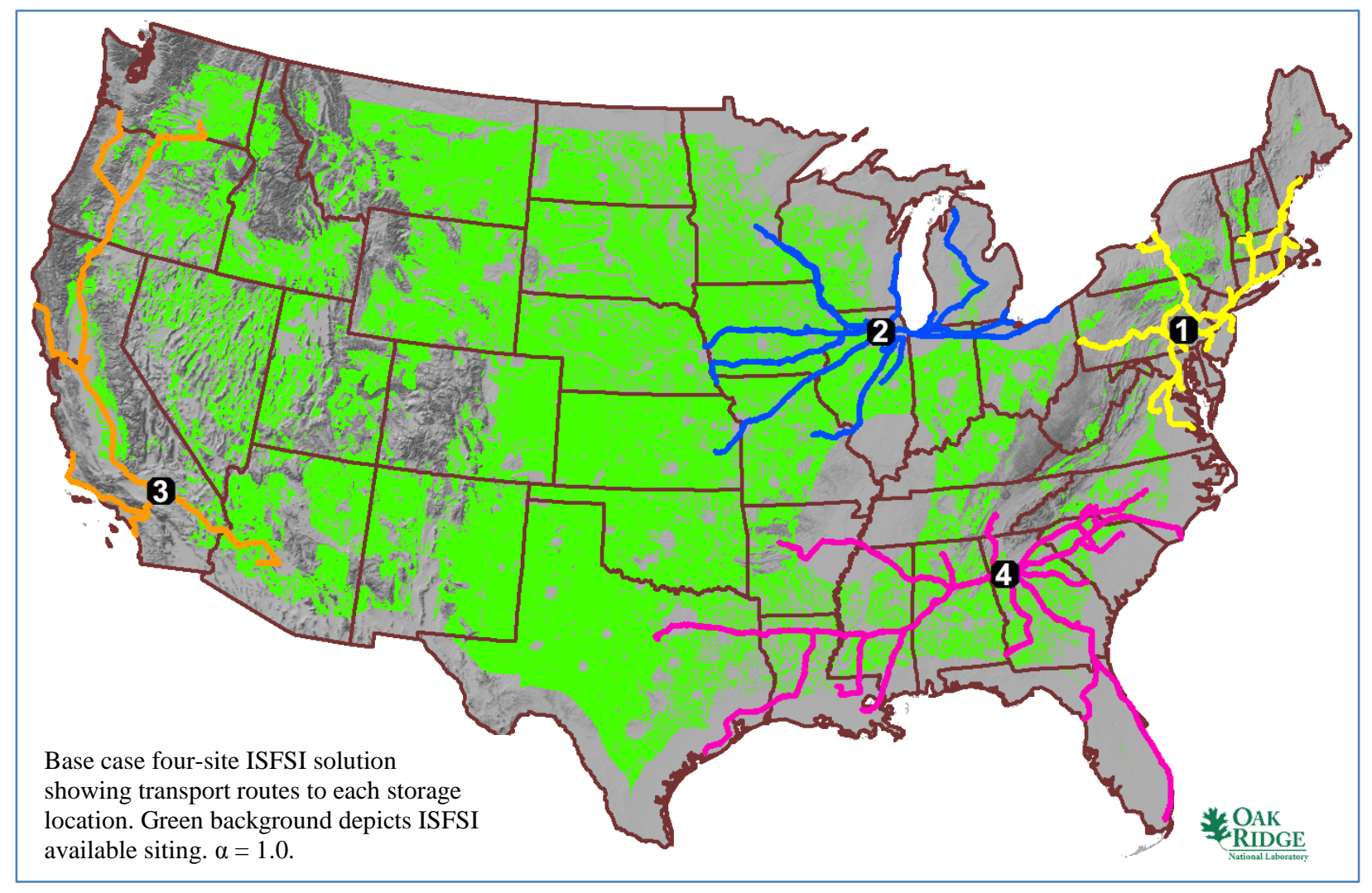

Fig. 47. Base case four-site ISFSI solution based on transportation distance $(\alpha=1.0)$.

Table 10. Base case SNF inventory and capacity factors for each storage site with four ISFSIs

\begin{tabular}{|c|c|c|c|}
\hline & ISFSI site & $\begin{array}{c}\text { Stored SNF inventory } \\
\text { (MTHM) }\end{array}$ & $\begin{array}{c}\text { Used capacity } \\
(\%)\end{array}$ \\
\hline \multirow{4}{*}{ 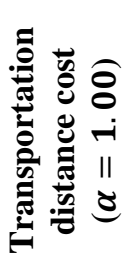 } & 1 & $36,446.18$ & 52.07 \\
\hline & 2 & $29,389.14$ & 41.98 \\
\hline & 3 & $11,193.11$ & 15.99 \\
\hline & 4 & $46,691.55$ & 66.70 \\
\hline \multirow{4}{*}{ 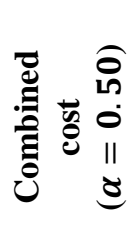 } & 1 & $32,875.13$ & 46.96 \\
\hline & 2 & $43,501.33$ & 62.14 \\
\hline & 3 & $11,193.11$ & 15.99 \\
\hline & 4 & $36,150.42$ & 51.64 \\
\hline \multirow{4}{*}{ 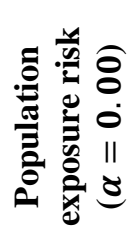 } & 1 & $32,875.13$ & 46.96 \\
\hline & 2 & $44,300.77$ & 63.29 \\
\hline & 3 & $12,147.27$ & 17.35 \\
\hline & 4 & $34,396.82$ & 49.14 \\
\hline
\end{tabular}




\subsubsection{Three Interim Storage Facilities}

The simulation results obtained for three consolidated ISFSI sites are shown in Fig. 48 for the optimization calculation based on transportation distance. Also shown in Fig. 48 are the preferred rail routes connecting the reactor sites and the consolidated ISFSI sites. The SNF inventory stored at each ISFSI site and the site's anticipated utilization factor is listed Table 11. This solution divides the country into three distinct sections. The combined capacity of three storage facilities would be $59 \%$ utilized in 2050 , providing tremendous flexibility for future reactor plant expansion or operation past 2050. Given that the two-site ISFSI solution is the minimum acceptable solution, this result may provide the most flexibility at the least cost based on the simplified optimization parameters. Also listed in Table 11 is the estimated inventory and utilization factor for the weighting factor values of 0.5 and 0.0 . Table 11 shows that none of the depicted results under varying values of alpha exceeds the nominal capacity of the ISFSI.

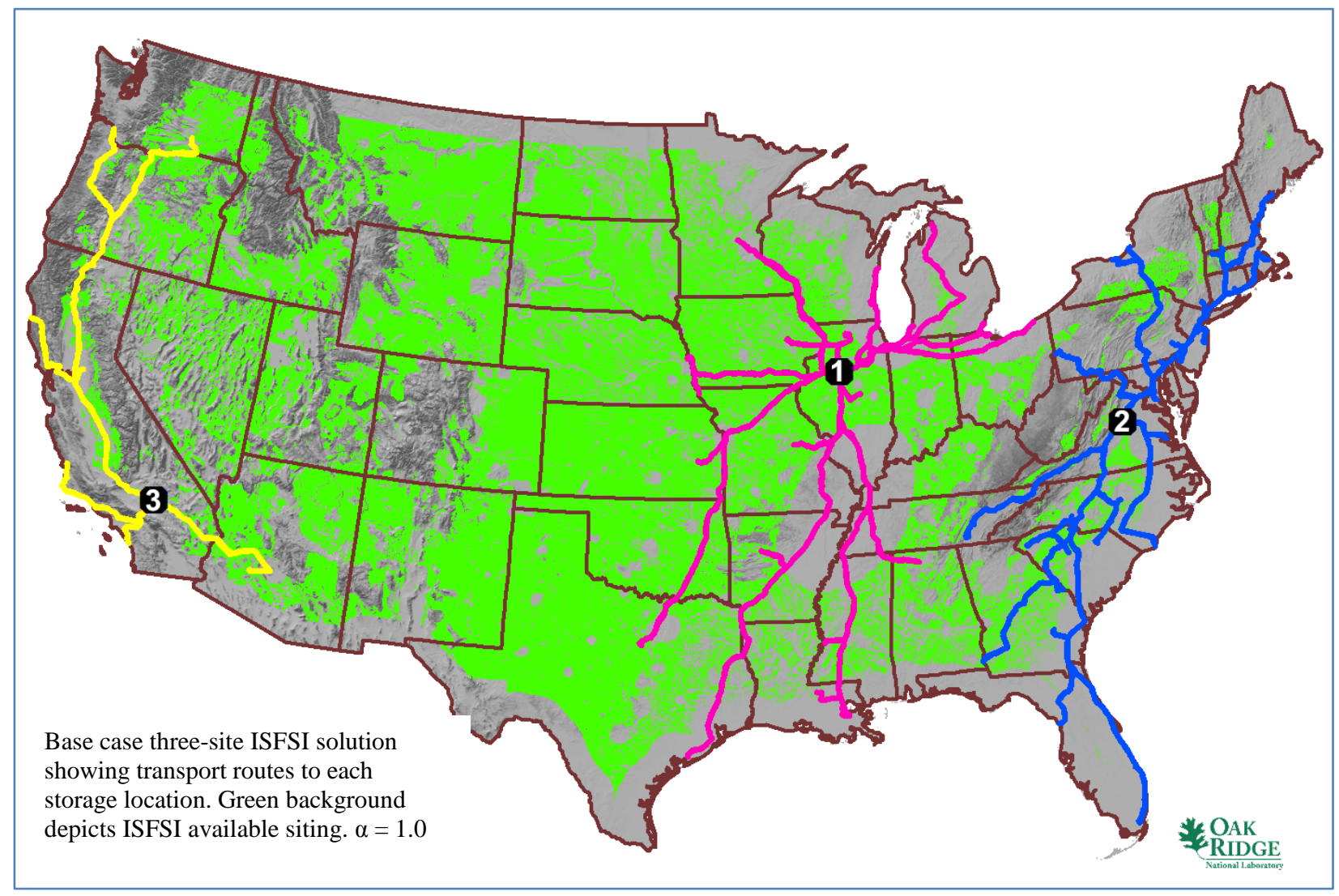

Fig. 48. Base case three-site ISFSI solution based on transportation distance $(\alpha=1.0)$.

This simulation confirms the dominance of the SNF inventory in the eastern United States. The results with three storage facilities preserve the ISFSI site in California, ISFSI Site \#3. It can be seen in Table 11 that the facility utilization increases drastically, with the exception of ISFSI Site \#3, which is highly underutilized. Note that ISFSI site \#2 in the eastern United States is almost at capacity in 2050 when the emphasis is only on minimizing transportation distance, $\alpha=1.0$. However, as the weighting factor is shifted toward minimizing population exposure, $\alpha<1.0$, the distribution is more evenly spread. ISFSI site \#3 actually picks up customers from the Midwest in this latter case. 
Table 11. Base case SNF inventory and capacity factors for each storage site with three ISFSIs

\begin{tabular}{|c|c|c|c|}
\hline & ISFSI site & $\begin{array}{c}\text { Stored SNF inventory } \\
\text { (MTHM) }\end{array}$ & $\begin{array}{c}\text { Used capacity } \\
(\%)\end{array}$ \\
\hline \multirow{3}{*}{ 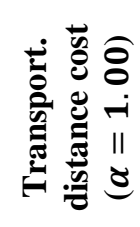 } & 1 & $44,481.05$ & 63.54 \\
\hline & 2 & $68,045.83$ & 97.21 \\
\hline & 3 & $11,193.11$ & 15.99 \\
\hline \multirow{3}{*}{ 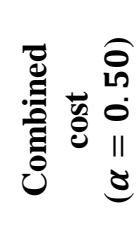 } & 1 & $32,875.13$ & 46.96 \\
\hline & 2 & $46,790.96$ & 66.84 \\
\hline & 3 & $44,053.91$ & 62.93 \\
\hline \multirow{3}{*}{ 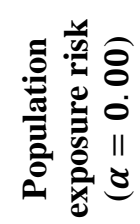 } & 1 & $30,875.63$ & 44.11 \\
\hline & 2 & $58,447.55$ & 83.50 \\
\hline & 3 & $34,396.82$ & 49.14 \\
\hline
\end{tabular}

\subsubsection{Two Interim Storage Facilities}

The simulation results obtained for two consolidated ISFSI sites are shown in Fig. 49 for the optimization calculation based on transportation distance. Also shown in Fig. 49 are the preferred rail routes connecting the reactor sites and the consolidated ISFSIs. The SNF inventory stored at each ISFSI site and the site's anticipated utilization factor are listed in Table 12. Also listed in Table 12 is the estimated inventory and utilization factor for the weighting factor values of 0.5 and 0.0 .

With two storage facilities, ISFSI Sites \#1 and \#3 in Fig. 48 are combined into a single site, ISFSI Site \#1. The customer base remains largely unchanged for ISFSI Site \#2, as listed in Table 12.

The optimization based only on minimizing transportation distance yields a more balanced distribution of SNF inventory, whereas the other optimization schemes with other weighting factors are skewed toward the eastern facility, ISFSI Site \#2. Clearly, two interim storage facilities is the bare minimum to meet the 70,000 MTHM SNF storage requirements with no new nuclear capacity installation or disposal pathway. This provides little flexibility for any growth. Table 12 shows that there are some values of the weighting factor (alpha) that allow a consolidated ISFSI site to exceed the allowed capacity, though this is not the case where minimizing distance only is considered. 


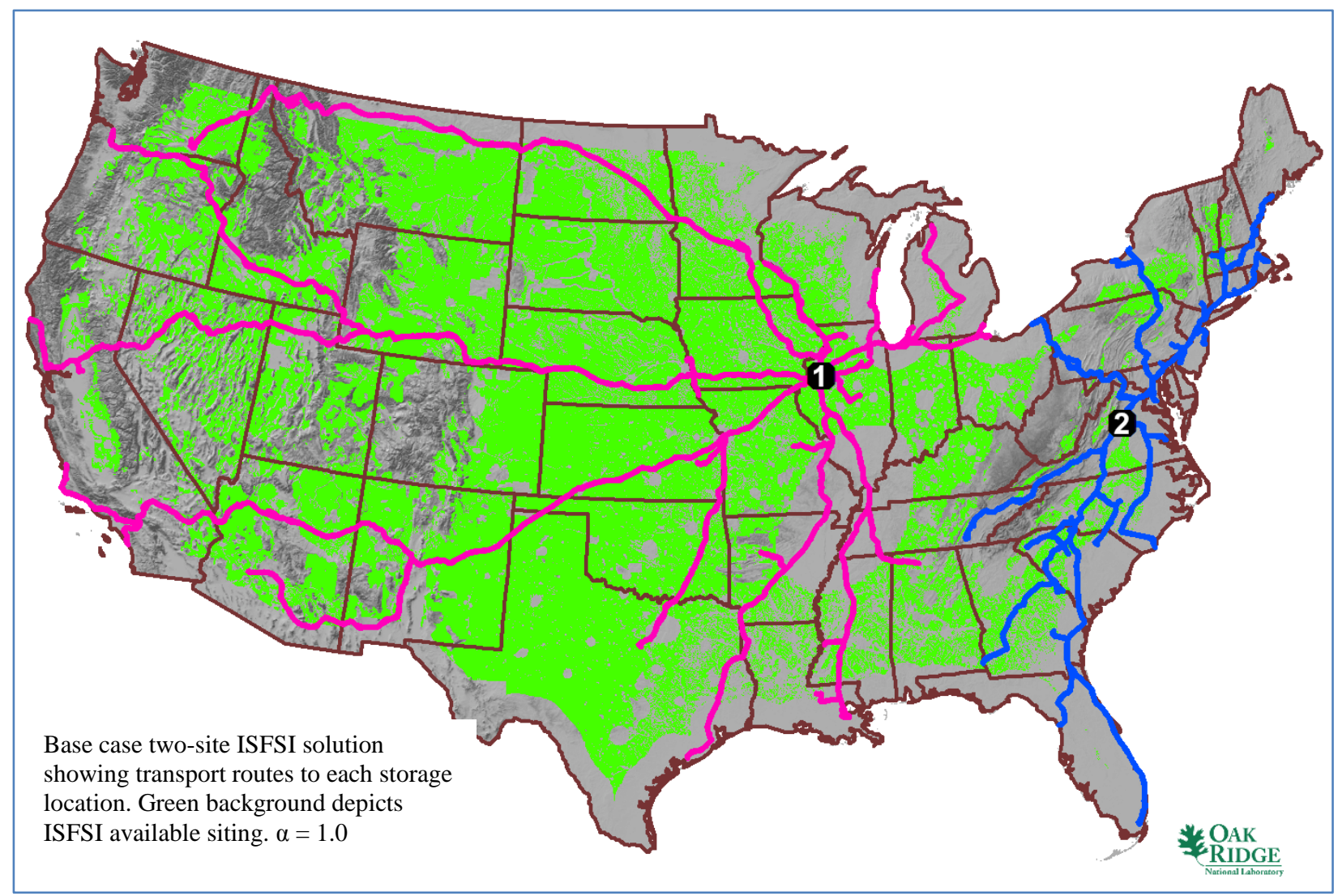

Fig. 49. Base case two-site ISFSI solution based on transportation distance $(\alpha=1.0)$.

Table 12. Base case SNF inventory and capacity factors for each storage site with two ISFSIs

\begin{tabular}{|c|c|c|c|}
\hline & ISFSI site & $\begin{array}{c}\text { Stored SNF inventory } \\
\text { (MTHM) }\end{array}$ & $\begin{array}{c}\text { Used capacity } \\
(\%)\end{array}$ \\
\hline \multirow{2}{*}{$\begin{array}{l}0 \\
\text { - } \\
\text { II } \\
\text { o }\end{array}$} & 1 & $54,694.45$ & 78.13 \\
\hline & 2 & $69,025.55$ & 98.61 \\
\hline \multirow{2}{*}{$\begin{array}{l}\text { n } \\
0 \\
11 \\
\text { d }\end{array}$} & 1 & $39,159.25$ & 55.94 \\
\hline & 2 & $84,560.75$ & 120.80 \\
\hline \multirow{2}{*}{$\begin{array}{l}0 \\
0 \\
\ddot{0} \\
\ddot{\sigma}\end{array}$} & 1 & $35,426.40$ & 50.61 \\
\hline & 2 & $88,293.60$ & 126.13 \\
\hline
\end{tabular}




\subsubsection{One Interim Storage Facility}

This particular simulation was intended to illustrate the center of gravity of the nation's SNF inventory in year 2050 with the current nuclear fleet. The state of Tennessee, as shown Fig. 50, appears to offer the most favorable location that minimizes the transportation burden and provides the shortest routes between the ISFSI site and the customers. This calculation is out of bounds with regard to the maximum storage capacity of 70,000 MTHM. However, this is a useful result showing the single central ISFSI location with regard to minimizing transportation distance for the entire United States. This may provide some insight to the initial consolidated ISFSI location in a time sequence analysis.

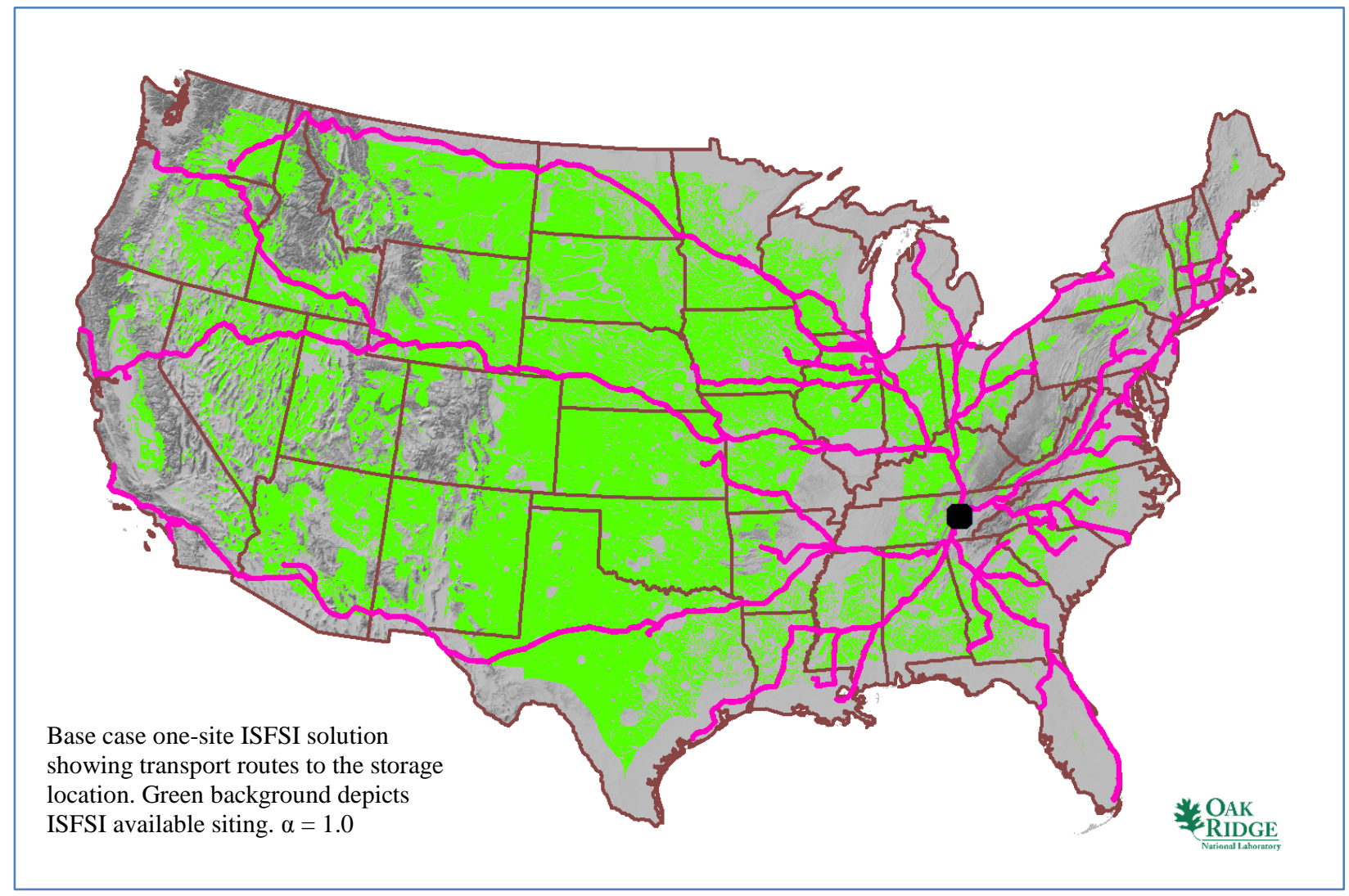

Fig. 50. Base one-site ISFSI solution based on transportation distance $(\alpha=1.0)$.

\subsubsection{Sensitivity Study with a Forced ISFSI Siting at Skull Valley, Utah}

An important strength of ORNL's methodology developed for this project is the "biased solution." This approach forces the optimization algorithm to place storage facilities at arbitrarily selected geographical locations, which is quite a powerful capability to perform various sensitivity analyses to study the effectiveness of a particular location. At the end of the optimization simulation, the algorithm guarantees that the "forced" locations are included in the final solution set. This type of solution could incorporate volunteer ISFSI sites.

Since development of this capability was not within the scope of this project, the emphasis was only given to demonstrate its utility for potential further analyses. For this reason, coordinates of the Skull Valley ISFSI, which is owned by Private Fuel Storage, LLC and located in the Skull Valley Goshute Reservation in Tooele County, Utah, was input as the "forced" solution. 
A five-site consolidated ISFSI solution based on minimizing the distance travelled is depicted in Fig. 51. Without input from the northwestern reactors, the California ISFSI site is shifted toward the three Palo Verde reactors in Arizona but with minimal input, as listed in Table 13. Likewise the Skull Valley site has minimal input. The consolidated ISFSI site on the Texas-Louisiana border is removed, and the remaining three consolidated ISFSI sites adjust to cover the remaining reactors.

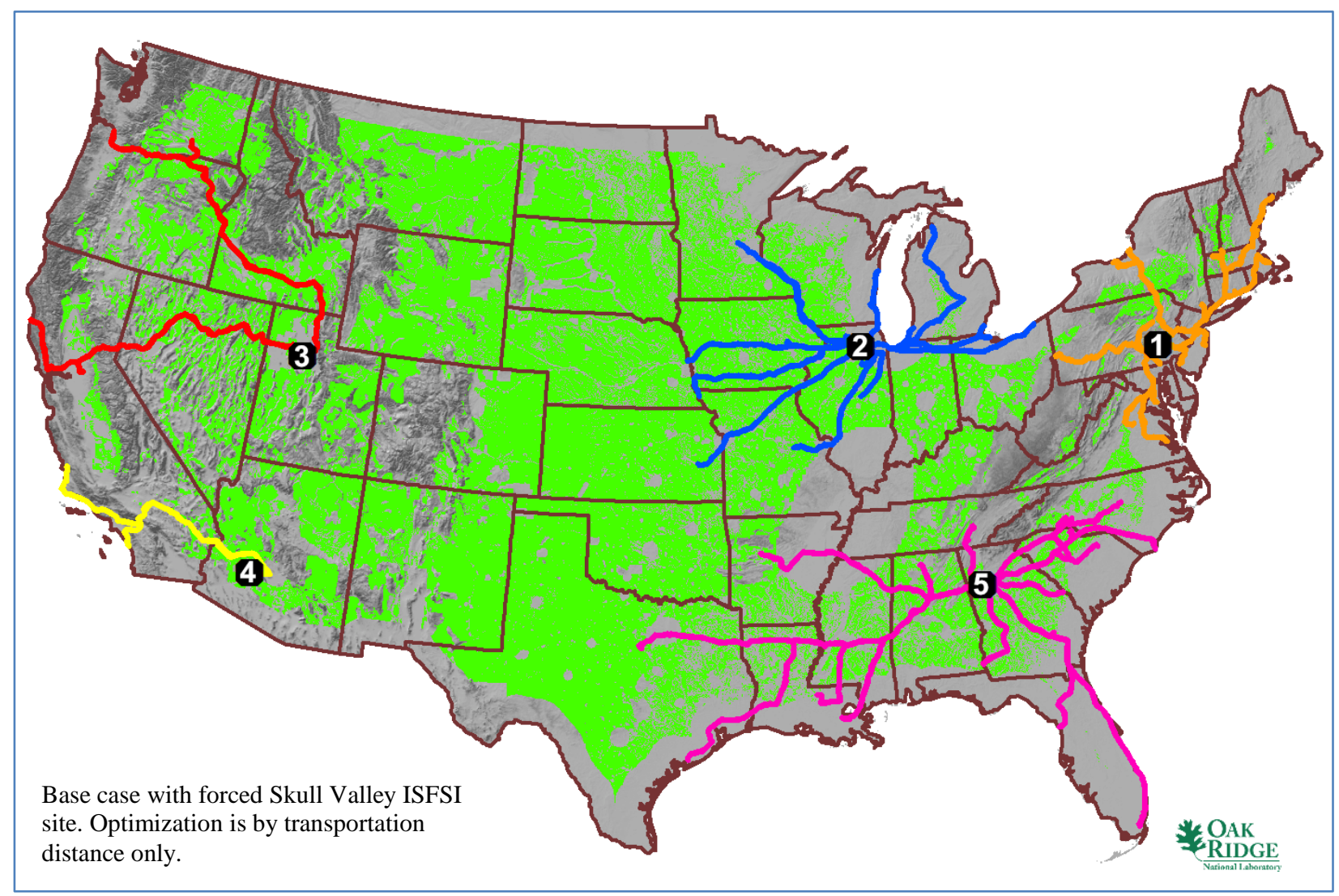

Fig. 51. Base case storage sites with the Skull Valley facility and four additional facilities.

Table 13. SNF inventory and the capacity factors for each storage facility with five ISFSI sites

\begin{tabular}{ccc}
\hline ISFSI site & $\begin{array}{c}\text { Stored SNF inventory } \\
\text { (MTHM) }\end{array}$ & $\begin{array}{c}\text { Used capacity } \\
(\boldsymbol{\%})\end{array}$ \\
\hline 1 & $36,446.18$ & 52.07 \\
\hline 2 & $29,389.14$ & 41.98 \\
\hline $3^{a}$ & $1,889.04$ & 2.70 \\
\hline 4 & $9,304.07$ & 13.29 \\
\hline 5 & $46,691.55$ & 66.70 \\
\hline
\end{tabular}

${ }^{a}$ Skull Valley site

Based on this study, the four-site consolidated ISFSI solution shown in Fig. 52 is more practical than the five-site consolidated ISFSI solution shown in Fig. 51. The amount of SNF to be stored at each site is 
shown in Table 14. In this case, the forced site at Skull Valley receives the waste from all the western reactor sites. The three consolidated ISFSI locations to the east split the remaining reactor sites.

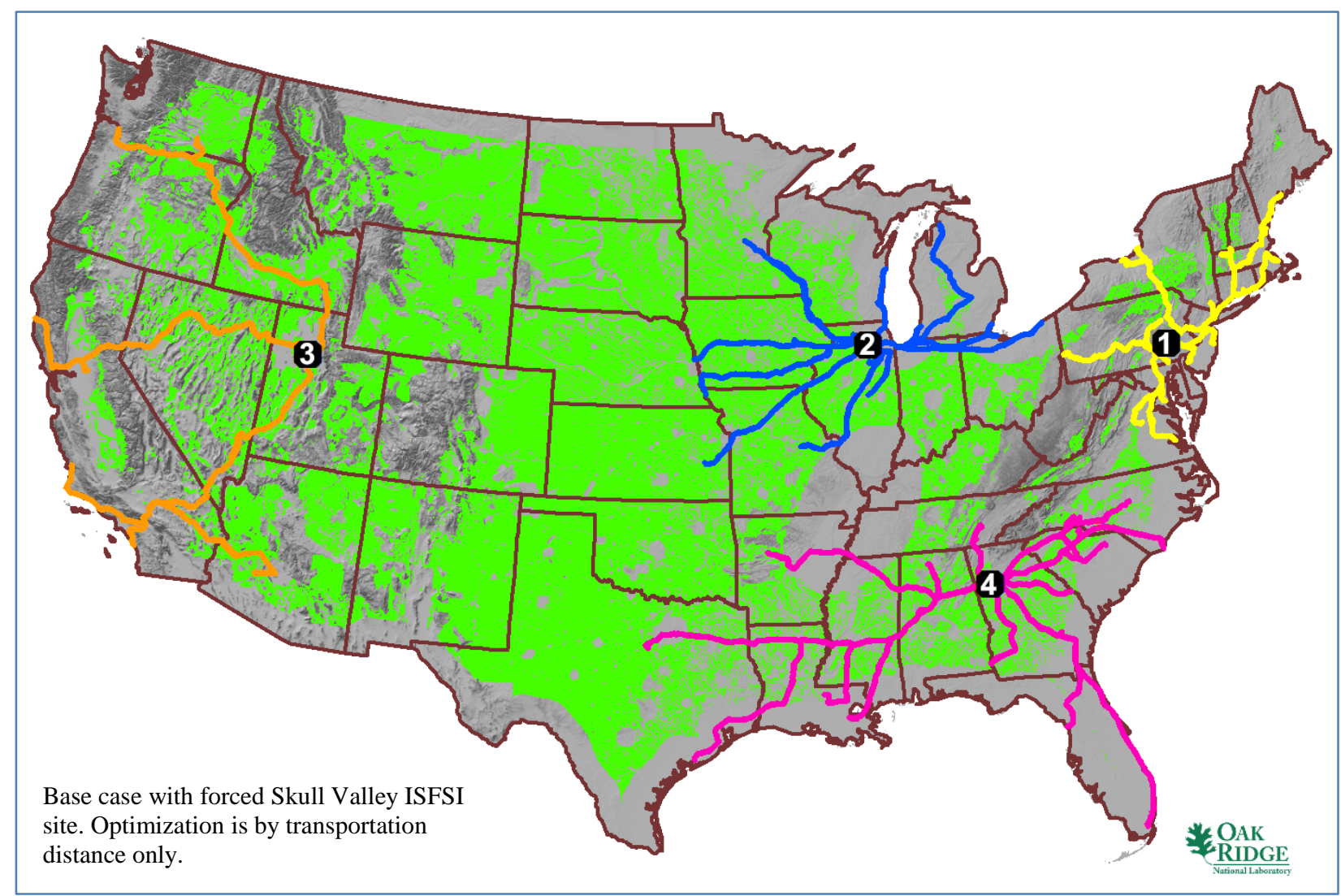

Fig. 52. Base case storage sites with the Skull Valley facility and three additional facilities.

Table 14. SNF inventory and the capacity factors for each storage facility with four ISFSI sites

\begin{tabular}{ccc}
\hline ISFSI site & $\begin{array}{c}\text { Stored SNF inventory } \\
\text { (MTHM) }\end{array}$ & $\begin{array}{c}\text { Used capacity } \\
(\mathbf{\%})\end{array}$ \\
\hline 1 & $36,446.18$ & 52.07 \\
\hline 2 & $29,389.14$ & 41.98 \\
\hline $3^{a}$ & $11,193.11$ & 15.99 \\
\hline 4 & $46,691.55$ & 66.70 \\
\hline
\end{tabular}

${ }^{a}$ Skull Valley Site

\subsubsection{Sensitivity Study for Optimized ISFSI Location for Orphaned Nuclear Plants}

One of Blue Ribbon Commission's key recommendations regards the SNF, also called stranded fuel, stored at orphaned reactor sites (p. vi): ${ }^{.6}$

\footnotetext{
${ }^{36}$ Blue Ribbon Commission on America's Nuclear Future, Transportation and Storage Subcommittee Report to the Full Commission-Updated Report, Washington, DC, January 2012.
} 


\section{Recommendation \#3: Spent fuel currently being stored at decommissioned reactor sites should be "first in line" for transfer to a consolidated storage facility as soon as such a facility is available.}

... [w] believe spent fuel at shutdown reactor sites should be moved to consolidated storage when such capacity is available and when the necessary transportation preparations have been made. ... [T] he rationale for giving priority to decommissioned reactor sites is straightforward: the benefits of removing spent fuel from these sites-in terms of reduced costs, management burdens, and security issues - are simply much larger than at still-operating reactors where an active on-site presence and various security measures must be maintained in any case....

Orphaned nuclear plant sites, such as the Trojan Nuclear Plant, do not include any operating nuclear units while continuing to store SNF. A sensitivity analysis on the base case was prepared assuming only the orphaned facilities were to transport their SNF to an optimized ISFSI site for comparison to the base case results. A consolidated list of shutdown plans is presented in Table 15.

Table 15. List of SNF stored at shutdown and orphaned reactor sites

\begin{tabular}{lcc}
\hline \multicolumn{1}{c}{ Plant } & $\begin{array}{c}\text { SNF inventory } \\
\text { (MTHM) }\end{array}$ & $\begin{array}{c}\text { SNF inventory } \\
{ }^{a} \\
\text { (MTHM) }\end{array}$ \\
\hline Big Rock Point & 59.0 & 58 \\
Haddam Neck & 462.84 & 412 \\
Humboldt Bay & 296.4 & 29 \\
LaCrosse & 40.08 & 38 \\
Maine Yankee & 544.9 & 542 \\
Rancho Seco & 227.3 & 228 \\
Trojan & 357.2 & 359 \\
Yankee Rowe & 145.5 & 127 \\
Zion Unit 1 \& 2 & 1009.5 & 1,019 \\
TOTAL & $\mathbf{3 1 4 2 . 8}$ & $\mathbf{2 , 8 1 3}$ \\
${ }^{a}$ Taken from DOE's report to Congress. ${ }^{37}$ &
\end{tabular}

The SNF inventory listed in the third column of Table 15 is taken from a DOE report submitted to Congress. ${ }^{37}$ Some of the SNF quantities seem to be in dispute between the two data source. ORNL used the SNF inventory reported in the RW-859 database to be on the conservative side. Based on the total SNF inventory of about 3,150 MTHM at these reactor sites, ORNL considered only one or two interim storage facilities. Centralized interim storage solutions based on minimizing the transportation distance are shown in Figs. 53 and 54 for two storage sites and a single storage site, respectively.

The one-site solution for stranded SNF based on minimizing the transportation distance matches the base case scenario with four and five storage sites for the most favorable ISFSI site in Illinois (47 and 44). The more cost-effective and flexible three-site ISFSI solution (Fig. 48) would move this site to northwest Illinois. Although the northwest Illinois location may not quite be optimized with respect to transportation distance for the case of stranded plant fuel, it may well fit into a national scheme for the current SNF storage issue. Therefore, establishing this general location as the initial consolidated ISFSI location would seem to have merit.

\footnotetext{
${ }^{37}$ Taken from US Department of Energy, Report to Congress on the Demonstration of the Interim Storage of Spent Nuclear Fuel from Decommissioned Nuclear Power Reactor Sites, DOE/RW-0596, US Department of Energy, Office of Civilian Radioactive Waste Management, Washington, DC, December 2008.
} 
This critical finding is encouraging considering the fact that Recommendation \#3 of the Transportation and Storage Subcommittee of the BRC, as excerpted previously, gave priority to the SNF stored at the orphaned plants. ORNL's conclusion is that, if the BRC's said recommendation is to be implemented as the pilot project of a larger, longer-term national fuel disposition campaign, the northwestern Illinois location seems to have geographical attributes and transportation infrastructure advantages that would facilitate the entire planning, implementation and operation phases of the campaign.

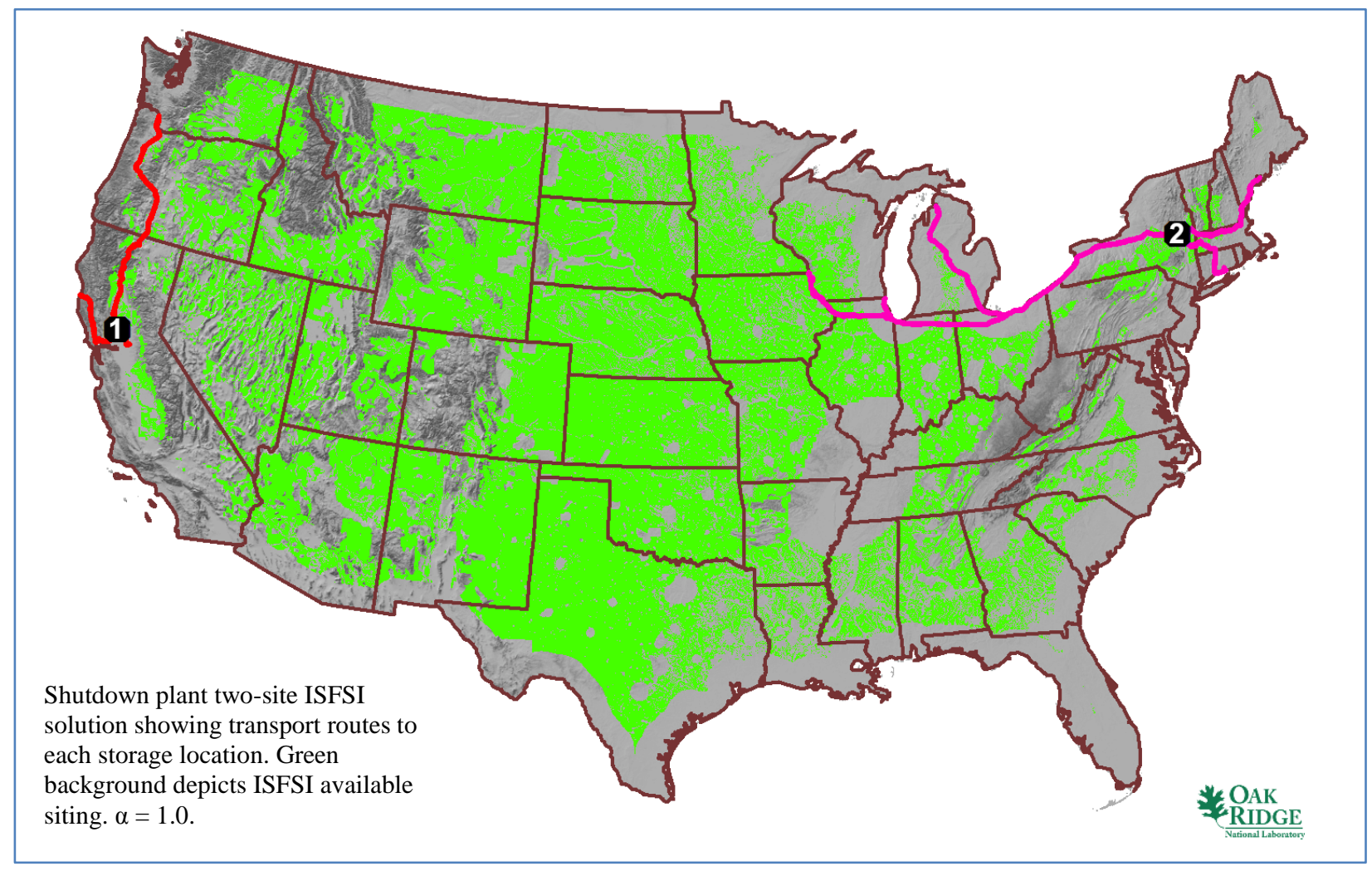

Fig. 53. Most favorable locations for two storage sites for shutdown plants. 


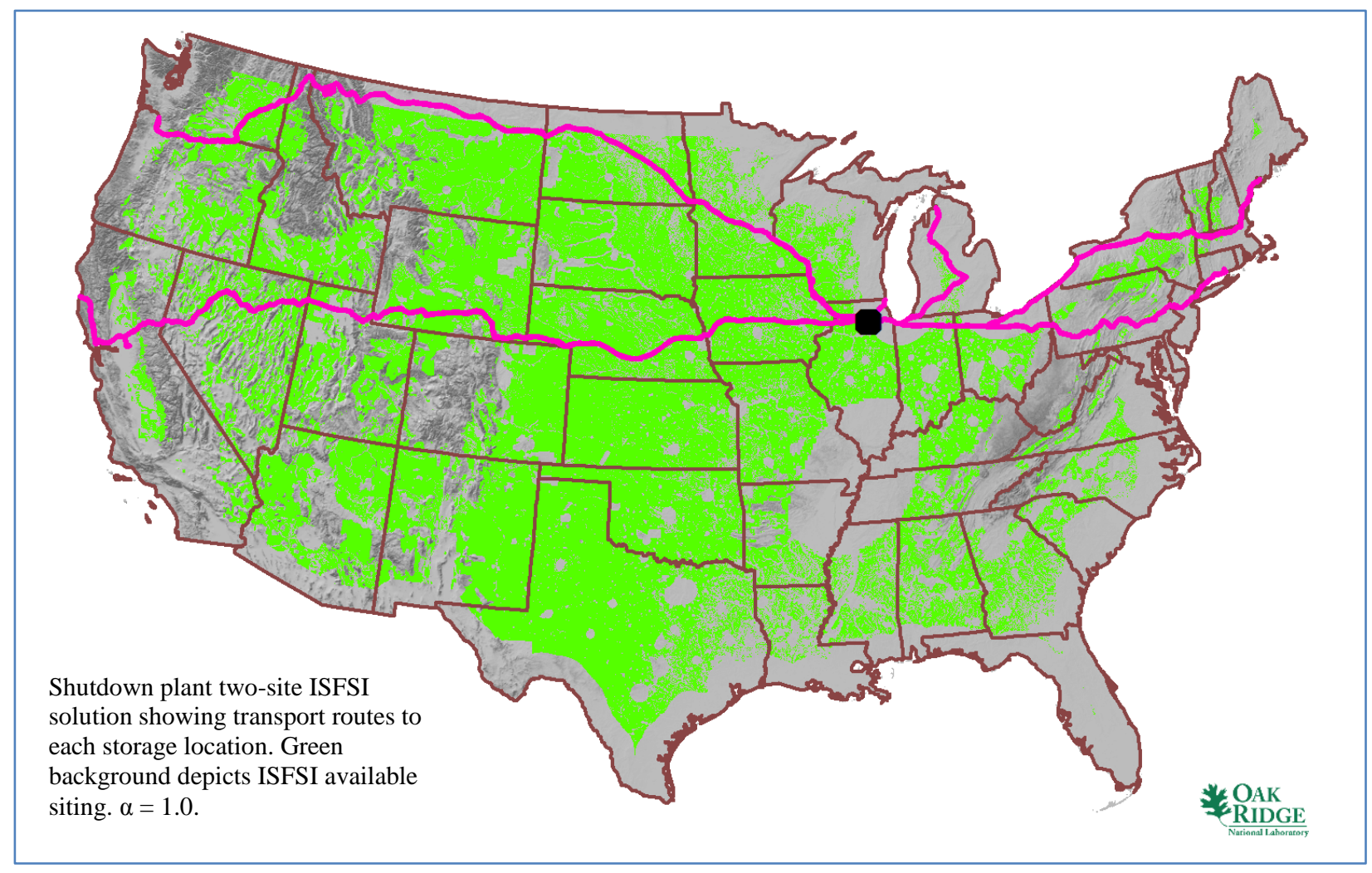

Fig. 54. Most favorable location for a single storage site for shutdown plants.

ORNL's result is consistent with and directly supports the recommendation of the Transportation and Storage Subcommittee of the BRC (p. 66): ${ }^{36}$

"The Going the Distance" study recommended that DOE initiate transport "through a pilot program involving relatively short, logistically simple movements of older fuel from closed reactors to demonstrate its ability to carry out its responsibilities in a safe and operationally effective manner." As discussed earlier, the Subcommittee recommends that one or more consolidated storage facilities be established, initially to accept stranded spent fuel from shutdown reactor sites.

It is worth noting that these results are obtained based on very minimalistic and mostly technical assumptions to facilitate a critical capability to support the DOE SNF mission. This capability can be expanded to address the requirements of more realistic constraints that would eventually transpire as a result of social, political, and operational complications.

\subsection{SCENARIO 2: MODERATE NUCLEAR POWER GENERATION GROWTH RESULTS}

Scenario 2 is intended to provide analysis for moderate growth in nuclear power generation based on current industry trends. This scenario builds upon the assumptions used in the base case and includes the following additional assumptions:

1. all current reactor units are approved for license renewal,

2. all applicants with combined operating license (COL) applications before the NRC are approved and built, 
3. plants currently under construction at Watts Bar, Vogtle, and Summer are completed, and

4. small reactors are completed at the Clinch River site in Tennessee and at the Callaway plant in Missouri.

More details can be found in Section 4.2.

The total amount of SNF generated by 2050 in Scenario 2 is 159,120 MTHM or an increase of 35,400 MTHM (29\%) over the base case scenario. Based on the current interim storage capacity limit of 70,000 MTHM, Scenario 2 requires a minimum of three interim storage facilities and $76 \%$ of the combined capacity of three storage facilities would be utilized in 2050 provided no disposal pathway is identified. Based on the minimum number of facilities and for ease of comparison with the other scenarios, only the case with five storage facilities is presented graphically in this report. However, results for one to four storage facilities are available.

The most favorable five-site consolidated ISFSI solution for Scenario 2 is shown in Fig. 55, and the distribution of SNF is listed in Table 16. This solution shows little difference when compared to Fig. 44. Much of the additional SNF generated in the moderate growth scenario is stored at existing reactor sites as these sites expand, so the lack of a change in the most favorable consolidated ISFSI locations is not an unexpected result. However, because most of the new reactor applications considered in this scenario are in the southeast, ISFSI \#4 becomes the most utilized facility, surpassing ISFSI \# 1 in the base case. The commonality of the results is reflected across the one-site through four-site ISFSI solutions as well.

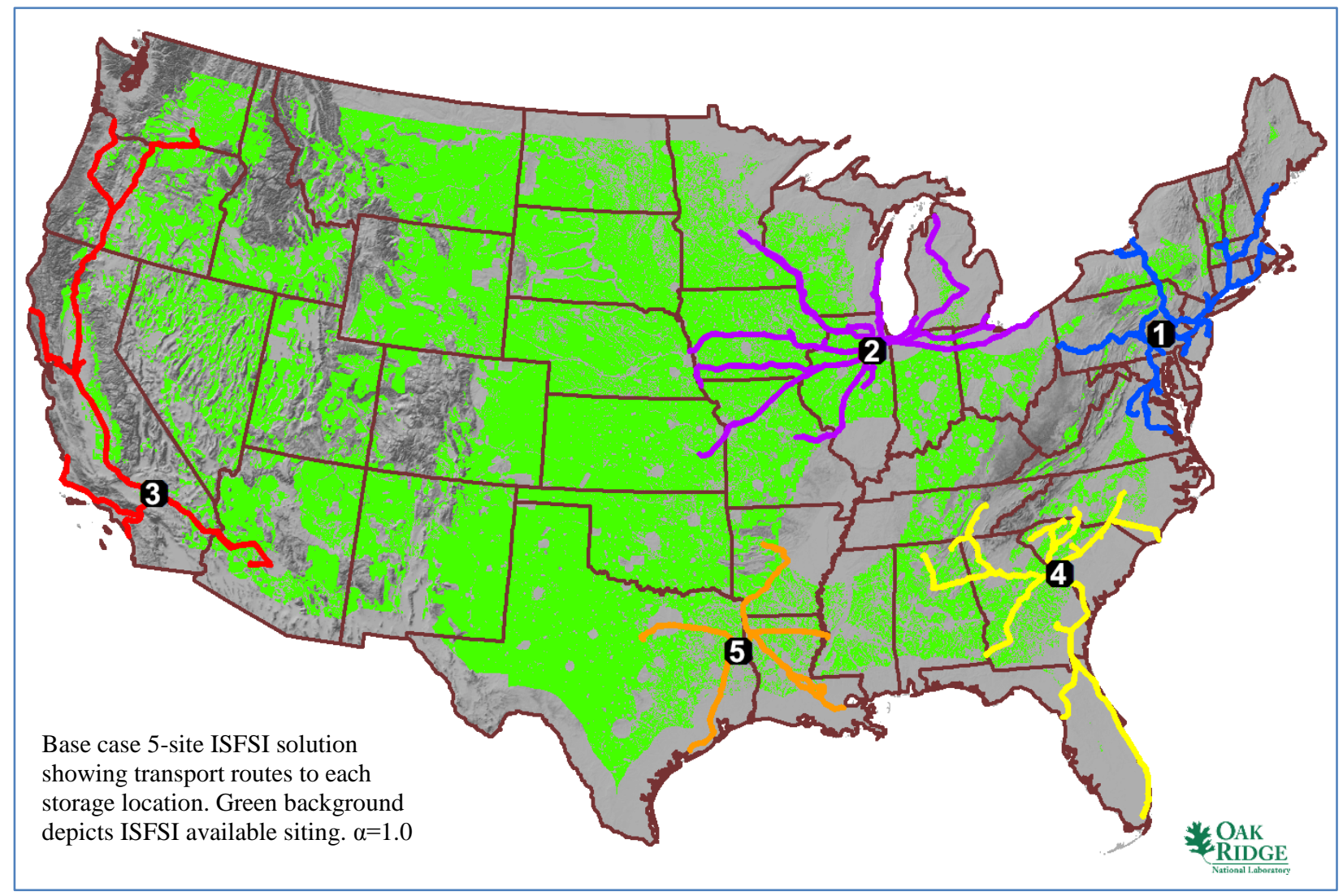

Fig. 55. Moderate growth five-site ISFSI solution based on transportation distance $(\alpha=1.0)$. 
Table 16. SNF inventory for Scenario 2 with capacity factors

for each storage site with five ISFSIs $(\alpha=1.0)$

\begin{tabular}{ccc}
\hline ISFSI site & $\begin{array}{r}\text { Stored SNF inventory } \\
\text { (MTHM) }\end{array}$ & $\begin{array}{c}\text { Used capacity } \\
(\boldsymbol{\%})\end{array}$ \\
\hline 1 & $42,350.80$ & 60.50 \\
\hline 2 & $32,366.01$ & 46.24 \\
\hline 3 & $12,619.84$ & 18.03 \\
\hline 4 & $45,500.07$ & 65.00 \\
\hline 5 & $19,233.09$ & 27.48 \\
\hline
\end{tabular}

\subsection{SCENARIO 3: AGGRESSIVE NUCLEAR POWER GENERATION GROWTH RESULTS}

Scenario 3 is intended to provide analysis for a perceived extreme case of nuclear power generation growth. This scenario builds upon the assumptions used in Scenario 2 and includes the following additional assumptions.

1. Scenario 2 reactors are built and operated.

2. Several iPWR small reactor designs are approved by the NRC and numerous sites are selected for construction in the United States, especially as coal plant back fits.

3. Several advanced high-temperature small reactor designs are approved by the NRC and numerous sites are selected for construction in the United States, especially for chemical industry heat applications.

Basically, this scenario assumes that an additional 25 SMRs (12 mPower SMRs, 12 Westinghouse-SMRs

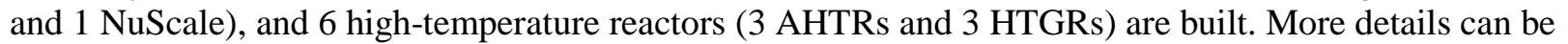
found in Section 4.3.

These newly forecast reactors generate a total of 2,970 MTHM additional SNF over the course of their operation through 2050. The total amount of SNF generated by all reactors combined, that is, considering the base case and the new reactors introduced in Scenario 2 and Scenario 3, is 162,090 MTHM or an increase of 38,370 MTHM (31\%) over the base case scenario. Based on the current interim storage capacity limit of 70,000 MTHM as written in the law, Scenario 3 also requires a minimum of three interim storage facilities and $77 \%$ of the combined capacity of three storage facilities would be utilized in 2050 provided no disposal pathway is identified. Based on the minimum number of facilities and for ease of comparison with the other scenarios, only the case with five storage facilities is presented graphically in this report. However, results for one to four storage facilities are available in the event that no ISFSI capacity limit is assumed.

The most favorable five-site consolidated ISFSI solution for Scenario 3 is shown in Fig. 56, and the distribution of SNF is listed in Table 17. This solution shows little difference when compared to Fig. 44. The aggressive growth scenario increases the projected quantity of SNF in 2050 by just $3 \%$ over the moderate growth scenario because the advanced reactors deployed in this scenario are small and arrive relatively late in the time sequence. Therefore, even the more diverse advance reactor locations associated with this scenario are not sufficient in the 2050 time frame to cause a shift in the previously identified favorable locations for consolidated ISFSIs. The commonality of the results is reflected across the onesite through four-site ISFSI solutions as well. 


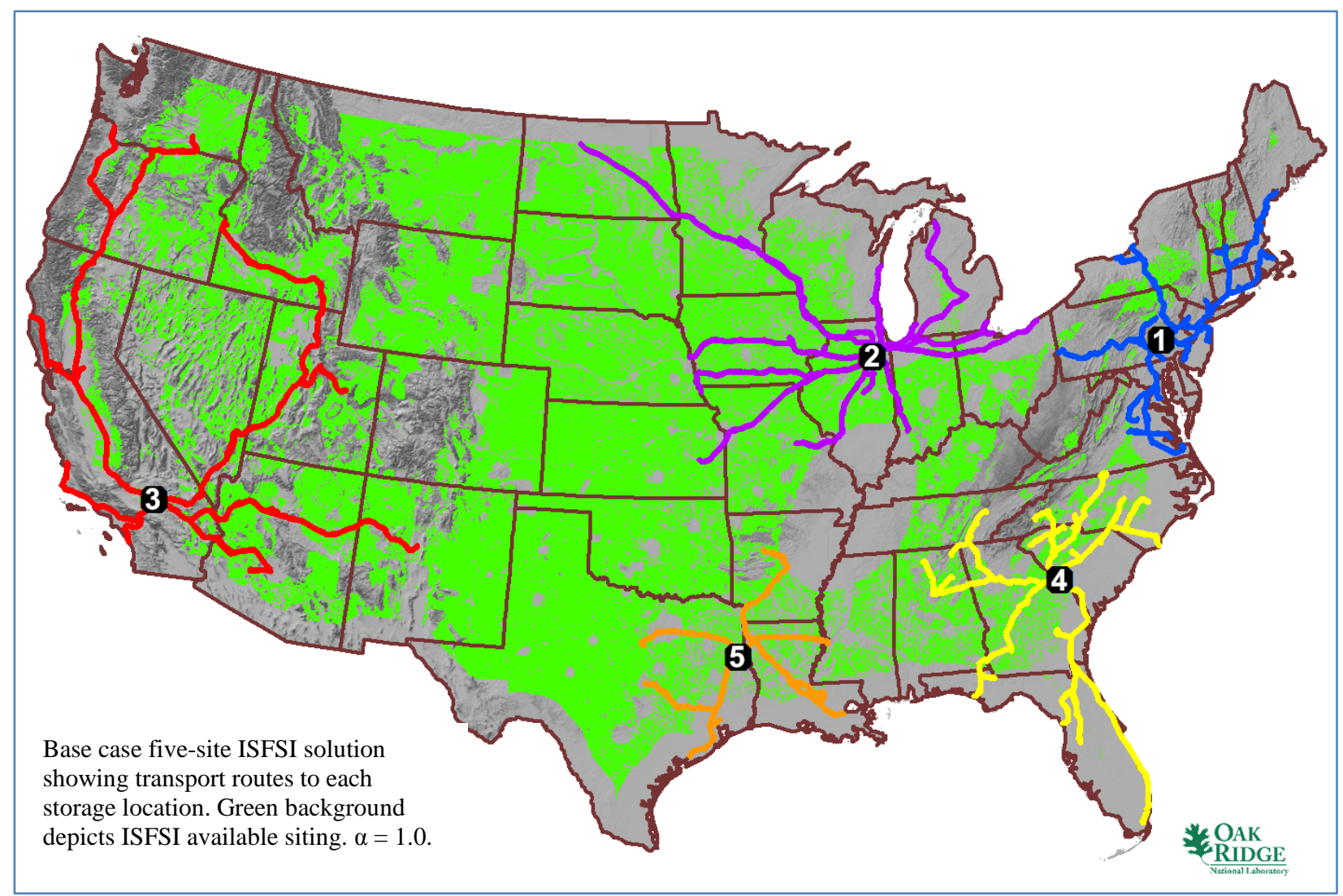

Fig. 56. Aggressive growth five-site ISFSI solution based on transportation distance $(\alpha=1.0)$.

Table 17. SNF inventory for Scenario 3 with capacity factors for each storage site with five ISFSIs $(\alpha=1.0)$

\begin{tabular}{ccc}
\hline ISFSI site & $\begin{array}{c}\text { Stored SNF inventory } \\
(\text { MTHM) }\end{array}$ & $\begin{array}{c}\text { Used capacity } \\
(\boldsymbol{\%})\end{array}$ \\
\hline 1 & $42,842.77$ & 61.20 \\
\hline 2 & $32,870.27$ & 46.96 \\
\hline 3 & $13,246.32$ & 18.92 \\
\hline 4 & $47,275.51$ & 67.54 \\
\hline 5 & $19,804.69$ & 28.29 \\
\hline
\end{tabular}

Both growth scenarios suggest that the SNF inventory from the US operation history will dominate for decades until the SNF generated by new reactors builds up to comparable levels. Even with aggressive nuclear growth, contribution from new reactors will be a small fraction of the total inventory by 2050 . Based on this analysis, it may very well be rational to make policy decisions based on the projected inventory and the geographical distribution of SNF from the current fleet of reactors and orphaned sites. 


\subsection{MODEL SENSITIVITY}

The waste generated by the 104 current reactors and the 10 shutdown reactors dominates the generated waste at 2050 in all three scenarios analyzed for this report. As a result, there was not much variability in the optimized results for a given number of ISFSIs and associated weighting factors. However, to further demonstrate the responsiveness of the optimization model, a contrived real-world change was inserted to demonstrate that the optimized ISFSI locations would move to a new location. For the aggressive growth scenario, the quantity of waste accumulated at the existing reactor sites in 2050 was decreased by a factor of 100, and the quantity of waste accumulated at the proposed new reactor sites in 2050 was increased by a factor of 100. The resulting shift for five optimized ISFSI locations weighted to minimize distance travelled is shown in Fig. 57.

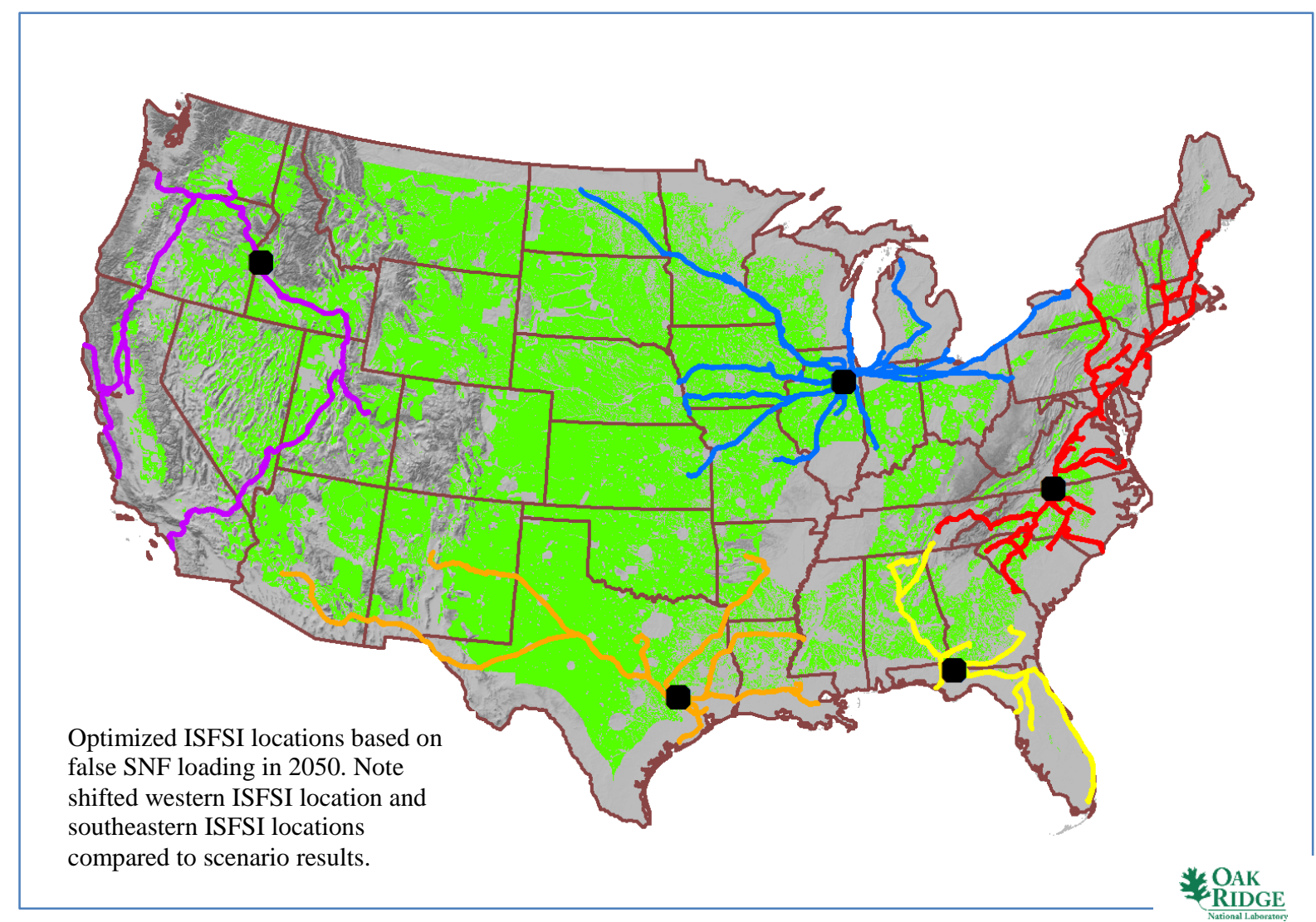

Fig. 57. Artificial SNF loading in 2050 to demonstrate optimization model sensitivity.

As expected, the suddenly large new reactor site in Idaho pulls one optimized ISFSI location to that site. Likewise, with the current reactor locations in New England deemphasized, the optimized ISFSI location that previously supported the New England region waste is pulled toward the modeled new SMR sites in the Southeast. A second southeastern ISFSI site is located at the intersection of the Florida, Alabama, and Georgia state lines to support the southeastern reactors in this contrived scenario. The fourth ISFSI site is pulled further west into Texas. Only the ISFSI site located near the Great Lakes remains relatively unmoved. Therefore, the optimization modeling is actually very responsive to changes, but the real-world domination of the current reactor contribution to the total waste at 2050 forces the model to yield nearly identical results in each of the three analyzed scenarios. This sensitivity analysis further confirms that the near-term siting of one or more ISFSIs is highly dependent on the current fleet of reactors. This sensitivity analysis also demonstrates a need to consider other modeling parameters such as different forecast end dates and a need to factor time-sequencing into the modeling at some point. 


\section{SUMMARY}

\subsection{INTEGRATED STUDY HIGHLIGHTS}

Based on the stated assumptions and selected values for the ISFSI plant SEC, over $40 \%$ of the contiguous United States, or more than 700 million acres, is available for siting consolidated ISFSI facilities. This represents more than 1.7 million possible 400-acre nominal ISFSI sites with no siting issues based on the selected ISFSI SEC and values available in all regions of the country. Varying the ISFSI SEC values would affect the possible ISFSI siting results, which subsequently has an effect on the calculation of the most favorable or optimized ${ }^{7}$ ISFSI sites. Therefore, what is presented by this study is a single static result from a range of possible siting factors and values.

Three simple nuclear growth scenarios were evaluated relative to the best or optimized ${ }^{7}$ location(s) based on certain selection metrics for consolidated interim waste storage facilities. The three commercial nuclear power scenarios are (1) the status quo scenario with no future commercial nuclear power growth, (2) a scenario with moderate commercial nuclear power growth, and (3) a scenario with aggressive commercial nuclear power growth that includes advanced reactor concepts. Two sensitivity studies based on the status quo scenario were also conducted; one included forcing an ISFSI location to be the Skull Valley, Utah location, and the second focused on calculating the most favorable ISFSI location relative to the orphaned reactor sites only. An additional sensitivity study based on the aggressive growth scenario was performed to demonstrate the optimization model sensitivity to changes in SNF quantities and location. Each scenario was analyzed by optimizing one to five consolidated ISFSI sites with weighting factors for shipping distance and rail corridor population risk.

The three base scenarios provided a number of key observations. The most significant observation is that in 2050 the most favorable locations for ISFSI siting are dominated by the current fleet of operating reactors. The addition of new reactors and the limited time available by 2050 to accumulate SNF are small compared to the amount of SNF already generated by the current operating fleet as well as that which is expected to be generated by 2050 by the current fleet. Without further license renewals beyond 60 years, most of the current operating fleet will be retired by 2050. Therefore, with the limits imposed by this study, the most favorable locations for ISFSI siting did not change significantly between each of the three main scenarios analyzed. A second observation is that the most favorable ISFSI locations are sensible with regard to where the current reactors are located. This is summarized in Fig. 58 where the five-site ISFSI calculation for the three main scenarios and two of the three sensitivity studies, based only on transportation distance, is presented. The green background in Fig. 58 shows the area available for ISFSI siting based on the selected criteria and values. The size of the dots in Fig. 58 is not significant, but the varying size allows the results of the different scenarios and sensitivity studies to be displayed simultaneously. The most favorable locations for the five-site ISFSI calculation status quo scenario are shown as small purple dots. The results for the moderate growth scenario are shown as slightly larger black dots or as a ring around the purple dots. The results for the aggressive growth scenario are shown as a yellow ring around each of the black dots. As can be seen in Fig. 58, the five-site ISFSI solution considering distance travelled is nearly identical for each of the three main scenarios. One exception is the movement of the most favorable ISFSI location in northwestern Louisiana for the status quo case into Texas in the moderate and aggressive growth scenarios. This movement can be attributed to license renewal at the two South Texas reactor units in the moderate growth scenario. A second exception is the slight movement of the most favorable ISFSI location in northern Illinois for the status quo case southward in the moderate and aggressive growth scenarios. Similar results are obtained among the three scenarios for the one-, two-, three-, and four-site ISFSI most favorable or optimized calculation.

The five-site ISFSI calculation for the status quo scenario where the Skull Valley, Utah, site is included as a volunteer site is depicted by the blue dots or rings. It is interesting to note in this sensitivity analysis that 
by forcing a volunteer site in Utah, two other favorable ISFSI locations are significantly changed. The western ISFSI location in southern California is pulled east toward the Palo Verde reactor site in Arizona. Likewise, the more favorable ISFSI site on the Georgia-South Carolina border gets pulled westward across Georgia to the northwestern Alabama in order to be more centrally located among the southeastern reactor sites. However, in this scenario the two western consolidated ISFSI locations would be extremely underutilized. The Arizona site would be dropped in a four-site ISFSI solution with a volunteer site in Utah.

Based on the results, the optimization modeling might appear to be unresponsive. As discussed in Section 6.4 , the SNF inventory at the current reactors was significantly reduced, while the SNF inventory at the proposed new reactors was significantly increased to observe the effect on the calculation of the most favorable five-site ISFSI solution. The large red dots or rings in Fig. 58 reflect the results of this calculation showing significant movement of the most favorable or optimized ISFSI sites in four of the five previous favorable ISFSI sites in the five-site ISFSI calculation. This demonstrates the model responsiveness.

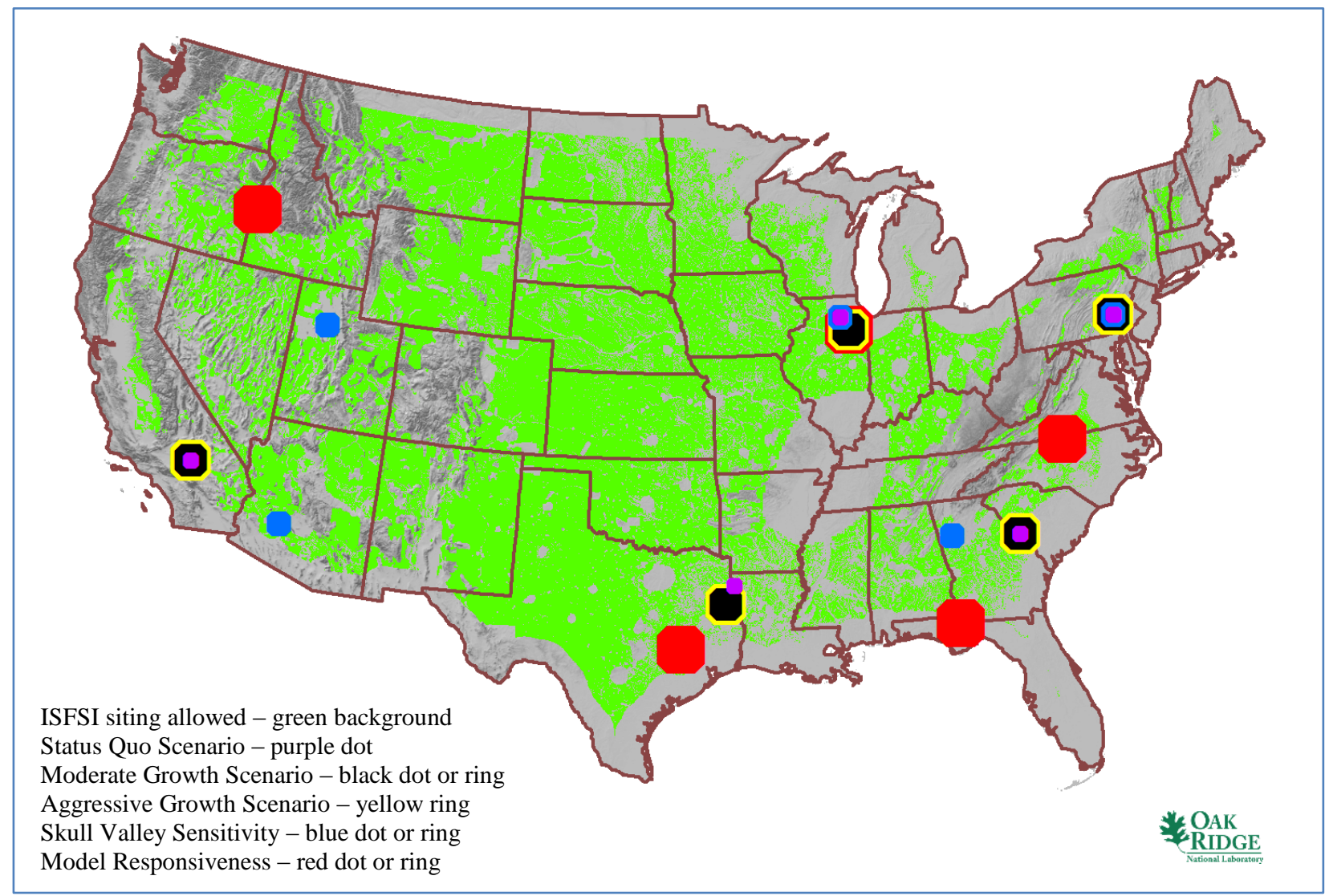

Fig. 58. Summary of the most favorable ISFSI locations for the five-site ISFSI calculation based solely on transportation distance.

A similar comparison can be made for the five-site ISFSI calculation for the three main scenarios and two of the three sensitivity studies, based only on population risk, as shown in Fig. 59. In general, it can be seen that the consolidated ISFSI sites move away from population centers. As before, the green background in Fig. 59 shows the area available for ISFSI siting based on the selected criteria and values. Again, the size of the dots in Fig. 59 is not significant, but the varying size allows the results of the different scenarios and sensitivity studies to be displayed simultaneously. The most favorable locations for the five-site ISFSI calculation status quo scenario are shown as small purple dots. The results for the 
moderate growth scenario are shown as slightly larger black dots or as a ring around the purple dots. The results for the aggressive growth scenario are shown as a yellow ring around each of the black dots. The results of the sensitivity study placing an ISFSI at Skull Valley, Utah, are shown as a blue dot or ring. The five-site ISFSI solution considering population risk identifies a change in the most favorable ISFSI location from the status quo scenario to the subsequent two growth scenarios. The initial ISFSI site in Mississippi is pulled west into Texas as a result of relicensing at South Texas and four new large reactor units in Texas for the moderate growth and aggressive growth scenarios. The west coast ISFSI moves to Utah in response to the fictional volunteer ISFSI site placed at that location.

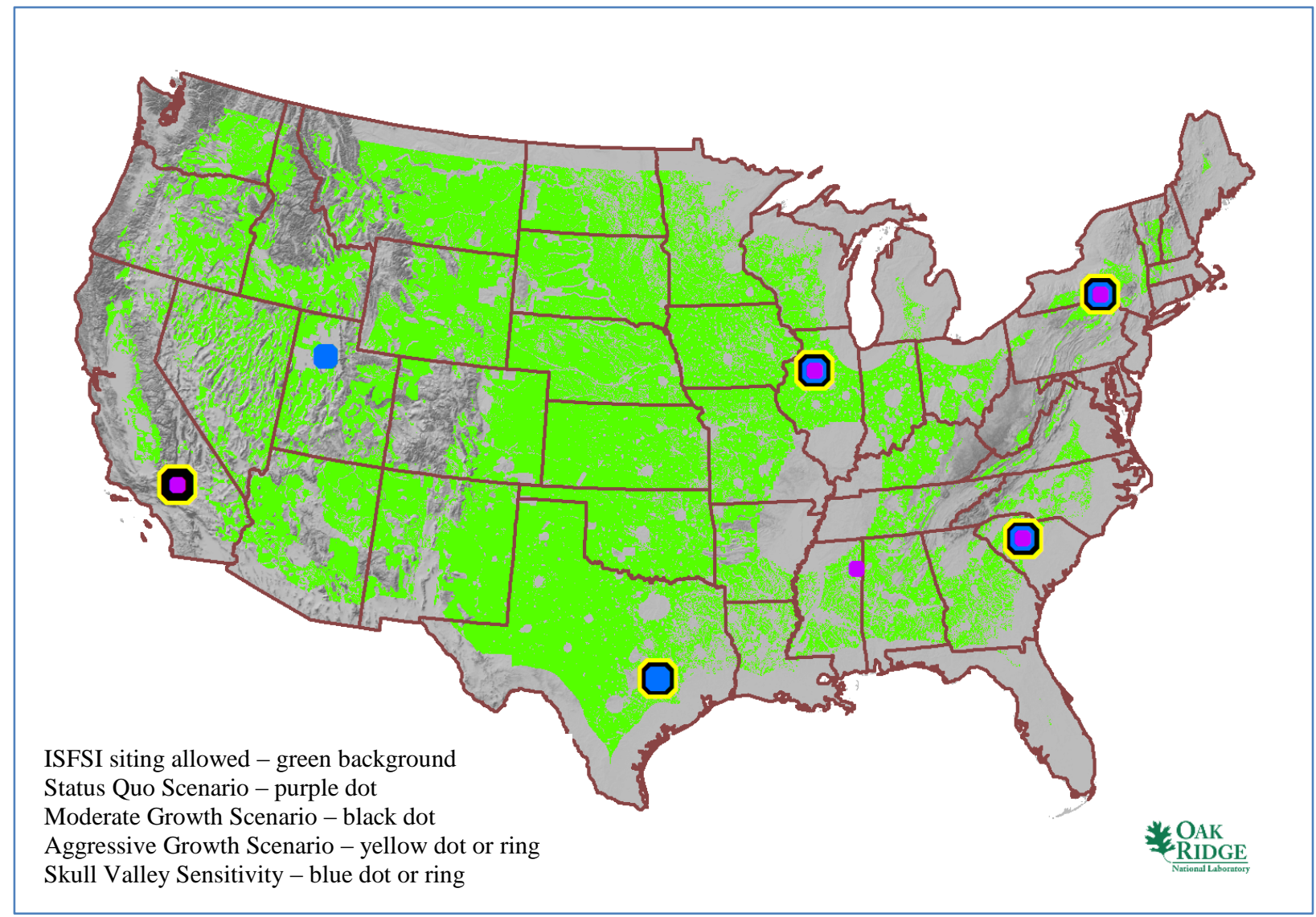

Fig. 59. Summary of the most favorable ISFSI locations for the five-site ISFSI calculation based solely on population risk.

For the near-term accumulated SNF represented by the status quo reactor growth scenario in 2050, at least two consolidated ISFSI locations would be required to store all accumulated SNF and to stay within the nominal maximum storage capacity of 70,000 MTHM at a single ISFSI location provided no disposal pathway is identified. The most favorable two-site ISFSI result (Fig. 49) for the status quo scenario based solely on limiting transportation distance provides two locations within the stated capacity. However, with variations in the solution toward minimizing population risk, the eastern consolidated ISFSI location would quickly exceed 70,000 metric tons of heavy metal. Therefore, to minimize capacity and transportation distance, a three-site consolidated ISFSI solution (Fig. 48) may provide a better minimal storage solution. The most favorable three-site ISFSI result for the status quo scenario based solely on limiting transportation distance retains the same western ISFSI location in southern California and divides the eastern ISFSI siting into two parts - one site near the Great Lakes and one site in North Carolina. Again the results make visual sense. 
One or two consolidated ISFSI sites would more than adequately accommodate the 11,330 MTHM of SNF stored at stranded plant sites. The same storage location in Illinois is identified in the one-site solution based only on the stranded plant SNF input. This indicates the spread of the stranded SNF in the United States Therefore, a north central United States location as the initial consolidated ISFSI location would seem to have merit. This observation is supported further when compared to the base case scenario with four and five storage sites. One of the favorable locations from the base case for the four- and fivesite ISFSI calculation is the same southeastern Illinois site. The more cost-effective and flexible three-site ISFSI solution based on minimizing transportation distance would move this site slightly westward while remaining in Illinois. Although the latter location may not quite be optimized with respect to transportation distance for the case of stranded plant fuel, it may well fit into a cost-effective national scheme for the current SNF storage issue.

\subsection{FUTURE STUDY PHASES}

The goal of this study was to show a capability for ISFSI siting optimization based on a limited number of factors and several nuclear power plant growth scenarios. Assumptions were made to support the ability to make the initial observations. There are numerous opportunities to expand upon this initial study. A few are listed here.

\subsubsection{State, Tribal, or Local Government Transportation Limitations}

States, Indian tribes, or other local governments may want to limit or disallow possible SNF transportation routes through their jurisdiction. Considerations can be based on overall public safety or public acceptance. Routing was not limited as part of this optimization study, but more limited routing could be considered as part of a future ISFSI siting study.

\subsubsection{Type of Rail Line}

All rail lines were considered for this optimization study. In reality, many branch lines and short lines have speed and weight restrictions that may limit the use of those lines for SNF transport. Utilizing the Transportation Routing Analysis Geographic Information System (TRAGIS), an advanced ISFSI optimization siting study could consider only main rail lines for the transport of SNF.

\subsubsection{Evaluation of Skull Valley Operators}

The private storage facility proposed by the Skull Valley Band of the Goshute Indian Tribe in Utah was to be owned by eight US companies: Indiana-Michigan Power Company (American Electric Power), Entergy Corporation, GPU Nuclear Corporation, Xcel Energy, Florida Power and Light Company, Southern Nuclear Operating Company, Southern California Edison Company, and Genoa FuelTech, Inc. The facility was licensed to receive no more than 40,000 metric tons of uranium of SNF. These utilities and the site cap on storage could be evaluated as part of an advanced optimization siting study.

\subsubsection{Impact of Volunteer Sites on Optimization}

The Blue Ribbon Commission on Waste has recommended that sites receive incentives to volunteer to accept SNF. Obviously, consolidated volunteer ISFSI sites cannot be optimized. However, the impact of one or more volunteer sites on the remaining siting optimization can be evaluated as part of an advanced optimization siting study. Also, multiple volunteer sites can be evaluated against the optimization results. Conversely, focused areas for offering incentives can be evaluated based on optimization results and additional parameters. 


\subsubsection{Sequential Timing of Waste Transportation}

This optimization study did not consider the time sequence for SNF relocation, that is, the limitations on how much SNF can be moved per year. Additionally, no prioritization of fuel at closed plants or heavily loaded power plant fuel storage facilities was considered. In addition, all consolidated ISFSI sites were assumed to exist when needed in 2050. A more complex consolidated ISFSI optimization study could investigate various annual transportation campaigns, prioritization of closed plants, prioritization of crowded power plant SNF storage facilities, and sequencing of the construction of multiple consolidated ISFSI sites.

\subsubsection{Cost of Transportation}

This optimization study did not consider the actual cost of SNF relocation, that is, the cost per SNF package, the cost per mile to ship, etc. Although minimizing cost can be equated to minimizing the distance shipped, various SNF campaign strategies could significantly alter the most favorable locations for consolidated ISFSI siting. A more complex consolidated ISFSI optimization study could investigate various annual transportation campaigns and the associated cost as individual factors of the optimization.

\subsubsection{ISFSI Optimization for Separate Fuel Forms}

For the purposes of this study, all fuel forms were assumed to be amenable to storage in a common dry storage container. Therefore, a specific consolidated ISFSI would not be required to accept differing storage containers. This is a reasonable assumption for LWRs. However, if increased use of advanced reactors is anticipated, unique storage containers would likely be required. This could require separate consolidated ISFSI facilities for the various fuel forms. A more advanced optimization siting study could consider this issue.

\subsubsection{Development of a Graphical User Interface and Decision Support Application for Independent Spent Fuel Decision Making}

As an important part of the nuclear waste storage and control strategy, analysts and decision makers need effective and efficient decision making tools integrating quantitative analysis models. Just as vital as these quantitative models is the need for an efficient and user-friendly graphical user interface (GUI) that includes decision makers' preferences and perspectives in the decision making process of siting ISFSIs. In this project, we will develop a GUI that integrates multi-criteria siting methodology with optimization model intended for decision-making in independent SNF storage. Since usability is an important part of this process, a usability test will be conducted to evaluate the GUI prototype for all stakeholders. The GUI prototype will allow users to choose siting criteria and optimize potential siting area with respect to different operational, economic, and safety criteria. The GUI will be developed to be compatible with smart devices such as an iPad.

\subsubsection{Development of a Framework for Optimization Model in Case of ISFSI Facility Interdiction}

The ranking or optimization of potential SNF storage sites assumes that all storage facilities will be available and open at all times. However, there are operational and security constraints that may necessitate the closing of one or more facilities. In the event of an unplanned closure of a facility, the other facilities may experience operational needs that they were not designed to handle. Thus, potential study would involve developing robust multi-objective optimization models to understand the trade-offs of designing under two concurrent scenarios, namely, facilities siting without failure and worst-case consequence due to the unavailability of exactly $\mathrm{M}$ facilities out of $\mathrm{N}$ facilities due to natural disasters or 
other similar extreme events. The decision to analyze worst case allows modeling for a minimum number of facilities required to get the job done with the unavailability of $M$ facilities. 


\section{BIBLIOGRAPHY}

\subsection{GIS DATA SOURCES}

Population: excluding all areas with population density greater than 500 people per square mile LandScan Global 2009 Population Dataset (ORNL) [30 arcsecond ( 1-km) resolution, ambient population distribution], http://www.ornl.gov/sci/landscan

LandScan USA 2009 Population Dataset (ORNL)

Safe Shutdown Earthquake: excluding areas having a 2\% chance in 50-year return period of peak ground acceleration greater than 0.3

USGS National Seismic Hazard Mapping data (2008) http://earthquake.usgs.gov/hazards/products/

Tectonic Sources/Faults: excluding areas using a variable buffer distance based on the length of the fault line

USGS Quaternary Fault and Fold Database, http://earthquake.usgs.gov/hazards/qfaults/

Wetlands: excluding areas defined as open water or wetlands through satellite remote sensing of land cover

2001 National Land Cover Dataset, http://www.mrlc.gov/finddata.php

Protected Land Uses: excluding managed lands and built environment (see following list)

\begin{tabular}{|c|c|c|c|}
\hline Name & Notes & Date & Link \\
\hline $\begin{array}{l}\text { National parks } \\
\text { National monuments } \\
\text { National forests } \\
\text { Wilderness areas }\end{array}$ & $\begin{array}{l}\text { National Atlas- } \\
\text { Federal Lands }\end{array}$ & $\begin{array}{l}\text { Current, } \\
\text { accessed } \\
9 / 29 / 2009\end{array}$ & http://www.nationalatlas.gov/maplayers.html \\
\hline Other parks & $\begin{array}{l}\text { Contains national, } \\
\text { state, county, } \\
\text { local parks, and } \\
\text { forests }\end{array}$ & & ESRI 9.3 mapping data \\
\hline Wild/scenic rivers & $\begin{array}{l}\text { 2-mile buffer } \\
\text { added }\end{array}$ & 2008 & http://www.rivers.gov/maps.html \\
\hline Wildlife refuges & $\begin{array}{l}\text { Merged from all } \\
\text { regions }\end{array}$ & Varies & http://www.fws.gov/refuges/realty/gis.html \\
\hline Hospitals & $\begin{array}{l}0.25 \text {-mile buffer } \\
\text { around points }\end{array}$ & & HSIP Gold 2008 \\
\hline Correctional facilities & $\begin{array}{l}0.25 \text {-mile buffer } \\
\text { around points }\end{array}$ & & HSIP Gold 2008 \\
\hline Schools/colleges & $\begin{array}{l}0.25 \text {-mile buffer } \\
\text { around points }\end{array}$ & & HSIP Gold 2008 \\
\hline Inventoried roadless areas & & & National Forest Service \\
\hline $\begin{array}{l}\text { Areas of critical } \\
\text { environmental concern }\end{array}$ & $\begin{array}{l}\text { Merged from state } \\
\text { data }\end{array}$ & & Bureau of Land Management \\
\hline
\end{tabular}


Landslides: excluding all areas with moderate or high incidence or susceptibility to landslides

USGS Landslide Hazards Program (2002), http://landslides.usgs.gov/learning/nationalmap

100-year Floodplain: excluding all areas within the 100-year floodplain. Data quality and availability vary by county.

FEMA National Flood Hazard Layer (2009), http://www.msc.fema.gov

Hazardous Facilities: EPRI siting guidelines consider these existing facilities as avoidance criteria. Major airports have a 10-mile buffer zone; all other facilities have a 1-mile buffer.

Major Airports-Federal Aviation Administration and Bureau of Transportation Statistics (2008).

Military Bases-US Census Bureau (2008), http://www2.census.gov/cgi-bin/shapefiles/national-files

Refineries-active facilities, HSIP Gold 2008

Railroads: ORNL Dataset (2010)

Navigable waterways: Bureau of Transportation Statistics, National Transportation Atlas Database, http://www.bts.gov/publications/national transportation atlas database

\subsection{ENERGY SOURCE MATERIALS THAT PROVIDED INSIGHTS ON SELECTING ISFSI SSEC AND SUBSEQUENT OPTIMIZATION}

\section{ISFSI SSEC:}

Bechtel Power Corporation, Early Site Permit Demonstration Program, Plant Parameter Envelopes, Comparison with Ranges of Values for Four Hypothetical Sites, Gaithersburg, MD, 1992.

R. B. Briggs, C. C. Burwell, R. E. Meunier, M. J. Ohanian, D. L. Phung, B. D. Sivazlian, and A. M. Weinberg, Feasibility of a Nuclear Siting Policy Based on the Expansion of Existing Sites,

ORAU/IEA-78-19(R), Institute for Energy Analysis, Oak Ridge Associated Universities, Oak Ridge, TN, November 1978.

C. C. Burwell, M. J. Ohanian, and A. M. Weinberg, A Siting Policy for an Acceptable Nuclear Future, Science, Vol. 204, No. 4397 (June 8, 1979), pp. 1043-1051 published by the American Association for the Advancement of Science, URL: http://www.jstor.org/stable/1748705.

Dominion Energy, Inc., and Bechtel Power Corporation, Study of Potential Sites for the Deployment of New Nuclear Plants in the United States, prepared for the US Department of Energy, September 2002.

Electric Power Research Institute, Siting Guide: Site Selection and Evaluation Criteria for an Early Site Permit Application, Technical Report 1006878, Palo Alto, CA, March 2002.

G. T. Mays, R. J. Belles, O. A. Omitaomu et al., Application of Spatial Data Modeling and Geographical Information Systems (GIS) for Identification of Potential Siting Options for Various Electrical Generation Sources, ORNL Technical Report ORNL/TM-2011/157 prepared for EPRI, December 2011.

Nuclear Energy Institute, Lessons Learned from Initial Early Site Permit Experience, NEI 08-03, Washington, DC, February 2008.

Nuclear Regulatory Commission, Site Evaluations and Design Earthquake Ground Motion for Dry Cask Independent Spent Fuel Storage and Monitored Retrievable Storage Installations, Regulatory Guide 3.73, October 2003. 
Nuclear Regulatory Commission, General Site Suitability Criteria for Nuclear Power Stations, Regulatory Guide 4.7, April 1998.

Nuclear Regulatory Commission, Office of Special Studies, Nuclear Energy Center Site Survey-1975 (NECSS-75) Report NUREG- 0001, Washington, DC, January 1976.

\section{Optimization:}

10 CFR 72, Licensing Requirements for the Independent Storage of Spent Nuclear Fuel, High-Level Radioactive Waste, and Reactor-Related Greater than Class C Waste, Subpart E, Siting Evaluation Factors.

A. Machiels, Electric Power Research Institute, Program on Technology Innovation: Advanced Fuel Cycles - Impact on High Level Waste Disposal, Technical Report 1016643, Palo Alto, CA, September 2008.

A. Machiels, Electric Power Research Institute, Transportation of Commercial Spent Nuclear Fuel, Technical Report 1016637, Palo Alto, CA, December 2010.

D. B. Rigby, US Nuclear Waste Technical Review Board, Evaluation of the Technical Basis for Extended Dry Storage and Transportation of Used Nuclear Fuel, December 2010.

Blue Ribbon Commission on America's Nuclear Future, Report to the Secretary of Energy, January 2012.

DOE, Report to Congress on the Demonstration of the Interim Storage of Spent Nuclear Fuel from Decommissioned Nuclear Power Reactor Sites, DOE/RW-0596, December 2008.

International Atomic Energy Agency, Selection of Away-From-Reactor Facilities for Spent Fuel Storage, A Guidebook, IAEA-TECDOC-1558, Vienna, Austria, September 2007.

J. Kesler, Electric Power Research Institute, Technical Bases for Extended Dry Storage of Spent Nuclear Fuel, Technical Report 1003416, Palo Alto, CA, December 2002.

J. Kesler, Electric Power Research Institute, Spent Nuclear Fuel Transportation - An Overview, Technical Report 1009226, Palo Alto, CA, February 2004.

J. Kesler, Electric Power Research Institute, Industry Spent Fuel Storage Handbook, Technical Report 1021048, Palo Alto, CA, July 2010.

J. Konefal and D. Rackiewicz, Survey of HTGR Process Energy Applications, MPR-3181 Rev. 0, MPR Associates Inc., May 2008.

J. T. Carter, A. J, Luptak, J. Gastelum, C. Stockman, and A. Miller, Fuel Cycle Potential Waste Inventory for Disposition, prepared for US DOE, October 2011.

John A. Volpe, National Transportation Systems Center, Identification of Factors for Selecting Modes and Routes for Shipping High-Level Radioactive Waste and Spent Nuclear Fuel, prepared for the US Department of Transportation, April 1998.

National Academy of Sciences, Going the Distance? - The Safe Transport of Spent Nuclear Fuel and High-Level Radioactive Waste in the United States, Committee on Transportation of Radioactive Waste, 2006.

Nuclear Regulatory Commission, Standard Review Plan for Spent Fuel Dry Storage Facilities, NUREG1567, March 2000.

Nuclear Regulatory Commission, Information Handbook on Independent Spent Fuel Storage Installations, NUREG-1571, December 1996.

Nuclear Regulatory Commission, Final Environmental Impact Statement for the Construction and Operation of an Independent Spent Fuel Storage Installation on the Reservation of the Skull Valley Band 
of Goshute Indians and the Related Transportation Facility in Tooele County, Utah, Volume 1 and Volume 2, NUREG-1714, December 2001.

P. E. Johnson and R. D. Michelhaugh, Transportation Routing Analysis Geographic information System (WebTRAGIS) User's Manual, ORNL Technical Report ORNL/TM-2000/86, prepared for DOE, April 2000.

Public Law 101-615, Hazardous Materials Transportation Uniform Safety Act of 1990, As Amended, November 1990.

T. S. Chang, L. K. Nozick, and M. A. Turnquist, "Multiobjective Path Finding in Stochastic Dynamic Networks, with Application to Routing Hazardous Materials Shipments," Transportation Science 39(3), 383-399 (August 2005).

Y. W. Chen, C. H. Wang, and S. J. Lin, "A Multi-Objective Geographic Information System for Route Selection of Nuclear Waste Transport," The International Journal of Management Science, April 2006. 